\title{
Kinetic Processes of Mantle Minerals
}

By

Kenneth Tadao Koga

B.S. Geology, Rensselaer Polytechnic Institute, 1993

Submitted in partial fulfillment of the requirements for the degree of

Doctor of Philosophy

at the

MASSACHUSETTS INSTITUTE OF TECHNOLOGY

and the

WOODS HOLE OCEANOGRAPHIC INSTITUTION

September 1999

(C) 1999 Kenneth T. Koga

All rights reserved.

The author hereby grants to MIT and WHOI permission to reproduce paper and electronic copies of this thesis in whole or in part and to distribute them publicly.

Signature of Author

Joint Program in Oceanography, Massachusetts Institute of Technology and Woods Hole Oceanographic Institution September 1999

Certified by

Noburnichi Shimizu, Thesis Supervisor

Certified by

Timothy L. Grove, Thesis Supervisor

Accepted by

Timdthy L. Grove Chair, Joint Committee for Marine Geology and Geophysics Massachusetts Institute of Technology/

Woods Hole Oceanographic Institution 


\title{
Kinetic Processes of Mantle Minerals
}

\author{
by \\ Kenneth Tadao Koga
}

Submitted in partial fulfillment of the requirements for the degree of Doctor of Philosophy at the Massachusetts Institute of Technology and the Woods Hole Oceanographic Institution

\begin{abstract}
This dissertation discusses the experimental results designed to constrain the processes of MORB generation. The main focus of this study is to investigate the location and the related processes of the transformation boundary from spinel to garnet peridotite facies at subsolidus conditions, because the presence of garnet in melting residues has significant influence to the conclusion drawn from geochemical/geophysical observations. Using an approach that monitors the rate of reaction progresses, the experimental results confirmed the presence of a region that garnet and spinel coexist in peridotite compositions. The trace element distribution among the product phases (opx and cpx) subsequent to the garnet breakdown reaction is in disequilibrium, due to the differences of diffusivity between major and trace elements. The presence of disequilibrium distribution in nature may be used to infer time scales of geodynamic processes. Diffusion coefficients of $\mathrm{Al}$ in diopside are experimentally determined, and used for modeling the equilibration of major elements in pyroxene during MORB genesis. In summary, this dissertation contributes two major inferences: the location of the transformation boundaries of the garnet-spinel peridotite; the presence of disequilibrium trace elements distribution with equilibrium major elements distribution in mantle pyroxenes.
\end{abstract}




\section{Acknowledgments}

First and the most of all, I would like to thank my parents, Tadashi, and Yasuko Koga for encouraging me to explore my curiosities throughout my earlier life. Without such kind of support, I would not have been here, today. My parents in the US, Charles and Melinda O'Donnell have generously provided me a home (in the emotional sense) throughout my undergraduate and graduate education. The kindness they have shown to me gave a fundamental emotional stability while living in a foreign culture, (given that I was born here, there is a little hesitation to call this country "foreign"). Thank you.

My mentor, Nobumichi Shimizu, led me through six years of graduate school program by unlimited support, unlimited openness, and unlimited trust. With this freedom, I passed various phases: At the beginning, I did not know what science is about; Then, I was unsure about my accomplishments. And, at last, I think I know what I want to do. Throughout those confusing years, with minor progresses in science, Nobu has shown me great trust and support. I wish I learnt to see science as he does.

Timothy Grove taught me how to think like an experimentalist. Since my thesis project bridged MIT and WHOI, the experimental and analytical, and petrology and geochemistry, I was always confused with how to think-perhaps because experimentalist and analyst have different approaches to science. Tim was patient enough to let me flipflop my scientific pursuit, and always showed me what the bottom line was.

My thesis committee was very generous despite the last minute rush I created. Although the time was limited, I benefited from many comments and suggestions. Mark Kurz became my thesis chair at the last minute. Bruce Watson, who inspired me to pursue a graduate school career, generously squeezed my defense into his tight schedule. Stan Hart showed me constant interest and curiosity about mantle processes. Although I may be pursuing the science he once showed unimportant, he was always generous in inviting me his great parties. Greg Hirth's enthusiasm always helped me to pursue new ideas. Henry Dick reminded me to view science as a large interdisciplinary project. Brian Evans showed generous interest in the project I was working on, but showed me the sensitive kindness of reducing the number of my defense committee, at the last minute.

Graham Layne and Neel Chatterjee maintained the top quality of ion probe and electron microprobe analytical facilities at WHOI and MIT, despite my occasional inspired 
attempt to reduce the productivity of these facilities. The scientific benefit I received from the WHOI geochemistry seminar was enormous. I wish this unparalleled casual and inspiring seminar, will continue for years to come. Similarly, the paper reading seminar led by Fred Frey taught me what paper reading is all about. It was a fundamental education that helped me throughout graduate school.

I also have to recognize the importance of my friends and future colleagues. Long hours of discussion with Jim Van Orman were always exciting and new. In this thesis, there must be a lot of ideas initiated from those chats, though I might now fail to recognize how or when these ideas were born. Steve Parman, Glenn Gaetani, and Tom Wagner all showed patience in letting me be Ken Koga in the MIT office, whatever that means. Debbie Hassler shared the office at the other end (WHOI) for some years. She showed me many tricks, on Mac and on life, which make everyday comfortable. In those days when I did not have a radio in my car, Alberto Saal helped me by being the (interactive) car radio during long commutes between MIT and WHOI.

I also benefited a lot from discussions I had with the ion probe users at late night. Interactions with people at $12^{\text {th }}$ floor of building 54 were always fun. The student body at WHOI and MIT also gave me insight and impact to the attitude I have towards science and life. I appreciate the comrade feeling I shared with many.

When I was feeling down, there were many friends from Japan, New York, and Boston who gave me encouragement. I am in debt of their friendship. I also thank two people, $\mathrm{KT}$ and SW, who made great impacts and differences to the personal aspects of my graduate school years. 


\section{Table of Contents}

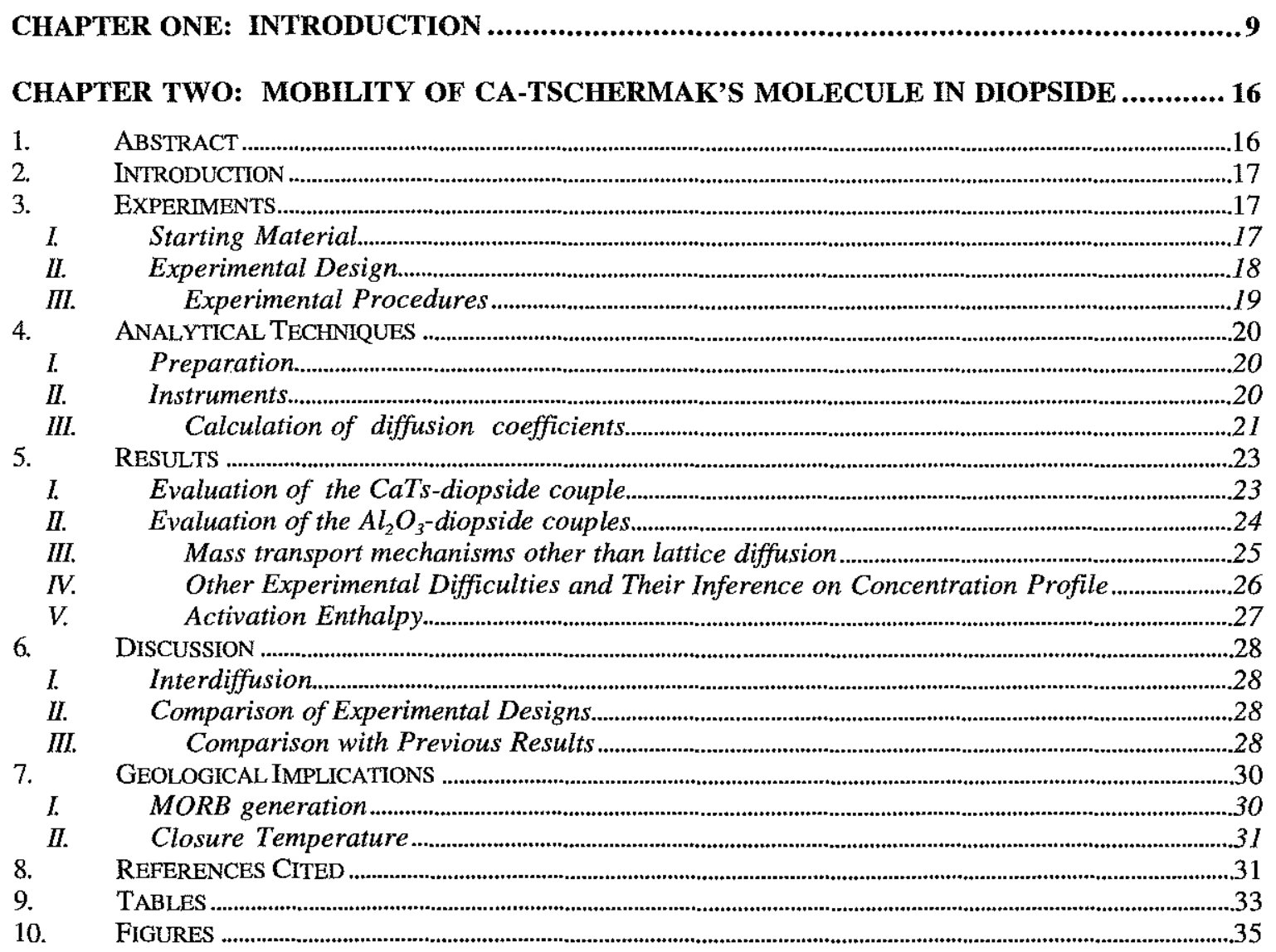

CHAPTER THREE: A KINETIC APPROACH FOR EXPERIMENTAL DETERMINATION OF THE GARNET-SPINEL PERIDOTITE FACIES TRANSFORMATION BOUNDARIES:

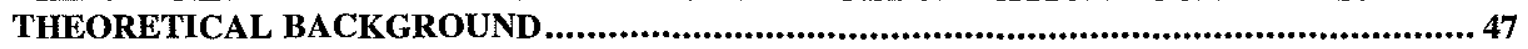

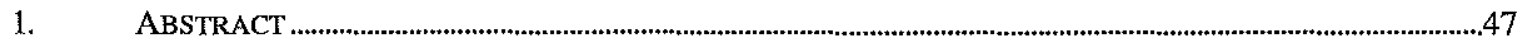

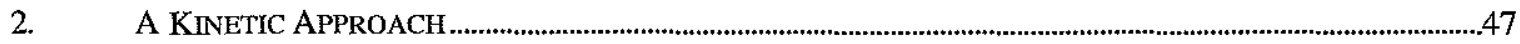

3. THEORY OF REACTION KINETICS .........................................................................................................................48

I. What is the reaction rate? .....................................................................................................................49

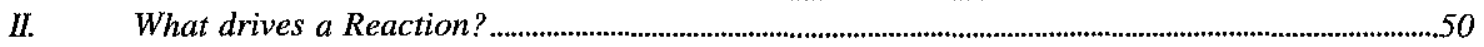

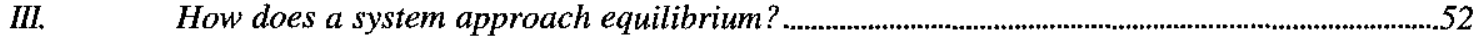

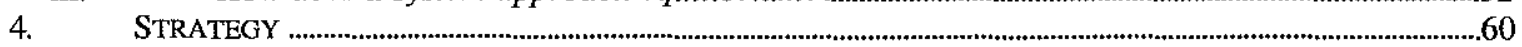

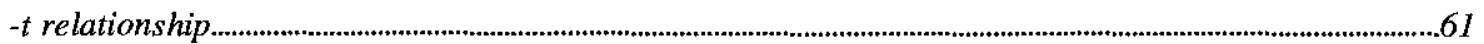

II. Relationship between reaction rate constant and intensive variable.............................................63

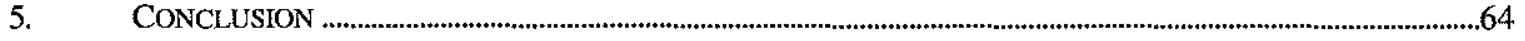

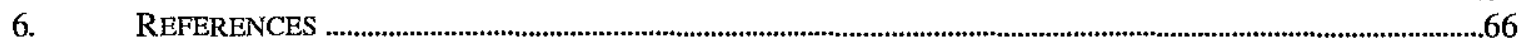

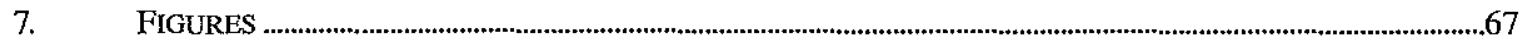

CHAPTER FOUR: A KINETIC APPROACH FOR EXPERIMENTAL DETERMINATION OF THE GARNET-SPINEL PERIDOTITE FACIES TRANSFORMATION BOUNDARIES:

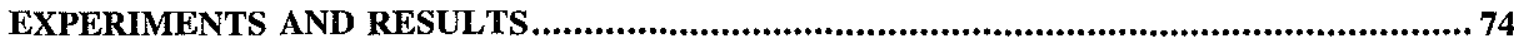

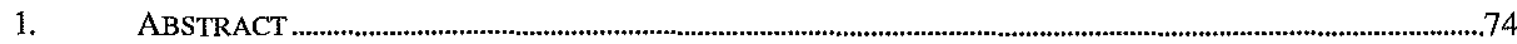




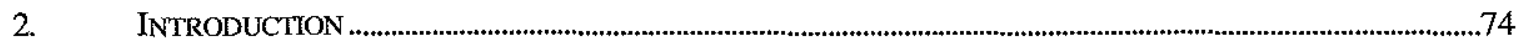

3. EXPERIMENTAL PROCEDURE …………………………………………........................................................................76

I. Starting materials..............................................................................................................................................76

II. Preparation.........................................................................................................................................................77

III. Experimental procedures................................................................................................................78

IV. Analytical procedures.........................................................................................................................78

4.

RESULTS AND DISCUSSIONS ...................................................................................................................

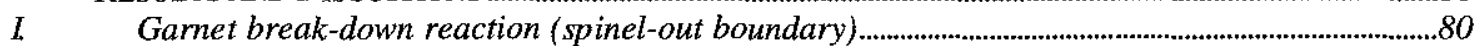

II. Mechanism of the garnet break-down reaction.............................................................................................83

III. $\quad$ Garnet formation (garnet-in) reaction ……….............................................................................................86

IV. Mechanism of garnet formation reaction...................................................................................................8

$V . \quad K-P$ relationship and boundary..................................................................................................

VI. Comparison with other experimental results...................................................................................91

5.

CONCLUSIONS ....................................................................................................................................................92

I. Pressure of garnet-spinel transformation ……..........................................................................................92

II. Metastable garnet in upwelling mantle?......................................................................................................92

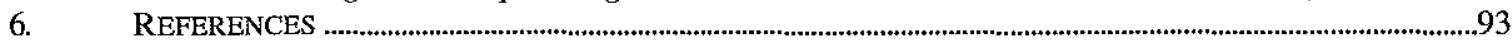

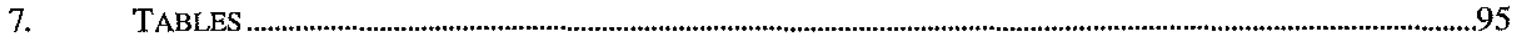

8. FIGURES ......................................................................................................................................................111

CHAPTER FIVE: WHERE DO TRACE ELEMENTS GO, AFTER THE GARNET-SPINEL

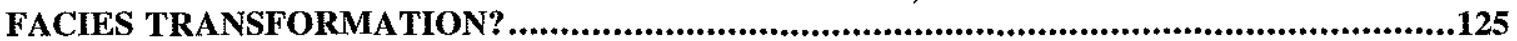

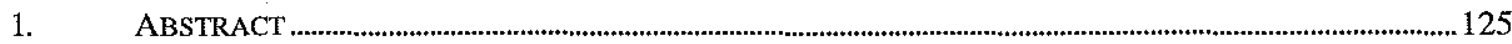

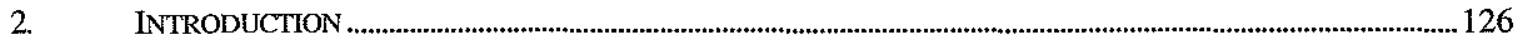

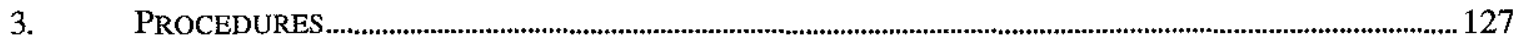

I. Conditions of experiments …………................................................................................................................... I27

II. Starting material............................................................................................................................................ 127

III. High pressure-temperature apparatus ............................................................................................. 127

IV. Ion probe analysis ............................................................................................................

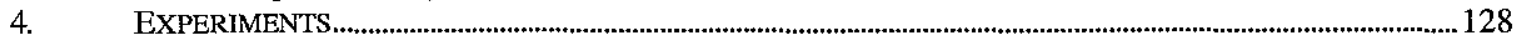

I. Measurements on experiments........................................................................................................ 128

II. Garnet break-down reaction in experiments............................................................................................ 129

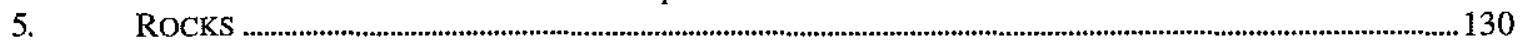

I. Lashaine peridotites ....................................................................................................................................

II. The Ronda Massif........................................................................................................................................ 132

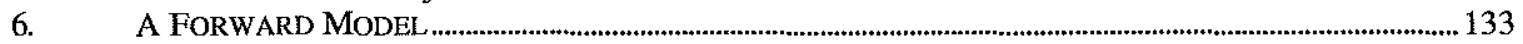

I. Results of the calculation.......................................................................................................... 134

II. Extent of disequilibrium ................................................................................................................................ 135

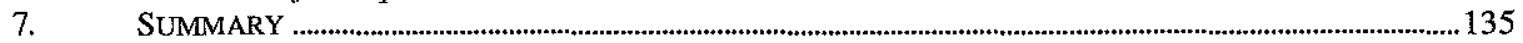

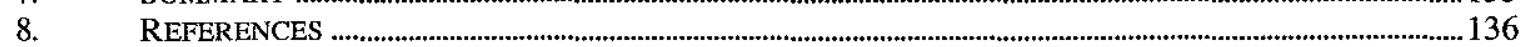

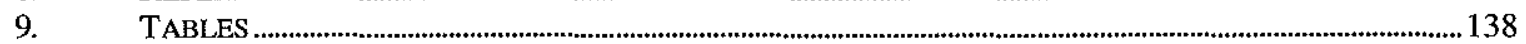

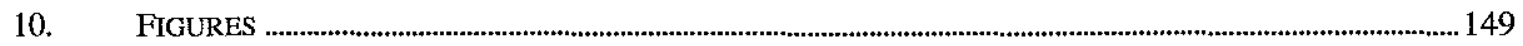

APPENDIX I

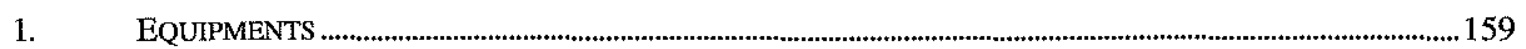

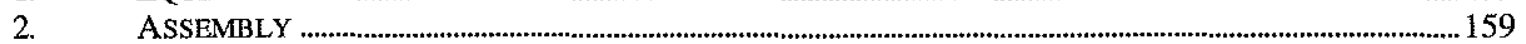

3. RUN PROCEDURE.....................................................................................................................................159

4. CALIBRATION …...............................................................................................................................................

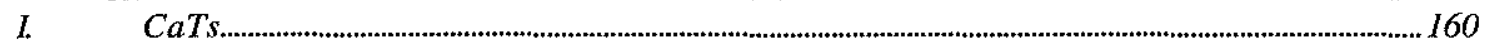

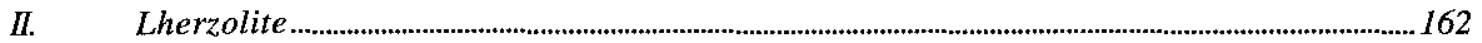

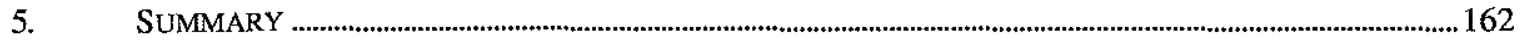

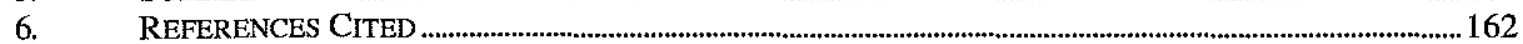

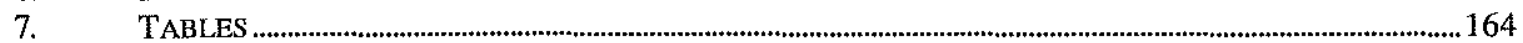

APPENDIX II 
1. "CLRPHASE2.M", MATLAB SCRIPT FILES FOR THE IMAGE ANALYSIS ……............................................165

2. "PHDET.M", A MATLAB SCRIPT FILE FOR DETERMINATION OF PHASE .....................................................166 


\section{Chapter One}

\section{Introduction}

Mid-ocean ridges are the largest magmatic systems on Earth that continuously erupt basalts produced by partial melting of the upper mantle, and are considered to be a zone where one of the planetary-scale chemical differentiation mechanisms is operating. One of the outstanding questions in MORB (mid-ocean ridge basalt) genesis is the relationship between magma quantities observed as crustal thicknesses and depths of magma generation.

With the widely accepted views of melt generation beneath ocean ridges such as those of McKenzie and Bickle (1988) and Langmuir et al. (1992), crustal thickness depends critically on mantle temperature and thus depth of melting. With an assumption of the melt production rate of $10 \% / \mathrm{GPa}(\sim 0.3 \% / \mathrm{km})$, a $7 \pm 1 \mathrm{~km}$ thick crust is produced when melting begins at depths shallower than $65 \mathrm{~km}$ (see summary and discussion in Hirschmann and Stolper, 1996).

A controversy began when geochemists accumulated evidence for the presence of garnet in the residue during MORB generation. The lines of geochemical evidence are: (1) the Hf paradox (Salters and Hart, 1989); (2) ${ }^{230}$ Th excess (e.g., Beattie, 1993; LaTourrette et al., 1993; among others); (3) Trace element patterns of some MORBs (e.g., Bender et al., 1984; and many others). Because it was commonly believed that garnet is stable at the peridotitic solidus at pressure greater than $3 \mathrm{GPa}$, the geochemical "garnet signatures" require that melting begin at depths greater than $100 \mathrm{Km}$, thereby conflicting with the "common" view mentioned above.

There have been several proposals for possible resolutions to this problem. Hirschmann and Stolper (1996) argued that geochemical garnet signatures are derived from melting garnet pyroxenite layers that are mixed in a peridotitic matrix. Since garnet is stable in basaltic compositions to lower pressures than in peridotites, mixing melts produced from 
peridotite in the spinel facies and from garnet pyroxenite could reconcile crustal thickness and garnet signatures.

There have been some efforts at examining whether an assumption about the melt production rate was correct, and whether it is plausible to reduce it to the extent that melting at depth where garnet is stable could still produce crust with appropriate thickness (e.g., Asimow et al., 1997; Yang et al., 1998).

For instance, Asimow reported a series of analysis on melting of multi-component systems and showed that $\mathrm{dF} / \mathrm{dP}$ (melt production rate) at constant $\mathrm{S}$ (entropy) is less than that at constant $\mathrm{H}$ (enthalpy) (Asimow et al., 1997) and that the melt production rate could be significantly reduced (or even zero) during the garnet to spinel lherzolite transformation (Asimow et al., 1995). Hirschmann (1994) also discussed reduction of $\mathrm{dF} / \mathrm{dP}$ by fractional melting.

The Bristol group published a series of papers recently on trace element partitioning between clinopyroxene and melt and argued that at the peridotite solidus at $1.9 \mathrm{GPa}$ where garnet is not believed to be stable, the cpx-melt partitioning resembles the garnet-melt relationship at least for $\mathrm{U}$ and $\mathrm{Th}$ to create ${ }^{230} \mathrm{Th}$ excess without garnet (Blundy et al., 1998; Robinson and Wood, 1998; Wood et al., 1999; Wood and Blundy, 1997).

Hirth and Kohlstedt (1996) proposed a creative solution to this problem. Based on the solubility of water and the water contents of nominally anhydrous mantle minerals at high pressures, they argued that upwelling mantle begins to melt at the water undersaturated solidus at a depth where garnet is stable. Because of high solubility of water in silicate melts, the system dries up and melting stops until the same parcel of mantle crosses the dry solidus at low pressures. In this scheme, melts extracted to form oceanic crust are mixtures between very small proportions of deep hydrous melt fractions that carry garnet signatures and shallow dry melt fraction, thus reconciling crustal thickness and geochemistry.

Dispite all these efforts, a fundamental question still remains; where is the spinel-garnet facies boundary for natural peridotite compositions? This thesis is an attempt to tackle this question head-on from the point of view of laboratory experiments.

Since Kushiro and Yoder (1966), experimental studies determined pressure-temperature conditions for the spinel-garnet facies boundary using synthetic and natural compositions. Figure 1.1 is a summary of experimental data, showing the location of the boundary for 
different bulk compositions. Comparing with the $\mathrm{CaO}-\mathrm{MgO}-\mathrm{Al}_{2} \mathrm{O}_{3}-\mathrm{SiO}_{2}$ (CMAS) system, O'Neil (1981) and Nickel (1986) examined effect of $\mathrm{Cr}$ and $\mathrm{Fe}$ on the location of the boundary. It was found that $\mathrm{Cr}$ shifts the boundary to higher pressures, whereas $\mathrm{Fe}$ exerts opposite effects. It is important to note that the spinel-garnet boundary is univariant for the CMAS system, but with more components added, the boundary becomes multivariant, and garnet and spinel coexist within a range of pressuretemperature conditions. The range is defined by the garnet-in boundary for the lowest pressure limit of garnet stability, and the spinel-out boundary for the highest-pressure limit for spinel stability.

One of the reasons for the widely scattered results shown in Figure 1.1 could be of experimental origin. Solid state reactions are known to be sluggish and attainment of equilibrium is always difficult, and some studies could have encountered this difficulty.

An approach taken for the present study is to take advantage of the difficulties for reaching equilibrium. The idea is to determine the rate of reaction as a function of distance from the equilibrium boundary, and determine its location by finding the pressuretemperature condition where the reaction rate becomes zero.

It is a common notion in metamorphic petrology that metamorphic reactions occur only when reaction boundaries are over stepped, and indeed the same approach has been attempted by several investigators (see a summary by Kerrick, 1990) for determination of reaction boundaries. For instance, Holdaway (1971) attempted to determine the boundary between andalusite and kyanite by placing andalusite at $\mathrm{P}, \mathrm{T}$ conditions where kyanite is stable. He determined the relationship between the rate of weight decrease of andalusite and temperature, and the location of the boundary was estimated from temperature where the rate approached zero.

The reaction of present interest is:

$$
\text { garnet }+ \text { olivine }=\text { opx }+ \text { cpx }+ \text { spinel. }
$$

Two sets of experiments were conducted. One was the "garnet breakdown reaction:" that is to bring a garnet + olivine mixture to pressure-temperature conditions where the assemblage is unstable (i.e., low-P side of the facies boundary) and determine the rate of reaction as a function of affinity. The other was the "garnet formation reaction", i.e. to 
bring a sp+opx $+\mathrm{cpx}$ mixture to the high $-\mathrm{P}$ side of the boundary and determine the rate laws.

A key to understanding the kinetics of these reactions is quantitative measurements of progress of the reaction. Back-scattered electron images of each experimental charge were digitally processed and quantities of reaction product minerals were determined.

A functional relationship between the reaction progress variable $(\xi)$ and time provides important insights into the mechanism of the reaction. Reaction progress was quantified using image processing of experimental charges. This approach has never been taken explicitly to determine a complex mineral facies boundary such as the one studied here, and it will be demonstrated that it really works. One chapter of this thesis is dedicated to a review of the theoretical background for the approach. It is to bring together a macroscopic kinetic theory (e.g., the KJMA theory, Avrami, 1939; Avrami, 1940; Avrami, 1941; Johnson and Mehl, 1939), in particular, the Avrami equation and its relationships to nucleation, growth and affinity. This exercise establishes a foundation for interpretation of the experimental results.

A question arises as to how trace elements behave during mineralogical reactions. For the garnet breakdown reaction, for example, elements residing in garnet must find residence in product minerals (mainly cpx and opx) accordingly to equilibrium partitioning. Is trace element equilibrium attained at the same rate as the major elements? If not, what are controlling factors for the retardation and how is the time scale of trace element reequilibration determined?

If trace element re-equilibration lags behind major elements after a phase change, and if it occurs in upwelling mantle beneath ocean ridges, does it affect melt compositions in any significant fashion? These questions require the knowledge of diffusive transport of trace elements in mantle minerals. Experimental determinations of diffusivities of important trace elements are in progress (Van Orman et al., 1998). An attempt is made in the present study along this line to determine the mobility of Ca-Tschermak's components in diopside. This was pursued with the idea that diffusion of many geochemically important non-divalent ions could be associated with that of charge-balancing aluminum, and the CaTs mobility could provide a benchmark data set. 
Overall, natural processes occur because of initially disequilibrium conditions and kinetics of natural processes hold an important step toward a better understanding of the workings of the Earth.

\section{Reference}

Asimow P. D., Hirschmann M. M., Ghiorso M. S., O'Hara M. J., and Stolper E. M. (1995) The effect of pressure-induced solid-solid phase transitions on decompression melting of the mantle. Geochimica et Cosmochimica Acta 59, 4489-4506.

Asimow P. D., Hirschmann M. M., and Stolper E. M. (1997) An analysis of variations in isentropic melt productivity. Philosophical Transaction of the Royal Society of London, Series A 355, 255-281.

Avrami M. (1939) Kinetics of Phase Change. I. Journal of Chemical Physics 7, 1103-1112.

Avrami M. (1940) Kinetics of Phase Change. II. Journal of Chemical Physics 8, 212-224.

Avrami M. (1941) Granulation, phase change and microstructure: Kinetics of phase change III. Journal of Chemical Physics 9, 177-184.

Beattie P. (1993) Uranium-thorium disequilibria and partitioning on melting of garnet peridotite. Nature 363, 63-65.

Bender J., Langmuir C., and Hanson G. (1984) Petrogenesis of basalt glasses from the Tamayo region, East Pacific Rise. Journal of Petrology 25, 213-254.

Blundy J., Robinson J., and Wood B. (1998) Heavy REE are compatible in clinopyroxene on the spinel lherzolite solidus. Earth and Planetary Science Letters 160, 493-504.

Holdaway, M. J. (1971) Stability of andalusite and the aluminum silicate phase diagram. Amer. J. Sci. 271, 97-131

Hirschmann M. M. and Stolper E. M. (1996) A possible role for garnet pyroxenite in the origin of the "garnet signature" in MORB. Contribution to Mineralogy and Petrology 124, 185-208.

Hirschmann M. M., Stolper E. M., and Ghiorso M. S. (1994) Perspectives on shallow mantle melting from thermodynamic calculations. Mineral Magazine 58A, 418-419.

Hirth G. and Kohlstedt D. L. (1996) Water in the oceanic upper mantle: implications for rheology, melt extraction and the evolution of the lithosphere. Earth Planetary Science Letter 144, 93-108.

Johnson W. and Mehl R. F. (1939) Trans AIME 135, 416-442.

Kerrick D. (1990) The $\mathrm{Al}_{2} \mathrm{SiO}_{5}$. The Mineralogical Society of America.

Kushiro I. and Yoder H. S. J. (1966) Anorthite-Forsterite and Anorthite-Enstatite Reaction and bearing on the Basalt-Eclogite Transformation. Journal of Petrology 7, 337-362.

Langmuir C. H., Klein E. M., and Plank T. (1992) Petrological Systematics of Mid-Ocean Ridge Basalts: Constraints on Melt Generation Beneath Ocean Ridges. In Mantle Flow and Melt Generation at Mid-Ocean Ridges, Vol. 71 (ed. J. P. Morgan, D. K. Blackman, and J. M. Sinton), pp. 183-280. Americal Geophysical Union. 
LaTourrette T. Z., Kennedy A. K., and Wasserburg G. J. (1993) Thorium-Uranium Fractionation by Garnet: Evidence for a Deep Source and Rapid rise of Oceanic Basalts. Science 261, 739-742.

McKenzie D. and Bickle M. J. (1988) The Volume and Composition of Melt Generated by Extension of the Lithosphere. Journal of Petrology 29, 625-679.

Nickel K. G. (1986) Phase equilibria in the system SiO2-MgO-A12O3-CaO-Cr2O3 (SMACCR) and their bearing on spinel/garnet lherzolite relationships. Neues Jahrbuch Miner. Abh. 155, 259-287.

O'Neill H., St.C. (1981) The transition between spinel lherzolite and garnet lherzolite, and its use as a geobarometer. Contrib. Mineral. Petrol. 77, 185-194.

Robinson J. A. C. and Wood B. J. (1998) The depth of the spinel to garnet transition at the peridoite solidus. Earth and Planetary Science Letters 164, 277-289.

Salters V. J. M. and Hart S. R. (1989) The hafnium paradox and role of garnet in the source of mid-ocean-ridge basalts. Nautre 342, 420-422.

Van Orman J. A., Shimizu N., and Grove T. L. (1998) Rare earth element diffusion in diopside and disequilibrium melting in the mantle. EOS. Transactions, $\mathrm{S} 371$.

Wood B., Blundy J., and Robinson J. (1999) The role of clinopyroxene in generating U-series disequilbirum during mantle melting. Geochimica $t$ Cosomochimca Acta 63, 1613-1620.

Wood B. J. and Blundy J. D. (1997) A predictive model for rare earth element partitioning between clinopyroxene and anhydrous silicate melt. Contributions to Mineralogy and Petrology 129, 166-181.

Yang H.-J., Sen G., and Shimizu N. (1998) Mid-ocean ridge melting: Constraints from lithospheirc xenoliths at Oahu, Hawaii. Journal of Petrology 39, 277-295. 


\section{Figure}

Figure 1.1: Experimentally determined spinel to garnet facies reaction boundaries in simple and natural peridotitic compositions. [a] CMAS-Na solidus. Subsolidus reaction boundaries (dashed curves) are inferred (Walter and Presnall, 1994). [b] CMAS (Kushiro and Yoder, 1966). [c1] Natural, and [c2] CMAS (Jenkins and Newton, 1979). [d1] CMAS, [d2] CMASCr at $\mathrm{XCrSp}=0.1$, and [d3] CMASCr at $\mathrm{XCrSp}=0.2$ (O'Neill, 1981). [e] Natural system by O'Hara et. al. (1971). [f1] CMASCr at garnet-in and [f2] spinel-out by Nickel (1986).

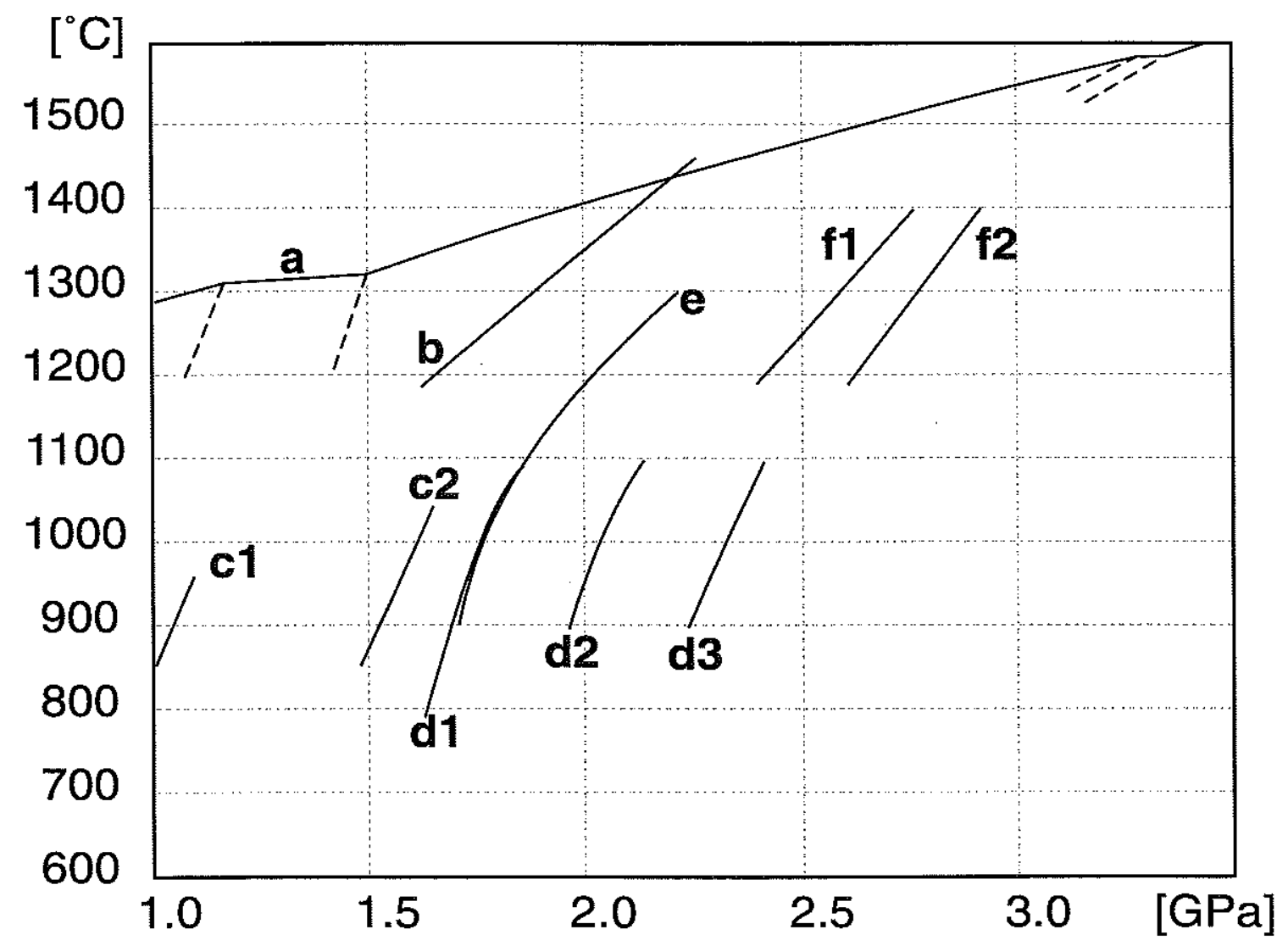




\section{Chapter Two}

\section{Mobility of \\ Ca-Tschermak's Molecule in Diopside}

\section{Abstract}

This work reports the results of experiments designed to measure the diffusion rate of $\mathrm{Al}$ in diopside at conditions relevant to melting in the upper mantle. Interdiffusion rates of $\mathrm{A}^{\mathrm{VI}} \mathrm{Al}^{\mathrm{IV}}-\mathrm{Mg}^{\mathrm{VI}} \mathrm{Si}^{\mathrm{VV}}$ were measured using both $\mathrm{CaTs}\left(\mathrm{CaAlAlSiO}{ }_{6}\right)$ - diopside $\left(\mathrm{CaMgSi}_{2} \mathrm{O}_{6}\right)$, and corundum $\left(\mathrm{Al}_{2} \mathrm{O}_{3}\right)$-diopside couples. The Arrhenius relation determined at $1.5 \mathrm{GPa}$, over a temperature range of 1250 to $1350^{\circ} \mathrm{C}$ is:

$$
D=\left[4.05 \times 10^{-4}\left(\mathrm{~m}^{2} / \mathrm{s}\right)\right] \exp \left[\frac{-374(\mathrm{~kJ} / \mathrm{mol})}{R T(\mathrm{~K})}\right] \quad\left(\mathrm{m}^{2} / \mathrm{s}\right) .
$$

When the diffusion rates for $\mathrm{Al}$ in clinopyroxene are evaluated in the context of the time necessary for a pyroxene grain to equilibrate from its core to rim, the time scales of pyroxene equilibration are rapid relative to the time scale of melt generation beneath midocean ridges. Thus, this major element in the melt is in equilibrium with high-Ca clinopyroxene during melting. In contrast, trace element diffusivities in diopside are significantly slower than that of major elements. This difference in diffusivities suggests the decoupling of major and trace element behavior during melting of diopside.

Chemical transport mechanisms other than diffusion are also observed in these experiments. These transport mechanisms are apparently related to the presence of a fluid phase on the crystal interface, which is inferred to be a water-rich silicate melt. These new mechanisms may be grain boundary migration and suggest that chemical transport mechanisms other than diffusion operate in the melt production regime. 


\section{Introduction}

Kinetics of diffusion of elements in mantle minerals can potentially exercise important controls on a number of geological processes. As diffusion rates diminish, the possibility arises that a mineral can be out of equilibrium with its surroundings. Solid state diffusion processes limit a system's ability to approach chemical equilibrium. Determination of diffusivities is a key to uncovering temporal constraints on equilibration. Aluminum diffusion into pyroxene is critical in following applications: 1) temporal constraints on chemical reactions (e.g. mantle melting) where Al diffusion in pyroxene likely to limit the equilibration processes, 2) partitioning of trivalent incompatible elements $\left(\mathrm{R}^{3+}\right)$ influenced by CaTs content in high-Ca clinopyroxene (Gaetani and Grove, 1995), and 3) closure temperature determination for pyroxene geobarometers (i.e. opx) using $\mathrm{Al}$ distribution.

Aluminum is incorporated into pyroxene by the Tschermak's substitution where $\mathrm{Al}^{\mathrm{VI}} \mathrm{Al}^{\mathrm{IV}}-\mathrm{Mg}^{\mathrm{VI}} \mathrm{Si}^{\mathrm{iV}}$ allows charge balance with trivalent cations in the IV-fold and VI-fold sites. The interdiffusion of the Tschermak's substitution with the MgSi couple is chemical diffusion that occurs in the presence of chemical potential gradient. This paper describes results of an experimental study of the diffusion of $\mathrm{Al}$ in clinopyroxene. Interdiffusion coefficients were determined over a range of pressures and temperature conditions.

\section{Experiments}

\section{Starting Material}

The starting diopside crystals for the diffusion experiments are an essential component of experimental design. Ideally, the starting crystal should be homogeneous and free of fluid inclusions. Two natural diopsides were used for the experiments. Metamorphic diopside from Eden Mills, New York, USA contain clear regions and parts that are opaque (white), due to the presence of micro fractures and fluid inclusions. Only the clear part of the diopside was used for experiments. The composition of Eden Mills diopside is close to pure diopside (Table 2.1). Even in the optically clear parts of the Eden Mills starting material, there were fluid inclusions. These were often discovered when the run products were examined after an experiment. We also used diopside from Kunlun Mountains, Xinnang Uygur, China, which proved to be a significantly better crystalline starting 
material. Kunlun Mts. diopside is clear, green diopside that contains slightly higher $\mathrm{Na}$ and Al (Table 2.1) than the Eden Mills sample. This starting material is homogeneous and contains cm-sized volumes that are optically free of fluid inclusions The conditions of formation of the Kunlun starting material are unknown. In following sections, we use the terms, "wet" and "dry" conditions, for high and low water activities imposed by the fluid inclusions in the diopside starting material.

\section{Experimental Design}

Two diffusion couples were used: in the first, a Ca-Tschermakite (CaTs, CaAlAlSiO 6 ) polycrystalline aggregate was placed against a single diopside crystal and annealed, and in the second, $\mathrm{Al}_{2} \mathrm{O}_{3}$ oxide powder was deposited on a single crystal of diopside and annealed. Concentration profiles of $\mathrm{Al}$ were obtained both by cross-section traversing using the electron microprobe, and by vertical depth profiling using the ion microprobe. All starting diopside crystals were carefully picked, avoiding inclusions, fractures, and any optically detectable inhomogeneity. The crystals were cut perpendicular to the c-axis and the surface was polished using alumina powder to $0.3 \mu \mathrm{m}$ grit. Most of starting crystals were heat treated at $1200^{\circ} \mathrm{C}$ under controlled oxygen fugacity near the FMQ buffer for 24 hours. This process is intended to drive off any volatile component in the crystal, to heal surface damage caused by polishing, and to impose a defect concentration at a controlled oxygen fugacity. Later we found that preconditioning starting diopside crystals prevented experiments from melting.

Two types of diffusion couples were designed to meet the requirements of boundary conditions for the models of diffusion. The first design was a CaTs - diopside diffusion couple. A single crystal slab of Eden Mills diopside was juxtaposed against a polished slab of pre-synthesized polycrystalline CaTs. This geometry approximates a two semiinfinite reservoir boundary condition (Figure 2.2a). The other experimental configuration was an $\mathrm{Al}_{2} \mathrm{O}_{3}$ - diopside diffusion couple in which a thin source of corundum was deposited on top of the polished surface of Kunlun Mts. diopside (Figure 2.3). This geometry approximates a boundary condition of either a thin source semi-infinite sink or two semi-infinite reservoirs, depending on diffusivity and duration of experiments. Also, a thin diffusant layer facilitated sample preparation for the ion microprobe analysis, and it was also important because the ion microprobe can resolve the finer details of 
concentration profiles. The direction of diffusion for all experiments was parallel to the caxis of diopside, which is the fastest diffusion direction (e.g., Sneeringer et al., 1984).

\section{Experimental Procedures}

For the preparation of CaTs - diopside diffusion couples, polycrystalline CaTs was synthesized from a CaTs composition glass powder in a piston cylinder apparatus at pressure and temperature in the stability region of CaTs. The synthesized CaTs was recovered from a charge and polished using $\mathrm{SiC}$ sanding paper to 600 grit. The polished CaTs surface was placed against the polished surface of the diopside slab and the couple was wrapped in Pt foil. The diffusion couples were then packed in a Pt capsule with graphite powder. The capsule was dried for least 10 hours in $110^{\circ} \mathrm{C}$ oven before being sealed.

For $\mathrm{Al}_{2} \mathrm{O}_{3}$ - diopside diffusion couples, aluminum was deposited on the surface of a polished Kunlun Mts. diopside from a nitric acid solution. This solution was evaporated by heating on a hot plate. The remaining aluminum nitrate compound was oxidized to drive off the nitrogen by exposing the crystal to a flame for a few seconds. White $\mathrm{Al}$ oxide powder was then formed on the surface. The diopside with $\mathrm{Al}$ oxide layer was then wrapped in Pt foil, and packed in a Pt capsule with graphite powder, and sealed after drying for at least 5 hours in $110^{\circ} \mathrm{C}$ oven. During the run, $\mathrm{Al}$ is expected to be incorporated into diopside. The details of the incorporation mechanism are discussed in a later section.

All the experiments were run under pressure-temperature conditions of CaTs stability (Fig. 1; Hays, 1967), where CaTs and diopside form a complete solid solution (Hays, 1967; Wood, 1979). At $1 \mathrm{~atm}$, solubility of $\mathrm{Al}$ into the diopside is limited (9.35 $\mathrm{wt} \%$ $\mathrm{Al}_{2} \mathrm{O}_{3}$ ) and CaTs pyroxene breaks down to corundum, gehlenite, anorthite, and spinel (de Neufville and Schairer, 1962). In order to exchange AlAl-MgSi at complete solid solution, the pressure-temperature condition had to be in the stability field of CaTs. The sealed capsules were annealed isothermally for 10 to 190 hours in a piston cylinder apparatus. Detailed procedures for the piston cylinder apparatus are found elsewhere (e.g., Wagner, 1995). 


\section{Analytical Techniques}

\section{Preparation}

Following the diffusion anneal, crystals were cut and polished perpendicular to the crystal interface for electron microprobe analysis. Samples used for ion probe depth profiling analysis were polished semi-parallel to the interface at a slight angle to prevent the loss of the interface and polishing into the underlying diopside below the interface. This polishing method made it possible to recognize the interface, because the interface should be at the boundary between the polished and unpolished surface. Depth profile analyses were conducted around this exposed interface. The tilt of crystals was found in all cases to be less than $10^{\circ}$, which resulted in less than $2 \%$ depth correction.

\section{Instruments}

An electron microprobe at MIT (JEOL 733 superprobe) was used to measure major element compositions in sectioned experiments. The beam current was $10 \mathrm{nA}$ and accelerating voltage was $15 \mathrm{kV}$. The cross-section samples were traversed in $2 \mu \mathrm{m}$ increments, which was the minimum increment considering $\sim 3 \mu$ m diameter excitation volume. The entire compositional profile often could not be measured, because of the rounding of the edge of the crystal by polishing, . This necessitated the development of a numerical method for computing the diffusion coefficient that did not require measurement of the exact composition at the upper boundary.

The ion microprobe at WHOI (Cameca IMS 3f) was used to determine concentration profiles of $\mathrm{Na}, \mathrm{Mg}, \mathrm{Al}, \mathrm{Si}$, and $\mathrm{Ca}$ by a depth profiling method described in detail elsewhere (e.g., Sneeringer et al., 1984; Zinner, 1980). Typically, a primary beam current of $100 \sim 50 \mathrm{nA}$ with $80 \sim 50 \mu \mathrm{m}$ beam diameter was achieved. The analytical conditions consisted of a $40 \mu \mathrm{m}$ raster with $8 \mu \mathrm{m}$ field aperture centered at rastering area, $\pm 10 \mathrm{~V}$ energy window with an $-80 \mathrm{~V}$ energy offset. The beam crater depth was measured by a stylus-type profilometer (DEKTAK8000). Five cations were monitored and used to reconstruct pyroxene composition. Because the elements have different ionization efficiencies that have not been quantitatively calibrated, we used six-oxygen normalized cation abundances determined by electron probe analyses on the starting diopside as a standard. For calculation of diffusion coefficients, the ratio of counts of ${ }^{27} \mathrm{Al}^{+}$to ${ }^{40} \mathrm{Ca}^{+}$ $\left({ }^{27} \mathrm{Al}^{+} / 40 \mathrm{Ca}^{+}\right)$was used as the analog of the concentration assuming that ${ }^{40} \mathrm{Ca}^{+}$ concentration is homogeneous in the annealed sample. 
In most ion probe depth profiles, there is a discrepancy between the diffusion model fits and the observations. For example, the near-surface part of the concentration profile always deviates from the model and the concentration profile converges to the model curve at approximately the same distances. The deviation is caused by the interactions of the ion beam and sample surface, and it is important to quantitatively assess the instrumental uncertainty. There are three phenomena that influence the shape of concentration profiles: gardening, knock-on, and sample surface roughness. Gardening is the contribution of material from the side wall of the crater. This effect is treated by introducing a mechanical aperture over the rastered area. The knock-on effect is the contribution of atoms that are knocked deeper into the sample. This effect dissipates within the first $200 \mathrm{~nm}$ (Zinner, 1980), and its influence on the shape of profile is limited. The crystal surface after long diffusion runs has rough topography with a range of $800 \mathrm{~nm}$ at most. Shorter duration experiments do not develop such roughness. Uncertainty contributed from surface roughness is inferred to be less than the estimated error of diffusivities, because the range of surface roughness is less than $0.5 \%$ length of diffusion profile. The first few points of an ion microprobe depth profile could not be accurately measured until beam cratering achieved steady state. As a consequence of these problems, we used a numerical inversion method that does not require the exact composition at the boundary for determining the diffusivity. Overall, the apparent fit of data to the model is judged to be acceptable, and the models of concentration versus depth are a reasonable approximation of the measured profiles. In the cases of longer depth profiles, these are similar to profiles obtained with the electron microprobe measurements, and the calculated diffusion coefficients from the two measurment techniques are in agreement (Table 2.2).

\section{Calculation of diffusion coefficients}

For the interdiffusion experiments of CaTs-diopside pairs that resulted in smooth change in concentrations from the both ends (Figure 2.2b), diffusion coefficients were calculated by the Boltzmann-Matano analysis (Matano, 1933). The Boltzmann-Matano interfaces determined from $\mathrm{Al}$ and $\mathrm{Mg}$ concentration profiles were located at the same point. The interface is indicated by the vertical line, (Figure 2.2b). The agreement in the interfaces is evidence for $\mathrm{Al}^{\mathrm{VI}} \mathrm{Al}^{\mathrm{IV}}-\mathrm{Mg}^{\mathrm{VI}} \mathrm{Si}^{\mathrm{IV}}$ interdiffusion, because $\mathrm{Al}$ and $\mathrm{Mg}$ fluxes in and out of diopside are balanced at the single boundary. Due to diffusion mass transport, the Boltzmann-Matano interface moved into the CaTs from the starting interface as the 
illustrated in idealized calculation (Figure 2.2a). Diffusion coefficients could be calculated at each point in the profile by numerical integration of the area under the concentration profile using a trapezoid approximation, and approximating the slope $(\mathrm{dx} / \mathrm{dc})$ by difference. At the tail end of $\mathrm{Al}$ concentration profiles, the combination of low $\mathrm{Al}$ concentrations and analytical errors results in significant variation in the diffusion coefficients calculated in this manner. The representative diffusion coefficients were calculated by taking the average of the values measured at each point in the concentration profile. This averaging assumes that the rate of $\mathrm{Al}^{\mathrm{VI}} \mathrm{Al}^{\mathrm{IV}}-\mathrm{Mg}^{\mathrm{VI}} \mathrm{Si}{ }^{\mathrm{V}}$ exchange in diopside is independent of $\mathrm{Al}$ concentration. This assumption is justified, because the systematic correlation of diffusion coefficients and $\mathrm{Al}$ concentration was not observed. The uncertainties in the diffusion coefficients were calculated from the spread of the values; one standard deviation was approximately $70 \%$ for each experiment.

Diffusion coefficients for the $\mathrm{Al}_{2} \mathrm{O}_{3}$ - diopside pairs were calculated from the concentration profiles based on electron microprobe and ion probe. As discussed below, concentration profiles inconsistent with diffusion were not used for the calculation. We assumed that the diopside was effectively a semi-infinite medium and that $\mathrm{Al}$ concentration at the interface was constant through out each diffusion anneal, which is one of the end member cases of the model (dash-dot line, Figure 2.3). A constant interface concentration is justified because concentration at the interface was similar for each experiment, and because $\mathrm{Al}$ oxide often remained on the interface. The solution for such geometry is described in detail by (Shewmon, 1989).

$$
C(x, t)=C i-(C i-C o) e r f\left(\frac{x}{2 \sqrt{D t}}\right)
$$

The diffusivities were calculated by a non-linear fit of Eqn. 1 by the gradient convergence method (Bevington, 1969). The same method was used for determining Ds for the both electron microprobe and ion probe depth profiles. The fit varies three parameters: $\mathrm{Ci}, \mathrm{Co}$, and $\mathrm{D}$, because interface concentration (Ci) could not accurately measured and $\mathrm{D}$ is unknown. An example of a fit to a concentration profile measured with the ion probe is shown in Figure 2.4. The errors associated with the fits for electron microprobe measurements were $\sim 40 \%$, and calculated by the Monte Carlo method. By varying observed distance and concentration values within the range of measurement uncertainties (i.e., $\mathrm{X} \pm 1 \mu \mathrm{m}$ and $\mathrm{C} \pm 3 \%$ ), more than one hundred randomly generated concentration 
profiles result in distributions of calculated values of $\mathrm{D}, \mathrm{Ci}$, and $\mathrm{Co}$. One standard deviation of these generated distributions are used as the propagated errors of the results of the non-linear fits. The same method determined the diffusivity error associated with ion probe profiles as $\sim 20 \%$ standard error, given $\mathrm{X} \pm 15 \%$, and $\mathrm{C} \pm 4 \%$.

\section{Results}

\section{Evaluation of the CaTs-diopside couple}

The diffusion coefficients from the CaTs - diopside interdiffusion experiments are plotted in Figure 2.5 and tabulated in Table 2.1. Error bars are $70 \%$ of the value as previously discussed. Filled symbols are the diffusivities measured in unconditioned Eden Mills diopside, and the open symbol is for preconditioned Eden Mills diopside. An increase of diffusivity with the increase in temperature is evident. The difference between "dry" and "wet" starting diopside can not be resolved within the accuracy of the experiments.

The CaTs - diopside interdiffusion couple confirmed interdiffusion of $\mathrm{Al}^{\mathrm{VI}} \mathrm{Al}^{\mathrm{IV}}$ and $\mathrm{Mg}^{\mathrm{VI}} \mathrm{Si}^{\mathrm{IV}}$. Continuous exchange from the CaTs end member composition to the diopside end member composition is shown by complementary compositional profiles of $\mathrm{Mg}$ and $\mathrm{Al}$ (Figure 2.2b). An idealized diffusion couple shows a smooth, near symmetric composition profile (Figure 2.2a).

Concentration profiles observed in a single experiment are presented as line 1 and line 2, respectively (Figure 2.2b). The penetration distance of $\mathrm{Al}$ is apparently different. The longer profile (line 1) has the long plateau inside the diopside crystal, and the shape of the profile is not near the shape expected from the model. Thus, it is not produced by diffusion (compare to Figure 2.2a). The longer concentration profile (line 1) resulted from a transport process other than lattice diffusion; the length of longer profile is $\sim 40 \mu \mathrm{m}$ from pure CaTs composition to diopside, while the shorter profile is $\sim 20 \mu \mathrm{m}$. The profiles of this kind are not included in the analysis of lattice diffusion. The second profile (line 2) is a typical concentration profile used for calculation of diffusion coefficients. It may not be as smooth as expected from the diffusion process due to cracks in the sample, but it more closely resembles a diffusion profile than line 1 (Figure 2.2). Following these arguments, the criteria used to discriminate processes other than diffusion are length of penetration and shape of profile. 


\section{Evaluation of the $\mathrm{Al}_{2} \mathrm{O}_{3}$-diopside couples}

The diffusion coefficients determined from each compositional profile for Al oxide diopside couples are plotted in Figure 2.6. The diffusivities determined from the both electron microprobe and ion probe are shown. The experiments are unable to resolve the effect of pressure on diffusivity. The diffusion coefficients from the 1.5 to $1.7 \mathrm{GPa}$ experiments overlap, and spread by about an order of magnitude. Diffusion coefficients estimated by electron microprobe and ion probe measurements are generally in agreement. All the results presented here used pre-conditioned Kunlun Mts diopside as starting material. The spread of diffusion coefficients is caused by the limited spatial resolution of the electron microprobe composition profiles, and compostional heterogeneity from non-diffusive transport mechanisms. The distinction between faster diffusion paths and lattice diffusion can be made by observing the shape of the concentration profile and the distance of penetration. Here, we assumed that the shortest diffusion profiles represented the closest approximation to the lattice diffusion. Given the confidence of fit and scatter of diffusivities, we used a simple average as the representative value of the lattice diffusion coefficient for each experiment.

Diffusion in the $\mathrm{Al}_{2} \mathrm{O}_{3}$ - diopside diffusion couples could occur by a process that is different from the CaTs - diopside diffusion exchange. Two kinds of $\mathrm{Al}$ incorporation into diopside are possible. The proposed substitution is one $\mathrm{Mg}$ and one $\mathrm{Si}$ with two $\mathrm{Al}$ atoms. This requires $\mathrm{Mg}$ and $\mathrm{Si}$ atoms to leave the surface, and diopside will not grow (Figure 2.3). Another possibility is Ca and Mg Tschermak's substitution of $\mathrm{Al}$ atoms into diopside. This will result in the growth of interface by incorporation of Al because:

(Figure 2.3),

$$
2 \mathrm{Al}_{2} \mathrm{O}_{3}+\mathrm{CaMgSi}_{2} \mathrm{O}_{6}->\mathrm{CaAlAlSi}_{2} \mathrm{O}_{6}+\mathrm{MgAlAlSi}_{2} \mathrm{O}_{6}
$$

The results of compositional variations used for diffusivity determination allow discrimination of these two diffusion mechanisms (Figure 2.7a). When the composition is projected on Wollastonite-Corrundum-Enstatite ternary, they follow the CaTs-Di join, instead of the Corrundum-Di join on CaTs-MgTs-Di solid solution plane. There were also compositional variations extending in directions other than the CaTs-Di join. They are usually shifted towards Wo-rich composition, and these compositional profiles are not used to determine diffusivity. We suspect that these variations are caused by inconsistency due to the amount of $\mathrm{Al}_{2} \mathrm{O}_{3}$ on the surface and unrecognized inhomogeneity 
in starting diopside. The profiles that deviated from CaTs - Di join do not show the characteristic diffusion shape, and good diffusion fits generally plotted on the CaTs - Di join. Thus, we only used Ca-Tschermak's interdiffusion in profiles that extended along the CaTs-Di join on the pyroxene ternary plot.

The electron microprobe analysis of a diffusion anneal of the $\mathrm{Al}$ oxide- diopside pair is shown (Figure 2.8). The undulation of concentration front is recognized by $\mathrm{Al} x$-ray mapping, and illustrated as shaded section in Figure 2.8. In order to confirm the undulatory structure of the penetration of $\mathrm{Al}$, multiple electron microprobe traverses were taken for each sample. Two representative lines have distinctively different concentration profiles (Figure 2.8). Each line corresponds to a line shown in the illustration. The near interface concentration is similar for all profiles $(14 \sim 16 \mathrm{wt} \%$ $\mathrm{Al}_{2} \mathrm{O}_{3}$ ). The shorter concentration profile (line 2) which is smooth and monotonically decreasing from the interface was selected for calculation of diffusion coefficients. The longer diffusion profile (line 1) had broader concave-down shape which is different from the concentration profile expected for diffusion. Other concentration profiles showed a hump, no concentration gradient, or a plateau near the interface.

\section{Mass transport mechanisms other than lattice diffusion}

Lattice diffusion should produce a planar concentration front parallel to the interface. However, most experiments reveal a non-planar undulating concentration front. We have described the criteria used to distinguish diffusion-like profiles from non-diffusion profiles, avoiding the discussion of the actual mechanism that causes the phenomenon. There are two transport processes other than lattice diffusion that can create complex geometry at the interface. Chemically induced grain boundary migration is one possible phenomenon. This phenomenon has been observed to generate an undulatory interface (Hay and Evans, 1987), and can explain the undulatory profile in the diopside. One of proposed mechanisms of chemically induced grain boundary migration is that a thin layer (nanometers thickness) of liquid wetting the grain boundary drives dissolution/reprecipitation to move the grain boundary (Evans et al., 1986; Handwerker, 1988). The presence of fluid inclusions and melts in some of our experiments suggests that liquid may be present at the interface. Thus, chemically induced grain boundary migration due to liquid film migration may operate in these experiments. To test for this mechanism, we would need to carry out a perfectly dry experiment, but this is not 
feasible with our natural starting material. Chemically induced grain boundary migration has not been reported in any silicate material. Therefore, this study may represent the first description of the operation of this process in geological materials.

In contrast, the presence of faster diffusion paths such as subgrain boundaries or dislocation pipes could also be responsible for undulation of the concentration front (Harrison, 1961). The faster diffusion paths would produce longer concentration profiles, while lattice diffusion profile would be shorter. The shape of long or short diffusion profiles would be similar when the direction of diffusion is the same. The combined effect of grain boundary and lattice diffusion has been demonstrated in natural crystal aggregates, and diffusion along grain boundaries is demonstrated to be three orders of magnitude faster than bulk diffusion for oxygen self diffusion in quartz (Farver and Yund, 1992). We may be seeing similar differences in our experimental charges. The effective diffusivity is a function of the thickness of subgrain boundary and diffusivities of lattice and subgrain boundary, and spacing of the grain boundaries. None of parameters to characterize the lattice-subgrain boundary diffusion is available for pyroxene.

Either chemically induced grain boundary migration or fast diffusion paths could be responsible for undulating concentration front, and the observations do not exclude either mechanism. In some experiments, we have observed presence of fluid inclusions and melt pockets that may become a source of a nano-meters thick liquid film on the interface. This could results in chemically induced grain boundary migration. We have also observed recrystallized subgrain boundaries near a part of the interface of diopside in a thin-sectioned experimental charge. These could be formed by grain boundary migration while providing faster diffusion paths.

\section{Other Experimental Difficulties and Their Inference on Concentration Profile}

Small patches of liquid are often found within CaTs polycrystalline aggregate and diopside. The liquid found in diopside is probably due to the presence of water that decreases the melting point. The presence of fluid inclusions in starting diopside from the early Eden Mills experiments led to melting. Despite our best efforts to choose only samples that were free of visible fluid inclusions, some experiments with Eden Mills diopside melted. Experiments with melts of this kind are not used for the calculation of diffusion coefficients. The liquid found in CaTs aggregate is melt that is probably residual of incomplete reaction during CaTs synthesis. The effect of the residual melts on the 
diffusion process could not be detected and it was assumed to be negligible, because they were rare and localized in small isolated pockets $(<1 \mu \mathrm{m})$.

We tested various materials for the thin source of diffusion experiments in the course of designing a diffusion couple suitable for depth profiling analysis. With Kunlun Mts. diopside, we tried thin sources of CaTs composition oxide, CaTs glass, and presynthesized CaTs crystal powder. All of the CaTs compositions reacted at the surface of diopside and formed melt. The melting was caused by incongruent melting of a higher silica phase (grossular or gehlenite) formed during the CaTs synthesis. During CaTs synthesis corundum forms before CaTs pyroxene and remains a non-reactive residual phase. The presence of metastable corundum leads to the growth of $\mathrm{Al}$ deficient phases such as grossular, anorthite and/or gehlenite. The slab of CaTs aggregates used for CaTs - diopside couples did not form melt at the interface, because the polycrystalline slab consisted almost entirely of of an equilibrium CaTs pyroxene and metastable phases are isolated and present in trace abundance. Ideally, a thin CaTs source is preferred but it was not accomplished in the thin layer source experiments.

\section{Activation Enthalpy}

The activation enthalpy of diffusion at constant pressure is calculated based on the 1.5 $\mathrm{GPa}$ experiments with temperature ranging from 1250 to $1350^{\circ} \mathrm{C}$. The determined Arrhenius fit was

$$
D=\left[4.05 \times 10^{-4}\left(\mathrm{~m}^{2} / \mathrm{s}\right)\right] \exp \left[\frac{-374(\mathrm{~kJ} / \mathrm{mol})}{R T(\mathrm{~K})}\right] \quad \quad\left(\mathrm{m}^{2} / \mathrm{s}\right) .
$$

Both diffusion coefficients measured by electron microprobe and ion probe were used for fitting. Uncertainties including a 95\% confidence envelope for the fitted values are \pm 199 for the activation enthalpy, and $\exp ( \pm 35)$ for the frequency factor. As the extremely large uncertainty shows, the frequency factor is not constrained. Thus, this Arrhenius relationship should not be used beyond the experimentally determined conditions. The actual fitted line is shown in Figure 2.9, with other previously reported diffusivities for various elements in pyroxene. 


\section{Discussion}

\section{Interdiffusion}

Our results represent the first reported diffusivities for the interdiffusion of $\mathrm{Al}^{\mathrm{VI}} \mathrm{Al}^{\mathrm{IV}}$ and $\mathrm{Mg}^{\mathrm{VI}} \mathrm{Si}^{\mathrm{IV}}$ at high pressure. The flux out of diopside $(\mathrm{Mg}, \mathrm{Si})$ is compensated by an influx of $\mathrm{Al}$ for both experimental configurations, and the stoichiometry of pyroxene is maintained. In the CaTs - diopside couple, the coincidence of the Boltzmann-Matano interfaces for $\mathrm{Al}$ and $\mathrm{Mg}$ is evidence of balanced flux interdiffusion. In the $\mathrm{Al}$ oxide diopside couple, the interchange of $\mathrm{Al}$ with $\mathrm{Mg}$ and $\mathrm{Si}$ is illustrated on the pyroxene ternary projection (Figure 2.7a), and diffusion profiles recalculated for pyroxene stoichiometry (Figure $2.7 \mathrm{~b}, \mathrm{c}$ ). The increase of CaTs component is accompanied by the decrease of diopside. This illustrates that the process involves interdiffusion in which $\mathrm{Al}^{\mathrm{VI}} \mathrm{Al}^{\mathrm{IV}}$ replaces $\mathrm{Mg}^{\mathrm{VI}} \mathrm{Si}^{\mathrm{IV}}$ in a balanced exchange reaction.

\section{Comparison of Experimental Designs}

An Arrhenius plot comparing our results to diffusivities of other elements in diopside is shown in Figure 2.9. Filled circles are averaged diffusion coefficients of CaTs - diopside couples, and each symbol represents each experiment (Figure 2.9). Crosses represents diffusivities of the $\mathrm{Al}$ oxide - diopside couples, and they are averaged diffusion coefficients for profiles in one experiment. The values for interdiffusion are identical within the experimental uncertainties. The two natural diopside crystals could have different diffusivities due to properties that were not measured: defects, and dislocations, etc. Defect density in starting diopside could influence diffusivity by supplying additional lattice vacancy sites for atom transport. Low defect density in synthetic clinopyroxene was proposed as the origin of the two order of magnitude lower diffusivity than that measured in natural clinopyroxene (Sneeringer et al., 1984). Dislocations in starting diopside could provide a faster diffusion path than lattice diffusion (Shewmon, 1989). The agreement of the diffusivites measured using the two crystals and two techniques indicates that there were no significant influence of these effects.

\section{Comparison with Previous Results}

A published value of $\mathrm{Al}$ diffusion in diopside is presented by Sautter et al. (1988), who measured $\mathrm{Al}$ diffusion by annealing natural diopside coated with a thin layer of $\mathrm{CaAl}_{2} \mathrm{SiO}_{6}$ compound that was radio-sputtered on the surface from a CaTs composition 
pellet. The diffusivity at $1180^{\circ} \mathrm{C}$ at $1 \mathrm{~atm}$ in air of $3 \times 10^{-17} \mathrm{~cm}^{2} / \mathrm{s}$ is about four orders of magnitude slower than the results obtained here at 1.6 GPa. Freer et al. (1982) demonstrated an upper bound of $\mathrm{A} 1$ diffusivity of $4 \times 10^{-14} \mathrm{~cm}^{2} / \mathrm{s}$ by the rule-of-thumb approximation, $\mathrm{x}=\sqrt{\mathrm{Dt}}$, at $1200^{\circ} \mathrm{C}, 1 \mathrm{~atm}$ for single crystal diopside annealed with $\mathrm{Al}$ bearing diopside powder. Both experiments were conducted outside the stability field of CaTs where solid solution of diopside toward Al-bearing end members is limited.

When diopside and a CaTs component mixture are placed together under atmospheric conditions, the CaTs composition will react to various intermediate compounds before it forms limited diopside solid-solution. The upper limit of $\mathrm{Al}$ solubility will be $9.35 \mathrm{wt} \%$ (de Neufville and Schairer, 1962). The present experiments were carried out under conditions where complete solid-solution exists between diopside and CaTs. Freer et al. (1982) approached the problem of lack of complete solid solution by annealing their 1 atm experiments with pyroxene composition of the solubility limit at $1 \mathrm{~atm}$. There should not be any kinetic barrier to limit the diffusion. Their results are approximately an order of magnitude lower than our slowest diffusion rates (Figure 2.9). Considering that they have approximated the solution, these two results are generally in agreement.

Due to the lack on information of the stoichiometry of the sputtered compound during the run and major elements composition near the interface, it is impossible to evaluate the experimental result of Sautter et al. (1988). During their experiments, the Al transport could be limited by the chemical reaction kinetics, due to the formation of several intermediate phases. Furthermore, while solubility of $\mathrm{Al}$ is limited in diopside at $1 \mathrm{~atm}$, the Al concentration profile of Sautter et al. (1988) shows a smooth transition from CaTs (assumed be CaTs) composition to diopside. If phases with limited $\mathrm{Al}$ solubility are at the surface of diopside, the profile should show step-wise breaks due to the solubility limits.

The coupled $\mathrm{Al}^{\mathrm{VI}} \mathrm{Al}^{\mathrm{IV}}$ diffusion is analogous to the process that must occur for other trivalent cations in pyroxene. In the case of the CaTs substitution the $\mathrm{Al}^{\mathrm{VI}}$ cation resides in the smaller, regular M1 site. For rare earth element charge-coupled diffusion, the larger trivalent cation is probably occupying the M2 site. It is possible that the mobility of trivalent tetrahedrally-coordinated cation could limit the diffussivity of the octahedrally coordinated atoms. However, this does not appear to be the situation. A recent diffusion study (Van Orman et al., 1998) demonstrates that Yb diffusion in diopside at $1.5 \mathrm{GPa}$ (Figure 2.9) is three orders of magnitude slower than Al. Furthermore, $\mathrm{Sm}^{3+}$ 
diffusion in synthetic diopside of Sneeringer et al. (1984) is a little slower than the value inferred from the temperature dependance of the present results (Figure 2.9). Apparently Al diffusion does not limit the mobility of REEs, since Al diffuses faster.

\section{Geological Implications}

\section{MORB generation}

The experiments were carried out under conditions equivalent to $30-60 \mathrm{~km}$ depth in the mantle, within the depth range for basalt generation (Kinzler and Grove, 1992; Klein and Langmuir, 1987). The present results provide constraints on element behavior during melting and on the chemistry of melts produced. Since $\mathrm{Al}$ is the slowest element to equilibrate in melting experiments (Kinzler and Grove, 1992), Al behavior may influence the production of melt, or may result in a melt produced under disequilibrium conditions. A non-dimensional scaling of melt production rate to equilibration rate by diffusion with solids provides an estimate of the mantle melting conditions required for equilibration (Hart, 1993; Figure 2.10). At $t_{\mathrm{m}} / \mathrm{t}_{\mathrm{D}}=1$, the melt produced would achieve $\sim 83 \%$ of melt equilibration with the mantle minerals. The melting condition is calculated on the bases of an assumption of passive upwelling with adiabatic decompression melting, the ClausiusClapeyron slope for mantle solidus, and enthalpy of melting reaction. We chose a partition coefficient $(\mathrm{K})$ of 0.1 to model equilibrium distribution of $\mathrm{Al}$ between melt and pyroxene. Larger $\mathrm{K}$ favors equilibrium melting, and smaller $\mathrm{K}$ promotes disequilibrium melting. Dotted lines are the upper and lower bound of our experimentally determined diffusion coefficients. For $1 \mathrm{~mm}, 5 \mathrm{~mm}$, and $10 \mathrm{~mm}$ grain radii, melting will be an equilibrium process for any reasonable upwelling rate. For a passive spreading model, the upper limit of mantle upwelling rate will be $8 \mathrm{~cm} /$ year given observed ridge spreading rates.

The partitioning of REE between clinopyroxene and melt is influenced by $\mathrm{Al}$ concentration in clinopyroxene (Gaetani and Grove, 1995); successively Al-depleted clinopyroxene will yield successively lower REE partition coefficients. If $\mathrm{Al}$ diffusion is slower than rate of melt production, a zoned clinopyroxene may be produced during fractional melting with rims depleted in Al. In subsequent melting, the Al-poor rim modifies the partitioning and successive melts will be more enriched in trace elements than equilibrium melting. Considering that melting at mid ocean ridge environment is an 
equilibrium process, and that REE diffusion is slower than $\mathrm{Al}$ in pyroxene, REE partitioning is less likely influenced by zoned pyroxene.

\section{Closure Temperature}

The results obtained here can be used to infer thermal histories of mantle rocks, based on the closure temperature arguments. Based on Dodson's formulation (Dodson, 1973), the closure temperature for CaTs-diopside interdiffusion is $710^{\circ} \mathrm{C}$ for grain size of $1 \mathrm{~cm}$ and for slow cooling bodies $\left(1000^{\circ} \mathrm{C} / \mathrm{My}\right)$. However, the $68 \%$ confidence limit of the closure temperature is $\pm 310^{\circ} \mathrm{C}$, which is due to the large uncertainty of activation enthalpy $(\mathrm{H})$ and frequency factor (Do). The closure temperature of $1 \mathrm{~mm}$ size pyroxene in a cooling magmatic body (i.e. $1 \mathrm{~km}$ dike cools $\sim 100,000^{\circ} \mathrm{C} / \mathrm{My}$ ) is approximately $860^{\circ} \mathrm{C}$. Since uncertainties are approximately $\pm 300^{\circ} \mathrm{C}(1 \sigma)$ for most of conditions, the value of the closure temperature calculated from our data should be used with caution.

The closure temperatures for this and previous studies (Jaoul et al., 1991; Sautter et al., 1988) provides a guideline for the geologic conditions under which an Al-based geothermobarometer could be applied. For example, our data indicate that the thermobarometer stops re-equilibrating below $700^{\circ} \mathrm{C}$ for $1 \mathrm{~cm}$ grain at cooling rate relevant to tectonic uplift rates $\left(1^{\circ} \mathrm{C} / \mathrm{My}\right)$. According to our data, pyroxene in abyssal peridotites should re-equilibrated to the low temperatures of metamorphic processes. In contrast, using diffusion data by Sautter et al. (1988), (the activation enthalpy is mentioned in, Jaoul et al., 1991), the closure temperature is $1300^{\circ} \mathrm{C}$ at the same condition. This suggests that pyroxene could record conditions of melting. Considering that the pyroxene composition in abbysal peridotites is generally equilibrated to low temperature, the predicted closure temperature also supports the relevance of out data.

\section{References Cited}

Bevington P. R. (1969) Data Reduction and Error Analysis for the Physical Sciences. McGraw-Hill.

de Neufville J. and Schairer J. F. (1962) The Join Diopside-Ca Tschermak's Molecule at Atomospheric Pressure. Carnegie Inst. Year Book 61, 56-59.

Dodson M. H. (1973) Closure temperature in cooing geochronological and petrological systems. Contrib. Mineral. Petrol. 40, 259-274.

Evans B., Hay R. S., and Shimizu N. (1986) Diffusion-induced grain-boundary migration in calcite. Geology 14, 60-63. 
Farver J. R. and Yund R. A. (1992) Oxygen Diffusion in a Fine-Grained Quartz Aggregate With Wetted and Nonwetted Microstructures. J. Geophys. Res. 97, 14017-14029.

Freer R., Carpenter M. A., Long J. V. P., and Reed S. J. B. (1982) "Null result" diffusion experiements with diopside: implications for pyroxene equilibria. Earth Planet. Sci. Lett. 58, 285-292.

Gaetani G. A. and Grove T. L. (1995) Partitioning of rare earth elements between clinopyroxene and silicate melt: Crystal-chemical controls. Geochim. Cosmochim. Acta 59, 1951-1962.

Handwerker C. A. (1988) Diffusion-Induced Grain Boundary Migration in Thin Films. In Diffusion Phenomena in the Thin Films and Microelecronic Materials (ed. D. Gupta and P. S. Ho). Noyes Publications.

Harrison L. G. (1961) Influence of Dislocations on Diffusion Kinetics in Solid with Particular Reference to the Alkali Halides. Transactions of Faraday Society 57, 1191-1199.

Hart S. R. (1993) Equilibration during mantle melting: A fractal tree model. Proceedings of National Academy of Science 90, 11914-11918.

Hay R. S. and Evans B. (1987) Chemically induced grain boundary migration in calcite: temperature dependence, phenomenology, and possible applications to geologic system. Contrib. Mineral. Petrol. 97, 127-141.

Hays J. F. (1967) Lime-Alumina-Silica. Carnegie Institution Year Book 65, 234-239.

Jaoul O., Sautter V., and Abel F. (1991) Nuclear Microanalysis: A Powerful Tool for Measuring Low Atomic Diffusivity with Mineralogical Applications. In Diffusion, Atomic Ordering, and Mass Transport, Vol. 8 (ed. J. Ganguly), pp. 198-220. Springer-Verlag.

Kinzler R. J. and Grove T. L. (1992) Primary Magmas of Mid-Ocean Ridge Basalts 1. Experiments and Methods. J. Geophys. Res. 97, 6885-6906.

Klein E. M. and Langmuir C. H. (1987) Global Correlations of Ocean Ridge Basalt Chemistry with Axial Depth and Crustal Thickness. J. Geophys. Res. 92, 8089-8115.

Matano C. (1933) 8. On the Relation between the Diffusion-Ceofficients and Concentrations of Solid Metals (The Nicke-Copper System). Japanese J. Phys. 8, 109113.

Sautter V., Jaoul O., and Abel F. (1988) Aluminum diffusion in diopside using the 27Al(p,r)28Si nuclear reaction: preminary results. Earth Planet. Sci. Lett. 89, 109-114.

Shewmon P. (1989) Diffusion in Solids. A Publication of The Minerals, Metal, and materials Society.

Sneeringer M., Hart S. R., and Shimizu N. (1984) Strontium and samarium diffusion in diopside. Geochim. Cosmochim. Acta 48, 1589-1608.

Van Orman J. A., Shimizu N., and Grove T. L. (1998) Rare earth element diffusion in diopside and disequilibrium melting in the mantle. EOS. Trans. 79, S371.

Wagner T. P. (1995) Experimental and Geochemical Studies of Terrestrial and Lunar Magmatic Process. Ph. D., Massachusetts Institute of Technology.

Wood B. J. (1979) Activity-Composition Relationships in $\mathrm{Ca}(\mathrm{Mg}, \mathrm{Fe}) \mathrm{Si} 2 \mathrm{O} 6-\mathrm{CaAl} 2 \mathrm{O} 6$ clinopyroxene solid solutions. Am. J. Sci 279, 854-875.

Zinner E. (1980) Depth Profiling by Secondary Ion Mass Spectrometry. Scanning 3, 57-78. 


\section{Tables}

Table 2.1: Compositions of mineral used in CaTs-Diopside and Corrundum-Diopside Experiments

\begin{tabular}{ccc}
\hline Oxide & Eden Mills & Kunlun Mts. \\
\hline $\mathrm{Na} 2 \mathrm{O}$ & 0.00 & 0.53 \\
$\mathrm{MgO}$ & 18.08 & 18.08 \\
$\mathrm{Al} 2 \mathrm{O} 3$ & 0.00 & 0.88 \\
$\mathrm{SiO} 2$ & 55.21 & 55.53 \\
$\mathrm{CaO}$ & 25.89 & 24.74 \\
$\mathrm{FeO}$ & 0.90 & 0.55 \\
$\mathrm{TiO} 2$ & 0.07 & 0.06 \\
$\mathrm{Total}$ & 100.14 & 100.36 \\
\hline
\end{tabular}


Table 2.2: Results of interdiffusion experiments

\begin{tabular}{|c|c|c|c|c|c|c|c|c|}
\hline Sample & $\mathrm{D} / \mathrm{W}$ & $\mathrm{E} / \mathrm{K}$ & $\begin{array}{c}\text { Pressure } \\
(\mathrm{kb})\end{array}$ & Temp. $\left({ }^{\circ} \mathrm{C}\right)$ & Duration (h) & $1 / \mathrm{T} * 1000$ & $\mathrm{D}$ (Elec. probe) & $\mathrm{D}$ (Ion probe) \\
\hline \multirow[t]{2}{*}{ B183* } & W & $\mathrm{E}$ & 17.4 & 1350 & 117.25 & 0.616 & $9.41 \times 10^{-17}$ & \\
\hline & W & $\mathrm{E}$ & 17.4 & 1350 & 117.25 & $\begin{array}{c}0.616 \\
\text { (average) }\end{array}$ & $\begin{array}{l}4.46 \times 10^{-17} \\
6.94 \times 10^{-17}\end{array}$ & \\
\hline B184* & W & $\mathrm{E}$ & 21.0 & 1450 & 2.40 & 0.580 & $3.60 \times 10^{-16}$ & \\
\hline B $185^{*}$ & W & $\mathrm{E}$ & 17.4 & 1350 & 3.05 & 0.616 & $2.27 \times 10^{-16}$ & \\
\hline B187* & W & $\mathrm{E}$ & 26.0 & 1550 & 4.20 & 0.548 & $2.32 \times 10^{-15}$ & \\
\hline B191* & D & $\mathrm{E}$ & 17.4 & 1340 & 95.77 & 0.620 & $1.47 \times 10^{-16}$ & \\
\hline \multirow[t]{4}{*}{$\mathrm{BPC} 92+$} & $\mathrm{D}$ & $\mathrm{K}$ & 16.0 & 1350 & 38.50 & 0.616 & $8.82 \times 10^{-17}$ & $5.72 \times 10^{-17}$ \\
\hline & D & $\mathrm{K}$ & 16.0 & 1350 & 38.50 & 0.616 & $3.73 \times 10^{-17}$ & \\
\hline & $\mathrm{D}$ & K & 16.0 & 1350 & 38.50 & 0.616 & $1.89 \times 10^{-17}$ & \\
\hline & & & & & & (average) & $\begin{array}{l}4.81 \times 10^{-17} \\
5.04 \times 10^{-17}\end{array}$ & $5.72 \times 10^{-17}$ \\
\hline \multirow[t]{5}{*}{$\mathrm{BPC} 93+$} & D & K & 20.0 & 1450 & 11.00 & 0.580 & $3.78 \times 10^{-16}$ & $8.16 \times 10^{-16}$ \\
\hline & D & $\mathrm{K}$ & 20.0 & 1450 & 11.00 & 0.580 & $1.88 \times 10^{-16}$ & \\
\hline & D & K & 20.0 & 1450 & 11.00 & 0.580 & $2.94 \times 10^{-16}$ & \\
\hline & D & K & 20.0 & 1450 & 11.00 & 0.580 & $1.95 \times 10^{-15}$ & \\
\hline & & & & & & (average) & $\begin{array}{l}2.64 \times 10^{-16} \\
3.74 \times 10^{-16}\end{array}$ & $8.16 \times 10^{-16}$ \\
\hline \multirow[t]{4}{*}{$\mathrm{BPC} 106+$} & D & K & 15.0 & 1250 & 60.00 & 0.656 & $2.54 \times 10^{-17}$ & $4.19 \times 10^{-17}$ \\
\hline & D & K & 15.0 & 1250 & 60.00 & 0.656 & $3.10 \times 10^{-17}$ & $1.70 \times 10^{-17}$ \\
\hline & D & K & 15.0 & 1250 & 60.00 & 0.656 & $3.90 \times 10^{-17}$ & \\
\hline & & & & & & (average) & $\begin{array}{l}3.18 \times 10^{-17} \\
3.09 \times 10^{-17}\end{array}$ & $2.94 \times 10^{-17}$ \\
\hline \multirow[t]{3}{*}{$\mathrm{BPC107+}$} & D & K & 17.0 & 1350 & 10.00 & 0.616 & $6.41 \times 10^{-17}$ & $2.67 \times 10^{-16}$ \\
\hline & D & K & 17.0 & 1350 & 10.00 & 0.616 & $5.21 \times 10^{-17}$ & $2.42 \times 10^{-16}$ \\
\hline & & & & & & (average) & $\begin{array}{l}5.81 \times 10^{-17} \\
1.56 \times 10^{-16}\end{array}$ & $2.54 \times 10^{-16}$ \\
\hline \multirow[t]{3}{*}{ BPC121+ } & D & K & 20.0 & 1390 & 47.08 & 0.601 & & $8.29 \times 10^{-17}$ \\
\hline & D & $\mathrm{K}$ & 20.0 & 1390 & 47.08 & 0.601 & & $4.89 \times 10^{-17}$ \\
\hline & $\mathrm{D}$ & K & 20.0 & 1390 & 47.08 & 0.601 & & $\begin{array}{l}2.38 \times 10^{-17} \\
5.19 \times 10^{-17}\end{array}$ \\
\hline $\mathrm{BPC} 122+$ & D & K & 15.0 & 1350 & 12.92 & 0.616 & & $2.13 \times 10^{-16}$ \\
\hline $\mathrm{BPC} 123+$ & D & $\mathrm{K}$ & 15.0 & 1300 & 7.933 & 0.636 & & $4.90 \times 10^{-17}$ \\
\hline \multicolumn{9}{|c|}{$\left(\mathrm{m}^{2} / \mathrm{s}\right)$} \\
\hline D & & \multicolumn{7}{|c|}{ Preconditioned experiments } \\
\hline W & & \multicolumn{7}{|c|}{ Not preconditioned } \\
\hline $\mathrm{E}$ & & \multicolumn{7}{|c|}{ Eden Mills diopside } \\
\hline $\mathrm{K}$ & & \multicolumn{7}{|c|}{ Kunlun Mts diopside } \\
\hline * & & \multirow{3}{*}{\multicolumn{7}{|c|}{$\begin{array}{l}\text { CaTs - diopside diffusion couple. The rest are Al oxide - diopside couple } \\
\text { Each row of diffusion coefficients is derived from Each Al concentration profile }\end{array}$}} \\
\hline+ & & & & & & & & \\
\hline \multirow{2}{*}{\multicolumn{4}{|c|}{ Standard errors are }} & & & & & \\
\hline & & \multirow{2}{*}{\multicolumn{7}{|c|}{$70 \%$ relative for CaTs - diopside couple }} \\
\hline & & & & & & & & \\
\hline
\end{tabular}




\section{Figures}

Figure 2.1 The stability field of CaTs (from Hays, 1967) is plotted on a pressure against temperature diagram, and shown by a region within gray lines that are reaction boundaries. Run conditions of experiments are shown by circles: open circles are CaTs - diopside pair, closed circles are Al oxide - diopside pair. All experiments are conducted within the stability field of CaTs, where CaTs and diopside form complete solid solution. The figure also illustrates the limited temperature for a given pressure.

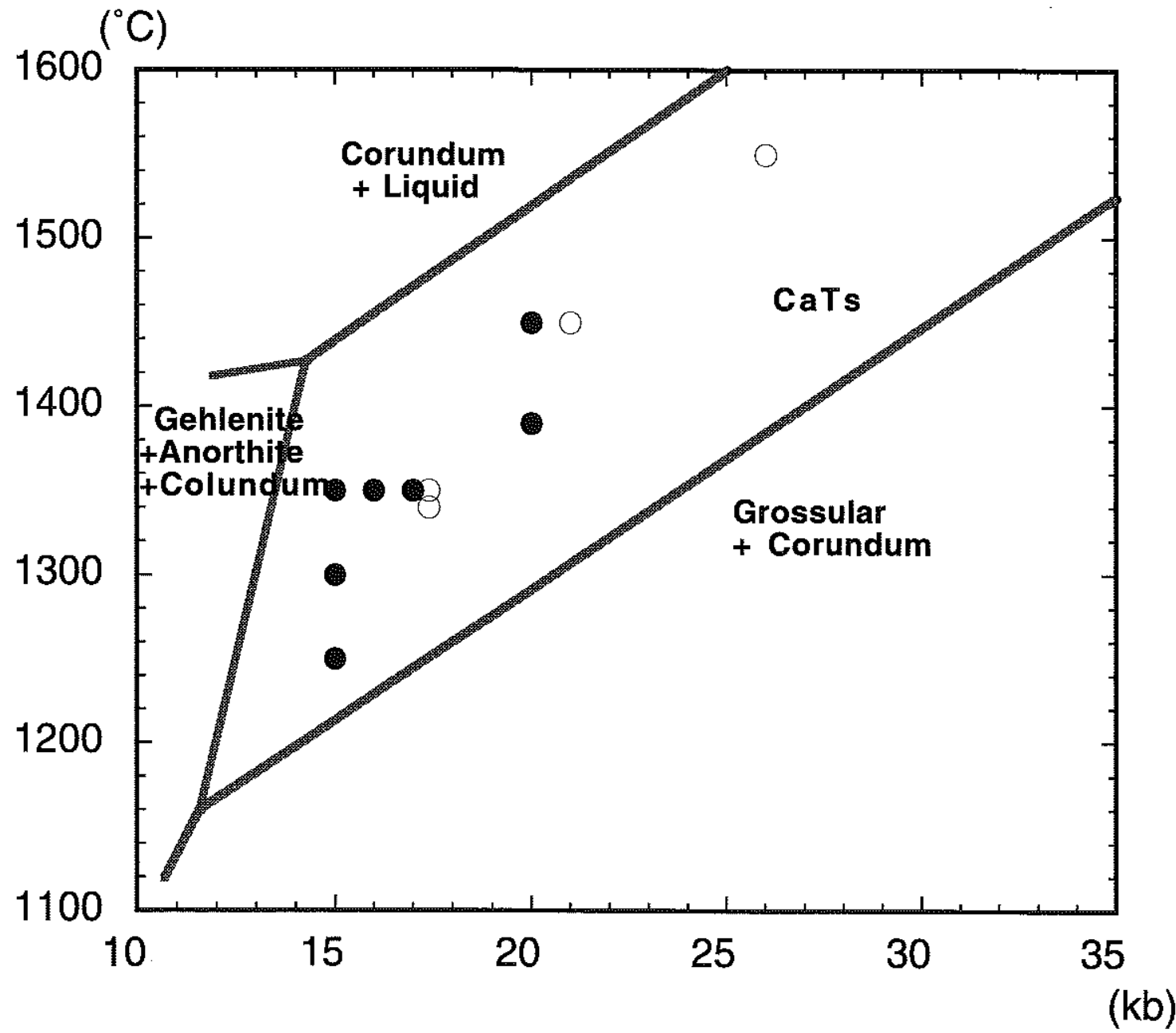


Figure 2.2 Figures (a) and (b) illustrates theoretical and experimental interdiffusion profiles. (a) Theoretical diffusion profiles in two media with different diffusivities, show the characteristics of interdiffusion. The Boltzmann - Matano interface is moved toward CaTs from the original interface. The Boltzmann - Matano interface moves toward the faster diffusing medium, since the Boltzmann-Matano interface is defined as a point where total flux in and out of diopside and CaTs is the same. This can be illustrated by the gray regions at either side of the interface, and the area of two gray regions are equal. Also, fluxes of Al and $\mathrm{Mg}$ are the same shown by mirror image-like profiles. The profile is calculated numerically, using $\mathrm{D}(\mathrm{Al}, \mathrm{Mg})$ of $6 \times 10^{-17} \mathrm{~m}^{2} / \mathrm{s}$ for diopside and $3.6 \times 10^{-16} \mathrm{~m}^{2} / \mathrm{s}$ for CaTs aggregates at 6.7 hours after. (b) Compositional line traverses in B-191 are plotted using normalized concentration for $\mathrm{Al}$ (closed symbols) and $\mathrm{Mg}$ (open symbols) oxides, and show distinct topology. The distance zero notes Boltzmann-Matano interface. Line 1 is shown by squares, and line 2 is shown by circles. They are compositional traverses obtained from a diffusion couple. The differences in the shape of the curve suggest the operation of transport mechanism other than diffusion. Diffusion coefficients are obtained from the curves like the line 2 , since it is topologically closer to the theoretical model than the line 1 , which shows the step-wise compositional profiles. 


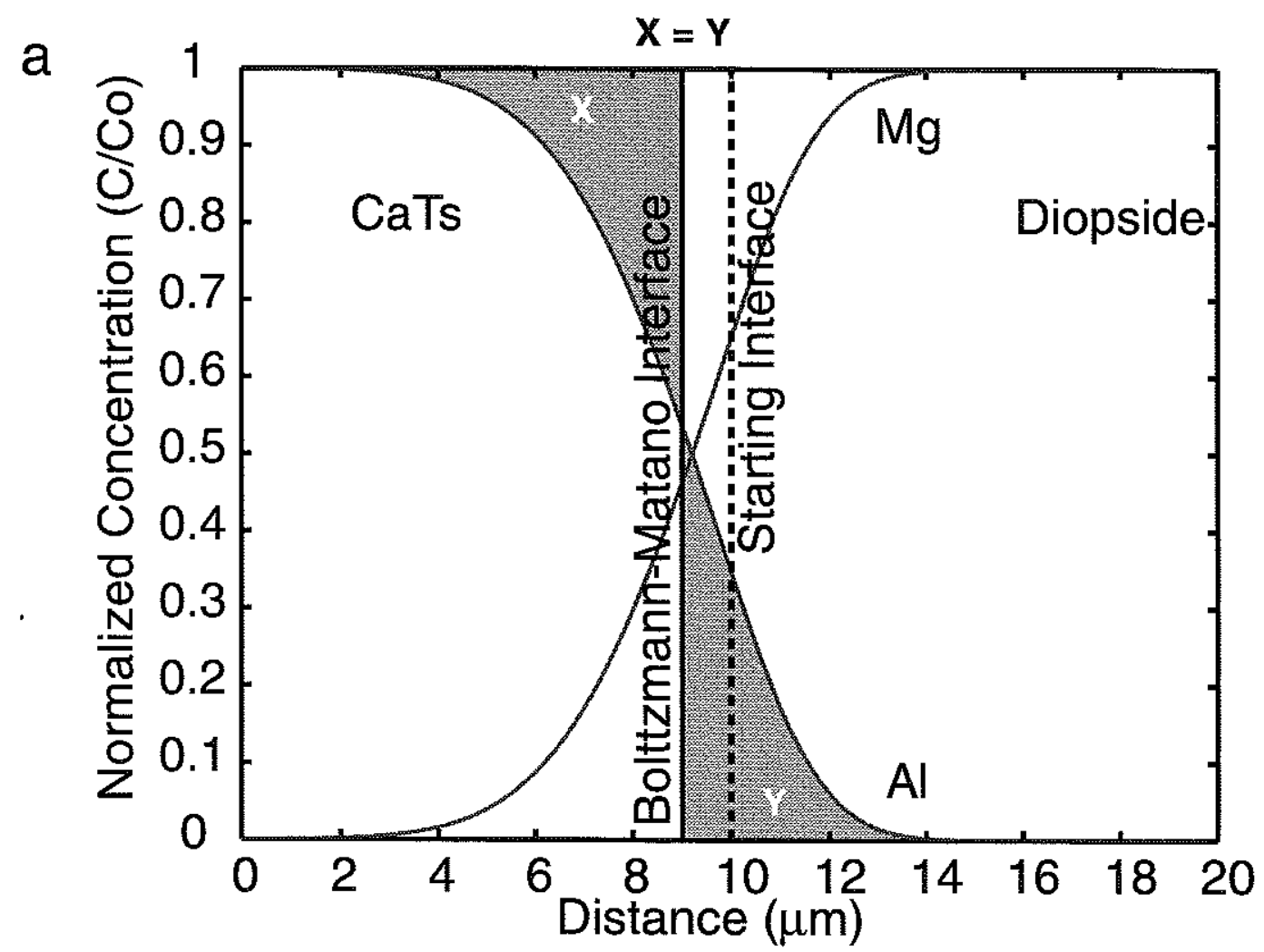

b

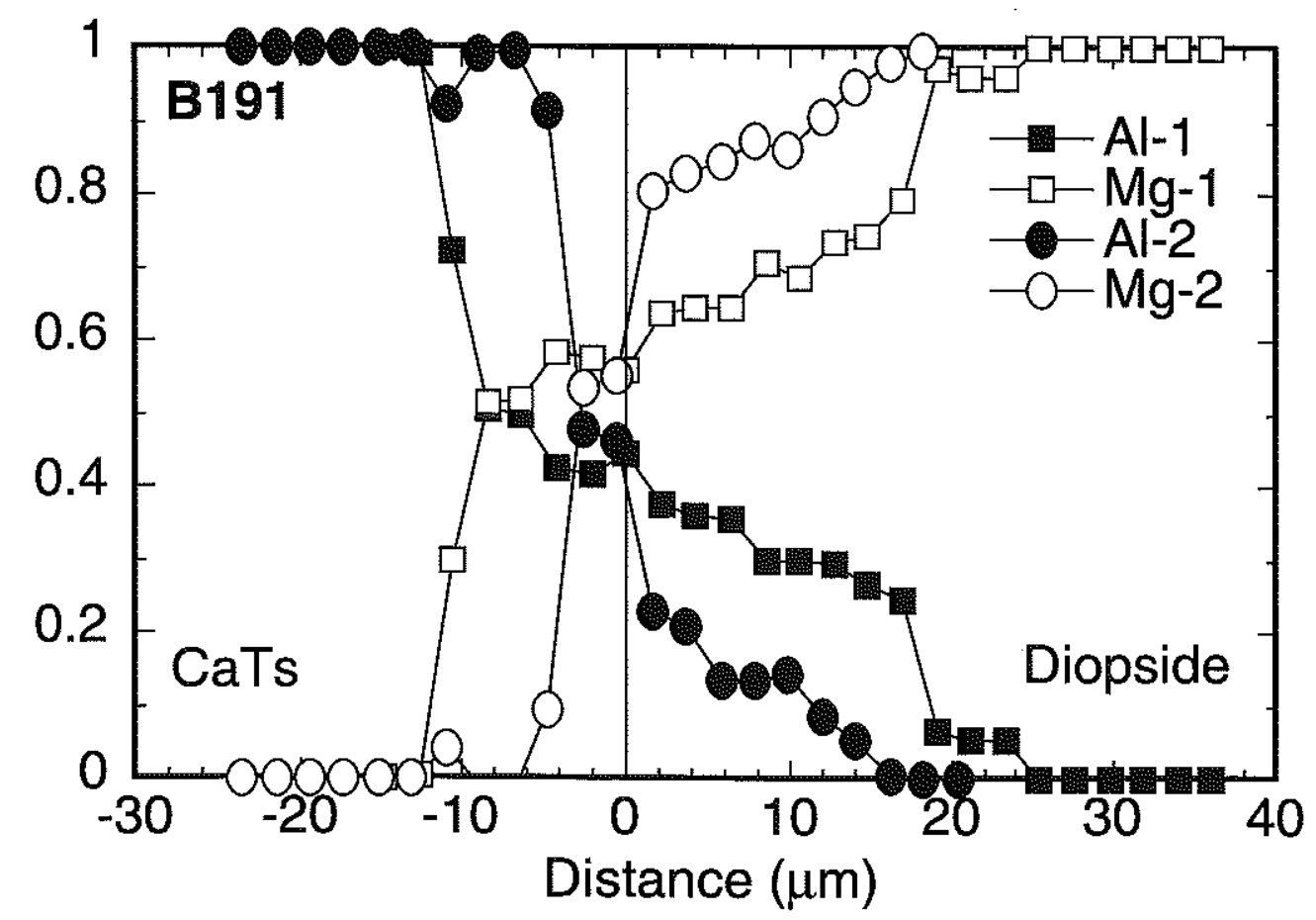


Figure 2.3 Theoretical profiles for the Al oxide - diopside couple and illustration of a diffusion couple. Lines represent model calculations for the growing interface model where diopside grows as $\mathrm{Al}_{2} \mathrm{O}_{3}$ diffuses in (solid line), and for the no-growth, tracer-diffusion-type model. $\mathrm{D}$ of $\mathrm{Al}$ oxide is assumed to be fast, and $\mathrm{D}$ of diopside is $6 \times 10^{-17}\left(\mathrm{~m}^{2} / \mathrm{s}\right)$. Time is at 27.8 hours. The figure illustrates that there are no significant differences between the shapes of profiles.

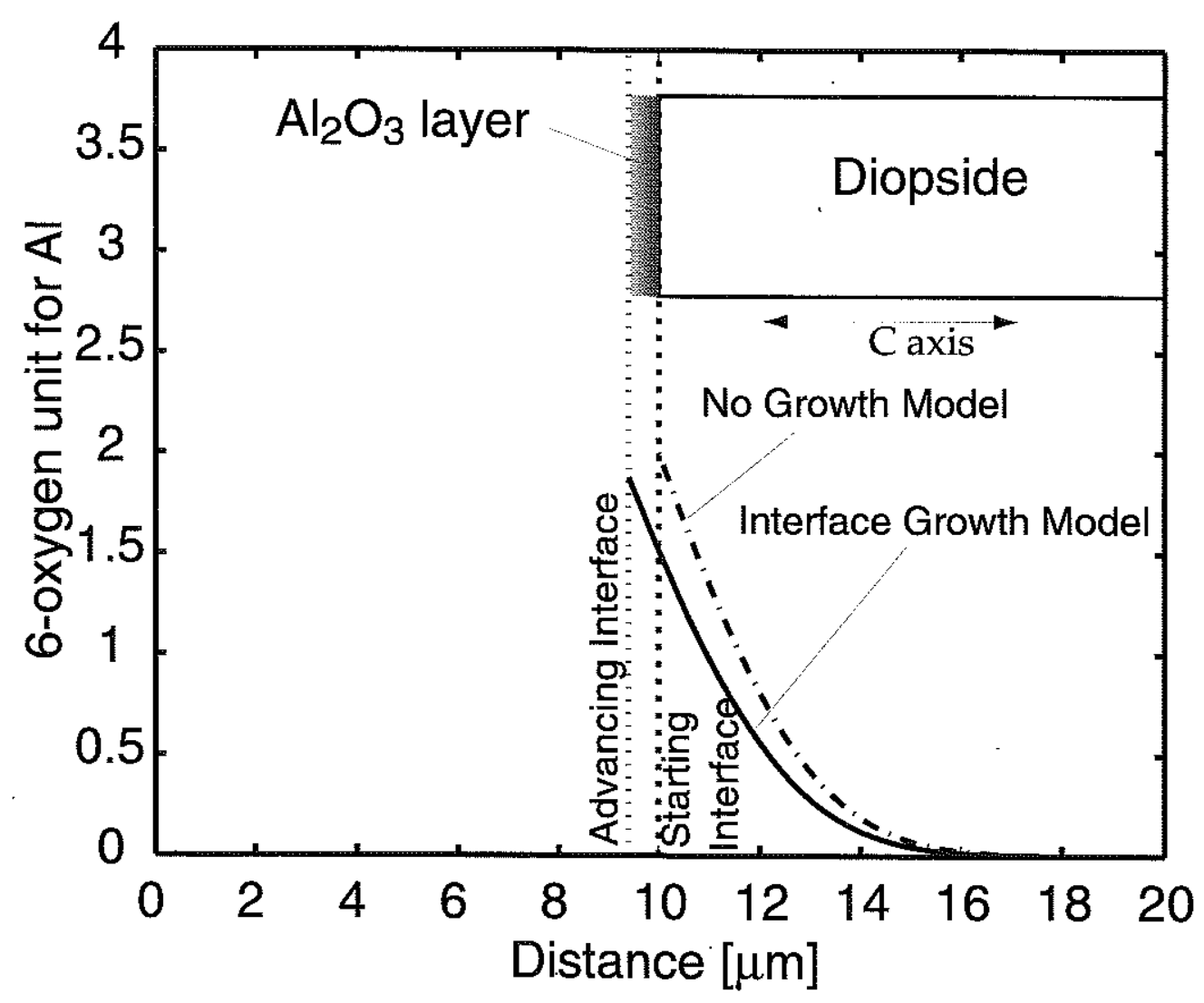


Figure 2.4 Typical fit of measured profiles. $\mathrm{Al} / \mathrm{Ca}$ ratios of row counts from the ion probe are used for diffusivity calculations (A1). The result is shown inside of the plot. The inverse error function plot also qualitatively shows the goodness of the fit (A2). Diffusion coefficients were determined by the method of gradient convergence described in text. D is also determined for a CaTs stoichiometric component $(\mathrm{B} 1,2)$. The result is not greatly different from $\mathrm{D}$ determined from $\mathrm{Al} / \mathrm{Ca}$ ratio.
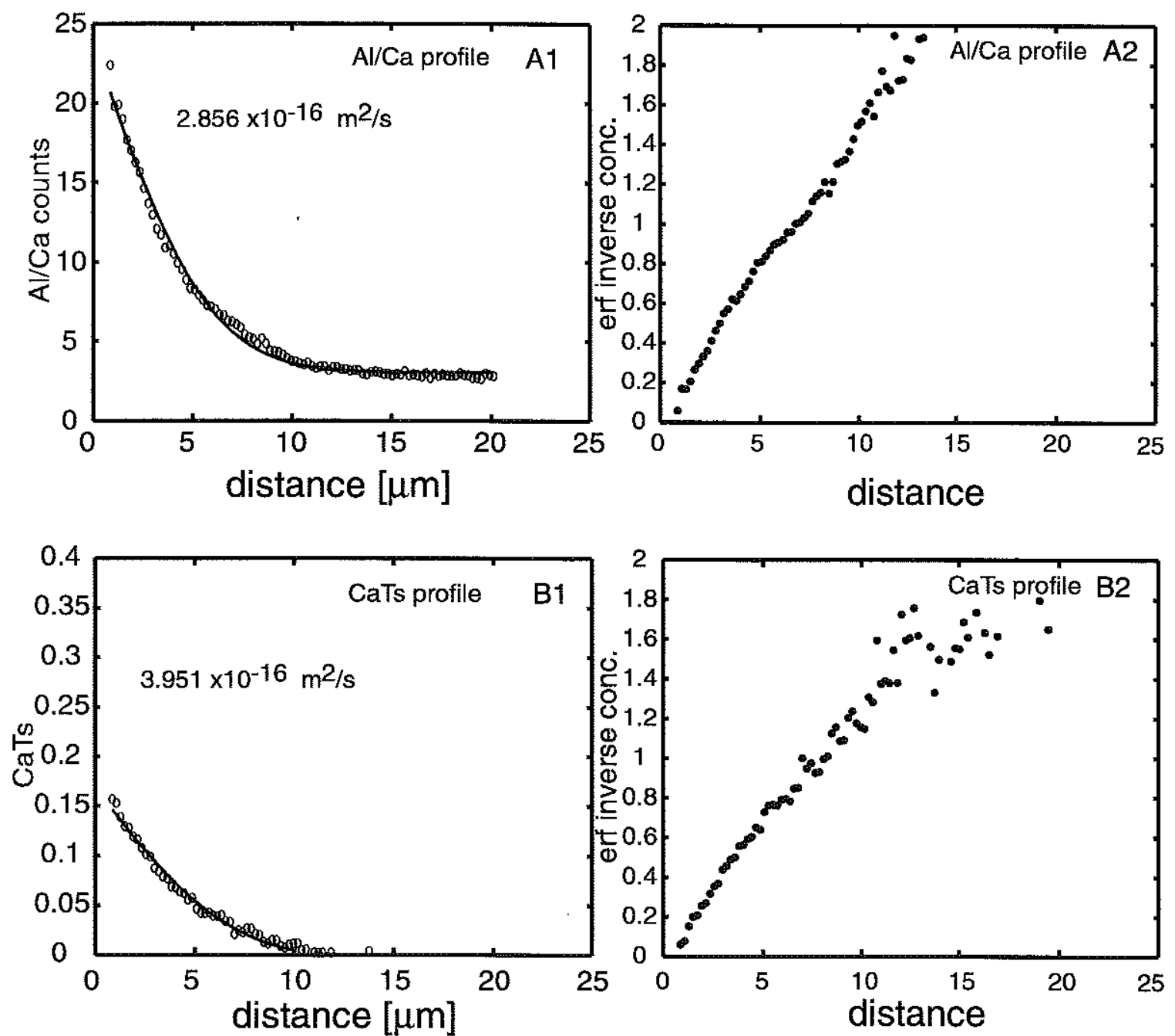
Figure 2.5 Arrhenius plot of the results from CaTs-diopside pairs. Filled symbols are results from un-preconditioned diopside. An open square is the only experiment conducted with reconditioned diopside. An Arrhenius-type inverse temperature relationship is shown here, but pressure conditions of experiments increase as temperature increases. Thus, the trend shown here does not allow to determine the activation enthalpy.

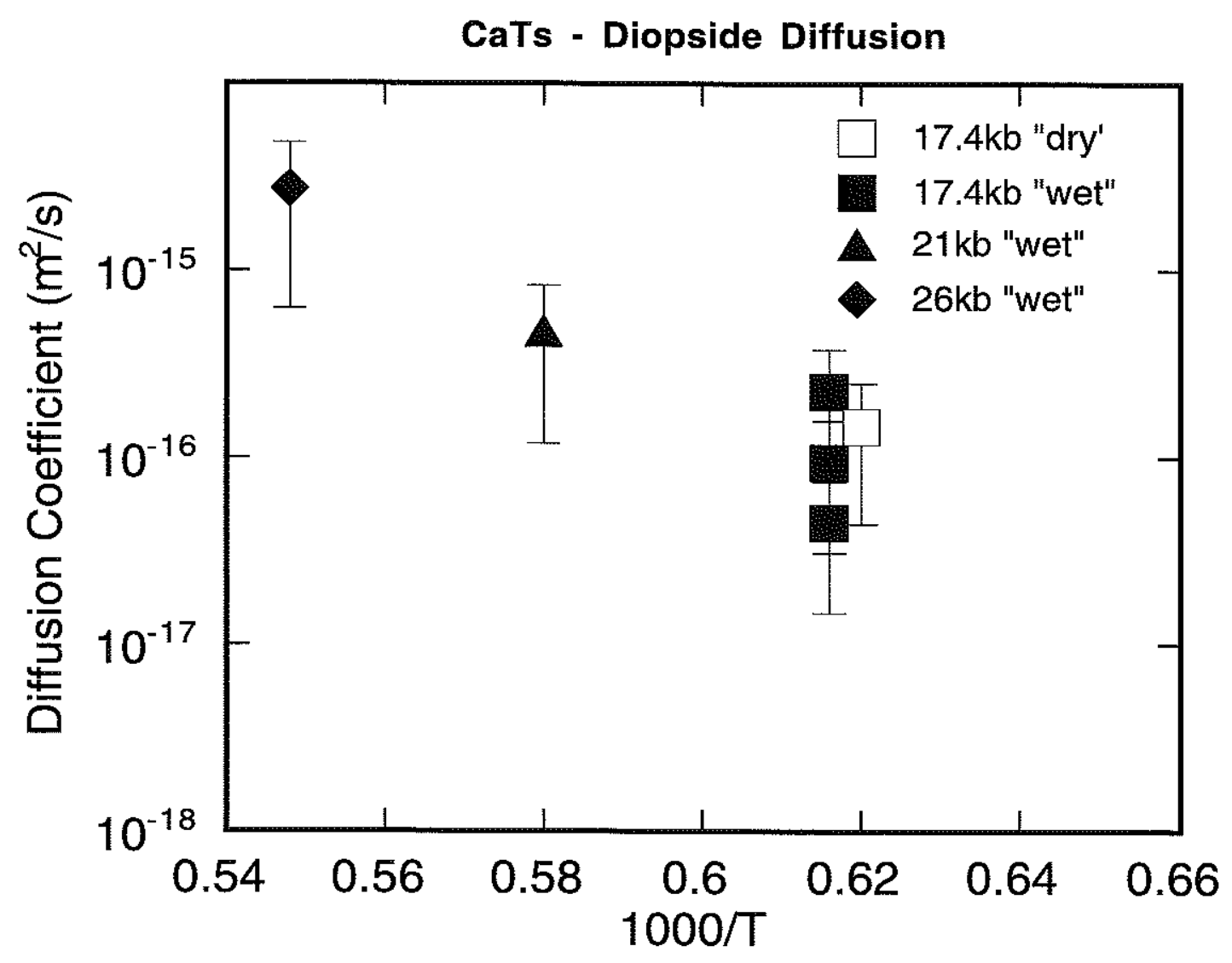


Figure 2.6 Arrhenius plot of the results from experiments conducted with Al oxide diopside pairs. EP and IP denote Ds calculated using data obtained by the electron microprobe or by the ion probe.

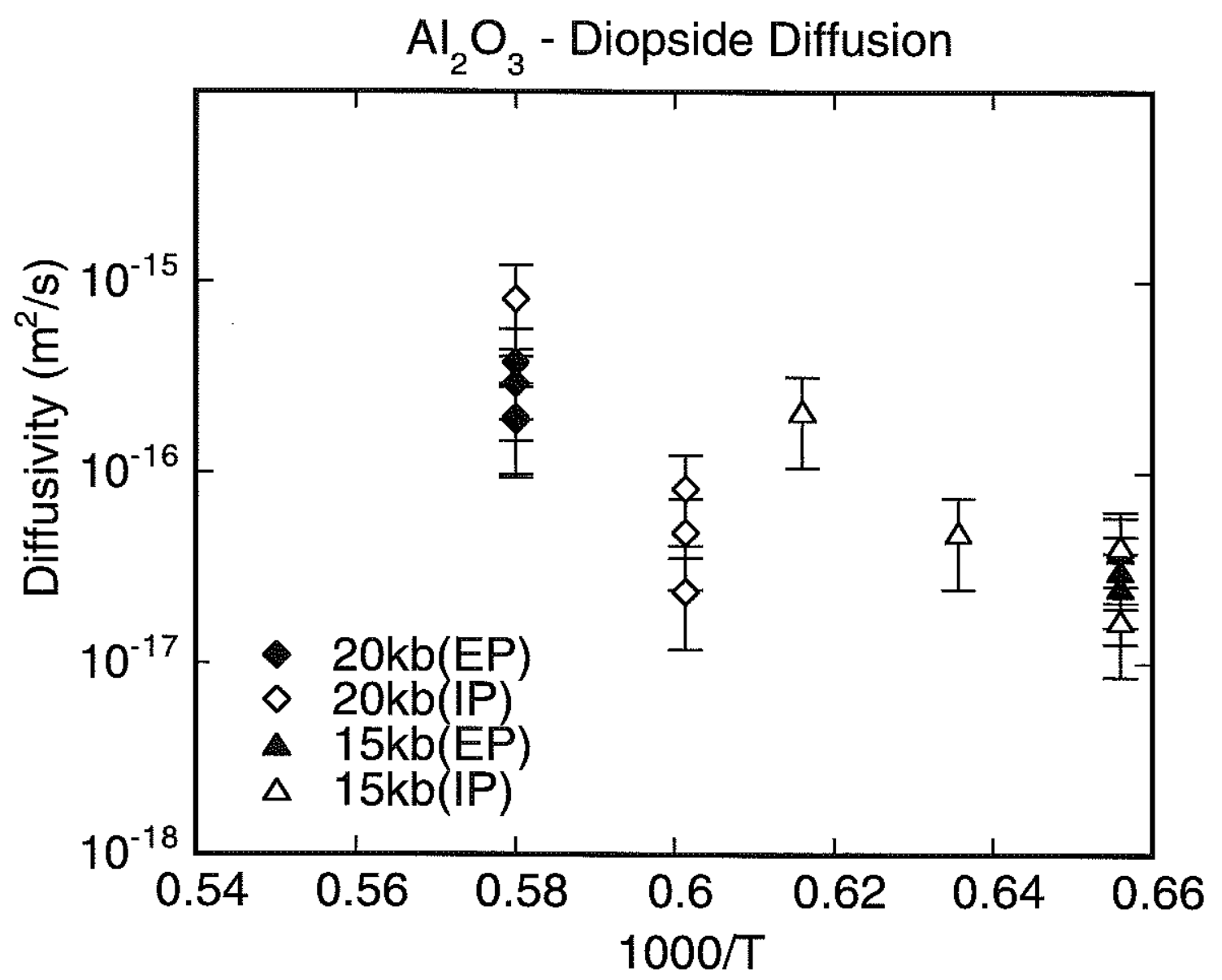


Figure 2.7 a), Results of diffusion anneals are projected on the pyroxene ternary plane, and the small ternary diagram illustrates positions of corundum and CaTs pyroxene. The shaded region shows idealized possible pyroxene compositions. Points are measured compositions by ion probe used for diffusivity calculations. Compositional variations extend towards CaTs instead of Cor, showing operation of CaTs-type interdiffusion. A typical result is projected onto calculated components: calculated 4-cation normalized components (b), and stoichiometric components (c). (c) illustrates the mobility of pyroxene molecules. Inset in (c) shows compositional trend projected on the pyroxene ternary. Apices are same as (a). 

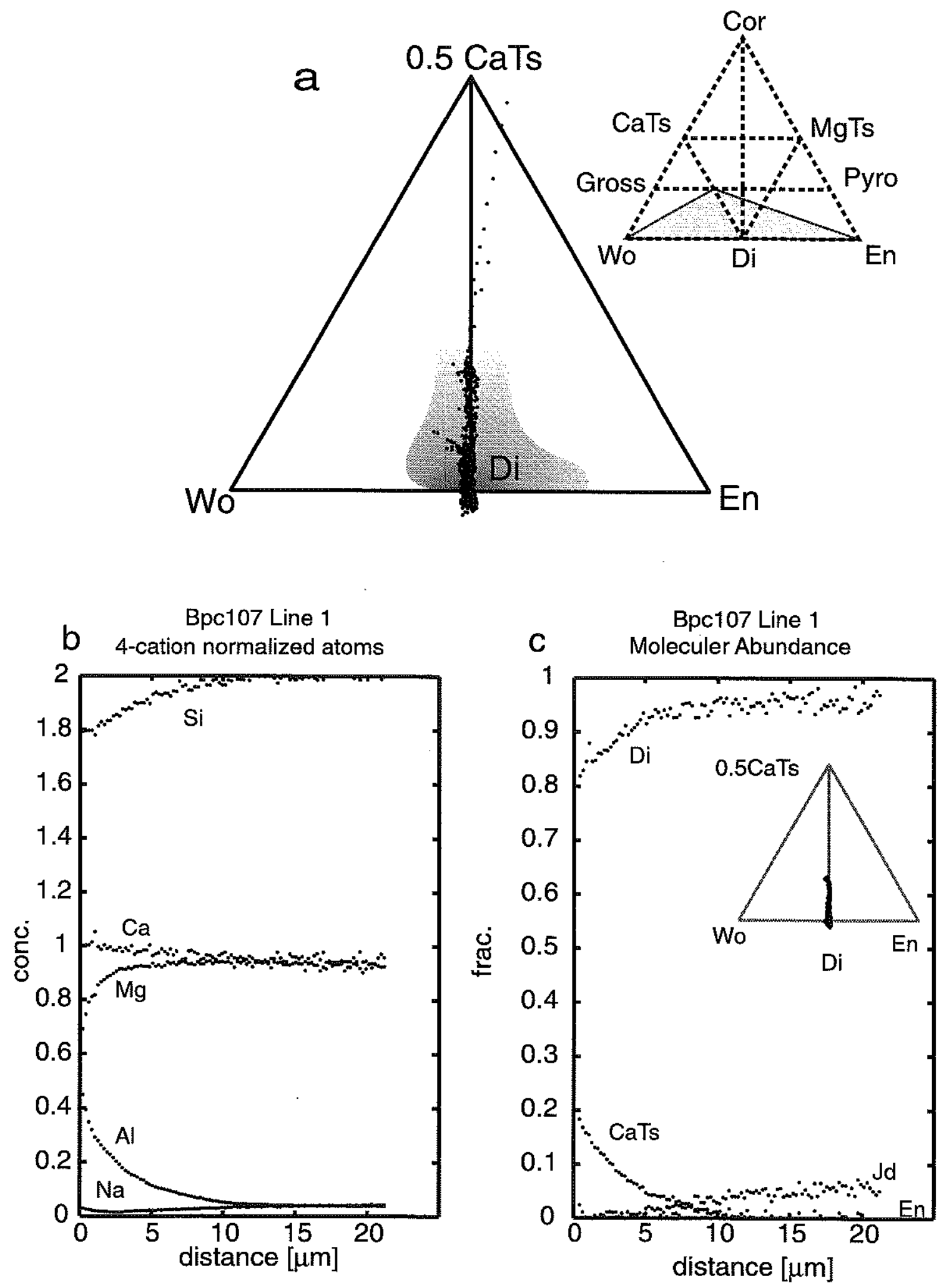
Figure 2.8 A sketch of a photomicrograph of experiment, BPC-92 and compositional variation measured by the electron microprobe illustrate the andulatory nature of the diffusion front. In this illustration, a cross-section of the crystal is shown, and the $\mathrm{Al}_{2} \mathrm{O}_{3}$ source is located on the left edge of the crystal. Backscattered and Al x-ray images are used to identify grading Al concentration "front," shown by graded shaded area. The line traverses, line 1 and 2, show differences between the topology of profiles. The measurement units are in $w t \%$. The longer profile tend to show the changes in slopes of diffusion profiles.

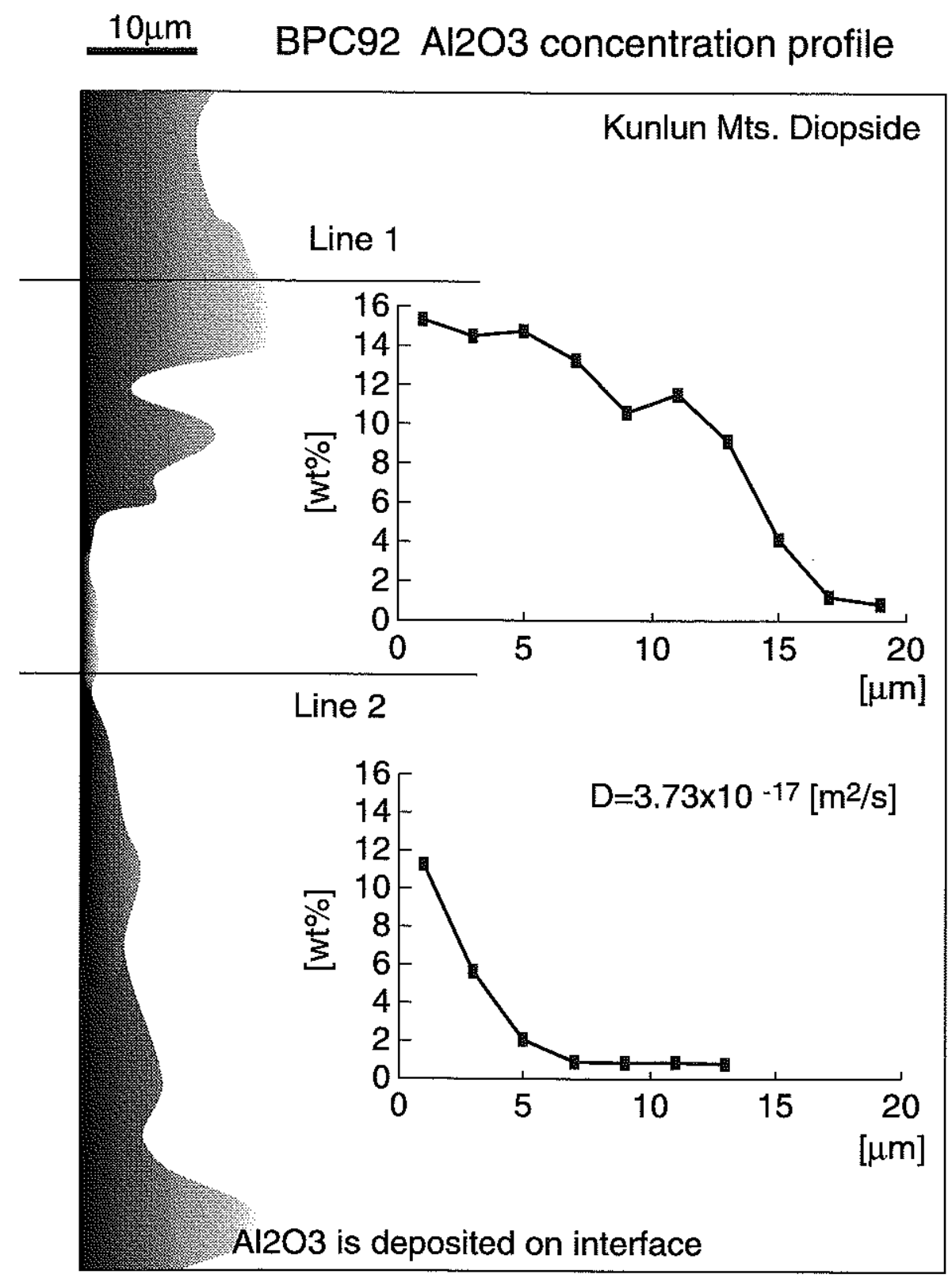


Figure 2.9 Comparison with previous pyroxene diffusion data. Synthetic tracer diffusion at 2.0 GPa (Sneeringer et al., 1984). Al diffusion at $1 \mathrm{~atm}$ (Freer et al., 1982; Sautter et al., 1988). Yb diffusion in Kunlun Mtns diopside at $1.5 \mathrm{GPa}$ (Van Orman et al., 1998). The results of this study were also plotted.

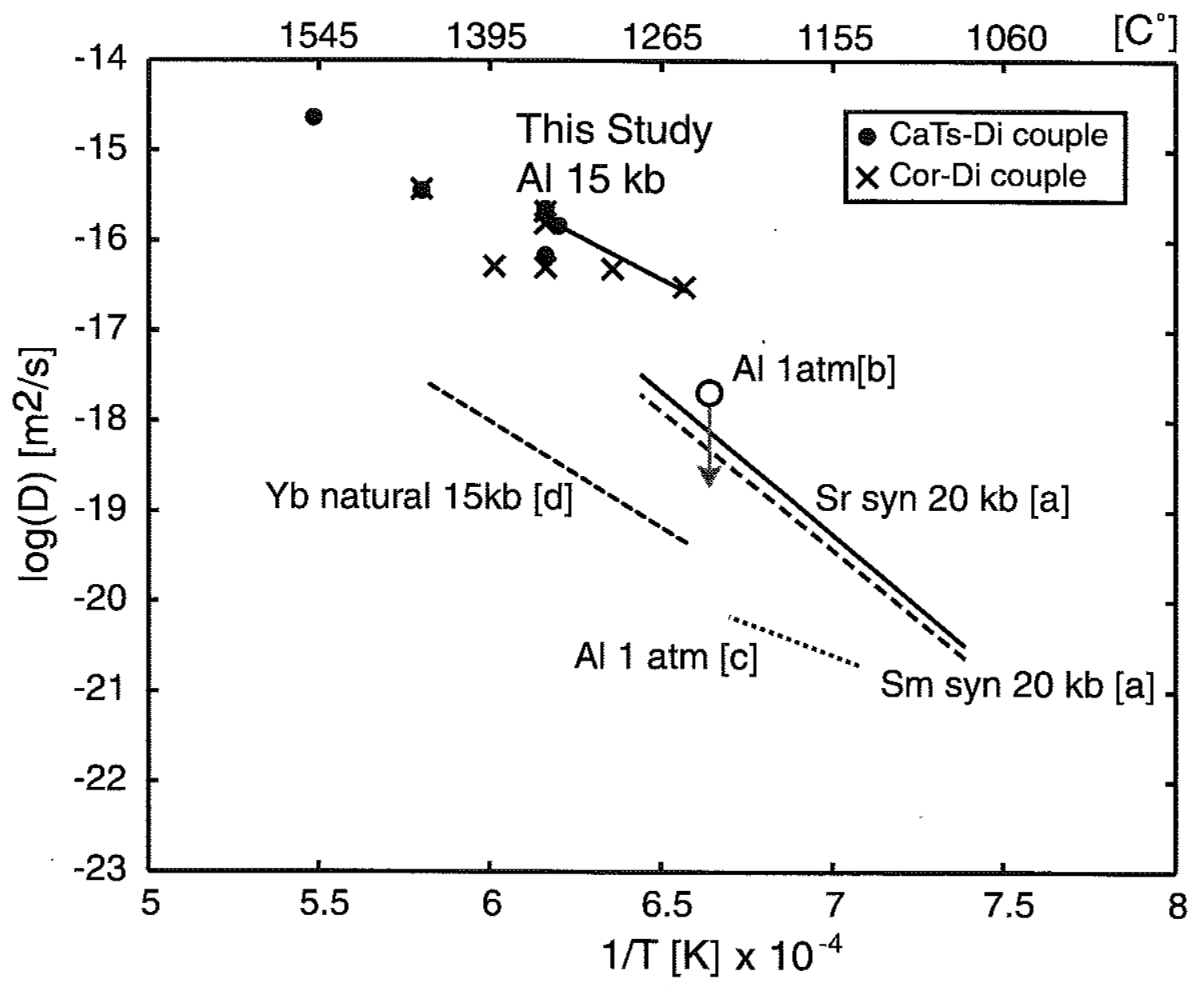


Figure 2.10 The scaling of equilibrium melting is plotted in three parameter space, spreading rate, grain size and diffusion coefficient. This plot shows the required diffusivity for incompatible elements in pyroxene to be in equilibrium with melt during mantle melting. Diffusivity above the solid curves is in the field of more than $83 \%$ equilibration at the given conditions. Our results, at temperature conditions of $1250-1400^{\circ} \mathrm{C}$, are above the equilibration for grain size less than $1 \mathrm{~cm}$ for any reasonble spreading rate.

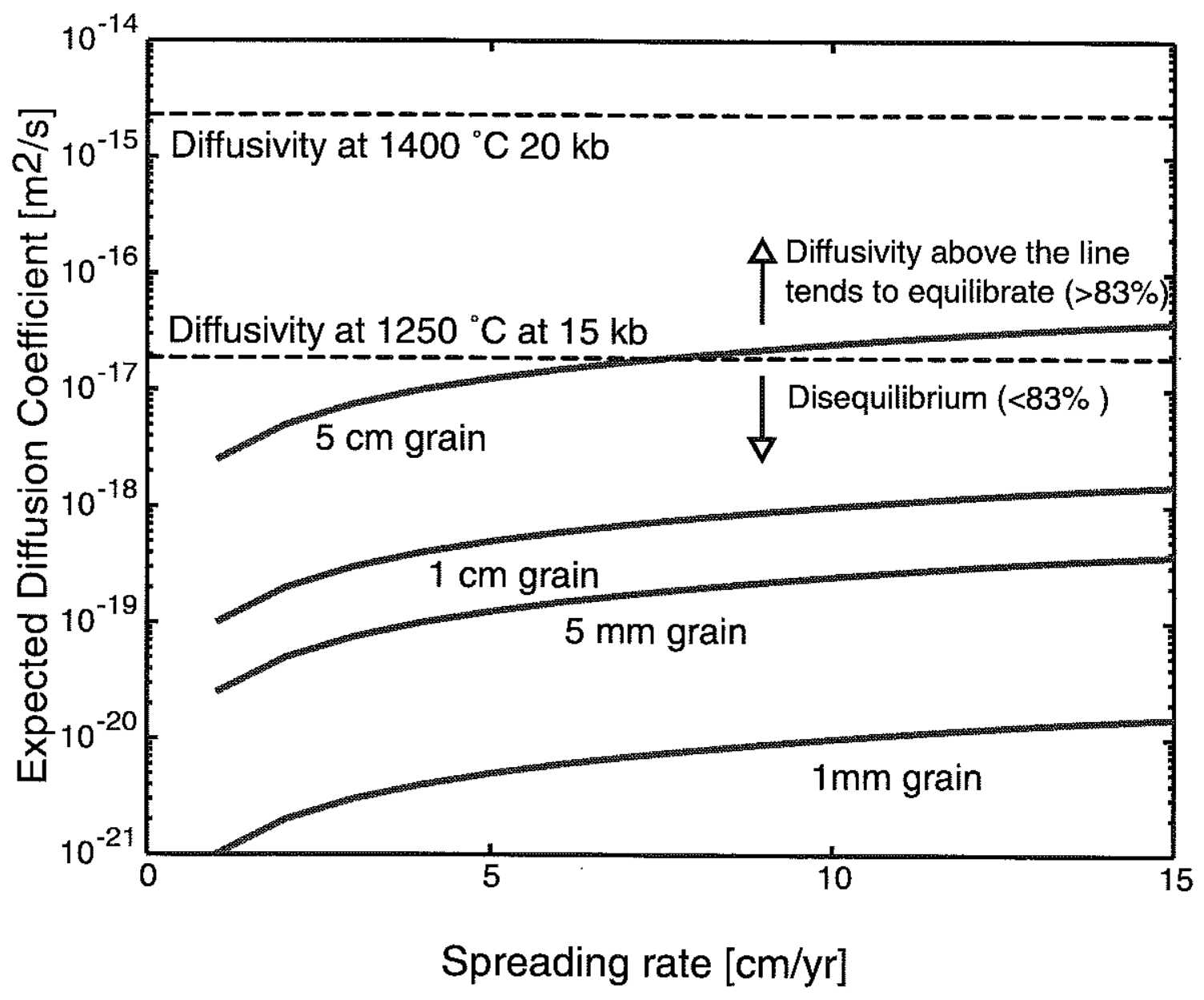




\section{Chapter Three}

\section{A Kinetic Approach for Experimental Determination of the Garnet-Spinel Peridotite Facies Transformation Boundaries: Theoretical Background}

\section{Abstract}

Theories and models for kinetics of reactions are reviewed in order to relate the information obtained from kinetic reaction experiments to the conditions where equilibrium should be achieved. The reaction rate constant, $\mathrm{K}$, that is a parameter of the reaction transformation models, is a linear or log-linear function of the thermodynamic driving force (affinity). The result of this derivation provides the theoretical basis for determining an equilibrium boundary by observing the reaction progress. An example of a reaction, garnet + olivine $=$ spinel + opx $+\mathrm{cpx}$, is discussed in this chapter.

\section{A Kinetic Approach}

In subsolidus reaction experiments, sluggish kinetics of solid state reaction hinders attainment of equilibrium. Traditionally, experimental petrologists have tried to minimize the effect of kinetic processes (e.g. use of fluxes are discussed in Holloway and Wood, 1988 ) and to achieve equilibrium. When the rate of reaction is slow, equilibrium may not be attained in a reasonable length of time. Failure to determine equilibrium conditions in the laboratory leaves assessment of equilibrium in natural rocks impossible.

A reaction for the garnet-spinel lherzolite facies transformation is:

Garnet: $(\mathrm{CaMg})_{3} \mathrm{Al}_{2} \mathrm{Si}_{3} \mathrm{O}_{12}+$ Olivine: $\mathrm{Mg}_{2} \mathrm{SiO}_{4}=$

Spinel: $\mathrm{MgAl}_{2} \mathrm{O}_{4}+$ Orthpyroxene: $\mathrm{Mg}_{2} \mathrm{Si}_{2} \mathrm{O}_{6}+$ Clinopyroxene: $(\mathrm{CaMg})_{2} \mathrm{Si}_{2} \mathrm{O}_{6}$,

Equation 3.1 . 
For this subsolidus reaction, sluggish kinetics hinders the demonstration of equilibrium and reversal reaction experiments only indicate that the equilibrium boundary span a range of pressures (Figure 3.1, O'Hara et al., 1971). In addition to the difficulty of attaining equilibrium, experimental uncertainties hinder precise determinations of reaction boundaries.

A different level of problem arises when a reaction boundary of interest is not univariant in P-T space. The determination of non-univariant boundaries requires determination of conditions where the higher or lower pressure boundaries of the reaction are crossed. For example, the reaction, Equation 3.1, is not univariant for natural compositions, and has garnet-in (the lower-pressure boundary) and spinel-out (the higher pressure boundary) boundaries with a range of condition over which spinel and garnet coexist. Previous experiments on this reaction used various techniques to reduce kinetic effects and promote the establishment of equilibrium (i.e. use of seed, and/or flux), but failed to quantify the range of pressure-temperature conditions for the garnet-spinel coexistence.

The approach and philosophy introduced here is that the equilibrium boundary can also be determined by understanding the kinetics of the reaction. This is based on a simple observation that the farther away a system is from equilibrium, the faster the reaction proceeds. If systematic determinations of reaction rates with respect to externally controlled variables are possible, conditions where the reaction rate converges to zero (i.e. equilibrium) can be determined.

The feasibility of this approach can be inferred from careful inspection of theories and models of reaction kinetics in subsolidus polyphase systems. In the following section, efforts were made to summarize reaction kinetics theories for heterogeneous reactions. The concept of affinity is introduced first, and the mechanisms that control heterogeneous reactions are discussed in relation to affinity. As the extent of reaction is often determined only on macroscopic scales as overall transformation, the KJMA theory is used to model the overall transformation of phases in a heterogeneous reaction. The functional relationship between reaction rate constants and affinity is discussed and its use for determining equilibrium boundaries is proposed.

\section{Theory of reaction kinetics}

A reaction can be classified as either homogeneous or heterogeneous. For example a gas oxidation reaction, $\mathrm{CO}+1 / 2 \mathrm{O}_{2} \rightarrow \mathrm{CO}_{2}$ is a homogeneous reaction. On the contrary, the 
subsolidus reaction such as Equation 3.1 is a heterogeneous reaction that involves multiple phases.

The mechanisms of a heterogeneous reaction are more complex than those of homogenous reactions. Mechanisms for attachment and detachment of atoms and molecules during a reaction are different between homogeneous and heterogeneous reactions.

\section{What is the reaction rate?}

\section{Definition}

The rate of reaction is defined by changes in quantities of phase components over time. For example, for a reaction, $\mathrm{aA}+\mathrm{bB}=\mathrm{cC}+\mathrm{dD}$, where small letters denote stoichiometric coefficients, changes of quantities of phase components with time can be expressed as follows:

$$
-\frac{1}{a} \frac{\partial[A]}{\partial t}=-\frac{1}{b} \frac{\partial[B]}{\partial t}=\frac{1}{c} \frac{\partial[C]}{\partial t}=\frac{1}{d} \frac{\partial[D]}{\partial t}=\frac{\partial \xi}{\partial t}
$$

Equation 3.2

where bracketed variables denote quantities of components, $\xi$ is the reaction progress variable, and is assigned to describe the extent of the reaction. The rate of reaction, $d \xi / d t$, can thus be defined independent of stoichiometry.

In a homogeneous reaction such as $\mathrm{CO}+1 / 2 \mathrm{O}_{2} \rightarrow \mathrm{CO}_{2}$, the rate of the reaction is a function of the frequency of molecular collision and average kinetic energy of collisions. The frequency and energy of collisions are functions of the concentration of molecules and temperature, and determine the probability that bonds are formed or broken after collision. The rate of homogeneous reaction is a function of concentration and temperature.

However, a heterogeneous reaction occurs in a system that consists of more than two phases and mechanisms (and rates) of reaction are more complex. For example, in the reaction presented as Equation 3.1, it is possible to conceptualize that garnet and olivine react by releasing molecules to grain boundaries, and they re-combine and attach themselves to the surface of growing pyroxenes and spinel. In this framework, transport and rate of overall attachment or detachment would be the rate limiting processes. Since actual attachment/detachment processes of atoms or molecules on the surface of grain are only known for limited conditions, further analysis of surface processes is required. 


\section{What drives a Reaction?}

The rate of subsolidus reactions increases with increasing degree of overstepping from equilibrium (Rubie and Thompson, 1985). For Equation 3.1, garnet formation from spinel, opx and cpx can be greatly promoted if an experiment were conducted at $3.5 \mathrm{GPa}$ instead of 2.5GPa. If one finds that more garnet formed under higher pressure conditions than lower ones, and one would realize that there is greater thermodynamic driving force under $3.5 \mathrm{GPa}$ than at $2.5 \mathrm{GPa}$.

The actual "force" driving the reaction is a state in which atoms mix, collide, and settle into a new state, such that the free energy is minimized. That is the condition that corresponds to the most probable distribution of atoms. In a gas, atomic collisions could result in bonding of the colliding atoms and that can be a minimum energy state at given pressure and temperature. In solids, a similar principle applies to the distribution of atoms. The difference is due to the restriction of movement of atoms caused by the interatomic bonding of the ordered structure in crystals. In short, the "force" driving a reaction is the tendency that a system converges to a high probability state, but no uniform physical force (i.e. gravity, magnetic) is driving the macroscopic aspects of the reaction. When a system is under disequilibrium, a quantity of the "driving force" is described as a difference in the chemical potential of the system relative to equilibrium. The difference in chemical potential among molecules in a system is described as affinity and can be derived from activities of the molecules. Therefore, the greater the departure from equilibrium, the greater the driving force; the greater affinity and the faster the rate of reaction.

The mechanism of reaction can also be described by kinetic energy of each atom (e.g. the transition state theory reviewed in Lasaga, 1981; Lasaga, 1998). Transition state theory determines the rate of a reaction by comparing kinetic energy of atoms to the energy requirement for a reaction. The transition state theory does not describe the "driving force" of reaction, because the energy requirement is not a quantity to "drive" the reaction.

\section{Affinity}

Affinity is a state function that quantifies the difference between equilibrium and actual state (Prigogine, 1955). It is chemical potential energy stored in a system that determines the ability to make a reaction proceed. 


\section{Definition}

Affinity is defined as the difference in the chemical potential between product and reactant. When $\mu_{\gamma}$ is chemical potential for a phase $\gamma$ and $v$ is a stoichiometric coefficient, affinity $(A)$ is defined as,

$$
A=-\sum_{\gamma} v_{\gamma} \mu_{\gamma}
$$

Equation 3.3

Furthermore, chemical potential can be substituted for the derivative of free energy with respect to individual components (number of mols: $n_{\gamma}$ ).

$$
A=-\sum_{\gamma} v_{\gamma}\left(\frac{\partial G}{\partial n_{\gamma}}\right)_{P, T, n_{\gamma}^{\prime}}
$$

Equation 3.4

This derivation shows the relationship between affinity and the slope of the Gibbs free energy surface in a compositional space; the steeper the slope of the tangent plane, stronger is the reaction driving force. Instead of taking the derivative for each species, using the relationship between the reaction progress variables $(\xi)$ and the number of atoms derived from Equation 3.2,

$$
d n_{\gamma}=v_{\gamma} d \xi
$$

Therefore, slope of free energy can be expressed in a simpler parameter, that is the direction of reaction in the compositional space described by $\xi$.

$$
\sum_{\gamma}\left(\frac{\partial G}{\partial n_{\gamma}}\right)_{P, T} \cdot v_{\gamma}=\sum_{\gamma}\left(\frac{\partial G}{\partial n_{\gamma}}\right)_{P, T} \cdot \frac{d n_{\gamma}}{d \xi}=\left(\frac{\partial G}{\partial \xi}\right)_{P, T}
$$

Thus,

$$
A=-\left(\frac{\partial G}{\partial \xi}\right)_{P, T}
$$

Equation 3.5.

In summary affinity is the chemical potential difference between reactant and product, and it can be expressed as the derivative of the free energy surface. Therefore, affinity can be understood as the driving force of a reaction. 


\section{How does a system approach equilibrium?}

The rate of a reaction at each time step may not necessarily be constant, because chemical affinity changes with the progress of the reaction. As a system approaches equilibrium, the rate of reaction should decrease asymptotically. Systematic understanding of changes in reaction rates is critical for predicting time scales of the overall transformation. The models of the overall transformation are based on the concept of crystal formation that requires sequential processes of nucleation and growth. Models of nucleation and growth during heterogeneous reactions are introduced prior to the reviews of the models for overall transformation.

\section{Heterogeneous reaction}

The rate of a heterogeneous reaction is controlled by the nucleation and growth of new phases. Nucleation and growth are driven by the internal energy of a system, (i.e., affinity) and can be limited by transport. For a heterogeneous reaction to approach equilibrium, new phases that are thermodynamically stable must nucleate and grow. Derivation and application of these heterogeneous reaction models are discussed in a number of textbooks (e.g., Lasaga, 1998), and can be summarized below.

\section{Nucleation}

Nucleation phenomena are classified as heterogeneous and homogeneous depending on the geometry of nucleation. In homogeneous nucleation the nucleation process occurs spontaneously. Heterogeneous nucleation occurs on an existing substrate. The difference between homogeneous vs. heterogeneous nucleation is the amount of energy consumed during the process and could result in the difference in rates of nucleation.

\section{Homogeneous Nucleation}

Nucleation is a process involving formation of clusters of atoms that grows large enough for steady growth of a phase. Nucleation has been modeled by the free energy balance between the bulk energy as a function of volume and the surface energy as a function of surface area. For nuclei to be stable, the free energy has to be less than zero. Thus, the relationship of energy required for nucleation is

(volume) (molecular bond energy) $+($ area $)($ surface energy $)=($ total energy of nuclei $)$ 
This relationship is illustrated in Figure 3.2 showing the functional relationship between the radius of the nuclei and the Gibbs free energy. Beyond the critical radius ( $r^{*}$ ), the clusters of atoms tend to grow rather than dissociate. The application of the transition state theory allows to develop the nucleation rate equation as follows.

$$
I=N_{0} \frac{k T}{\hbar} e^{\left(\frac{-E a}{k T}\right)} e^{\left(\frac{-\Delta G^{*}}{k T}\right)}
$$

Equation 3.7

The term associated with $E a$ is the probability of atoms forming the activation complex. $k T / \hbar$ is a frequency term. $\Delta G^{*}$ is energy needed to reach critical nuclei, and is also a function of affinity. $\mathrm{N}_{0}$ is total number of molecules in a system. The equation can be written as a function of affinity $(A)$ of the system,

$$
I=N_{0} \frac{k T}{\hbar} e^{\left(\frac{-E a}{k T}\right)} e^{\left(\frac{-\Lambda \sigma^{\prime \prime} / A^{m}}{k T}\right)}
$$

Equation 3.8

The equation shows that the greater the affinity, the faster the rate of nucleation. The constants, $\Lambda, n$, and $m$ are defined by geometry, and $\sigma$ is surface energy.

\section{Heterogeneous Nucleation}

Heterogeneous nucleation is a nucleation process that occurs on the surface of a foreign material. Due to the wetting characteristics between nuclei and the foreign surface, total surface energy is reduced more than in homogenous nucleation. The reason why heterogeneous nucleation is favored against homogeneous nucleations is illustrated in Figure 3.3. Unless the surface energy is zero (i.e. wetting angle becomes zero), the volume of a nuclei formed on the heterogeneous substrate is always smaller than a sphere formed in a medium. Therefore, the substrate serves to reduce surface energy of the nucleating material and lowers the negative contribution from the surface energy that is working against nucleation. Thus, critical nucleation energy $\mathrm{G}^{*}$ is smaller for heterogeneous nucleation than homogeneous nucleation. Computation of heterogeneous nucleation also uses Equation 3.8 with geometric parameters appropriate for surface nucleation, and the rate for heterogeneous nucleation is also a function of affinity of the system. 
Growth

Crystal growth processes involve transport of atoms, kinetics of reaction, and heat dissipation. Models of growth can be developed based on one of the processes that are rate-limiting.

\section{Reaction kinetics limited growth}

This model is also called "surface limiting growth" because it considers attachment of atoms (and molecules) to the surface of a growing crystal as rate limiting. The overall rate of attachment can be modeled as

$$
W=k_{0} \alpha e^{-\frac{E_{a}}{R T}} f(\Delta G)
$$

Equation 3.9

where $W$ is growth rate with a dimension of length/time. It is generally termed $\dot{G} . W$ is used here in order to avoid confusion with the Gibbs free energy. $\alpha$ is a constant. The first term, $k_{0} \alpha \exp \left(-E_{\alpha} / R T\right)$, is derived from the energy required to form the activated complex. $f(\Delta G)$ is a function to describe the driving force, in the form,

$$
f=-\left(1-e^{-\frac{\Delta G}{R T}}\right)
$$

Since $\Delta G$ is the difference in Gibbs free energy between an actual and equilibrium states, that is,

$$
\Delta G=R T \ln \left(\frac{\prod a_{i}^{v_{i}}}{K_{e q}}\right)=-A
$$

Equation 3.11

Thus, the rate of reaction kinetics-limited growth is a function of affinity,

$$
W=-k_{0} \alpha e^{-\frac{E_{a}}{R T}}\left(1-e^{\frac{A}{R T}}\right)
$$

Equation 3.12

\section{Diffusion-limited growth}

The growth of product phases can be limited by transport of material in a system.

Transport of elements required for a reaction can be hindered by the diffusive transport 
process and that can limit the growth rate. The full solution of this process requires solution of a differential equation,

$$
\frac{\partial C}{\partial t}=\nabla(D \nabla C)+V \nabla C
$$

Equation 3.13

Based on Fick's Law, the differentiation of the solution to the above equation gives the flux at the growth surface,

$$
f l u x=-D \nabla C=-D \frac{\partial C}{\partial x}
$$

For the one dimensional case, the solution showing the rate of interface growth is (Lasaga, 1998),

$$
\frac{d a}{d t}=q D \bar{V} \frac{C_{\infty}-C_{e q}}{a}
$$

Equation 3.14

where $a$ is a radius of growing crystal, and $\bar{V}$ is molar volume of diffusing species. $q$ is a factor that is a part of the analytical solution, but is generally close to unity. Instead of concentration, the diffusion equation can expressed in the Einstein form with respect to the chemical potential flux

$$
\frac{d a}{d t}=q D \bar{V} \frac{\mu_{\infty}-\mu_{e q}}{a}=q D \bar{V} \frac{-A}{a}
$$

Equation 3.15

The rate is directly proportional to affinity. When the steady state boundary layer is present, the solution reduces to (Lasaga, 1998):

$$
\frac{d a}{d t}=D \bar{V} \frac{\mu_{\infty}-\mu_{e q}}{h}=D \bar{V} \frac{-A}{h}
$$

Equation 3.16

\section{Overall transformation}

The ultimate goal for understanding the rate of mineralogical reactions is to determine the rate of overall transformation from reactants to products. For mineralogical phase transformations that are heterogeneous reactions, the rate of transformation is difficult to determine. Among theoretical treatments found in the literature, two approaches have 
had a certain degree of success and are presented here: a model known as the Avrami equation (i.e. the KJMA theory), and a variation of the Avrami equation specifically designed for grain boundary nucleation.

\section{The Avrami Equation}

The KJMA theory is a series of studies leading to the establishment of a quantitative way to understand the kinetics of overall transformation in heterogeneous reaction systems (Johnson and Mehl, 1939; Avrami, 1939; Avrami, 1940; Avrami, 1941; Lasaga, 1998). The basis of the concept is to quantify the time-dependent conversion of nuclei to crystals and the increase of crystal volume with a certain geometry. The total volume converted can be calculated by integrating the rate of nucleation and growth over time. For the reaction $\mathrm{A} \rightarrow \mathrm{B}$, the volume $\mathrm{B}$ created in $\mathrm{A}$ is

$$
\xi=\frac{V_{B}}{V}=\Lambda \int_{0}^{t} I[W(t-\tau)]^{n} d \tau
$$

where $\Lambda$ and $n$ are geometric factors. Equation 3.17 expresses the increase in volume from time 0 to $t$. A nucleus formed at $\tau$ can grow for a duration $(t-\tau)$. The integration of a product of the rate of nucleation and growth over time determines the number of grains of various sizes that are formed. When growth rate is in one dimension (e.g. m/s), volume growth is calculated by assuming geometry, for instance spherical grains are expressed by $n=3$ and $\Lambda=4 / 3 \pi r^{3}$. The shortcomings of this equation arise from the lack of consideration of the "already -transformed sphere", such that with Equation 3.17, nucleation can continue inside material already transformed, and growing grains can keep growing into other grains. The model was thus adjusted for parts of volume already converted.

Using assumptions of random distribution of nucleation sites and "isokinetic conditions" with $W / I=$ constant, the relationship is

$$
\frac{d V_{B}}{d V_{B, E x t}}=1-\frac{V_{B}}{V}
$$

Equation 3.18.

Integrating Equation 3.18 with respect to $d V_{B}$, and substituting Equation 3.17, gives 


$$
-\ln (1-\xi)=\Lambda \int_{0}^{t} I[W(t-\tau)]^{n} d \tau
$$

Equation 3.19 .

\section{Variations of the Avrami equation}

Cahn (1956) introduced a variation to the Avrami equation applicable for the grain boundary nucleation system. His integrated equation uses two steps: time and space. The assumption is that all nuclei exist on a plane in a space, the area of growing phase is projected on a plane. By integrating all planes in space, the transformed volume can be calculated. For geological applications, this equation has been used to model the rate of olivine $\beta-\gamma$ phase transformation in the mantle (e.g. Rubie and Ross, 1994).

$$
-\ln (1-\xi)=\Lambda \int_{0}^{y^{\prime}}\left[1-e^{\left(-Y_{e}\right)}\right] d y
$$

Equation 3.20

The above equation is derived using the same approach as Equation 3.19, except for the expression of the volume, which is determined by the integration of the area $\left(\mathrm{Y}_{\mathrm{e}}\right)$ of the growing phase projected on the plane, and they are integrated over the direction $(y)$ normal to the plane that the phase grows on. The time integrated area $\left(\mathrm{Y}_{\mathrm{e}}\right)$ of the phase projected on a plane is calculated from the integration of nucleation rates and growth rate adjusted for the projected plane.

$$
Y_{e}=\pi \int_{0}^{t-t^{\prime}} I\left[W^{2}(t-\tau)^{2}-y^{2}\right] d \tau
$$

Equation 3.21

\section{Applied forms of overall transformation equation}

When a constant nucleation rate $(I)$ and a growth rate $(W)$ are assumed, solutions to integration of equations (Equation 3.19, Equation 3.20) result in the same form,

$$
\xi=1-\exp \left(-K t^{n}\right)
$$

Equation 3.22,

where $\mathrm{n}$ is a geometric factor, and $K$ is the rate constant.

The constant, $K$, includes the rate of nucleation and growth. It is also noted that kinetics of nucleation and growth must be independently considered for the determination of the 
relationship between $K, I$, and $W$. For example, when nucleation sites are saturated, growth kinetics determines the rate of transformation. For example, Equation 3.19 is rewritten as

$$
-\ln (1-\xi)=\Lambda I_{0} \int_{0}^{t}[W(t-\tau)]^{n} d \tau
$$

Equation 3.23.

It is clear that knowledge of nucleation rate $(I)$ and growth rate $(W)$ is key in order to quantify the kinetics of transformation (Equation 3.19), and the mechanistic aspects of $W$ (e.g. reaction-limited vs. diffusion-limited) becomes an important issue. The functional form of $W$ can be substituted into Equation 3.19, to determine the models of overall transformations.

The exponent $n$ depends on how the growth rate function $W$ is defined geometrically. When assumed as constant, $W$ is defined as rate of change in dimension such as radius $r$, (i.e., $r(t)=W t), n=3$ for sphere, the volume of sphere at time $t$ is $\frac{-3}{3} \pi(W t)^{-}$. for circle $n=2$ and volume integral is $\pi(W t)^{2}$.

Using the number of atoms $N$, however, the volume change is proportional to the change in number of atoms, and

$$
\dot{V}=\dot{N} t \frac{v}{A_{0}}
$$

Equation 3.24

where, $A_{0}$ is Avogadro's number and $v$ is the molar volume of a phase. This simplifies the equation to $n=1$.

Affinity, rate, transformation, and their relationships.

The values of $I$ and $W$ are dependent on affinity $(A)$. For a reaction such as $\mathrm{ol}+\mathrm{gt}=\mathrm{sp}+$ opx + cpx in the pressure-temperature space, a distance from the equilibrium reaction line defines magnitude of the thermodynamic driving force and is proportional to affinity. This illustrates the relationship between net reaction rate and affinity, while it can be written as

$$
R_{n e t}=R_{+}\left(1-\exp \left(\frac{-A}{R T}\right)\right)
$$


since affinity $(A)$ is a function of activity $(a)$, temperature $(T)$ and pressure $(P)$, the rate of reaction is also a function of these variables. By changing these variables, affinity can change systematically, and so does the rate.

The KJMA equation uses rates of nucleation $I$ and growth $W$ to model the transformation of the heterogeneous reaction. Since rates of reaction processes such as nucleation and growth are related to affinity, the rate of overall transformation should also be expressed in terms of affinity. It should also be noted that transport affects the rate of reaction. The parameters that describe the overall transformation should then be a combined function of affinity and transport. In the following sections, simplified cases are analyzed to derive functional forms involving these parameters.

\section{Nucleation-saturated}

In heterogeneous nucleation processes, there could be a situation where nucleation sites are saturated due to some limitation of nucleation or a low nucleation rate. In this case, nucleation does not limit the transformation; and it is controlled by growth. The KJMA equation (Avrami equation, Equation 3.19) can be solved in the form of Equation 3.22, in which the rate constant $(K)$ can be expressed as the parameters of Equation 3.19.

$$
K=\Lambda I_{0} W
$$

Equation 3.26

Thus, the number of total nuclei becomes a part of the rate constant which does not change with time.

\section{Nucleation-dominated transformation}

On the other hand, when the growth rate is negligibly small, the nucleation rate controls the reaction. In this case, affinity, rate constant and reaction rate are related as

$$
K=\Lambda W N_{0} \frac{k T}{\hbar} e^{\left(\frac{-E a}{k T}\right)} e^{\left(\frac{-\Lambda \sigma^{n} / A^{m}}{k T}\right)}=(\text { const. }) e^{\left(\frac{-\Lambda \sigma^{n} / A^{m}}{k T}\right)}
$$

Equation 3.27 .

And there is a log-linear relationship between $K$ and $\sigma^{n} / A^{m}$. The exponents $\mathrm{n}$ and $\mathrm{m}$ are geometric factors. $\log K$ is also linearly proportional to intensive variables, $1 / T$ and $P$. 


\section{Growth-dominated transformation}

When the rate of growth exceeds that of nucleation, the transformation reaction could be dominated by growth kinetics. The case of nucleation-saturated reaction is an example of a growth-dominated reaction. Mechanisms for growth can be categorized as transport (diffusion-) and reaction (kinetics-) limited.

\section{Diffusion-limited}

In the case of diffusion-limited growth, the $W$ function takes a form involving the squareroot of $t$. As noted above, $W$ is dependent on affinity, and the reaction rate constant $(K)$ is expressed in a form derived from Equation 3.16,

$$
\begin{aligned}
& K=\Lambda I_{0} \sqrt{-D v A} \\
& K^{2} \propto-A
\end{aligned}
$$

The square of rate constant $K$ is proportional to pressure and inversely proportional to temperature when $D$ (diffusivity) is negligible. Affinity, can be expressed as $A=(-$ $H+P V) / R T$, where $H$ is enthalpy of reaction, $P$ is pressure, $V$ is reaction molar volume, $R$ is the molar Boltzmann constant. It is noted that $K^{2}$ and $P$ are linearly related

\section{Reaction-limited}

In the case of reaction limited growth, the $W$ function takes a form of Equation 3.12, and the reaction rate constant $(\mathrm{K})$ is expressed as,

$$
K=\Lambda I_{0} k_{0} \alpha e^{-\frac{E_{a}}{R T}}\left(1-e^{\frac{A}{R T}}\right)
$$

Given that the most of terms except one associated with affinity are constant for experiments, a log-linear relationship between $\mathrm{K}$ and $\mathrm{A}$ is clear from the equation.

\section{Strategy}

As discussed above, the rate of a phase transformation could take various functional forms with time, depending on the rate-limiting mechanisms. Since a rate-limiting mechanism specific to a given reaction is not known a priori, efforts were made here to identify it. As will be discussed in detail later, experiments were carried out at a given set 
of pressure-temperature conditions with different durations. These time-series runs were used to define the $\xi-t$ relationship, and $K$ was determined using Equation 3.22.

For heterogeneous reactions that are kinetically limited and nucleation dominated $\log K$ and $I / A^{m}$ are in linearly related. Since $A$ is always expressed as $A=-(H+P V) / R T, \log \mathrm{K}$ and $\mathrm{T}^{\mathrm{m}}$ could be linearly related. For heterogeneous reactions that are determined by diffusion-limited growth, a linear relationship is expected for $K^{2}$ and $A$, and thus $K^{2}$ and $1 / T$ are linear.

Reaction-limited growth transformation (Equation 3.29) can be approximated by a linear form using the first term of the Taylor series expansion, and $K$ becomes linearly proportional to affinity. The form of Equation 3.29 shows a linear convergence to zero growth rate near the equilibrium condition.

In summary, the approach used in the present study uses models of kinetics of heterogeneous reactions. It consists of three steps. 1) Systematic variation in affinity of the reaction allows observation of the rate of reaction at various oversteppings. 2) A model of reaction progress can be determined using the time series experiments, and the model allows determination of a characteristic parameters such as the rate constant. 3) The parameter ( $K$ : rate constant) varies with affinity, thus the condition of equilibrium is extrapolated to the point where affinity is zero.

\section{I. $\quad \xi$-t relationship}

At each condition of overstepping, a model of reaction progress is used to determine kinetic parameters. Since it is generally not possible to observe reactions in situ during high-pressure experiments, series of experiments with various durations were used to determine the rate-law. The goal is to identify a function that best describes the experimental results. Use of information deduced from texture and composition provides additional evidence for the determination of the reaction progress model.

Figure 3.4 shows a family of curves for explaining the progress of reaction over time. Depending on the mechanism of reaction, the functionality differs greatly. The first-order reaction model follows the exponential function,

$$
\xi=1-\exp (-K t)
$$


This could be an especially useful form of function since at $t=0$, the slope $d \xi / d t$ is equal to $K$. Once a reaction is determined to follow this law, $K$ can be determined by a number of experiments with relatively short durations.

Diffusion-limited transformation is considered to be characteristic for solid reaction/transformation systems (Fisher, 1978; Zhang et al., 1989). If this were the case, the function of the overall transformation is,

$$
\xi=1-\exp (-K \sqrt{t})
$$

Equation 3.31

If the time-dependent change of crystal radius is used as $\xi$, the rate of transformation is a function of $\sqrt{t}$.

When a spherical grain grows from nuclei formed at a constant rate, the transformation equation becomes,

$$
\xi=1-\exp \left(-K t^{n}\right)
$$

Equation 3.32

and $n=3$ for a nucleation-saturated condition.

When the texture of the experiment is uniform, and products are distributed uniformly throughout the system, the overall transformation is easy to measure. In some of the reaction textures, the new phase forms as a corona around a reactant. In this case, the thickness of the product phase must be accurately determined for measurements of $\xi$ for a local subsystem.

\section{Determination of a model from time series data}

After a series of experiments are conducted at the same temperature and pressure with various durations, the result are plotted on a $\xi$ - $t$ space to show the progress of reaction with time. It is then possible to determine a functional form of the reaction, which, in turn, constraints mechanisms of the reaction.

Figure 3.4 is one such example showing an exponential increase of $\xi$ with time. The application of an exponential function show a reasonable fit with $n=0.5$. Since higher geometrical powers would form sigmoidal curves, the curve shown here is probably a result of a reaction that does not require geometrical constraints. Figure 3.4 suggests $\mathrm{n}=0.5$ demonstrating that the reaction progresses as a function of $\sqrt{ }$. 
A $\log (\log (\xi))-\log (t)$ plot is often used to determine $n$ from the slope. The data is best fit with $\mathrm{n} \sim 0.5$. However, this relationship uses double-log on the $\mathrm{y}$-axis, and the error associated with the measurements is magnified. Therefore, an estimate of slope is not tightly constrained as a result (Figure 3.5 ).

\section{Determination of a model from textural characteristics}

The texture of the experimental charges also helps to determine the kind of model to be used. For example, garnet grows around spinel with a corona texture in the garnetformation experiments. In this case, measurements of the thickness of the product garnet can be made accurately. Figure 3.6 shows a clear $\sqrt{t}$-dependence, suggesting diffusionlimited growth.

\section{Determination of a model from compositional characteristics}

The presence or absence of compositional heterogeneity in the solid phases also helps to determine the type of reaction mechanisms. For example, dissolution of olivine in an andesitic melt (described by, Zhang et al., 1989) shows diffusion profiles within the melt near the interface, suggesting that diffusion-controlled dissolution is operating. The rate of dissolution was modeled by these authors based on a pseudo-binary diffusion model. For the present experiments (see chapter 4), compositional heterogeneity was not observed within the reactant phase. In product phases, however, heterogeneity was formed occasionally. This may indicate formation of product phases with a range of chemical potentials.

As will be discussed later, a diffusion-limited model appears to explain the experimental results; however, no prominent concentration gradients were observed in the phases present. Diffusion gradients within product garnet layer maybe present, but is not observable due to limitations of analytical resolution.

\section{Relationship between reaction rate constant and intensive variable}

From Equation 3.25 to Equation 3.29, the relationship between affinity and $K$ is derived. These relationships are useful in estimating the equilibrium conditions of the phase transition. 


\section{Model parameters}

By conducting experiments over a range of pressure or temperature conditions, the relationship between affinity and kinetics can be determined. The rate constant $(K)$ can be related to pressure-temperature conditions and can then be used to determine the conditions where the rate of reaction is zero and $A=0$.

Once the function relating $K$ and intensive variables is determined, it should be possible to extrapolate experimental results to estimate the equilibrium conditions. Equilibrium should be the condition where affinity and rate of reaction approach zero. Figure 3.7 illustrates how $K$ varies as the equilibrium conditions are approached and demonstrates that $P-T$ condition of equilibrium boundary can be determined.

For a heterogeneous reaction in which diffusion-limited growth dominates, the linear relationship between $K^{2}$ and $A$ allows determination of the conditions where $K^{2}$ approaches zero. This relationship is only possible when the change of diffusivity is relatively small compared with the change of affinity (Equation 3.28). As an example, Figure 3.8 shows a $K^{2}-P$ relationship and, how a linear extrapolation of rate constants can be used to determine conditions where $\mathrm{K}$ approaches zero (i.e., equilibrium). As long as the transformation reaction is adequately described in this way, an accurate determination of equilibrium conditions is possible. Since the growth of many silicates in subsolidus reactions is considered to be diffusion limited, similar $K^{2}-A$ and hence $K^{2}-P$ or $1 / T$ relationships can be expected for various geological systems.

\section{Conclusion}

Experimentalists have recognized the difficulty of attaining equilibrium for some time (i.e. Bowen, 1928). The approach and strategy discussed here enable experimentalists to achieve a better determination of equilibrium reaction boundaries than the traditional method of reversal experiments. The approach requires determination of a characteristic rate constant $(K)$ at various conditions $(P, T)$, and thus requires a time-series experiment at a set of conditions with various durations. As a result, a number of experiments required to determine an equilibrium boundary at one temperature is by a factor of 5-6 more than traditional experiments, and requires a factor of ten more time to complete.

Nevertheless, this approach is especially powerful in two cases that are geologically significant. Subsolidus reactions are usually sluggish due to slow diffusion at lower 
temperatures. When reaction kinetics hinders "tight" reversal experiments, there is no clear way to determine a reaction boundary. Determination of the reaction rate constant is, however, still possible, and provides an effective way to tightly constrain the equilibrium boundary.

The second case is where two reaction boundaries are so close to each other in the P-T space that effective separation is experimentally difficult. For example, it is predicted that garnet-in and spinel-out should occur at different pressure-temperature conditions for natural peridotites and the "width" of garnet-spinel coexisting zone may only be 0.2-0.3 $\mathrm{GPa}$, approximately corresponding a precision of pressure control in reversal experiments. In order to attain separation for the two reaction boundaries, ratedetermining experiments from both directions can be made and used to determine the conditions of the respective boundaries (Figure 3.8). When curves for the reaction rate constants cross each other, garnet-in reaction must be located on the lower-pressure side than the spinel-out reaction. If there were only one boundary, rate constant curves must converge to one value of pressure at constant temperature. 


\section{References}

Avrami M. (1939) Kinetics of Phase Change. I. Journal of Chemical Physics 7, 1103-1112.

Avrami M. (1940) Kinetics of Phase Change. II. Journal of Chemical Physics 8, 212-224.

Avrami M. (1941) Granulation, phase change and microstructure: Kinetics of phase change III. Journal of Chemical Physics 9, 177-184.

Bowen N. L. (1928) The Evolution of Igneous Rocks. Princeton University Press.

Cahn J. W. (1956) The kinetics of grain boundary nucleated reactions. Acta Metallurgica 4, 449-459.

Fisher G. W. (1978) Rate laws in metamorphism. Geochimica et Cosmochimica Acta 42, 1035-1080.

Holloway J. R. and Wood B. J. (1988) Simulating the Earth: Experimental Geochemistry. Unwin Hyman.

Lasaga A. C. (1981) Transition state theory. In Kinetics of geochemical processes, Vol. 8 (ed. A. C. Lasaga and R. J. Kirkpatrick), pp. 398. Mineralogical Society of America.

Lasaga A. C. (1998) Kinetic theory in the earth sciences. Princeton University Press.

O'Hara M. J., Richardson S. W., and Wilson G. (1971) Garnet-Peridotite Stability and Occurrence in Crust and Mantle. Contributions to Mineralogy and Petrology 32, 48-68.

Prigogine I. (1955) Introduction to thermodynamics of irreversible processes. John Wiley and Sons.

Rubie D. C. and Ross C. R. I. (1994) Kinetics of the olivine-spinel transformation in subducting lithosphere: experimental constraints and implications for deep slab processes. Physics of the Earth and Planetary Interiors 86, 223-241.

Rubie D. C. and Thompson A. B. (1985) Kinetics of Metamorphic Reactions at Elevated Temperatures and Pressures: An Appraisal of Available Experimental Data. In Metamorphic Reactions, Vol. 4 (ed. A. B. Thompson and D. C. Rubie), pp. 27-79. Springer-Verlag.

Spear F., S. (1993) Metamorphic phase equilibria and pressure-temperature-time paths. Mineralogical Society of America.

Zhang Y., Walker D., and Lesher C. E. (1989) Diffusive Crystal Dissolution. Contrib. Min. Petrol. 102, 492-513. 


\section{Figures}

Figure 3.1: Experimental data from O'Hara el.al. (1971) shows the wide range of possible pressures for the garnet-spinel boundary. The arrows indicate the direction of the reaction (i.e. garnet formation or spinel formation). Open or closed symbols show the minerals formed. The circles with dark dots in the center indicate that garnet and spinel coexisted in the experiment. By inspection of the figure, the reaction boundary is determined with in $0.2 \sim 0.3 \mathrm{GPa}$.

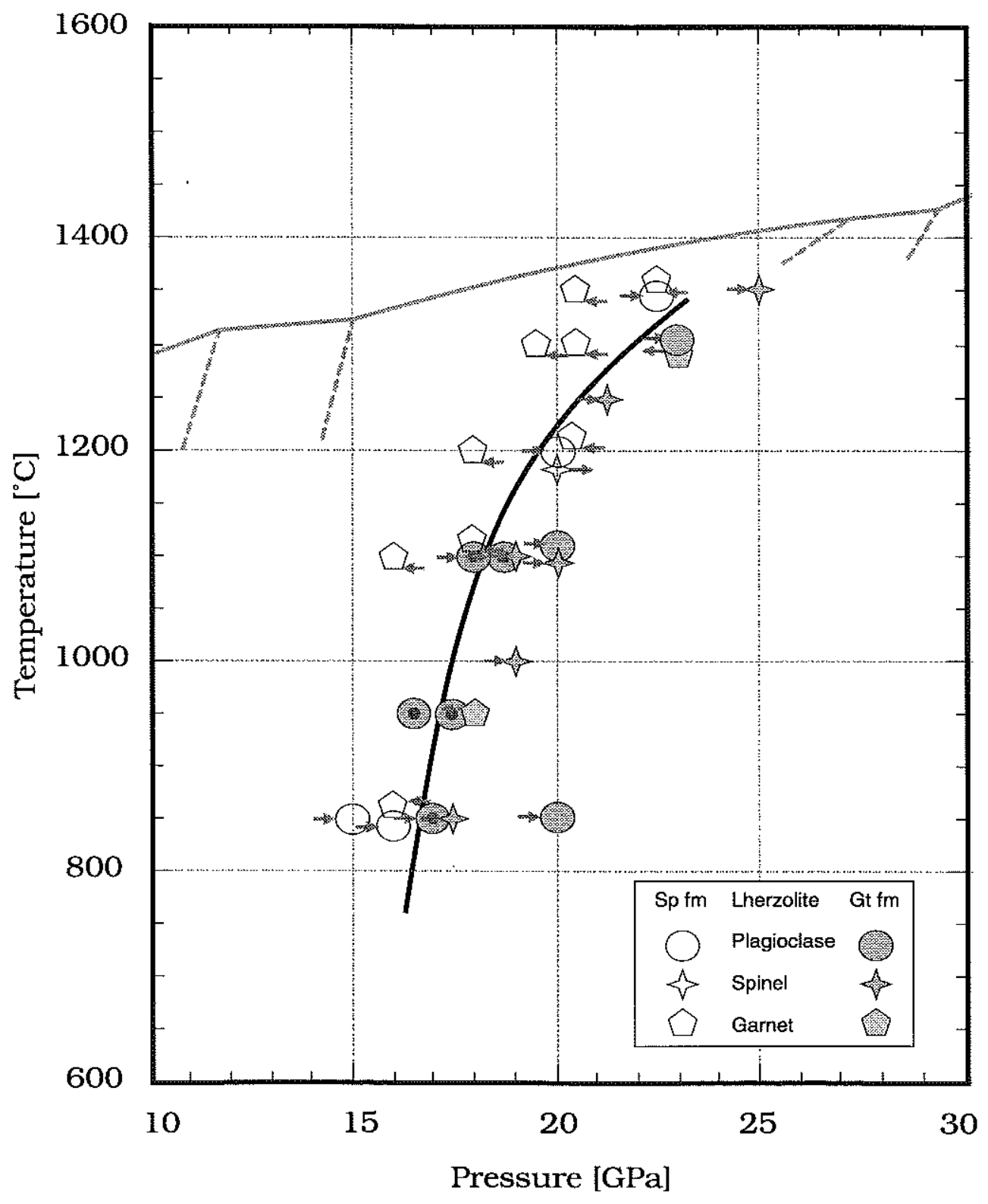


Figure 3.2: Illustration of energy of formation of nucleus as a function of radius. X-axis is the radius of nuclei and y-axis is Gibbs free energy. When nuclei is larger than $r^{*}, d G / d r$ is negative, thus the growth of nuclei is favored beyond $r^{*}$.

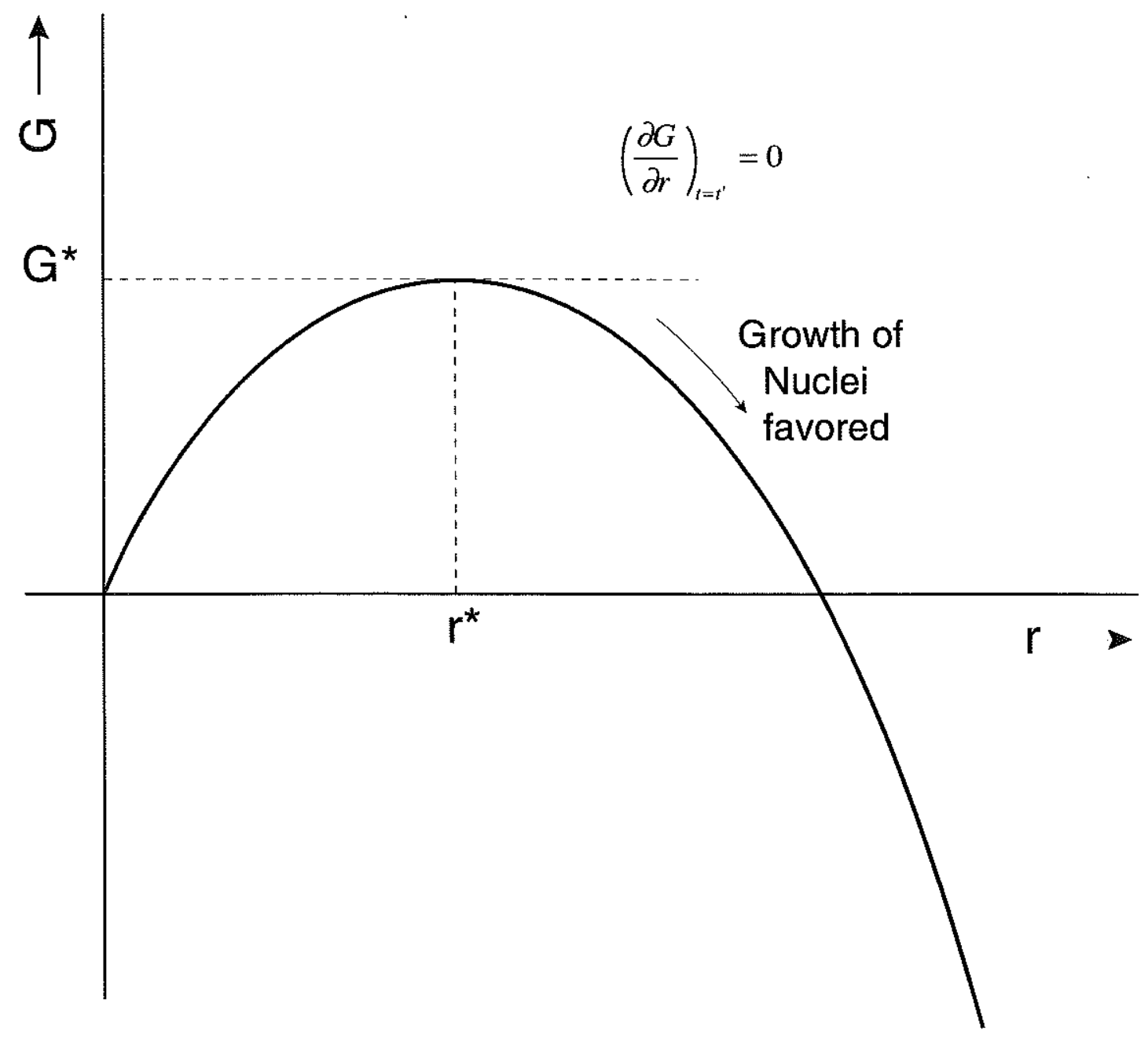


Figure 3.3: Illustration of geometrical differences for heterogeneous and homogeneous nuclei. Top illustrations show the differences in geometry of the nucleus, and bottom illustrations show how nuclei are distributed in a system reacting to $\mathrm{A} \rightarrow \mathrm{B}$.

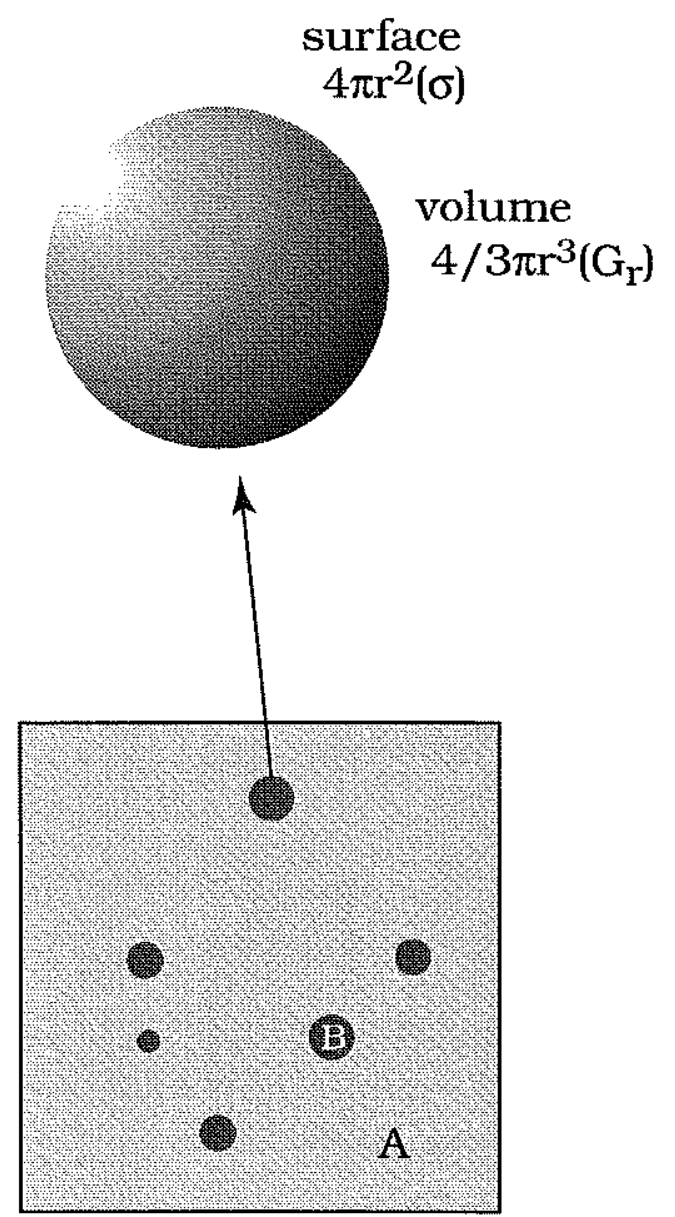

Homogeneous Nucleation

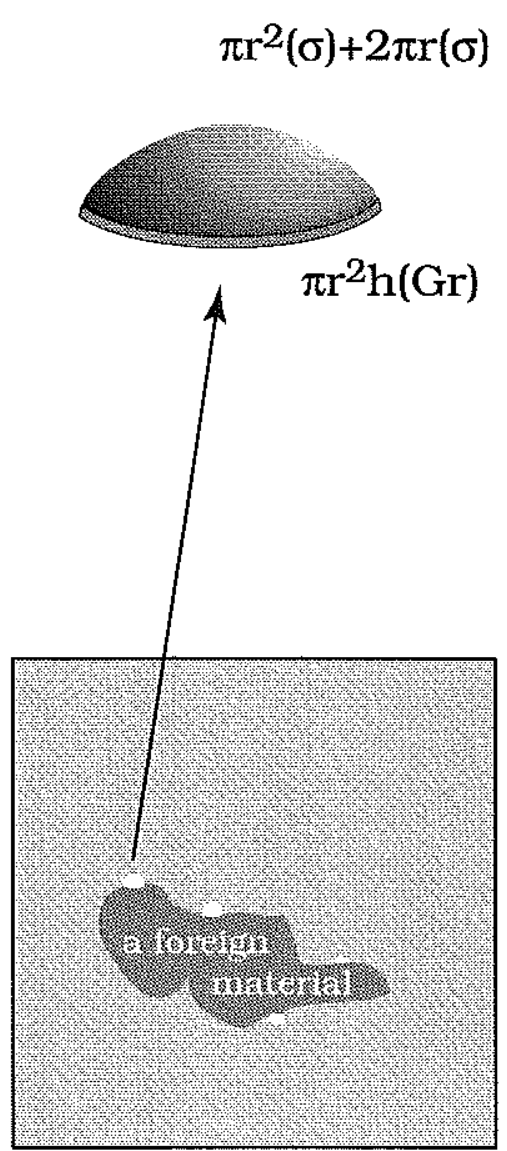

Hetrogeneous Nucleation 
Figure 3.4: $\xi$-t plots illustrating a family of curves showing overall transformation.

Experimental data is plotted on the $\xi$-t plot. Dashed lines are $n=1 / 2$ and the best-fit $n \sim 1 / 2$, dotted line is $n=1$, representing a first order reaction, and gray line is for $n=2$. Higher order $n$ produces a curve similar to, but steeper than $n=2$.

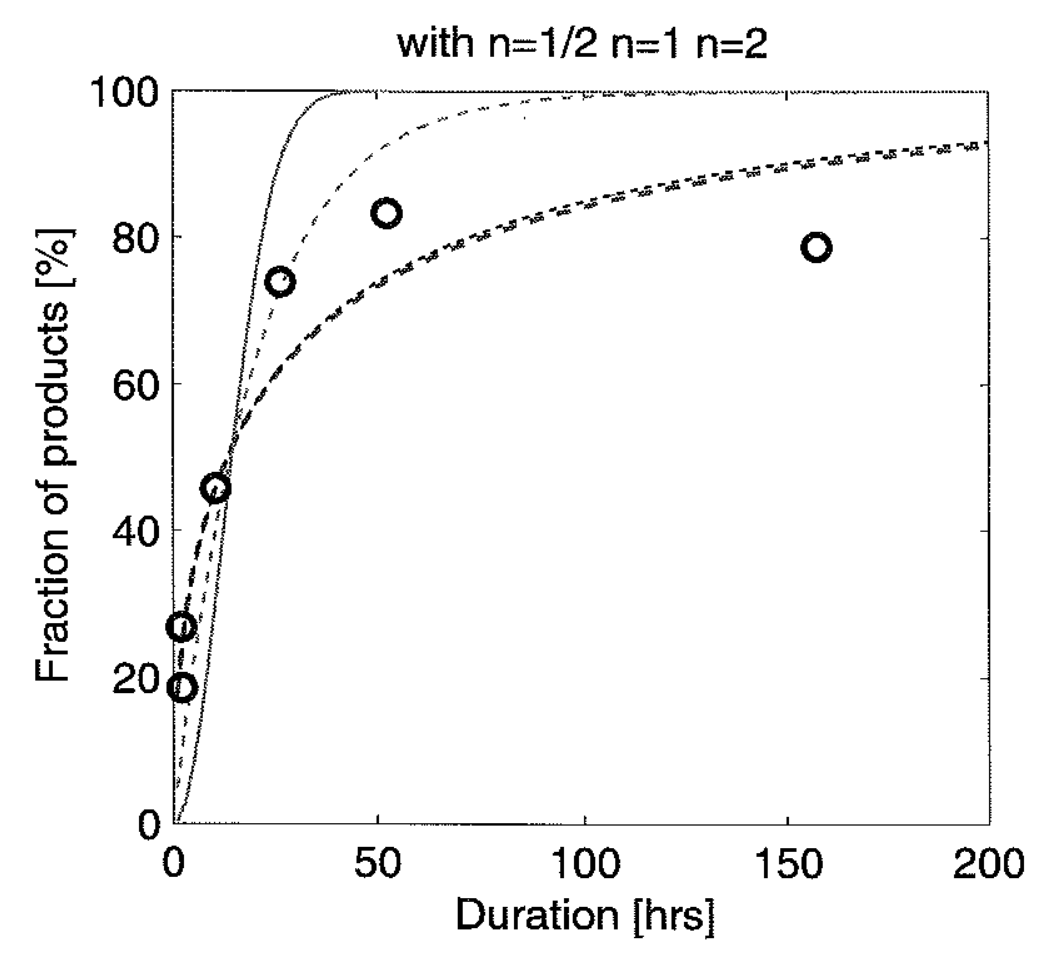


Figure 3.5: This figure shows how the value of $n$ could be determined from the slope on a $\log (\log (\xi))-\log (\mathrm{t})$ plot. Legend is the same as Figure 3.4.

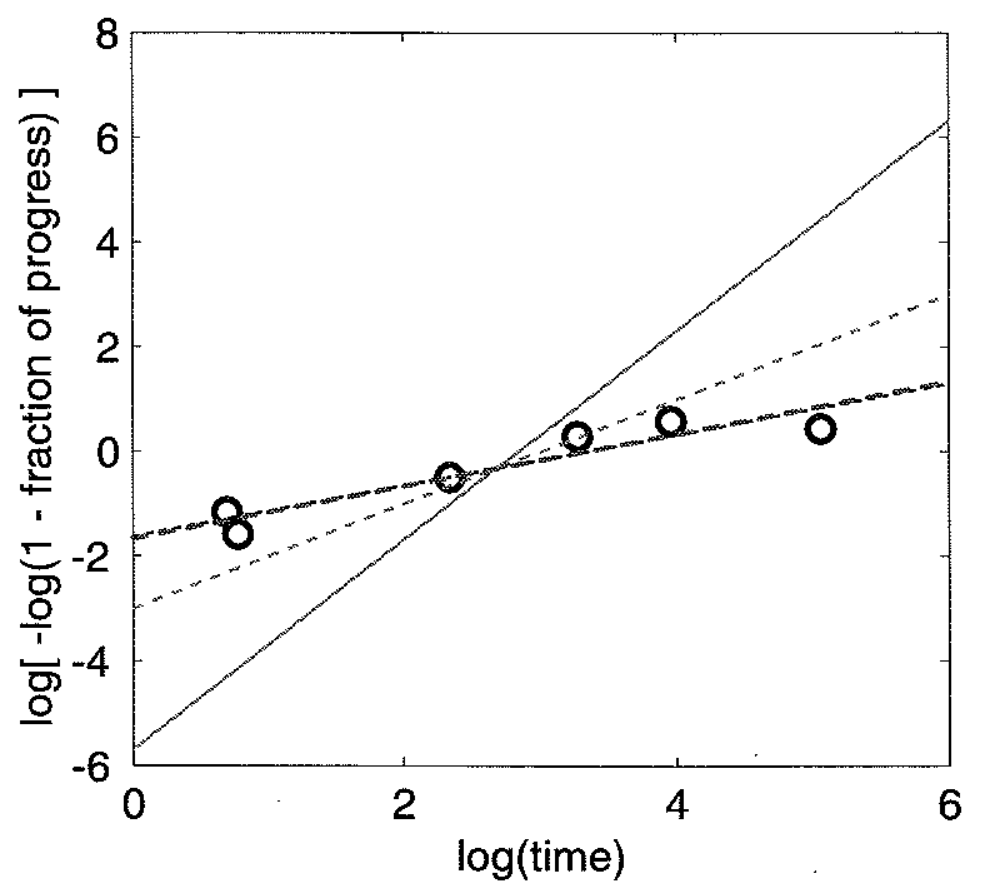


Figure 3.6: A typical reaction texture of an experiment

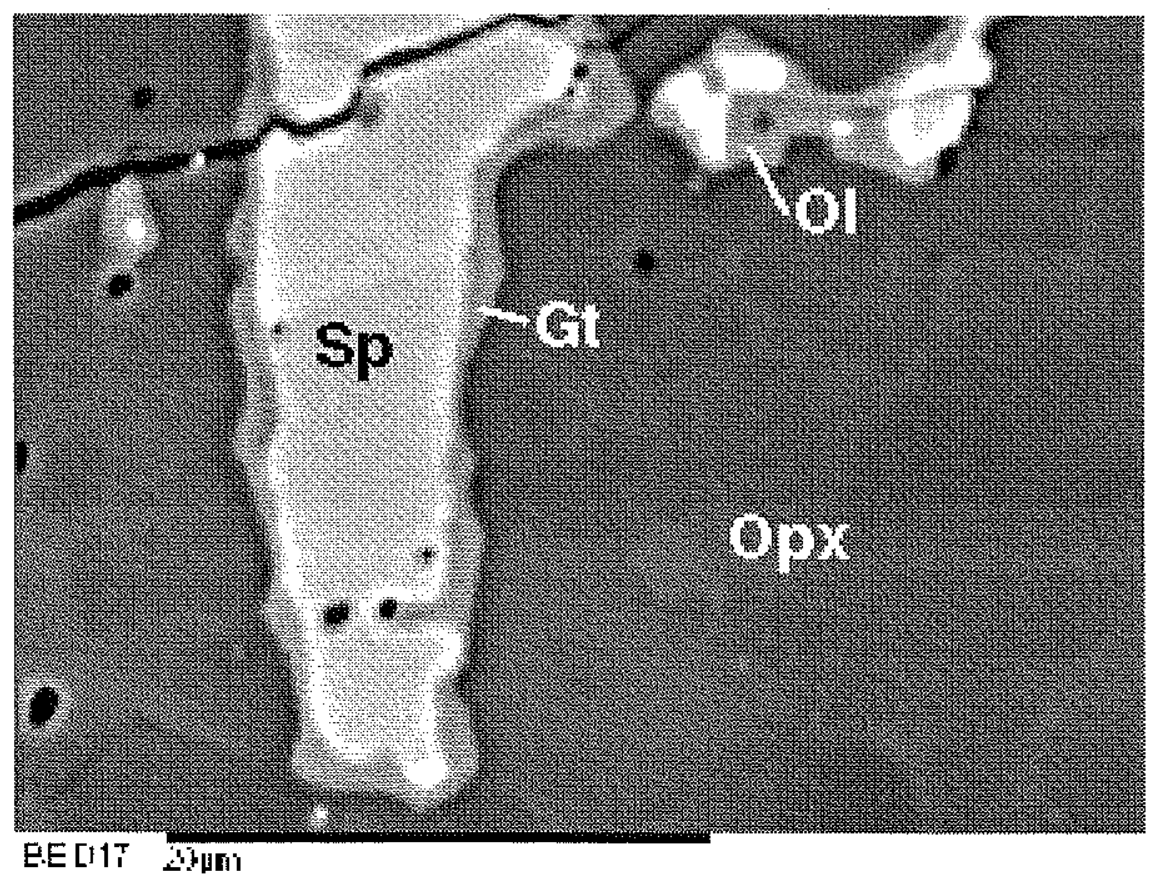


Figure 3.7: Illustration of $\ln K-P$ relationships. As the equation shows, the rate constant $\mathrm{K}$ is the sum of diffusion and reaction parameters (shown as the gray line). If the volume change of the reaction is negligible, diffusion (solid line) is the dominant control of the rate constant $K$. If the diffusion process does not change with pressure and temperature (i.e. slope of solid line is zero), the reaction term (dotted line) determines the change of rate constant $K$.

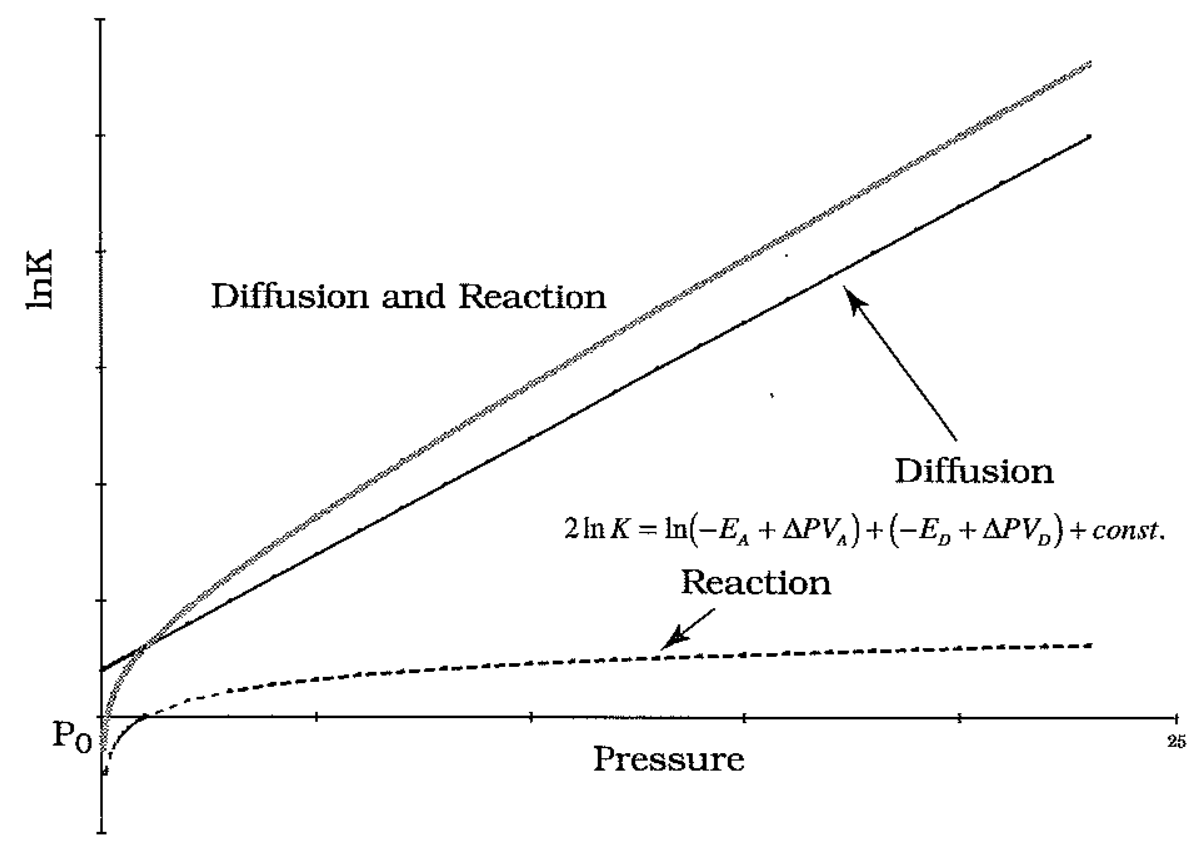

Figure 3.8: $K^{2}-P$ relationship. When the pressure dependence of the diffusion process is negligible, this relationship can be linear.

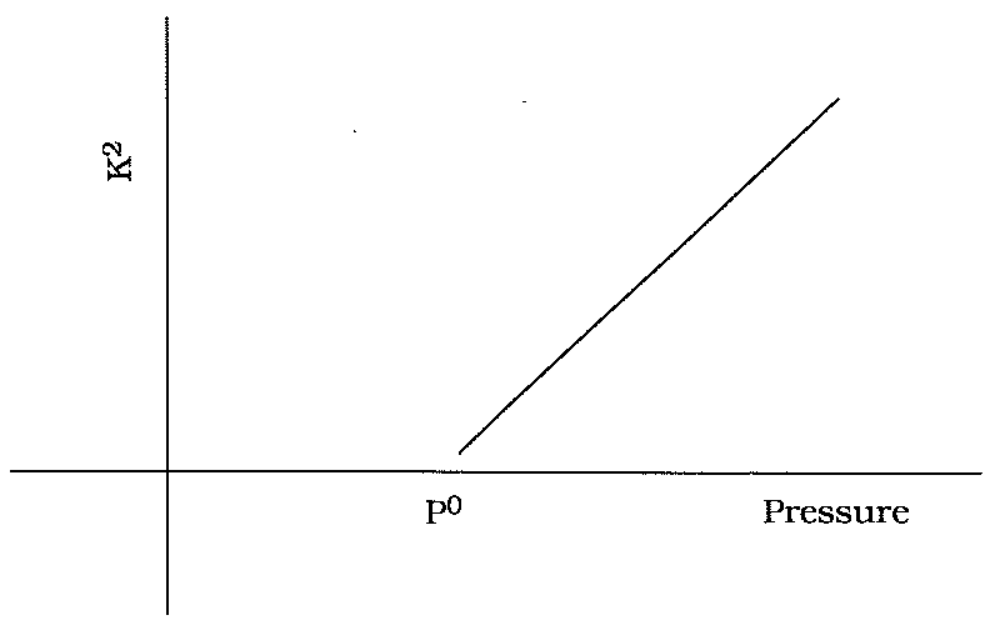




\section{Chapter Four}

\section{A Kinetic Approach for Experimental Determination of the Garnet-Spinel Peridotite Facies Transformation Boundaries: Experiments and Results}

\section{Abstract}

Fifty isothermal experiments were conducted to determine the boundary of the mantle facies transformation from spinel lherzolite to garnet lherzolite. The results were analyzed using kinetic theory, and show a presence of the divariant field where garnet and spinel exist. The width of this field is approximately $0.2 \mathrm{GPa}$ at $1360^{\circ} \mathrm{C}$. The reaction boundaries are located at $2.3 \pm 0.2 \mathrm{GPa}$ for the garnet-in and at $2.5 \pm 0.2 \mathrm{GPa}$ for the spinelout boundaries at $1360^{\circ} \mathrm{C}$.

\section{Introduction}

The depth at which garnet lherzolite becomes stable is an important parameter for models of MORB generation, since trace element geochemistry successfully demonstrated that MORB is generated where garnet is a stable phase in melt residues (e.g. Beattie, 1993). However, if melting of peridotite starts at the depth where garnet peridotite is stable, the final quantity of melt produced by adiabatic upwelling, using thermodynamically predicted melt production rates, exceeds the observed quantity of basalt as thickness of oceanic crust determined by geophysical observations. This so called "garnet paradox" has evoked various hypotheses to reconcile these geochemical and geophysical observations (e.g. Hirschmann and Stolper, 1996). It should be recognized that there are still important constraints to be made to clearly illustrate the paradox and to resolve it. One of the fundamental knowledge is the depth at which garnet is stable in the mantle, and that is not known precisely. The garnet to spinel facies boundary has been experimentally investigated by many scientists since Kushiro and Yoder (1966). The 
previous investigations demonstrated a wide range of possible, but inconclusive, pressures and temperatures where the transformation may occur (Figure 1). This diversity of transformation boundaries is mainly due to differences in the experimental methods, and the variations in the composition of the material used in the experimental study.

Figure 1 illustrates the locations of garnet-spinel peridotite transformation boundaries,

$$
\text { Garnet }+ \text { Olivine }=\mathrm{Opx}+\mathrm{Cpx}+\text { Spinel, }
$$

Equation 4.1

and a possible solidus for peridotite. The range of pressures for the experimentally determined boundaries is $>1.0 \mathrm{GPa}$. This range strongly depends on the composition of the system. For example, the addition of $\mathrm{Cr}$ moves the transformation boundary to higher pressure (line e and $\mathrm{f}$ in Figure 1) compared to the CMAS (Ca-Mg-Al-Si-O) simple system. The addition of $\mathrm{Fe}$, in contrast, shifts the boundary to lower pressure (O'Neill, 1981). One would expect the phase boundary in natural compositions to vary in response to variation in the abundance of minor elements $(\mathrm{Ti}, \mathrm{Cr}, \mathrm{Fe}, \mathrm{Na})$, but there is not enough information to allow construction of a complete solution model. Therefore, the phase boundary determined by O'Hara et al. (1971) represents the only reaction boundary yet determined for natural compositions. However, the absence of reported mineral compositions prevents direct comparison of O'Hara's results to natural rocks. For the facies transformation boundary, the phase rule demonstrates that Equation 4.1 becomes divariant for more than four system components (e.g. CMAS vs. CrCMAS). The garnet-in boundary is located at lower pressure than the spinel-out boundary, and an analysis of the simple system (NaCAMS) demonstrated the coexistence of garnet and spinel (Walter and Presnall, 1994). Previous studies in both natural and simple (CrCMAS) bulk compositions have had limited success in determining the lowest possible pressure at which garnet is stable (Nickel, 1986).

It is well known among experimental petrologists that subsolidus reactions are extremely slow and that it is difficult to attain equilibrium within a reasonable amount of time. Previous studies have used various techniques to speed up the rate of reaction, with limited success (e.g., $\mathrm{H}_{2} \mathrm{O}$ flux: Jenkins and Newton, 1979). Although a garnet breakdown reaction seems to be promoted, the result of the reverse reaction (garnet formation reaction) was not enhanced and appears to require large overstepping. Typically, reversal 
experiments for garnet-spinel facies transformation reaction result in a 0.1 to $0.3 \mathrm{GPa}$ range of pressures for the equilibrium boundary (e.g. O'Hara et al., 1971). The sluggish reaction hinders the separate determination of the garnet-in and spinel-out transformation boundaries. Also, the subsolidus reaction does not reach a complete equilibrium state in the experiments.

The goal of this study is to carefully investigate the facies transformation boundaries for the garnet-in and spinel-out reaction in natural lherzolite compositions.

An approach based on reaction kinetic theory was developed and used to investigate the presence of the garnet-spinel coexisting peridotite facies. This approach requires careful measurements of reaction progress, and the reaction rate is used to infer the magnitude of the reaction driving force at different pressures. Using isothermal experiments, the trends of the reaction driving force with respect to pressure are extrapolated to zero net driving force, which defines the equilibrium state. This approach allows development of a clear picture about the nature of the transformation boundary, and location of the boundaries are inferred from the analysis of reaction rates.

\section{Experimental Procedure}

\section{Starting materials}

Well documented natural peridotite samples were chosen as starting materials. Because the experiments sought to determine the reaction progress instead of the final achievement of equilibrium, a clear understanding of the starting state is important. Thus the natural starting materials were chosen based on several criteria. First, the compositions of mineral phases should be close to the equilibrium compositions at the conditions of the experiments. For example, the concentration of $\mathrm{Al}_{2} \mathrm{O}_{3}$ in clinopyroxene at $1300^{\circ} \mathrm{C}$ and $3 \mathrm{GPa}$ should be around $6 \mathrm{wt} \%$. Second, the bulk composition should be close to the geochemically estimated mantle composition, such as pyrolite (Ringwood, 1979) or PUM (Hart and Zindler, 1986). Third, the composition should be uniform within a crystal and among crystals of the same phase. Fourth, coarse grained peridotites were preferred for picking phases that are free of inclusions. The use of natural starting materials enabled clear identification of a progressing reaction. This strategy is a clear contrast to peridotite reaction experiments that used either glass or gel (precipitated silicate compound from organic solvent) as starting material to attain fast reaction. 
A garnet lherzolite (TM-0) from Pali Aike, Chile was chosen for the starting material for the garnet break-down experiments. This lherzolite included minerals with compositions similar to those expected for fertile mantle (Stern et al., 1989). Mineral compositions are reported in Table 1.

A spinel lherzolite (KH 4-5) from Kilbourne hole was used for the garnet formation experiments. The mineral compositions are similar to those of KLB-1 that has been used as a representative fertile mantle (e.g., Takahashi, 1986). $\mathrm{Cr}_{2} \mathrm{O}_{3}$ in $\mathrm{KH} 4-5$ spinel (9.9wt\%) is slightly more abundant than that of KLB-1 (7.8wt\%) suggesting slight depletion of $\mathrm{KH}$ 4-5.

\section{Preparation}

Each chosen rock was crushed and sieved. Grains were magnetically separated to $70 \sim 80 \%$ purity of mineral phases of interest. Further separation was done under a binocular microscope by picking individual grains. Selected grains were washed with warm $\mathrm{HCl}$ and water. Grains were further picked for clarity and lack of surface alteration. Spinel grains were often associated with olivine and physical separation was not possible. In this case, separated spinel bearing grains were washed with $\mathrm{HF}$ followed by weak $\mathrm{HCl}$ and water. This procedure allows the extraction of pure spinel grains. Separated crystals were recombined according to the stoichiometry of the garnet break-down reaction, that is 1:1 molar quantities of garnet and olivine. For the garnet formation reaction, spinel, opx, and cpx grains were mixed to constitute a bulk composition similar to the garnet and olivine mixture used for the garnet breakdown experiments. Combined minerals were crushed to a size of approximately $<100 \mu \mathrm{m}$, and grains were not sorted for size. Since the grains become angular during the course of crushing, packing of unsorted grains in a capsule reduces the initial porosity. For some fine grained experiments designed to see the change in reaction rate due to grain size, mixed grains were ground further to the approximate size of $<50 \mu \mathrm{m}$.

Some experiments were prepared with seed crystals to promote the reaction. For the garnet break-down reaction, cpx (and one case of opx) was added to a olivine-garnet mixture as a layer consisting of $8-20 \mathrm{wt} \%$ of the total sample weight. For the garnet formation reaction, a layer of garnet was added as seed. Layer geometry was chosen to facilitate determination of the reaction product and seeds. 


\section{Experimental procedures}

Piston cylinder type high pressure apparati (similar to Boyd and England, 1960) were used for the experiments. The starting material was packed in a graphite capsule sealed in a Pt tube, supported by an $\mathrm{Al}_{2} \mathrm{O}_{3}$ ring. The sealed charge was positioned at the center of a tubular graphite heater by $\mathrm{MgO}$ spacers. The tightly assembled graphite heater and a $\mathrm{BaCO}_{3}$ pressure-transmitting cell were inserted in a $12.7 \mathrm{~mm}$ diameter $\mathrm{WC}$ cylinder. A sheet of $\mathrm{Pb}$ foil was used for lubrication between the $\mathrm{BaCO}_{3}$ cell and $\mathrm{WC}$ cylinder. Temperature was monitored by a $\mathrm{W}_{97} \mathrm{Re}_{3}-\mathrm{W}_{75} \mathrm{Re}_{25}$ thermocouple positioned approximately $2 \mathrm{~mm}$ from the center of the sample. A $20^{\circ} \mathrm{C}$ temperature correction was applied to account for the temperature gradient across $2 \mathrm{~mm}$. Oil pressure transmitted to the piston was monitored by a Heise gauge. The gauge reading was calibrated against the CaTs break-down reaction $\left(1.35 \mathrm{GPa}, 1350^{\circ} \mathrm{C}\right)$ and the reaction boundary for plagioclase to spinel lherzolite facies transformation (above solidus, $0.85-1.0 \mathrm{GPa}, 1320^{\circ} \mathrm{C}$ ) in a CMAS system. The details of the design of the piston cylinder assembly were described in Wagner (1995). Details of the pressure calibration are described in Appendix I.

Experimental conditions were chosen to promote garnet break-down and formation reactions at various conditions. A temperature of $1360^{\circ} \mathrm{C}$ at the depth of $80 \mathrm{~km}$ is consistent with mantle potential temperature of $1320^{\circ} \mathrm{C}$. Also experiments at higher $\left(1420^{\circ} \mathrm{C}\right)$ and lower temperatures $\left(1320^{\circ} \mathrm{C}\right)$ were conducted to test the temperature effects. Experimental pressures ranged from 1.8 to $2.8 \mathrm{GPa}$ to create a systematic variation of chemical affinity. Duration of the experiments ranged from a few hours to ten days.

\section{Analytical procedures}

\section{Electron probe}

The electron probe facility at MIT (JEOL Superprobe 733) was used for major element analyses and create element mapping of run products. The electron beam was conditioned to $15 \mathrm{kV}$ acceleration voltage with a beam current of $10 \mathrm{nA}$. Weight fractions of oxides in minerals were determined by WDS analysis using the phi-rho-z correction scheme calibrated against known standards. Weight fraction oxides are also computed to determine oxygen based cation abundance, and used to confirm the stoichiometry of analyses. The spatial resolution of each analysis is limited to $2 \sim 3 \mu \mathrm{m}$, a length scale set by the size of the nearly spherical tear-drop shape excitation volume that is a function of 
the beam current, acceleration potential, and mean atomic density of sample. When measurements were not acceptable due to contamination of signal from neighboring phases, they were omitted from the report. Some grains were too small for successful analysis. Measurements of crystalline phases with similar dimension can be easily contaminated by neighboring phases due to the secondary fluorescent effects.

Contaminated signals were recognized by nonstoichiometric oxygen-normalized composition and the quality of weight percent total.

A back-scattered electron (BSE) image and x-ray maps of 600 by 600 pixels were typically collected over one hour period for each analysis. Dwell time for each pixel was approximately $12-18 \mathrm{~ms}$. Due to the geometrical configuration of the spectrometers, edges of images are darker than the center. Images collected from compositionally uniform silicate glasses were used to correct for this effect. $\mathrm{Mg}, \mathrm{Al}, \mathrm{Ca}$ and $\mathrm{Fe} \mathrm{x}$-rays were collected to create the maps, but $\mathrm{Fe}$ x-ray maps did not yield a strongly contrasting image and did not add any information.

Mosaic images were also created for covering larger area than a single image. BSE and xray signals were collected for at least $8 \mathrm{~ms}$ for each pixel to obtain enough counts in the detectors. The resolution was set to achieve a quality of more than 1pixel per $1 \mu \mathrm{m}$. As a result, completion of mosaic mapping took sometimes up to 3-5 hours.

\section{Image processing}

Images of x-ray maps and BSE intensity were processed to determine the proportions of mineral phases. The goal of image analysis is the identification of mineral phases using the combination of images. Figure 4.2 show BSE and $x$-ray maps of an experiment. Spinel grains are easily recognized by the Al element map (C) but the image is not as sharp as the BSE image (A); however the contrast of spinel in BSE image is similar to garnet and separating these two phases is difficult. An image processing software has a function to select a range of the gray gradients corresponding to spinel (slicing) and convert to the black-and-white image (binarizing). The sliced-binarized spinel image from an $\mathrm{Al}$ map isolates spinel successfully, but the edges appear fuzzy. In contrast, the sliced-binarized spinel image from the BSE image shows sharp edges of spinel, but the image is contaminated by similar gray scale of garnet. These images are combined by a logical operator, "AND", which is an operation that compares two images and accepts pixels that are on both images. This successfully creates a spinel image with a sharp 
edges $(\mathrm{H})$. Similar procedures are repeated for garnet (B), olivine (D), and cpx (not shown). Due to the lack of appropriate set of images, opx (F) and garnet (B) binary images are more likely contaminated with other phases. The contamination was treated by overlaying the images of other phases in order of opx, garnet, olivine, (cpx), and spinel. When the same pixel is determined as more than two phases, the phase for above layer is always true. The processed image shows the phases with sharp boundaries $(\mathrm{G})$. The MATLAB scripts used for the analysis is attached in Appendix II.

The image processing toolbox for MATLAB by The MathWorks Inc. and the NIH Image 1.62 image analysis software were used on a Macintosh computer to determine the area, perimeter and axes of fitted ellipses to each grain by calibrating pixel units to the scale bar. The NIH Image program is a public domain program developed at the U.S. National Institutes of Health and available on the Internet at http://rsb.info.nih.gov/nih-image/.

\section{Results and Discussions}

In following sections the results of garnet break-down and garnet formation experiments are reported and the mechanisms of the reaction are discussed. Garnet break-down and garnet formation reactions are presented in separate sections. The results of reactions progressing in opposite directions are used to determine the location and width of the garnet-spinel peridotite facies on a pressure-temperature diagram.

\section{Garnet break-down reaction (spinel-out boundary)}

34 experiments were conducted mostly at $1360^{\circ} \mathrm{C}$. To explore demonstrating temperature effects on the results, higher $\left(1420^{\circ} \mathrm{C}\right)$ and lower temperature $\left(1320^{\circ} \mathrm{C}\right)$ experiments were also also conducted. Pressure conditions of the experiments ranged from 1.8 to $2.4 \mathrm{GPa}$ and experiments at all pressures resulted in detectable amounts of reaction (pyroxene and spinel formation) after a sufficient length of time. Experimental runs closer to the equilibrium boundary with short duration did not produce the product minerals. The presence of a nucleation delay could not be determined for these conditions partly due to the limitation of the analytical procedure (see further discussion in Appendix II). At 1.8 $\mathrm{GPa}$, there was no recognizable nucleation delay. Durations of runs, types of starting materials, and final volume fractions of phases are reported in Table 4.1. Selected mineral compositions for reactant and products are listed in Table 4.2 and Table 4.3. 


\section{Texture}

Back-scattered electron images allowed petrographic analysis of experimental charges. There are distinctive characteristic textures which help in inferring the mechanism of the reaction. For example, the micrographs of run charges show that the reaction always begins at the interface between olivine and garnet (Figure 4.2). Small anhedral opx forms at the grain boundary between olivine and garnet. Spinel seems to form within the garnet immediately adjacent to opx. At the early stage of reaction, $\mathrm{cpx}$ is not detected within the reacting area. If cpx does not crystallize at the early stage of reaction, the opx composition is most likely not the equilibrium composition, having an excess of $\mathrm{CaO}$. Anhedral opx appears to grow more towards garnet than olivine, perhaps due to the difference in molar volumes. The molar volume of garnet is $\sim 2.5$ times larger than that of olivine, and thus one mole of consumption of garnet and olivine reduces the volume of garnet 2.5 times more than that of olivine. The reaction starting from the interface does not keep the original shape of the garnet crystal at the completion of garnet break-down. Thus, the common interpretaion of spinel-opx-cpx aggregates, appearantly pseudomorphic after garnet as evidence for precursor garnet (e.g., Takahashi and Arai, 1989), is not necessarily correct.

The order of product nucleation is inferred from the time progression of the texture (Figure 4.3). Opx is always the first phase to form, while cpx is the last phase to form. As Figure 4.2 and Figure 4.3 show, spinel formation occurs within the garnet or opx but not at the interface of garnet and olivine. Olivine is always associated with formation of opx, but there is no nucleating phase within olivine. When a cpx layer was added to the starting mix, formation of cpx was promoted and the nucleation of cpx became as early as opx.

Spinel grains have a range of sizes, suggesting that crystals were continuously nucleated. Normalized size distributions of the spinel show bell-shaped curves with the most probable value shifting to with time (Figure 4.4). The change of grain size with time does not seems to suggest a monotonic increase or decrease. There are differences in the number of grains counted for each experiment and this could add to the statistical uncertainty. If nucleation and grain coarsening are consistent with Ostwald ripening the most probable value shift is to larger grain size with time (Joesten, 1991). Textural development and coarsening of pyroxenes could not be determined since the grain boundary is not easily determined from images created by the electron probe. 


\section{Modal proportions}

Table 1 shows the modal proportions of mineral phases measured for each experiment. Each experiment represents a snapshot of the state that the progressing reaction achieved in a duration of run. A set of experiments with the same run conditions with varying duration represents a time-series. Comparing each measurement, a total product fraction that is a sum of the volume fractions of opx, cpx and spinel, increases systematically with respect to time. In contrast, the proportion of each product phase sometimes does not increases in the similar way (Figure 4.5). Considering the error involved in estimating phase proportions, it is premature to infer complex reaction mechanisms attributed to an increase or decrease in the phase proportions. Therefore, the total product fractions are used for the reaction progress variable $(\xi)$, and this reduces the error associated with small number of point counts.

The limitation of the measurement of phase proportions is shown by the reaction stoichiometry inferred from the proportions of reactant and product minerals (Table 4.1). The relative proportions of garnet to olivine by $\mathrm{mol} \%$ should be around one, but range from 0.5 to 10 with the most probable value at 1.1 to 0.8 . Considering the error reported for olivine and garnet phase proportions based on the counting statistics, the garnet to olivine ratio is consistent with a value of one, within error. This illustrates that determination of stoichiometric coefficients by image analysis is of limited success and easily offset by errors.

The ratio of spinel to opx suffers a similar problem and does not always show the constant stoichiometric reaction coefficients expected from Equation 4.1. In addition to the statistical errors, delayed spinel nucleation inferred from time series images could also contribute unreasonable opx/spinel ratios at the beginning of the reaction. If this is the case, the timing of crystallization of spinel and cpx and the change of opx composition with time can provide some inferences to the mechanism of the reaction. For instance, opx composition is out of equilibrium at the beginning of the reaction since it could contain excess $\mathrm{Al}$ before the formation of spinel, suggesting the importance of activity of $\mathrm{Al}$ (or Si for exchange) during the reaction.

\section{Mineral compositional change}

Major element compositions of mineral phases in experimental charges are reported in Table 4.2 and Table 4.3. Reactant phases are olivine and garnet, and the cpx composition, 
which is added as a layer, is listed. One standard deviation is calculated from multiple analyses on the same mineral phases.

Compositions of reactant minerals after the run are similar to compositions measured in the starting material. For example, garnet compositions after the experiment in all cases fall within two standard deviations of the starting mineral composition. Olivine, in contrast, reequilibrates to the run condition, observed by Fe-Mg exchange. From shorter duration experiments to longer duration, the $\mathrm{Mg}$ number decreases from 0.90 to 0.86 after 157 hours. Back-scattered electron images also show the slight zoning in olivine and garnet near the rims (Figure 4.3b).

Opx compositions show variations between experiments and within an experimental charge. For example, $\mathrm{Ca}$ and $\mathrm{Al}$ abundances vary from 1.2 to $2.2 \mathrm{wt} \%$ and 7.5 to 15.7 $\mathrm{wt} \%$, respectively. Spinel compositions vary less than those of opx. For example, Cr number varies only from 0.96 to 0.97 . Although the Ca content of cpx appears to vary, measurements for similar temperatures show similar compositions. The range of $\mathrm{Al}_{2} \mathrm{O}_{3}$ is smaller than for opx, from 7.9 to $10.0 \mathrm{wt} \%$ except one analysis that is $12.4 \mathrm{wt} \%$.

\section{Mechanism of the garnet break-down reaction}

\section{Types of reaction}

As discussed earlier (chapter 3), the progress of solid state reactions can be modeled by the KJMA theory (Avrami, 1939; Avrami, 1940; Avrami, 1941; Johnson and Meh1, 1939; Kolmogorov, 1937). When the number of nucleation sites is constant during the reaction, the KJMA theory predicts that reaction progress, $\xi$, is exponential function of $t^{n}$ :

$$
\xi=1-\exp \left(-K t^{n}\right)
$$

where $\xi$ is expressed as a total fraction of product phases. By transforming the above equation to the form below, the exponent $\mathrm{n}$ and reaction rate constant $\mathrm{K}$ can be determined by linear regression as the slope and the intercept:

$$
\ln \left(\ln \frac{1}{1-\xi}\right)=\ln K+n \ln (t) .
$$


Linear regression of $\ln (\ln 1 / 1-\xi)$ vs. $\ln (\mathrm{t})$ for the time-series experiments gives a nearly constant value of $n=0.5$. Within seven sets of time-series experiments, four show fitted $n$ values of 0.39 to 0.59 that are within the uncertainty of the fits (Figure 4.6, Table 4.7). Considering the error associated with measurements and the exaggerated uncertainty in log unit, $\mathrm{n}$ being close to 0.5 is not statistically conclusive. However, it should be emphasized that, if $\mathrm{n}$ is more than one, the discrepancy of fit to the measurements is large and easily discriminated by the inspection of $\xi$-t plot (Figure 4.6).

Processes of polycrystalline subsolidus reactions are not well studied for silicate systems. The reaction mechanisms can be inferred from the combination of the textural observation and the $\xi$-t relationship. Particularly important is a value of the exponent $n$. The KJMA theory predicts that the minimum for $n$ is 0.5 , where the overall transformation is diffusion controlled under the condition of a constant number of nuclei. Diffusion-limited reaction mechanism is strongly suggested by the reaction progress function and texture, although the assignment of $n=0.5$ for the present results may be statistically unconvincing.

\section{Local reaction mechanisms}

An overall chemical reaction usually consists of a number of elementary reaction mechanisms. From the texture and order of precipitation, a possible set of elementary reaction mechanisms at the interface between olivine and garnet can be inferred for the garnet breakdown overall reaction. From observation of the images, it is clear that opx always nucleates at the interface. One possible scenario to explain this observation is that grain boundary diffusion limits the rate of reaction by hindering transport of Si-bearing molecules. In this case, transport of $\mathrm{SiO}_{2}$ from the surface of garnet to the olivine can be the rate limiting process of opx formation. In contrast, spinel formation from garnet could be the process responsible for the $\mathrm{SiO}_{2}$ excess. Al diffusion along grain boundaries could be the rate-limiting process for spinel formation. By analogy to dissolution of a crystal in melt, the progress of reaction is likely controlled by the rate of chemical potential change at the interface due to diffusion in grain boundaries. The process of opx (or spinel) formation could be initiated by transport of $\mathrm{SiO}_{2}$ or $\mathrm{Al}_{2} \mathrm{O}_{3}$ at the grain boundaries. The apparent delay of spinel and cpx nucleation can be explained by the capacity of the pyroxene structure to accommodate a large range of solid solution. The first appearance of opx only at the interface suggests that the reaction progresses without formation of 
spinel, and cpx. Although pyroxene stoichiometry can be confirmed by oxygen normalization, this first appearing "opx" may not be structurally opx. Successive spinel nucleation following opx formation suggests that $\mathrm{Al}_{2} \mathrm{O}_{3}$ transport is critical in formation of spinel but opx-like pyroxene can promote the reaction with transport of $\mathrm{SiO}_{2}$. Late appearance of cpx could be due to a nucleation barrier, and it may be caused by lack of nucleation site in similar structured (ortho-)pyroxene.

\section{Major element equilibration}

Equilibrium among the product phases can be checked by cation distributions. When opx and cpx measurements were available, three sets of geothermometers were used to check the achievement of equilibrium (QUILF, Ca in Opx and Fe-Mg-Ca exchange). Results of the calculations show that good agreement exists (within the error) between the run temperature and the calculated temperature from two pyroxenes (Table 4.2). Therefore, chemical equilibrium seems to be achieved between opx and cpx by the time cpx is formed, although the bulk system is still reacting to produce more pyroxenes and spinel. This suggests that local major-element equilibration occurs within the duration of the experiments. Furthermore, since two of three product phases are in equilibrium the third phase spinel must be in equilibrium with the products, unless the product phases are highly heterogeneous, or the reaction is not stoichiometric.

Once equilibrium is verified, the geothermometers can also be used to confirm the temperature of the experiments. Misplacement of the thermocouple can cause a systematic offset from the target temperature. For example, experiment $\mathrm{C} 173$ shows progress of reaction much higher than expected from the time-series data. The twopyroxene thermometer recorded a $100^{\circ} \mathrm{C}$ higher temperature than the set temperature. Therefore experiment $\mathrm{C} 173$ is not included as part of the time-series data.

QUILF is a PASCAL program, and allows calculation of two pyroxene geothermometer (Andersen et al., 1993). It calculates error associated with the fits as well. Other geothermometers were calibrated by Brey and Köhler (1990) exclusively for peridotitic systems. All models include $\mathrm{Al}$ and $\mathrm{Na}$ corrections, suggesting that successful prediction of temperatures confirms equilibration of all the major element distribution between pyroxenes, in addition to equilibration of $\mathrm{Ca}-\mathrm{Mg}-\mathrm{Fe}$. There seems to be systematic differences between thermometers. However, as long as the calculated temperatures are similar, a set of time-series experiments is considered consistent. 


\section{Garnet formation (garnet-in) reaction}

Sixteen experiments were conducted at a constant temperature at $1360^{\circ} \mathrm{C}$, with pressure conditions ranging from 2.2 to $2.8 \mathrm{GPa}$. Thirteen out of the 16 experiments showed garnet formation. Experiments of very short duration ( $<15$ hours), low pressure $(<2.3$ $\mathrm{GPa}$ ), or a combination of both resulted in no detectable garnet formation. Information about run duration, starting material, and thickness of the garnet rims is given in Table 4.4. The compositions of the selected minerals are listed in Table 4.5 and Table 4.6.

texture

Back-scattered electron images depict the growing garnet phase around spinel (Figure 4.8). Results show thin layers of garnet form around spinel for both garnet seeded and nonseeded experiments, but not at the interfaces of opx-opx, cpx-cpx, or opx-cpx. In contrast, olivine grows as euhedral grains near pyroxene grain boundaries, while anhedral olivine forms at garnet rims. It appears that more garnet than olivine is formed in all experiments, especially for those with short duration. These results are expected since the molar volume ratio of garnet to olivine is about 2.5 .

\section{Garnet thickness}

The thickness of the garnet rims is assigned to the progress variable, $\xi$, which could be determined from the measurements with great accuracy. This approach was chosen, because exact determination of the garnet area following the procedure outlined in the previous section for opx was limited by the image resolution. The thickness of the garnet rims monotonically increases with time (Table 4.4).

The thickness of randomly oriented three-dimensional plates can not be inferred correctly from a two-dimensional section. Assuming plates of constant thickness cut at arbitrary angles, the actual plate thickness is approximated by the peak of the measured thickness distribution. Three different approaches used to estimate the actual plate thickness are listed in Table 4.4 (see table caption for detailed explanation of averaging methods).

\section{Mineral composition}

Inspection of Table 4.6 gives information on the compositional evolution trend during the experiments. The $\mathrm{Mg}$ number of olivine changes throughout the experiments, due to the equilibration during the reaction to slightly mafic bulk composition. Variations in garnet compositions seem to be created by contamination of signals from neighboring phases. 
Since the thickness of garnet around spinel is about $3 \mu \mathrm{m}$ at the longest duration of the experiments, it is difficult to separate the garnet and spinel signals with the electron microprobe. Although very careful and numerous measurements were performed, acceptable compositional analyses are limited in number. Garnet compositions demonstrate mixing trends between garnet and pyroxenes (opx and cpx). Reported garnet compositions in Table 4.6 represent the mean of garnet analyses and are computed from the points near the garnet end of the mixing trend. If the compositional variation were caused by the reaction kinetics, analysis of the chemical trend might allow the reaction processes to be deconvolved. However, in the case of the garnet formation reaction, the observed chemical trend is consistent with a garnet-pyroxene mixing and does not appear to represent the reaction processes.

Composition of cpx and opx, the reactants, show bimodal compositional distributions. One is similar to the starting $\mathrm{KH}$ mineral compositions, the other is a high temperature equilibrated pyroxene composition that is characterized by high Ca content in opx and low Ca content in cpx.

Using $\mathrm{Fe} / \mathrm{Mg}$ exchange between olivine and garnet, the equilibrium temperature of crystallizing phases were determined (O'Neill and Wood, 1979). The general tendency was that equilibrium temperatures for longer runs converge to $1270^{\circ} \mathrm{C}$. However, poorquality garnet analyses prevented obtaining reliable temperatures. At this point, there are no simple methods to demonstrate the achievement of local equilibrium as the result of reaction, as has been done for the garnet breakdown experiment.

\section{Mechanism of garnet formation reaction}

\section{Types of reaction}

From the texture of the growing garnet, mechanisms of growth can be inferred. Growth rate of garnet, the changes in thickness of the rims, can be determined by either the transport of material to the growth site or rate of reaction at the surface of garnet. In reaction controlled system, activity of the precipitating phase is inferred to be the same throughout the grain boundary, allowing garnet to nucleate at any interface. Garnet may prefer nucleation on the pyroxene surface, because the lattice mismatch between garnet and pyroxene is less than between garnet and spinel. The fact that garnet exclusively crystallized on the surface of spinel suggests the importance of transport and exchange of Al. Since spinel is the principal Al oxide provider for garnet formation reaction, limited 
transport of $\mathrm{Al}$ may be the rate limiting step, and the garnet-formation reaction may also be diffusion controlled.

The diffusion-controlled reaction mechanism is also confirmed by the plot of the reaction progress as a function of time (Figure 4.9). The increase in garnet thickness around spinel is linear in the square root of time. This functionality was predicted in the previous chapter. The slope of the line in Figure 4.9 is the reaction rate constant, $\mathrm{K}$, and it is proportional to square root of diffusivity and affinity. The unit of $\mathrm{K}^{2}$ for this case is the same as diffusivity.

\section{$\underline{\text { Reaction rate constant }}$}

As Equation 3.28 shows, the reaction rate constant obtained here involves the diffusion and affinity terms. The rates obtained are listed in Table 4.7, and are faster than conventional solid state diffusion rates. Furthermore, since these sets of experiments are performed under the same temperature, systematic changes of reaction rate with respect to temperature are not explained by diffusion alone. This suggests that chemical affinity is also important in determining the rate of reaction.

The linear fit (Figure 4.9) to the time series data is good $\left(\mathrm{R}^{2}\right.$ is 0.98$)$. This confirms the relevance of the diffusion controlled reaction rate. However, it should be noted that the measured line does not go through zero. This observation suggests a change in reaction mechanisms with time. For example, one experiment with 14.5 duration hours did not show a detectable layer of garnet. This suggests that the reaction experienced a nucleation delay followed by the rapid growth of garnet before further progress was hindered by diffusion. The time series experiments can still be used to measure the diffusion-limited part of the reaction.

\section{Gross reaction mechanisms}

Inferring the overall transformation mechanism from one dimensional local progress requires a clear understanding of the three dimensional geometry of the growing phase. Locally it is possible to demonstrate that the reaction progressed according to the square root of time. Using Avrami's formulation, the overall transformation can be modeled but it requires assumptions about geometry of the growing phase. If all the garnet and olivine grow in a spherical manner, the one dimensional growth rate must be cubed. Thus, the integrated reaction rate is $n=1.5$. In contrast, as with the garnet breakdown case, if the 
geometry of the growing phase somehow mimics one-dimensional growth, $n=1 / 2$. Further analysis of the overall transformation is required to determine the exponent $n$.

\section{Major element chemistry}

Since we can not explicitly confirm equilibrium, pathways to reach equilibrium can not be determined. To grow garnet on the surface of spinel, either $\mathrm{SiO}_{2}$ must be transported to the interface between garnet and spinel or $\mathrm{Al}_{2} \mathrm{O}_{3}$ must reach the interface between garnet and pyroxenes through product garnet. Considering the fast equilibrating nature of $\mathrm{Fe}$ and $\mathrm{Mg}$, it seems likely that activity and transport of $\mathrm{Si}$ and $\mathrm{Al}$ at the grain boundaries are the controlling process of reaction.

One question is whether the reaction is occurring at the boundary between garnet and spinel or garnet and pyroxenes. Since the occurrence of olivine is mostly outside of garnet and not in between garnet and spinel, $\mathrm{Si}, \mathrm{Fe}$, and $\mathrm{Mg}$ transport through the rimming garnet may perhaps control the major element behavior of this reaction. This possibility is consistent with the difficulty in making stoichiometric garnet composition measurements.

\section{K-P relationship and boundary}

The reaction rate constant, $\mathrm{K}$, and pressure, $\mathrm{P}$, show a $\log$ linear relationship for both the garnet break-down and garnet formation experiments (Figure 4.7 and Figure 4.9). For both directions of the reaction, $2.4 \mathrm{GPa}$ is the pressure at which the reaction becomes detectable within the duration of the experiments. Therefore, $2.4 \mathrm{GPa}$ is close to the equilibrium boundary for garnet-in and spinel-out reactions. It should be emphasized that the garnet formation reaction begins at pressure conditions below $2.4 \mathrm{GPa}$ while garnet break-down reaction begins at pressures higher than $2.4 \mathrm{GPa}$.

The $\log$-linear relationship of $\mathrm{K}$ and $\mathrm{P}$ suggests an Arrhenius relationship with a significant activation volume term (illustrated by Figure 3.7). The pressure dependence of the reaction rate is greater than that for diffusion in silicates, and this suggests that chemical affinity is also a significant factor in determining the rate. From Equation 3.31, $\mathrm{K}$ is expressed as a function of diffusivity, $\mathrm{D}$, and affinity, $\mathrm{A}$. By substituting the Arrhenius relationship for diffusion and affinity, the final form of the function of $\mathrm{K}$ with pressure is

$$
2 \ln K=\text { const. }+\ln D_{0}+\frac{-E+P V}{R T}+\ln A, \text { or }
$$




$$
2 \ln K=\ln \left(-E_{A}+\Delta P V_{A}\right)+\left(-E_{D}+P V_{D}\right)+\text { const }
$$

where Do is the entropy term in the Arrhenius relationship. A is affinity and denotes molar energy terms for affinity, and the subscript $\mathrm{D}$ denotes activation terms of diffusion. $\Delta \mathrm{P}$ denotes the difference between actual and equilibrium pressures. According to the derivation, pressure and $\mathrm{K}$ can show either a log linear or a linear relationship. When $\Delta \mathrm{P}$ is small, the absolute value of the diffusivity term is smaller than the affinity term. $\mathrm{K}$ should be linearly related to pressure when $\Delta \mathrm{P}$ is small. However, the results shows that $\mathrm{K}$ is a log-linear function of pressure (Figure 4.7). This suggests that the pressure conditions presented here are not close enough to the equilibrium to reach a regime where a linear K-P relationship holds. Using a similar analysis used by Van Orman and Grove (submitted), Equation 4.4 and Equation 4.5 can be written as

$\mathrm{V}_{\text {reaction }}=0.5 \mathrm{~V}_{\text {diffusion }}+\alpha \mathrm{V}_{\text {affinity. }}$

In the case of the garnet breakdown reaction, grain boundary diffusion transport limits the rate of reaction. In Figure 4.7, the activation volumes of the reaction rate constant are 29 and $54 \mathrm{~cm}^{3} / \mathrm{mol}$ for the coarse-crushed olivine garnet mix with and without cpx layer. A cpx-bearing fine grained olivine-garnet mix gives an apparent activation volume of 45 $\mathrm{cm}^{3} / \mathrm{mol}$. These values can be roughly compared with estimates of activation volume for grain boundary diffusion $\left(11 \mathrm{~cm}^{3} / \mathrm{mol}\right.$, estimated from molar volume of $\left.\mathrm{SiO}_{4}{ }^{4-}\right)$, and the activation volume of the reaction rate constant is up to factor of five larger. This simple analysis suggests that the garnet breakdown reaction rate is controlled by a combination of affinity and diffusion.

The growth rate constant of garnet mimics fast cation diffusion in silicate minerals, $10^{-17}$ to $10^{-18} \mathrm{~m}^{2} / \mathrm{s}$. for example Fe-Mg interdiffusion in garnet is $\sim 3.5 \times 10^{-17} \mathrm{~m}^{2} / \mathrm{s}$ at $2.4 \mathrm{GPa}$ and $1360^{\circ} \mathrm{C}$. This similarity suggests that the rate of growth may be limited by the transport of cations in silicate minerals instead of grain boundaries. Activation volumes for reaction rate constants of garnet formation are 37 and $50 \mathrm{~cm}^{3} / \mathrm{mol}$ for seeded and non seeded starting materials (Figure 4.10), and again these values are larger than the activation volume determine for Fe-Mg diffusion in garnet, of $5-6 \mathrm{~cm}^{3} / \mathrm{mol}$ (Chakraborty and Ganguly, 1992). This furthermore confirms that the contribution of affinity term to the rate of reaction is significant. 


\section{Comparison with other experimental results}

The conclusion regarding the location of the garnet-in and spinel-out reaction boundaries is that at $1360{ }^{\circ} \mathrm{C}$ they lie, respectively, below and above $2.4 \mathrm{GPa}$. These transformation boundaries are compared against previous experimental results in Figure 4.11. Also included are experimental results for natural and simple system starting compositions, and above and below the solidus of peridotite.

Only two sets of subsolidus natural sample experiments are reported (Jenkins and Newton, 1979; O'Hara et al., 1971). The result presented here is more consistent with O'Hara's experiments (Figure 4.11).

The reaction boundary of Jenkins and Newton (1979) goes through $900^{\circ} \mathrm{C}$ and $1.0 \mathrm{GPa}$. Their experiments are reversed under water-bearing conditions. The shortcoming of the study is the choice of the starting garnet. As in this study, they used coarse mineral separates, but the garnet was almandine rich ( $\mathrm{Mg}$ number is 0.79 ) and not relevant to the mantle. Peridotitic garnets, such as those used in this study, typically have $\mathrm{Mg}$ numbers in the range 0.83 to 0.85 . As the thermodynamic prediction suggests (O'Neill and Wood, 1979), higher Fe activity in system stabilizes garnet to lower pressure.

The CMAS simple systems were investigated by first Kushiro and Yoder (1966); subsequently, the Cr-bearing CMAS system was investigated by Nickel (1986) and by O'Neill (1981). The garnet-spinel facies boundary for CMAS compositions is located 0.1 to $0.3 \mathrm{GPa}$ below the boundary for the natural composition. The garnet-spinel facies transformation reaction for $\mathrm{Cr}$ bearing CMAS system is divariant, and a single boundary cannot be drawn. Cr-bearing garnet that is in equilibrium with spinel with $\mathrm{Cr}$ number 0.1 to 2.5 forms at 0.5 to $0.8 \mathrm{GPa}$ higher pressure than $\mathrm{O}^{\prime} \mathrm{Hara}$ 's natural composition boundary.

Garnet has also been synthesized above the solidus (Kinzler, 1997; Robinson and Wood, 1998; Takahashi and Kushiro, 1983; Walter and Presnall, 1994). Data partaining to garnet peridotite saturated melt is limited but they plot on the P-T diagram generally in agreement with extensions of the boundary from subsolidus conditions. 


\section{Conclusions}

\section{Pressure of garnet-spinel transformation}

The pressures of the transformation boundaries at $1360^{\circ} \mathrm{C}$ are at least above and below $2.4 \mathrm{GPa}$. O'Hara's data show up to $0.2 \mathrm{GPa}$ overlap of garnet-spinel coexistence. If indeed this is an indication of garnet spinel coexistence in peridotites, the range of the garnet-in and spinel-out reactions is approximately $0.2 \mathrm{GPa}$ apart. Considering the possibility of asymmetric reaction kinetics for these reactions, it is suggested that the slowest possible reaction at $2.4 \mathrm{GPa}$ is not the middle point of garnet-in, spinel-out boundaries, and the lowest possible pressure of garnet stability could be as low as 2.2 GPa.

The carefully chosen source rocks for the starting materials of the present experiments represent a close approximation of the Earth's mantle. Thus the location of the reaction boundary determined here should closely approximate the boundary in the mantle. Indeed, the present results are slightly higher pressures than CMAS of Kushiro and Yoder (1966) and lower than the low-Cr bearing mantle experiments (Figure 4.11). Dispite small differences, the results are most consistent with O'Hara's.

\section{Metastable garnet in upwelling mantle?}

A simple application of the KJMA equation yields an estimate of the time scale required for completion of the garnet breakdown reaction. Rearrangement of the KJMA equation gives,

$t=\left(\frac{\ln (1-\xi)}{-K}\right)^{1 / n}$

Table 4.7 shows the time required for $95 \%$ completion of the reaction at different pressure-temperature conditions. The reaction is effectively instantaneous on geological time scales. For example, coarse crushed cpx reaches $95 \%$ of reaction completion in about 4000 years. This is unreasonably long for achieving equilibrium in experiments and instantaneous for geology. It is unlikely that metastable garnet plays a major role in contributing to the trace element garnet signature during mantle melting. 


\section{References}

Andersen D. J., Lindsley D. H., and Davidson P. M. (1993) QUILF: A PASCAL program to assess equilibria among Fe-Mg-Mn-Ti oxides, pyroxenes, olivine, and quartz. Computers and Geosciences 19, 1333-1350.

Avrami M. (1939) Kinetics of Phase Change. I. Journal of Chemical Physics 7, 1103-1112.

Avrami M. (1940) Kinetics of Phase Change. II. Journal of Chemical Physics 8, 212-224.

Avrami M. (1941) Granulation, phase change and microstructure: Kinetics of phase change III. Journal of Chemical Physics 9, 177-184.

Beattie P. (1993) Uranium-thorium disequilibria and partitioning on melting of garnet peridotite. Nature 363, 63-65.

Boyd F. R. and England J. L. (1960) Apparatus for phase-equilibrium measurements at pressures up to 50 Kilobars and temperatures to 1750 C. J. Geophys. Res. 65, 741-748.

Brey G. P. and Köhler T. (1990) Geothermobarometry in Four-phase Lherzolites II. New Thermobarometers, and Practical Assessment of Existing Thermobarometer. Journal of Petrology 31, 1353-1378.

Chakraborty and Ganguly. (1992) Contributions to Mineralogy and Petrology 111, 74-86.

Hart S. R. and Zindler A. (1986) In Search of a Bulk-Earth Composition. Chemical Geology 57, 247-267.

Hirschmann M. M. and Stolper E. M. (1996) A possible role for garnet pyroxenite in the origin of the "garnet signature" in MORB. Contribution to Mineralogy and Petrology 124, 185-208.

Jenkins D. M. and Newton R. C. (1979) Experimental Determination of the Spinel Peridotite to Garnet Peridotite Inversion at $900^{\circ} \mathrm{C}$ and $1000^{\circ} \mathrm{C}$ in the System $\mathrm{CaO}-\mathrm{MgO}-\mathrm{Al} 2 \mathrm{O} 3-\mathrm{SiO} 2$, and $900^{\circ} \mathrm{C}$ with Natural Garnet and Olivine. Contribution to Mineralogy and Petrology 68, 407-419.

Joesten R. L. (1991) Kinetics of coarsening and diffusion controlled mineral growth. In Contact metamorphism, Vol. 26 (ed. D. M. Kerrick), pp. 507-582. Mineralogical Society of America.

Johnson W. and Mehl R. F. (1939) Trans AIME 135, 416-442.

Kinzler R. J. (1997) Melting of mantle peridotite at pressures approaching the spinel to garnet transition: Application to mid-ocean ridge basalt petrogenesis. Journal ofGeophysical Research 102, 853-874.

Kolmogorov A. N. (1937) Izv. Akad. Nauk SSSR, Ser. Matem. 3, 355-359.

Kushiro I. and Yoder H. S. J. (1966) Anorthite-Forsterite and Anorthite-Enstatite Reaction and bearing on the Basalt-Eclogite Transformation. Journal of Petrology 7, 337-362.

Nickel K. G. (1986) Phase equilibria in the system SiO2-MgO-Al2O3-CaO-Cr2O3 (SMACCR) and their bearing on spinel/garnet lherzolite relationships. Neues Jahrbuch Miner. Abh. $155,259-287$.

O'Hara M. J., Richardson S. W., and Wilson G. (1971) Garnet-Peridotite Stability and Occurrence in Crust and Mantle. Contributions to Mineralogy and Petrology 32, 48-68. 
O'Neill H., St.C. (1981) The transition between spinel lherzolite and garnet lherzolite, and its use as a geobarometer. Contrib. Mineral. Petrol. 77, 185-194.

O'Neill H. S. C. and Wood B. J. (1979) An Experimental Study of Fe-Mg Partitioning Between Garnet and Olivine and Its Calibration as a Geothermometer. Contributions to Mineralogy and Petrology 70, 59-70.

Ringwood A. (1979) Origin of the earth and moon. Springer-Verlag.

Robinson J. A. C. and Wood B. J. (1998) The depth of the spinel to garnet transition at the peridoite solidus. Earth and Planetary Science Letters 164, 277-289.

Stern C. R., Saul S., Skewes M. A., and Futa K. (1989) Garnet peridotite xenoliths from the Pali-Aike alkali basalts of southernmost South America. Fourth International Kimberlite Conference, 735-744.

Takahashi E. (1986) Melting of Dry Peidotite KLB-1 up to 14 GPa: Implications on the Origin of Peridotitic Upper Mantle. Journal of Geophysical Reseach 91, 9367-9382.

Takahashi E. and Kushiro I. (1983) Melting of a dry peridotite at high pressure and basalt magma genesis. American Mineralogist 68, 859-879.

Takahashi N. and Arai S. (1989) Textual and chemical features of chromian spinel-pyroxene symplectites in the Horoman peridotites, Hokkaido, Japan. Science Rep., Inst. Geosci., Univ. Tsukuba, Sect. B 10, 45-55.

Wagner T. P. (1995) Experimental and Geochemical Studies of Terrestrial and Lunar Magmatic Process. Ph. D., Massachusetts Institute of Technology.

Walter M. J. (1998) Melting of garnet peridotite and the origin of Komatiite and depleted lithosphere. Journal of Petrology 39, 29-60.

Walter M. J. and Presnall D. C. (1994) Melting Behavior of Simplified Lherzolite in the System CaO-MgO-Als2O3-SiO2-Na2O from 7 to 35 kbar. Journal of Petrology 35, 329359 . 


\section{Tables}

Table 4.1: $\quad$ Run conditions and results of the image analysis for garnet breakdown reactions. 


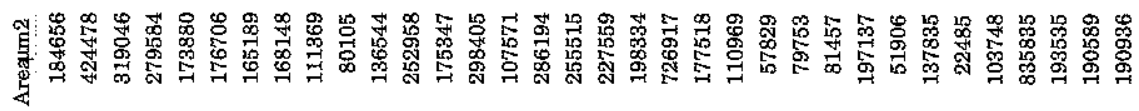

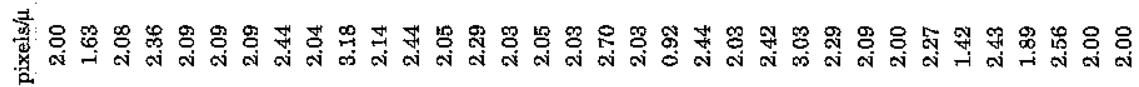

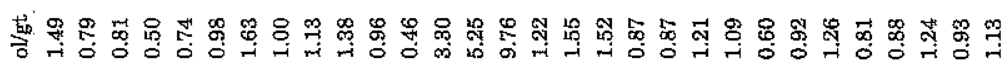

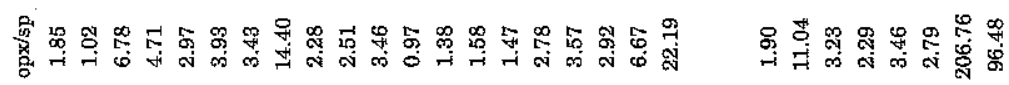

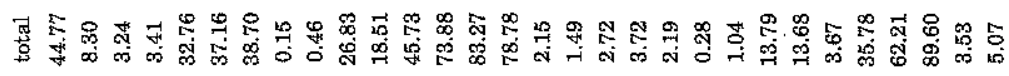

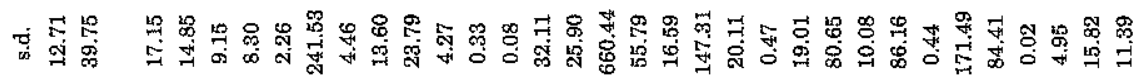

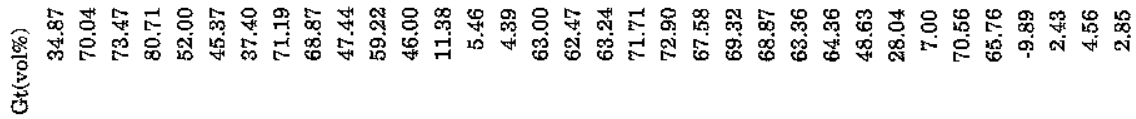

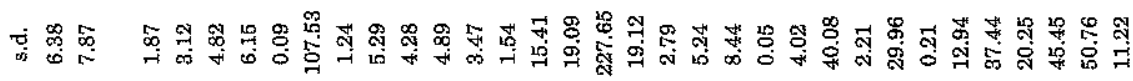

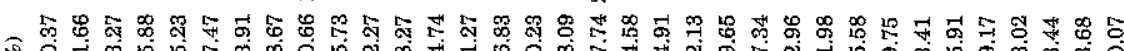

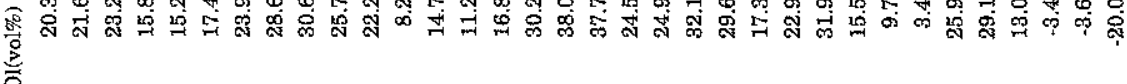

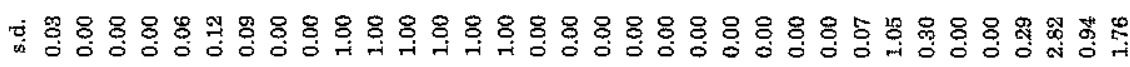
警

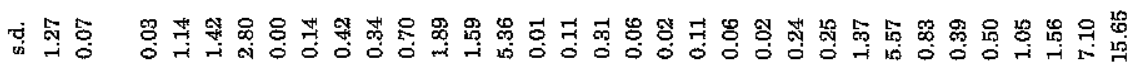

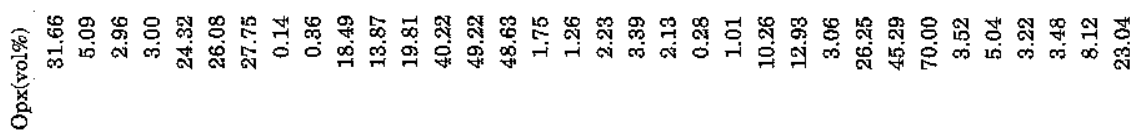

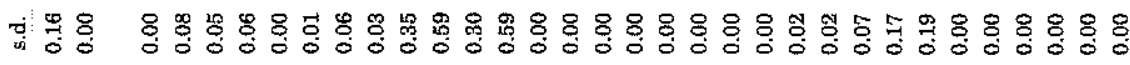

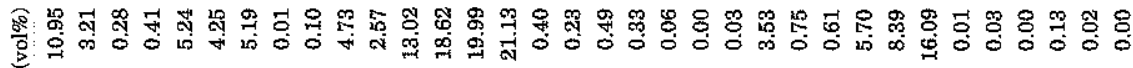
雷:

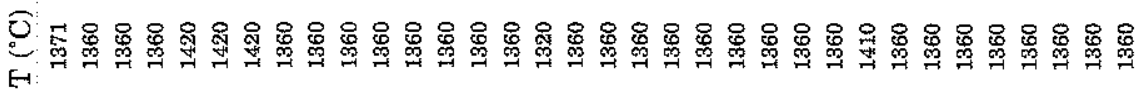

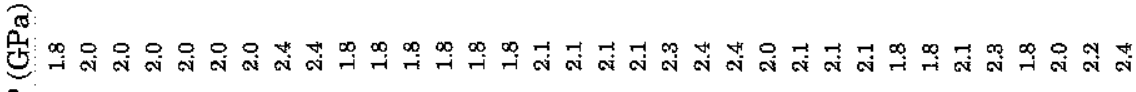
A.

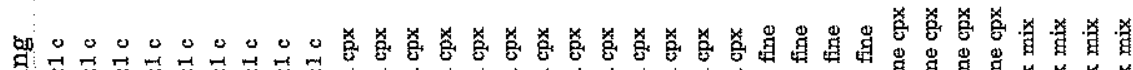

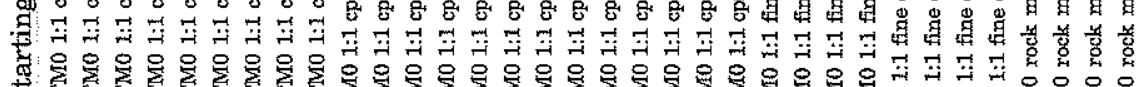

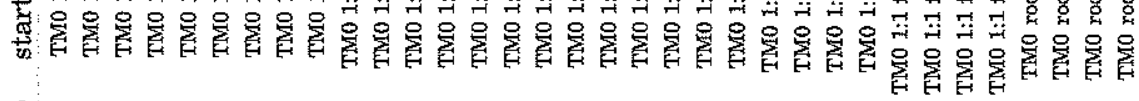
3)

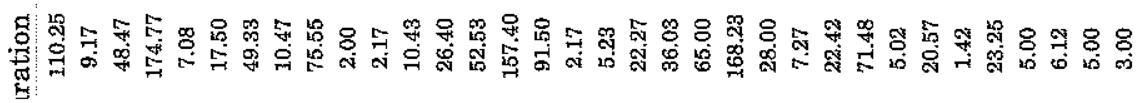


Table 4.2: $\quad$ Major element compositions of reactant phases of the garnet breakdown reaction, and the starting mineral compositions of TM-0. $\mathrm{Mg}$ number is a molar ratio of $\mathrm{Mg} /(\mathrm{Mg}+\mathrm{Fe})$, and $\mathrm{Al}$ number is a molar ratio of $\mathrm{Al} /(\mathrm{Al}+\mathrm{Cr})$.

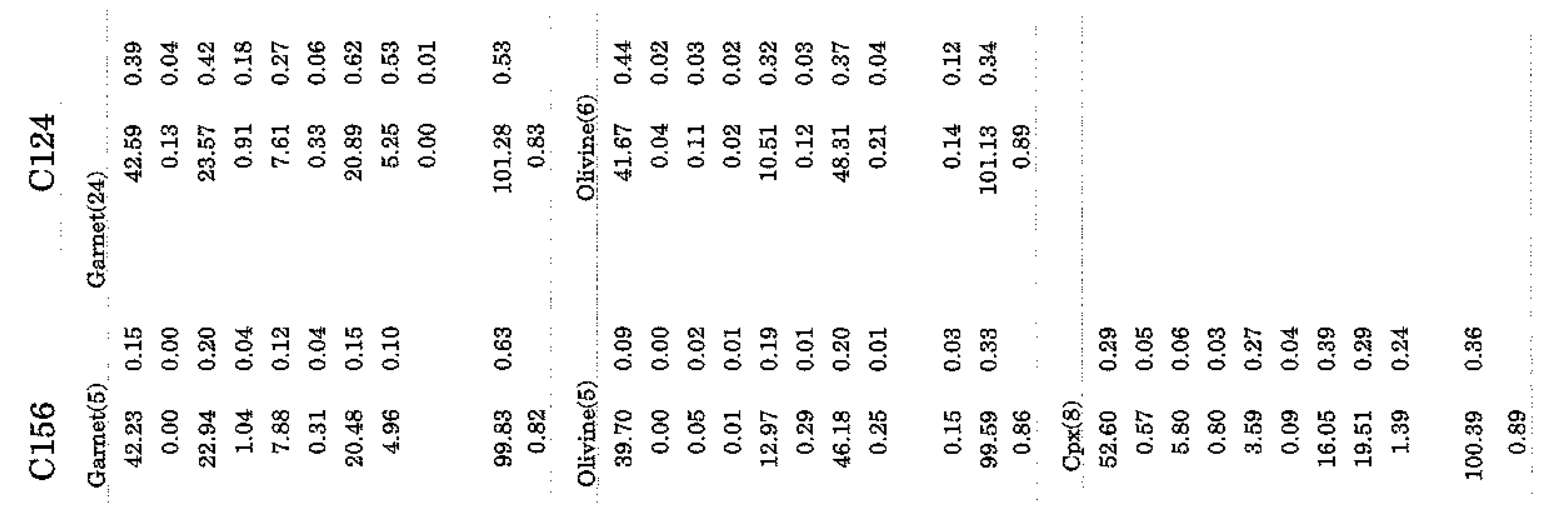

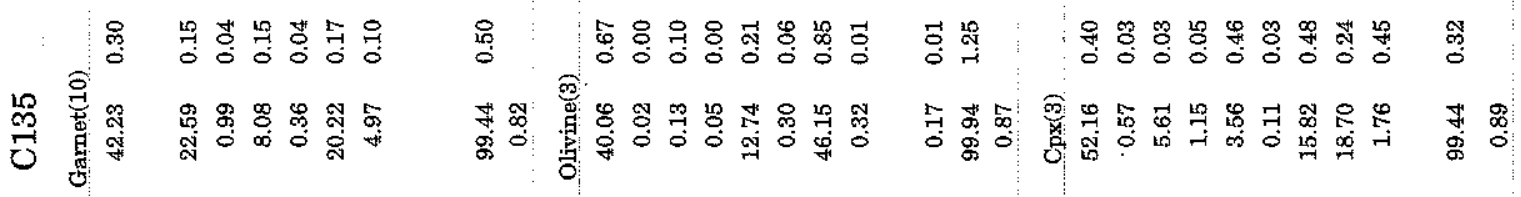

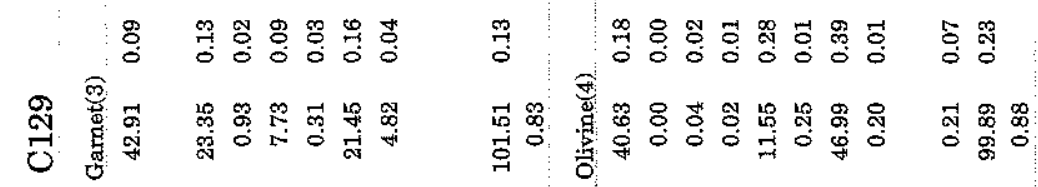

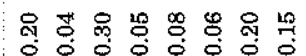

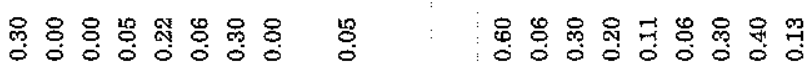

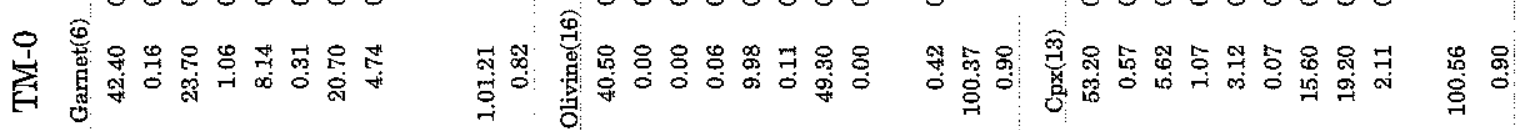

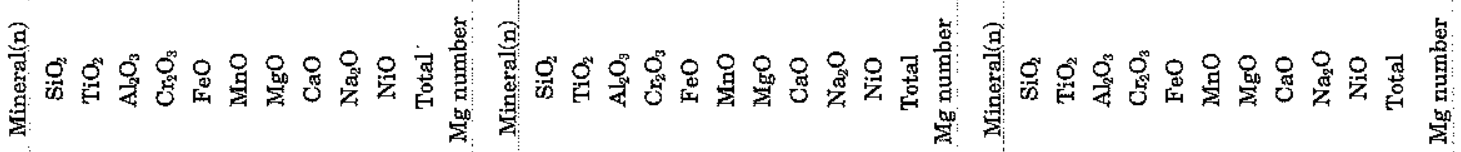




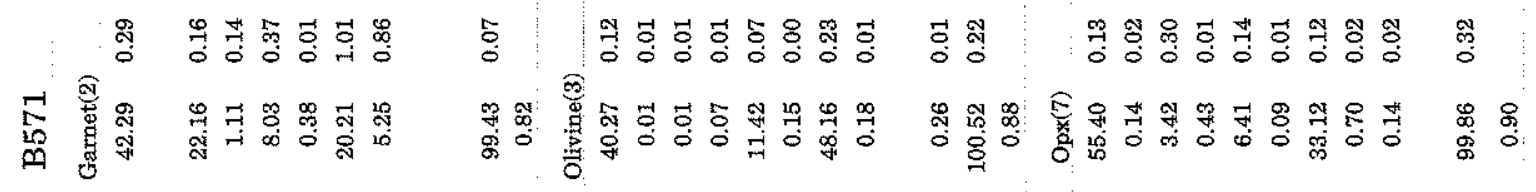

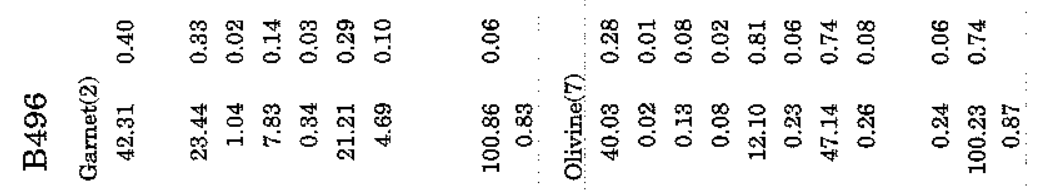

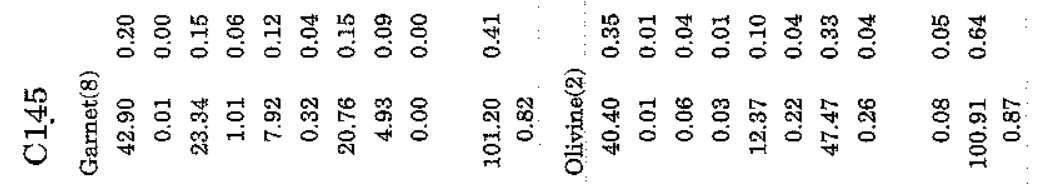

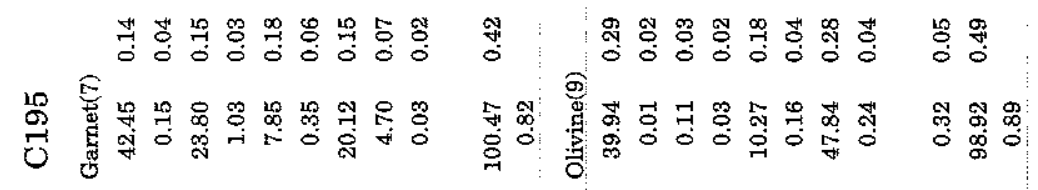

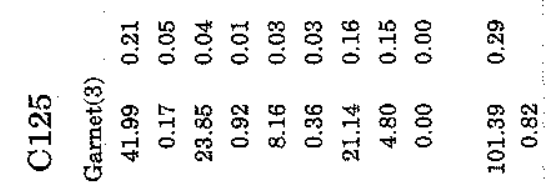

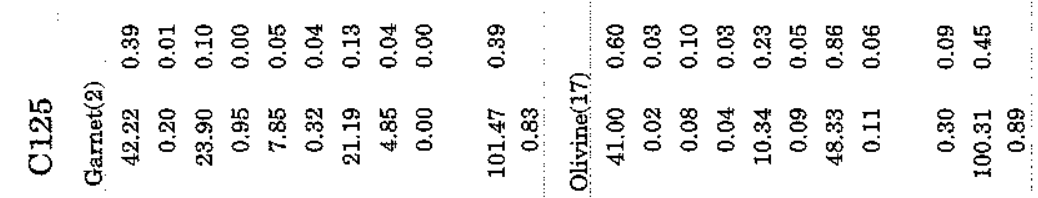

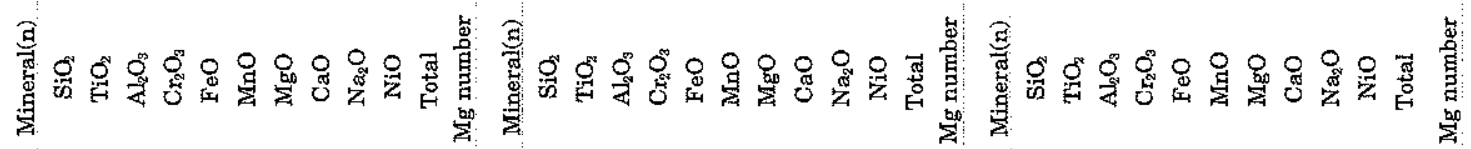


Table 4.3: Major element compositions of product phases of the garnet break-down reaction. Results of two pyroxene geothermometers are also presented. 


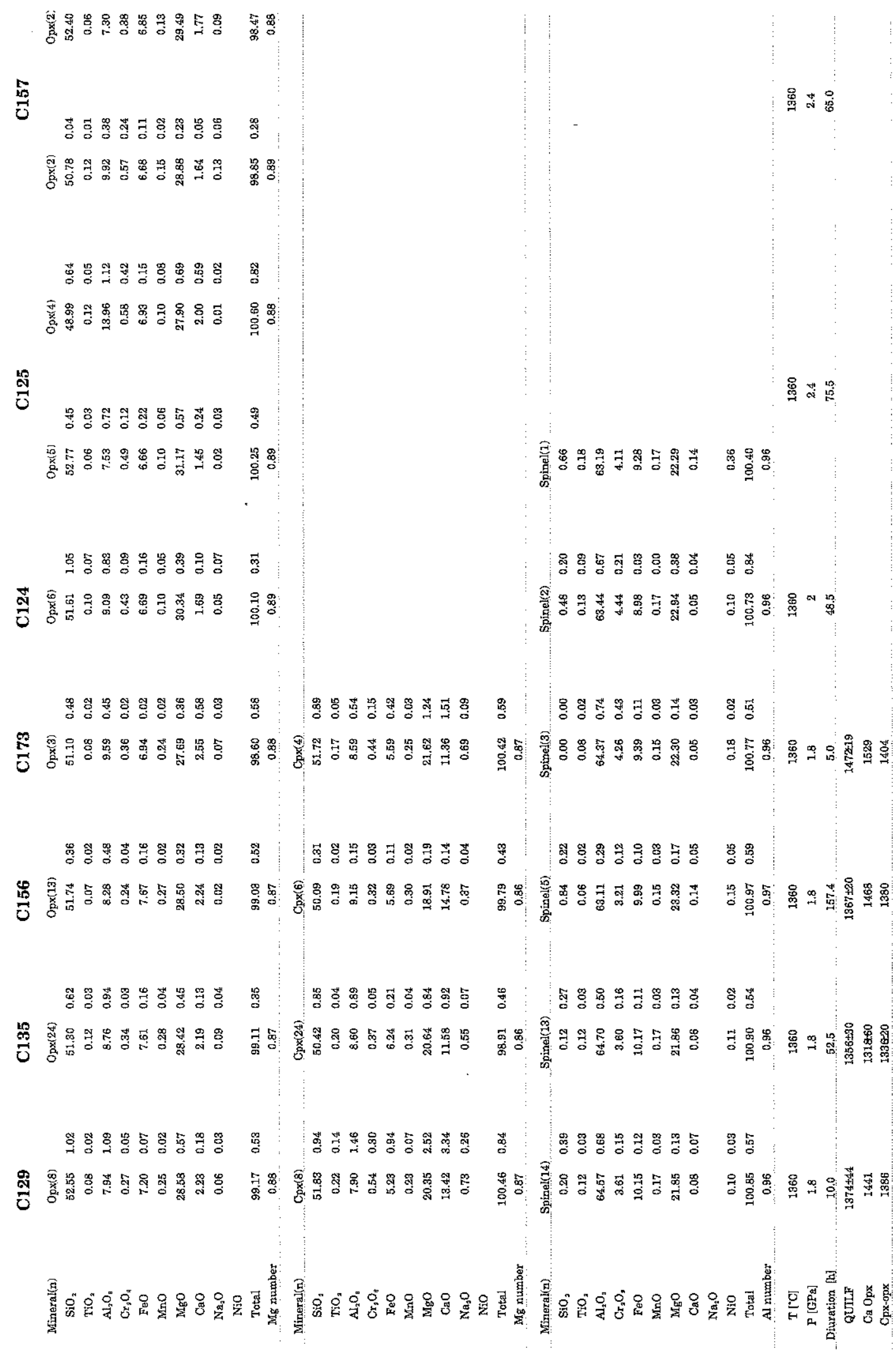



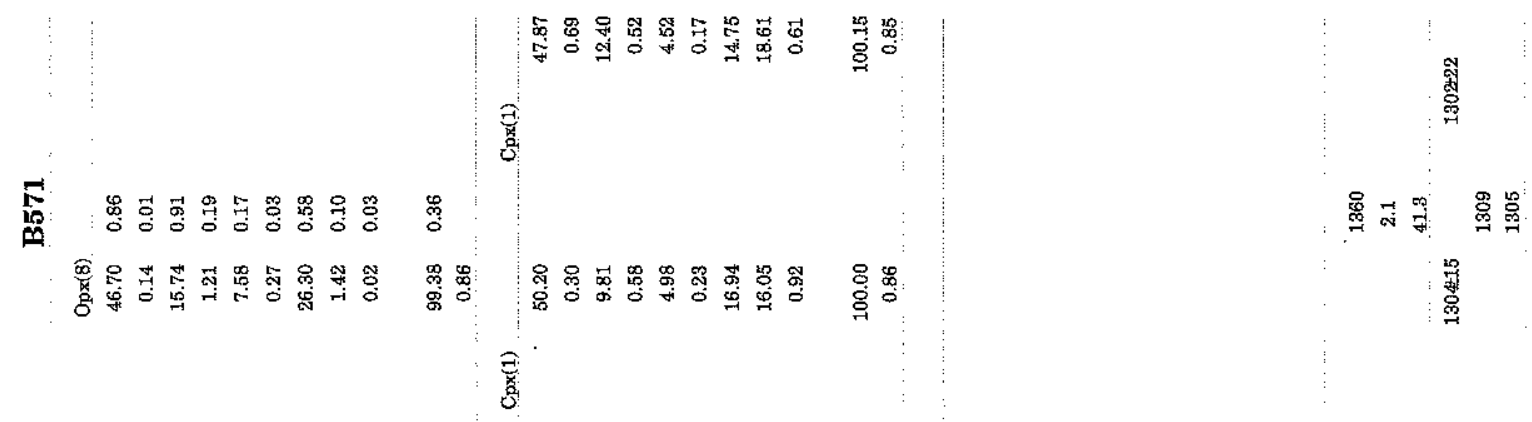

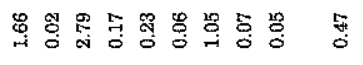

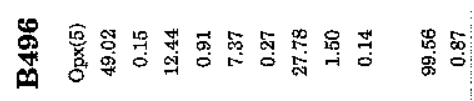

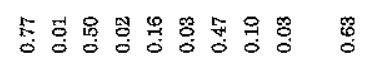

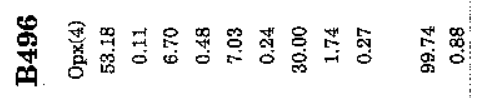

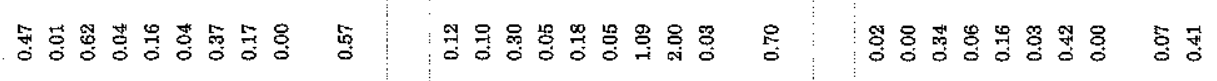

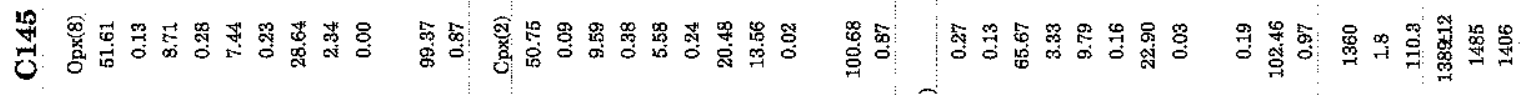

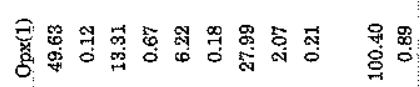

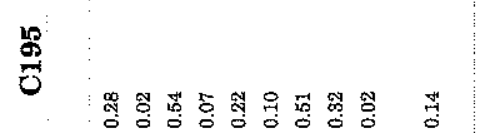

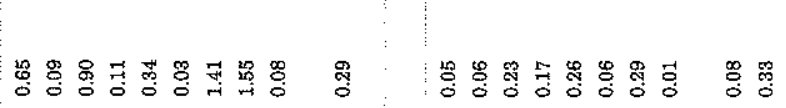

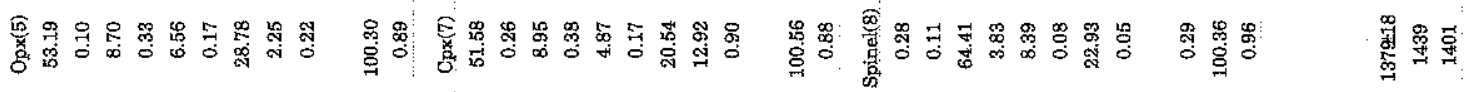

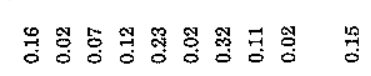

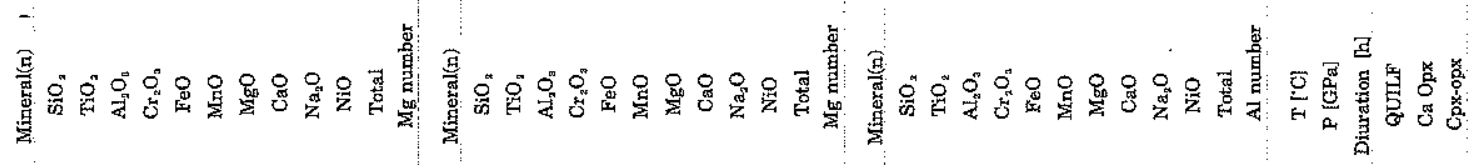


Table 4.4: Run conditions and measurements of the thickness of garnet rims. The column (TP) gives the mean thickness of all segments along the rim's edge with $0.2 \mu \mathrm{m}$ perimeter length, and was obtained from Jackknife averaging. Column (seg) gives the mean of the mean thickness of linearly approximated segment along the rims, using length weighted averaging. Column (adj) gives the mean recalculated from the same distribution as TP after excluding data plotted beyond two standard divination from the mean, that should determine the mean not biased by outliers. \%pop is the fraction of population used to calculate column (adj). Max and Min are maximum and minimum values. $N(\mathrm{seg})$ is number of measurement section with straight line approximation. $T$ length is total length measured for calculation of mean. 


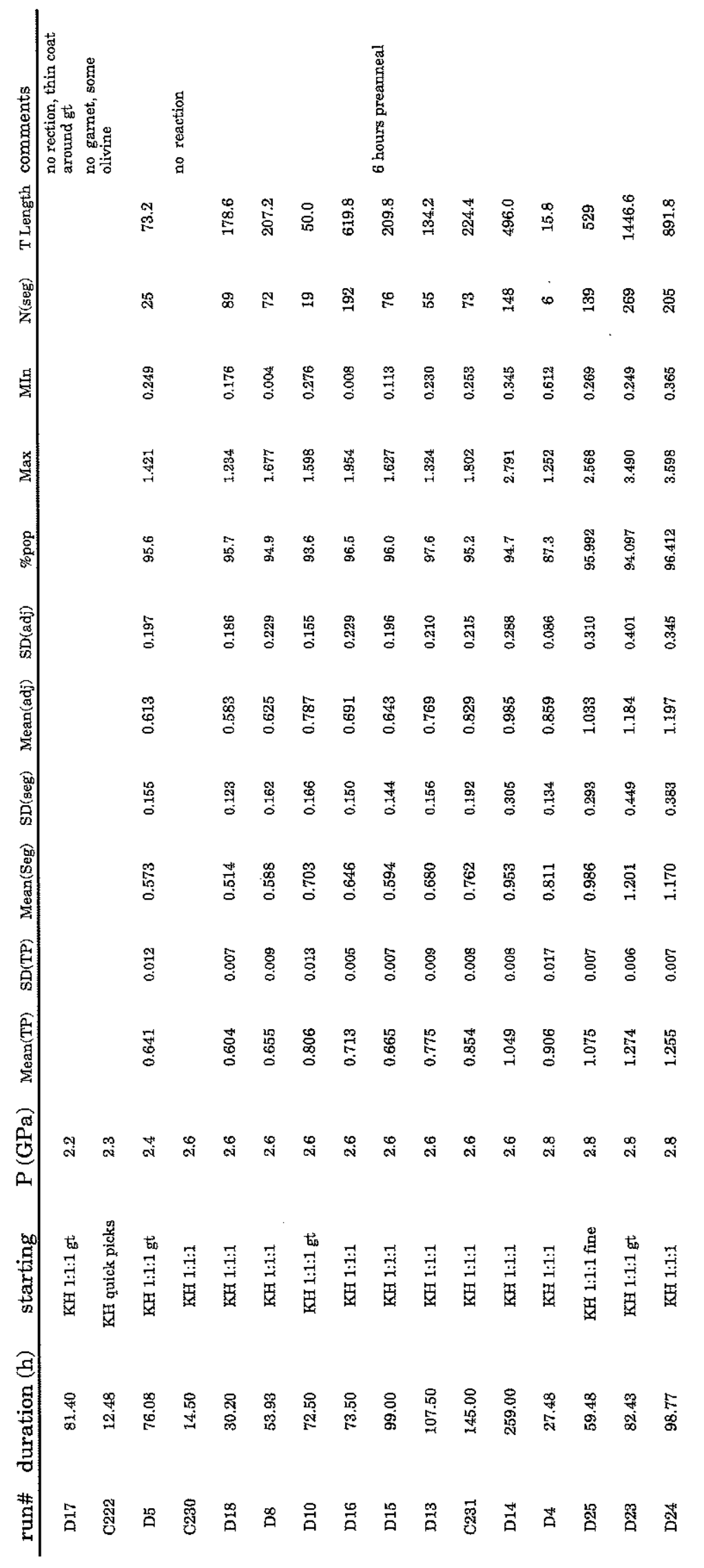


Table 4.5: Major element compositions of the reactant phases of garnet formation reaction, and the starting mineral compositions of $\mathrm{KH} \mathrm{4-5.}$ 


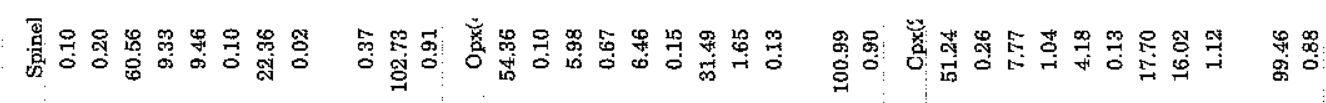

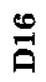

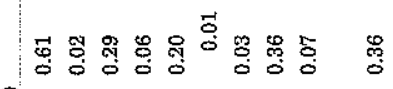

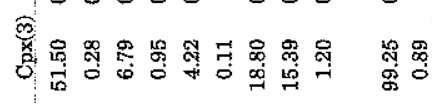

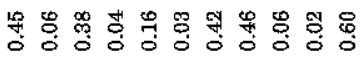

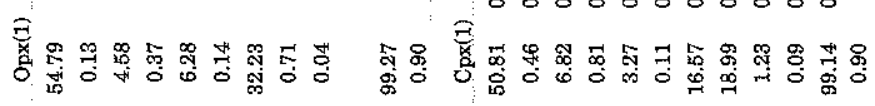

$\because$

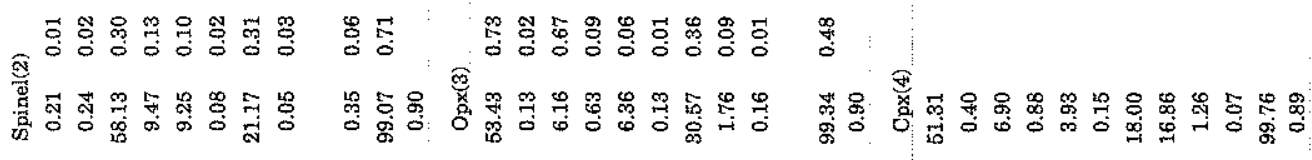

$\stackrel{\infty}{\circledR}$

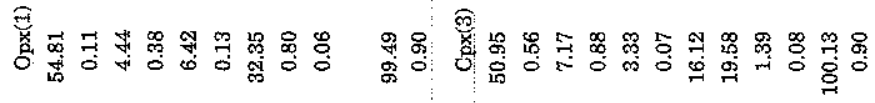

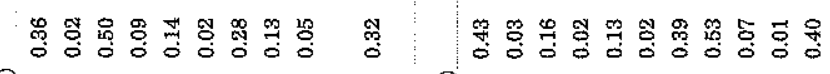

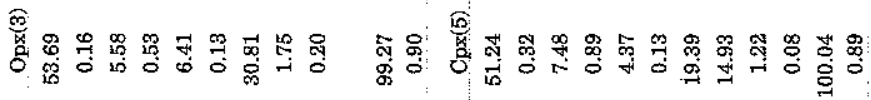

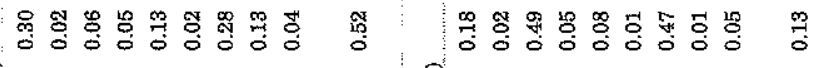

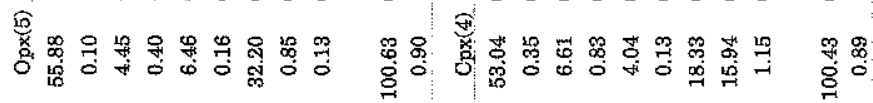

$\stackrel{\infty}{\square}$

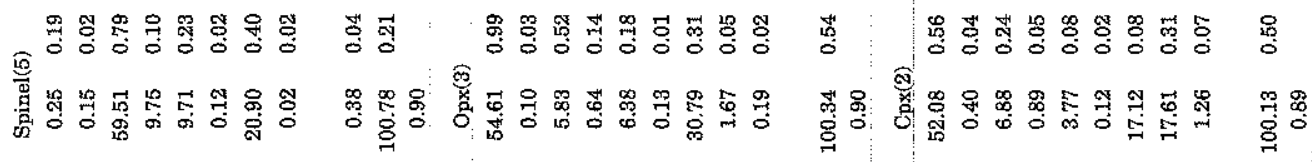

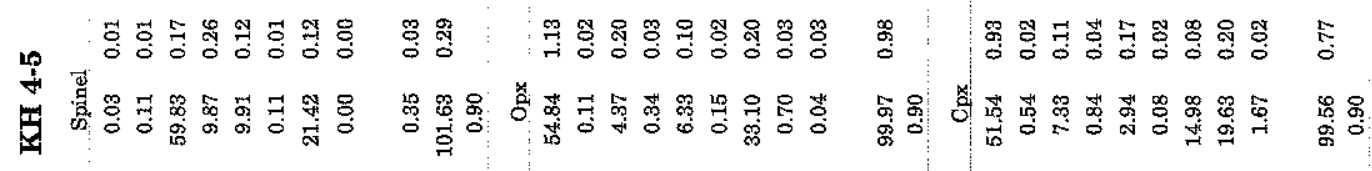

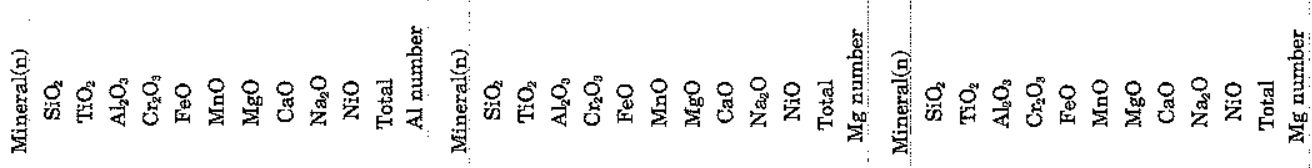


คี่

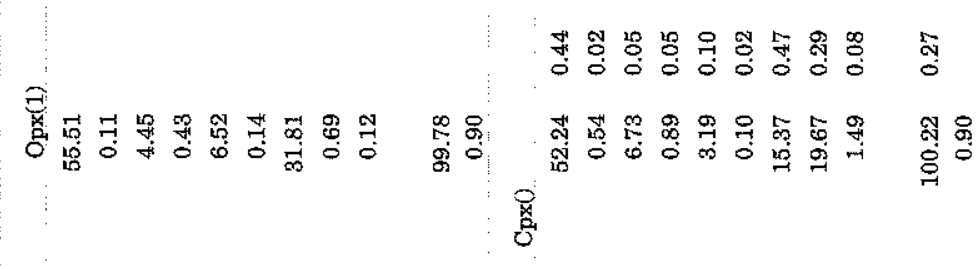

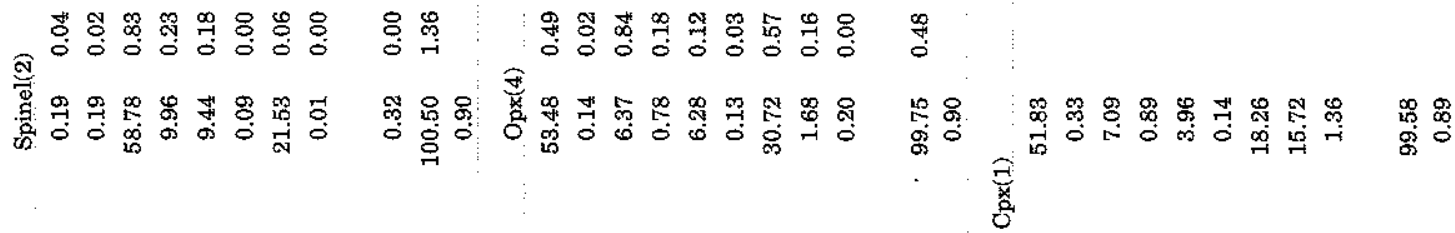

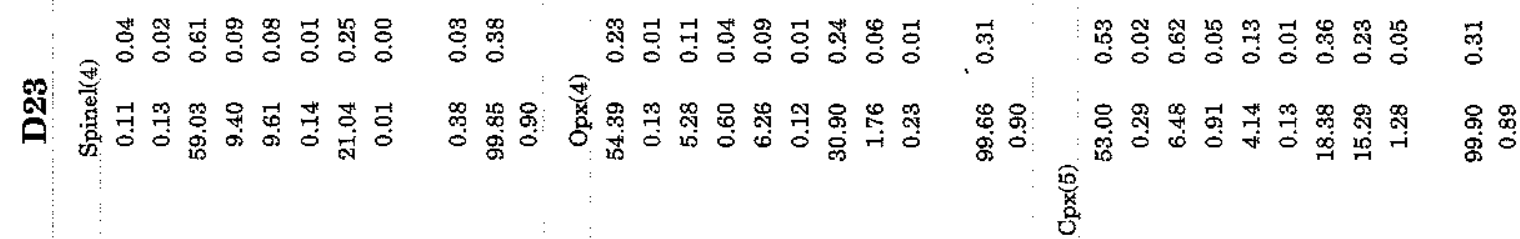

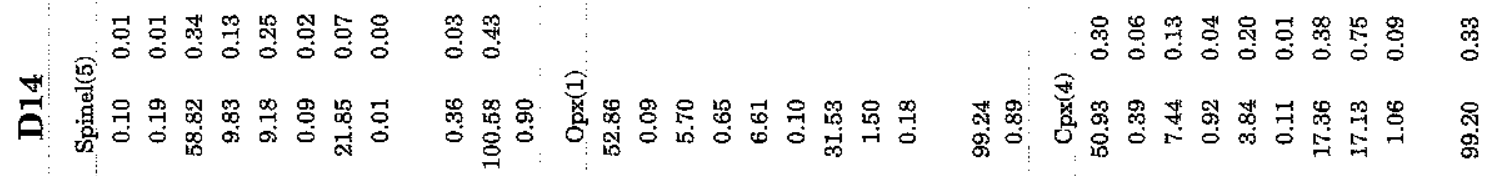

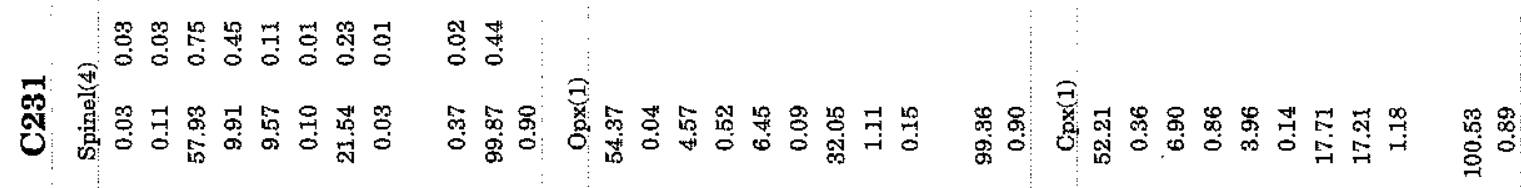

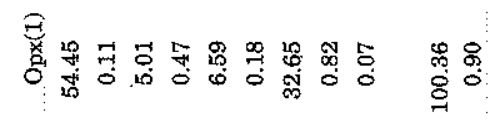

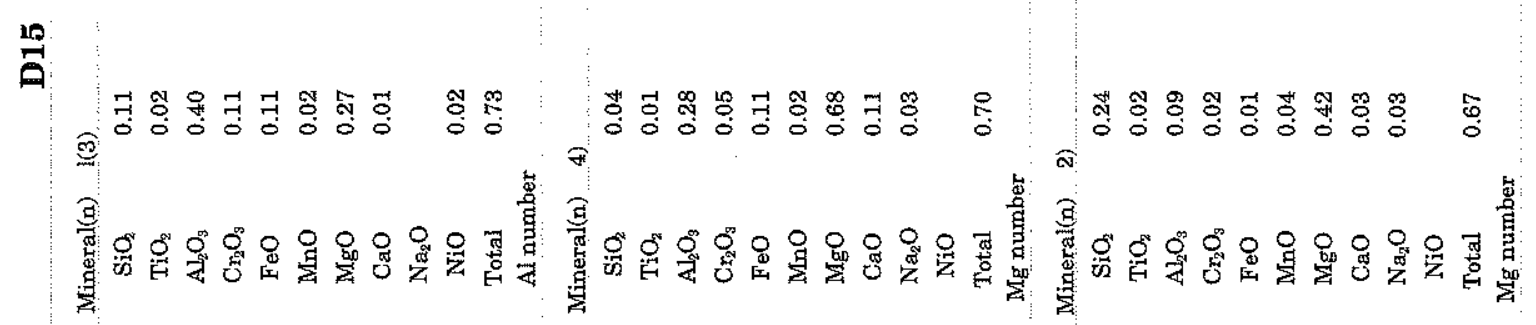


Table 4.6: Major element compositions of product phases of the garnet formation reaction. 


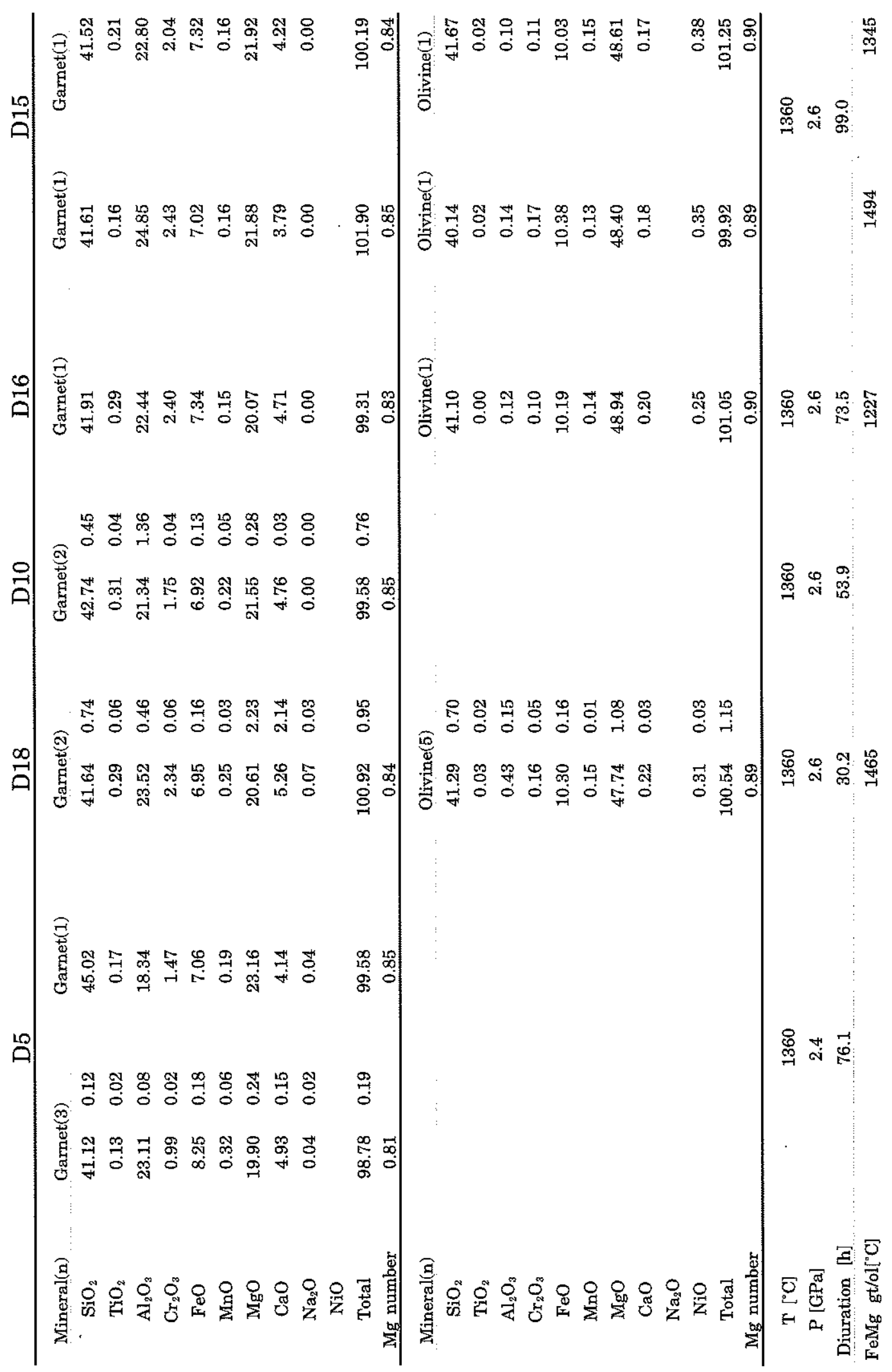




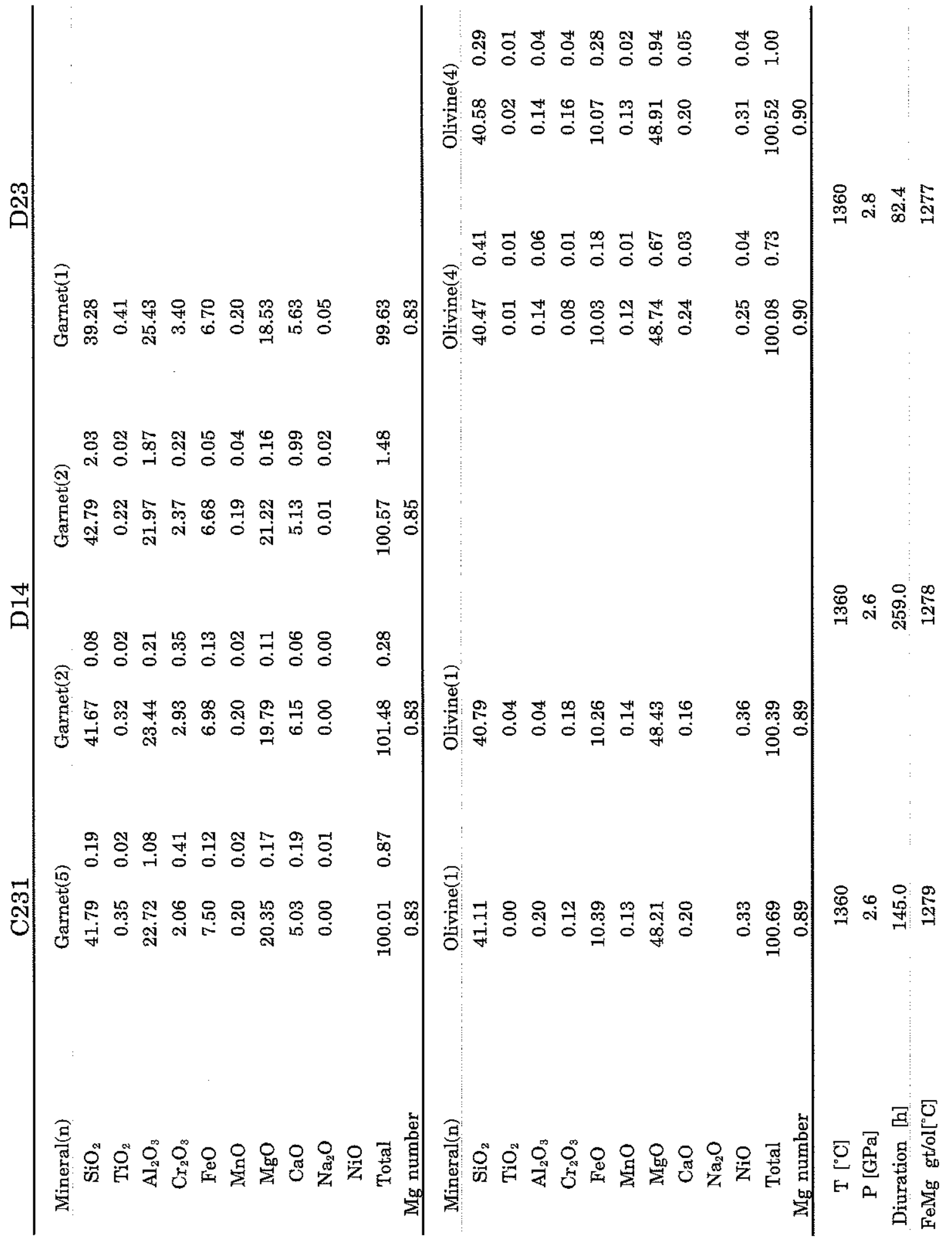


Table 4.7: Reaction rate constants, $\mathrm{K}$, for garnet break-down and formation experiment. Since the change of the thickness of garnet is measured for garnet formation experiment, unit can be converted to diffusion coefficient-like unit.

\begin{tabular}{|c|c|c|c|c|c|c|c|c|}
\hline Material & $\mathrm{N}$ & $\mathrm{P}(\mathrm{GPa})$ & $\mathrm{T}\left({ }^{\circ} \mathrm{C}\right)$ & $\ln K$ & $\mathrm{~K}^{2}(/ \mathrm{s})$ & $95 \%$ & power & $\ln K$ \\
\hline $\mathrm{C}$ & 1 & 1.8 & 1371 & -5.2242 & $8.05 \times 10^{-09}$ & 35.31 & & \\
\hline $\mathrm{C}$ & 2 & 2.0 & 1360 & -5.6483 & $3.45 \times 10^{-09}$ & 82.46 & 0.041 & -3.571 \\
\hline C & 3 & 2.0 & 1420 & -2.2548 & $3.06 \times 10^{-06}$ & 0.093 & 0.107 & -1.111 \\
\hline C & 2 & 2.4 & 1360 & -7.6088 & $6.84 \times 10^{-11}$ & 4160.21 & 0.568 & -7.835 \\
\hline C-cpx & 6 & 1.8 & 1360 & -1.6634 & $9.97 \times 10^{-06}$ & 0.03 & 0.487 & -1.628 \\
\hline C-cpx & 1 & 2.1 & 1320 & -6.0870 & $1.43 \times 10^{-09}$ & 198.30 & & \\
\hline C-cpx & 3 & 2.1 & 1360 & -4.6095 & $2.75 \times 10^{-08}$ & 10.33 & 0.380 & -4.388 \\
\hline C-cpx & 1 & 2.3 & 1360 & -5.6023 & $3.78 \times 10^{-09}$ & 75.21 & & \\
\hline C-cpx & 2 & 2.4 & 1360 & -7.5437 & $7.79 \times 10^{-11}$ & 3652.11 & 1.384 & -11.654 \\
\hline F & 1 & 2.0 & 1360 & -3.5741 & $2.18 \times 10^{-07}$ & 1.30 & & \\
\hline F & 1 & 2.1 & 1360 & -2.9085 & $8.27 \times 10^{-07}$ & 0.344 & & \\
\hline F & 1 & 2.1 & 1360 & -4.8413 & $1.73 \times 10^{-08}$ & 16.42 & & \\
\hline F & 1 & 2.1 & 1410 & -2.9492 & $7.62 \times 10^{-07}$ & 0.37 & & \\
\hline F-cpx & 2 & 1.8 & 1360 & -0.7645 & $6.02 \times 10^{-05}$ & 0.005 & 0.598 & -0.765 \\
\hline F-cpx & 1 & 2.1 & 1360 & -3.5013 & $2.53 \times 10^{-07}$ & 1.13 & & \\
\hline F-cpx & 1 & 2.3 & 1360 & -4.5291 & $3.23 \times 10^{-08}$ & 8.79 & & \\
\hline Material & $\mathrm{N}$ & $\mathrm{P}(\mathrm{GPa})$ & $\mathrm{T}\left({ }^{\circ} \mathrm{C}\right)$ & $\ln K$ & $\mathrm{D}\left(\mathrm{m}^{2} / \mathrm{s}\right)$ & $\log D$ & & \\
\hline $\mathrm{ns}$ & 2 & 2.8 & 1360 & -1.19 & $2.56 \times 10^{-17}$ & -16.59 & & \\
\hline $\mathrm{ns}$ & 6 & 2.6 & 1360 & -1.56 & $1.22 \times 10^{-17}$ & -16.91 & & \\
\hline $\mathbf{s}$ & 1 & 2.8 & 1360 & -1.14 & $2.86 \times 10^{-17}$ & -16.54 & & \\
\hline s & 1 & 2.6 & 1360 & -1.45 & $1.52 \times 10^{-17}$ & -16.82 & & \\
\hline $\mathrm{s}$ & 1 & 2.4 & 1360 & -1.68 & $9.57 \times 10^{-18}$ & -17.02 & & \\
\hline Fs & 1 & 2.8 & 1360 & -1.18 & $2.65 \times 10^{-17}$ & -16.58 & & \\
\hline
\end{tabular}




\section{Figures}

Figure 4.1: Experimentally determined spinel to garnet facies reaction boundaries in simple and natural peridotitic compositions. [a] CMAS-Na solidus. Subsolidus reaction boundaries (dashed curves) are inferred (Walter and Presnall, 1994). [b] CMAS (Kushiro and Yoder, 1966). [c1] Natural, and [c2] CMAS (Jenkins and Newton, 1979). [d1] CMAS, [d2] $\mathrm{CMASCr}$ at $\mathrm{XCrSp}=0.1$, and [d3] CMASCr at $\mathrm{XCrSp}=0.2$ (O'Neill, 1981). [e] Natural system by O'Hara et. al. (1971). [f1] CMASCr at garnet-in and [f2] spinel-out by Nickel (1986).

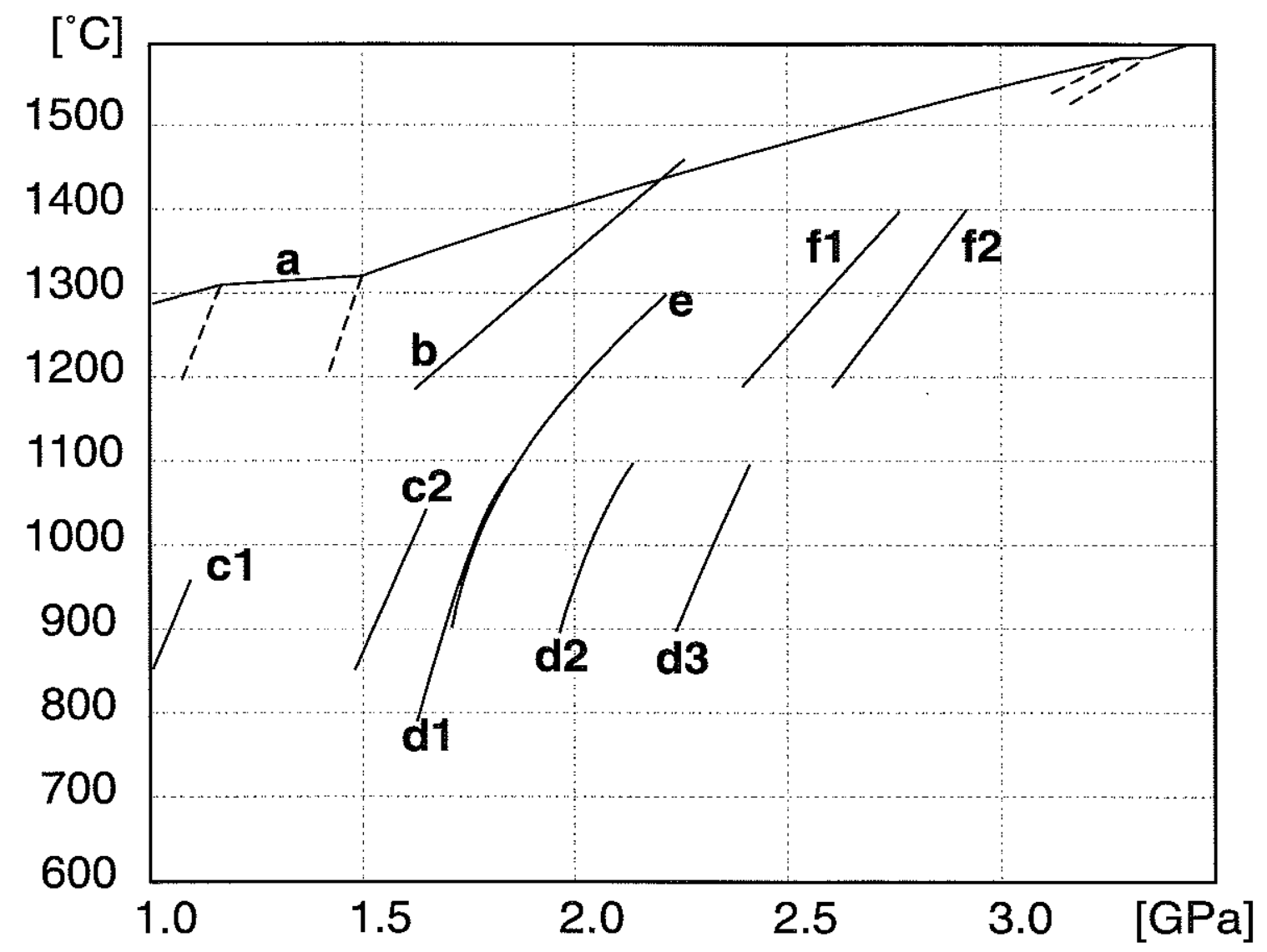


Figure 4.2: $\quad \mathrm{BSE}(\mathrm{A})$, and $\mathrm{Mg},(\mathrm{E})$, and $\mathrm{Al}(\mathrm{C})$, $\mathrm{x}$-ray images are made from the experiment B496. By binarizing gray scale of interest, garnet (B), olivine (D), opx (F) and spinel $(\mathrm{H})$ are made. Overlaying binarized images produce the processed image $(\mathrm{G})$. The processed image make the clear identification of phases possible. 

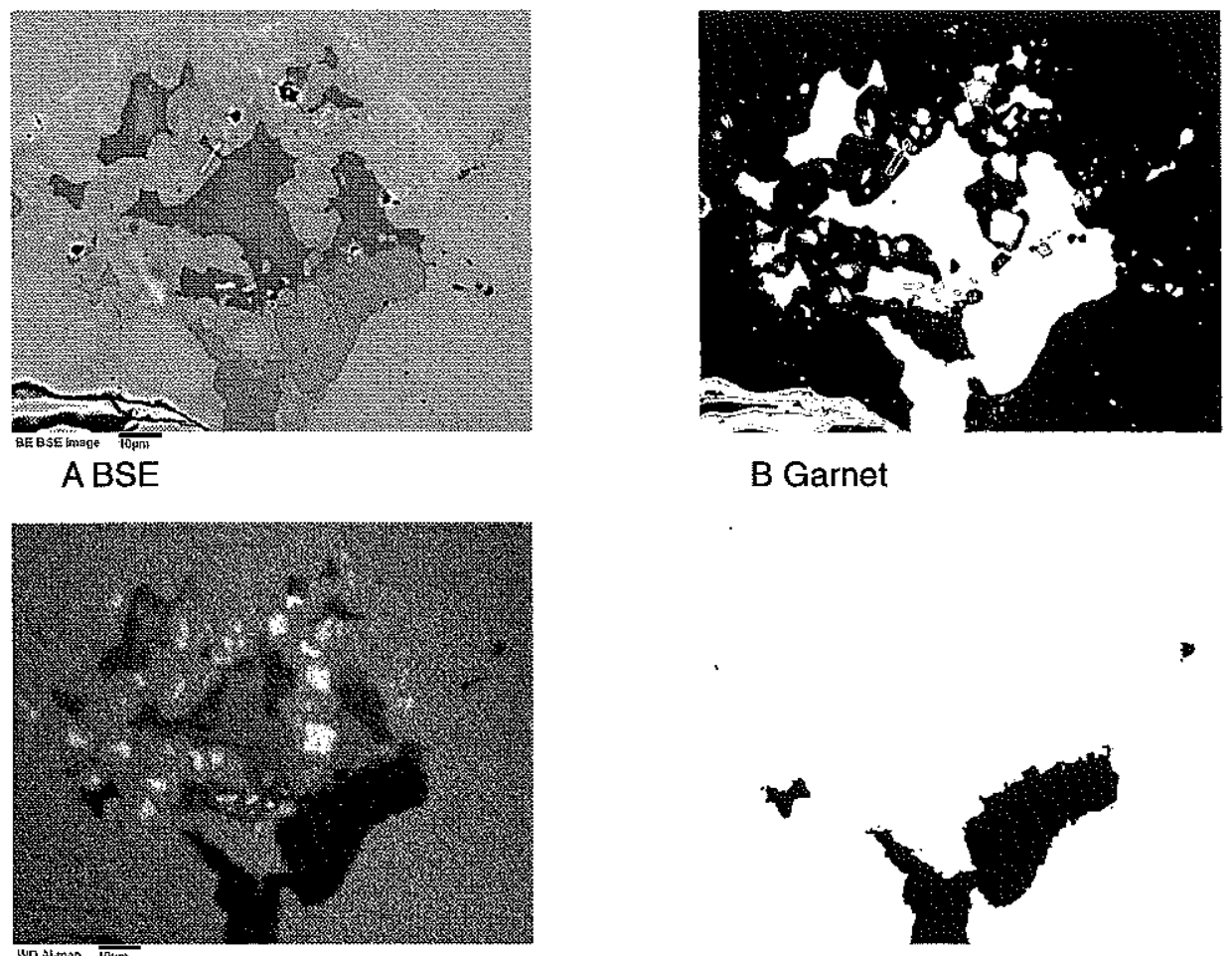

C Al x-ray map

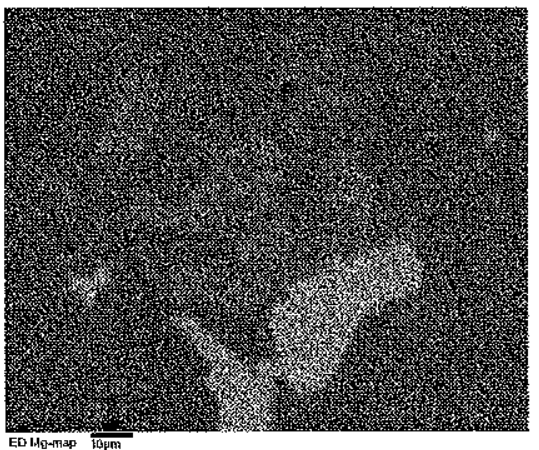

E Mg x-ray map

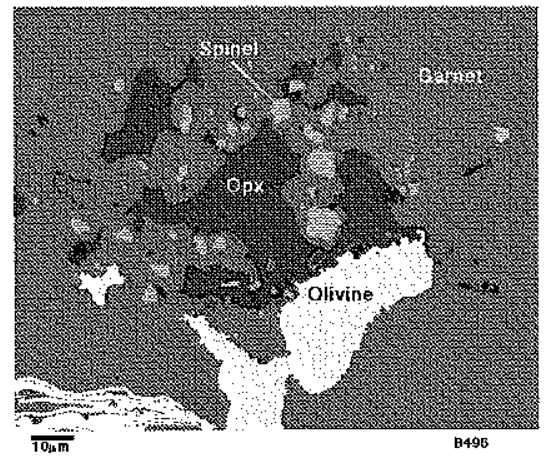

G Processed image

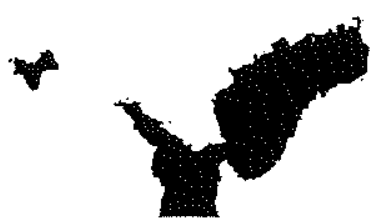

D Olivine
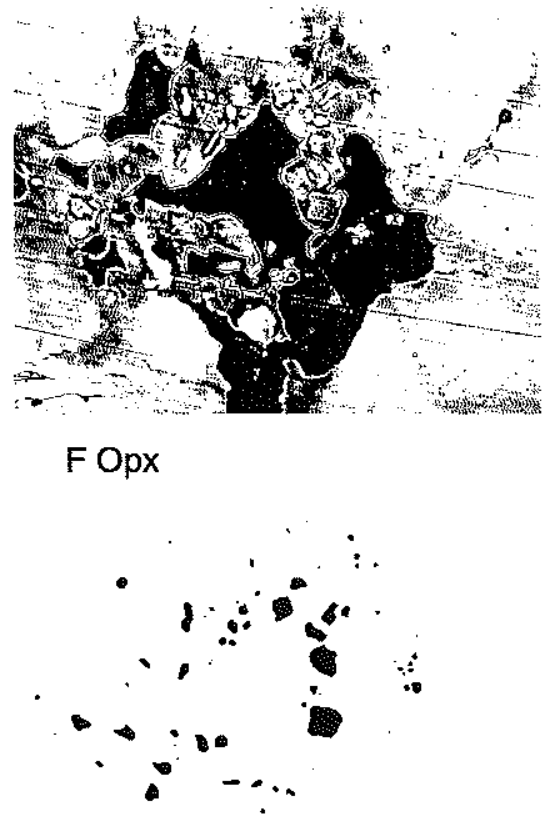

H Spinel 
Figure 4.3: Four sets of time progressing BSE images for the condition at $1.8 \mathrm{GPa}$, and $1360^{\circ} \mathrm{C}$ are shown. Coarse crushed starting material with a layer of cpx (except for panel $\mathrm{B}$ ) grains are used as starting material. Note the schane of texture.

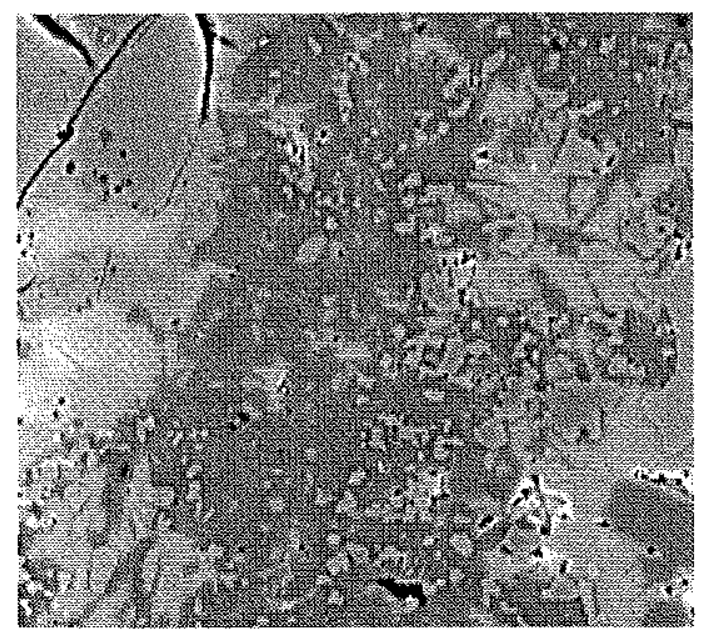
A. $\mathrm{C} 129$ 10h $+\mathrm{Cpx}$

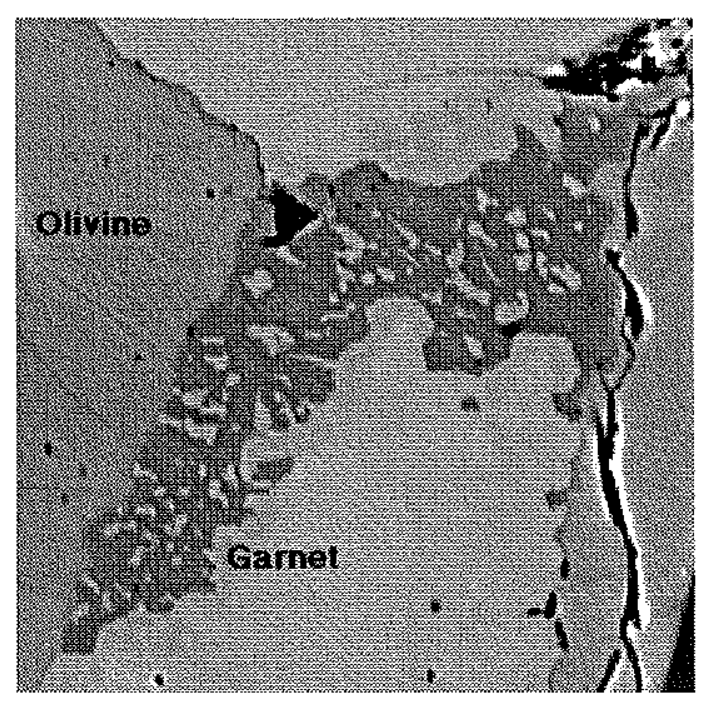

B. C124 48.5h coarse
C.C135 52.5h +Cpx

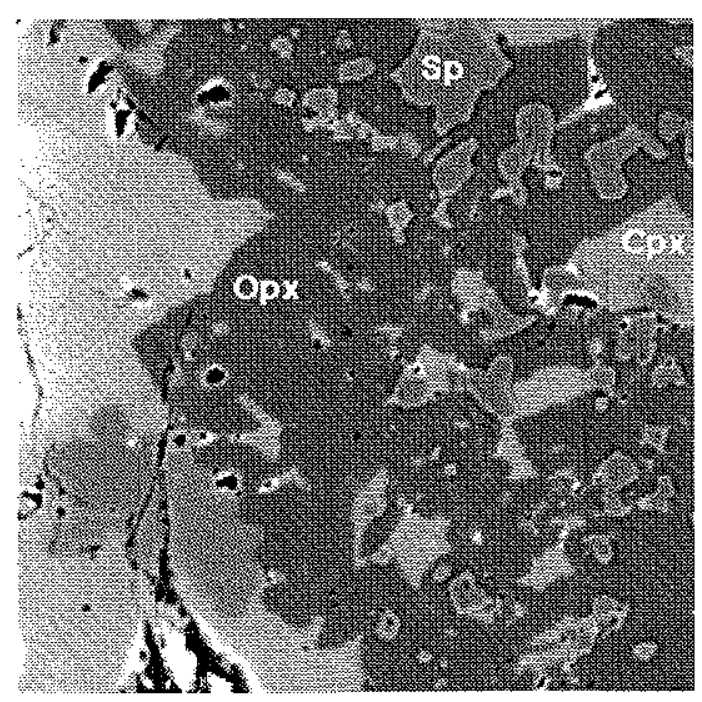

D. $C 156157 \mathrm{~h}+\mathrm{Cpx}$

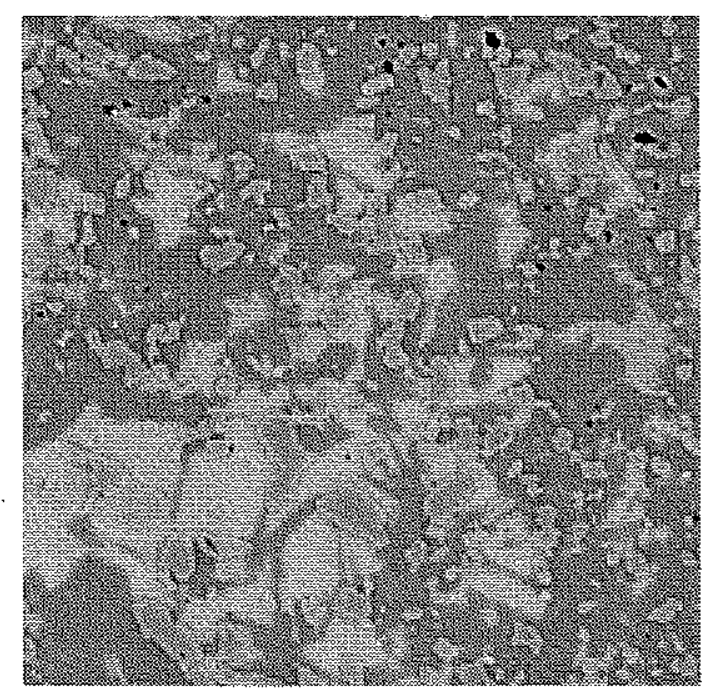


Figure 4.4: Geometric parameters for spinel grain size are plotted against their frequency " of occurrence.
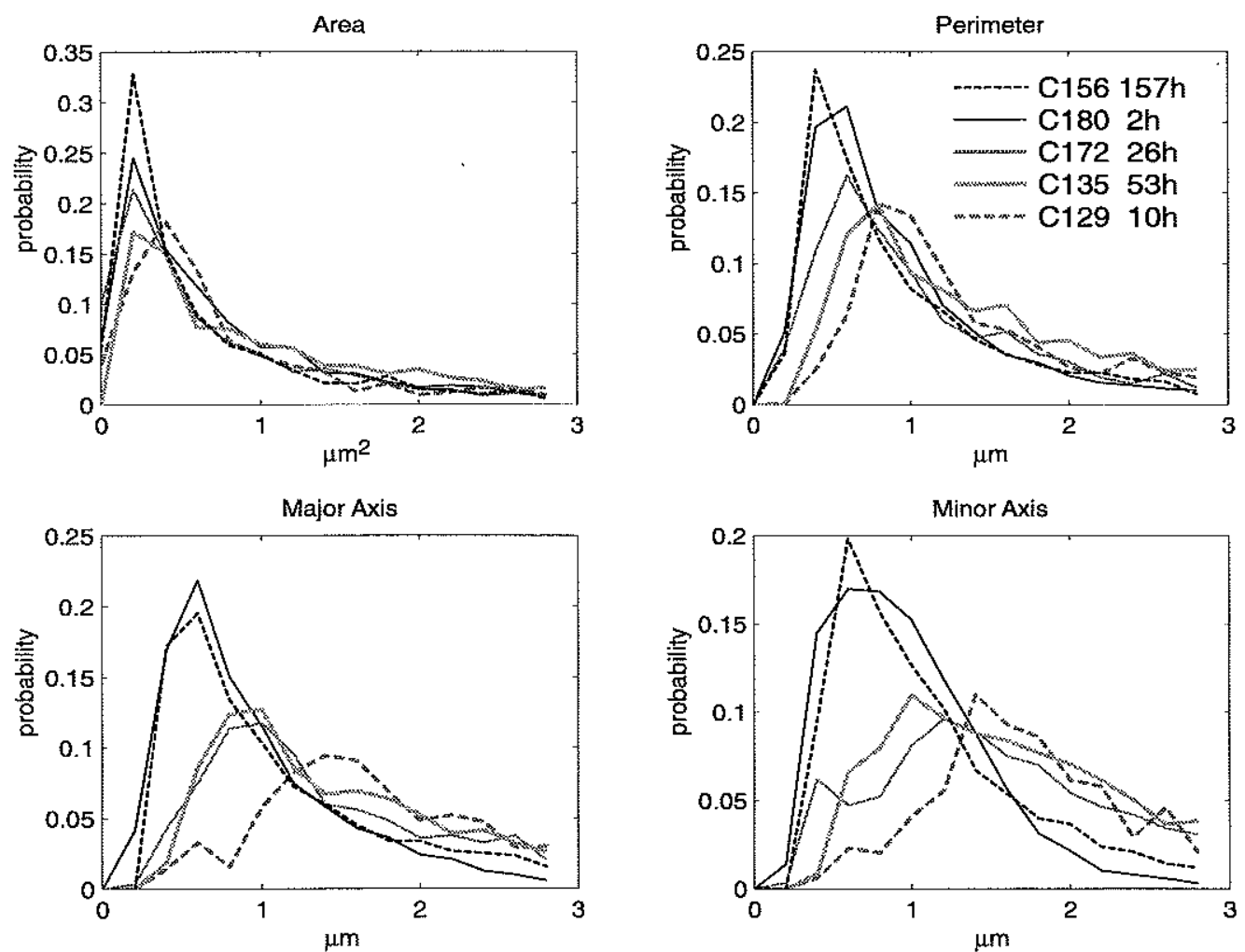
Figure 4.5: A representative $\xi-t$ plot shows the change of volume fraction of phases.

The total product volume fraction increase with time while cpx shows the decreasing trend.

The significance of the decreasing trend is not clear and is not statistically valid.

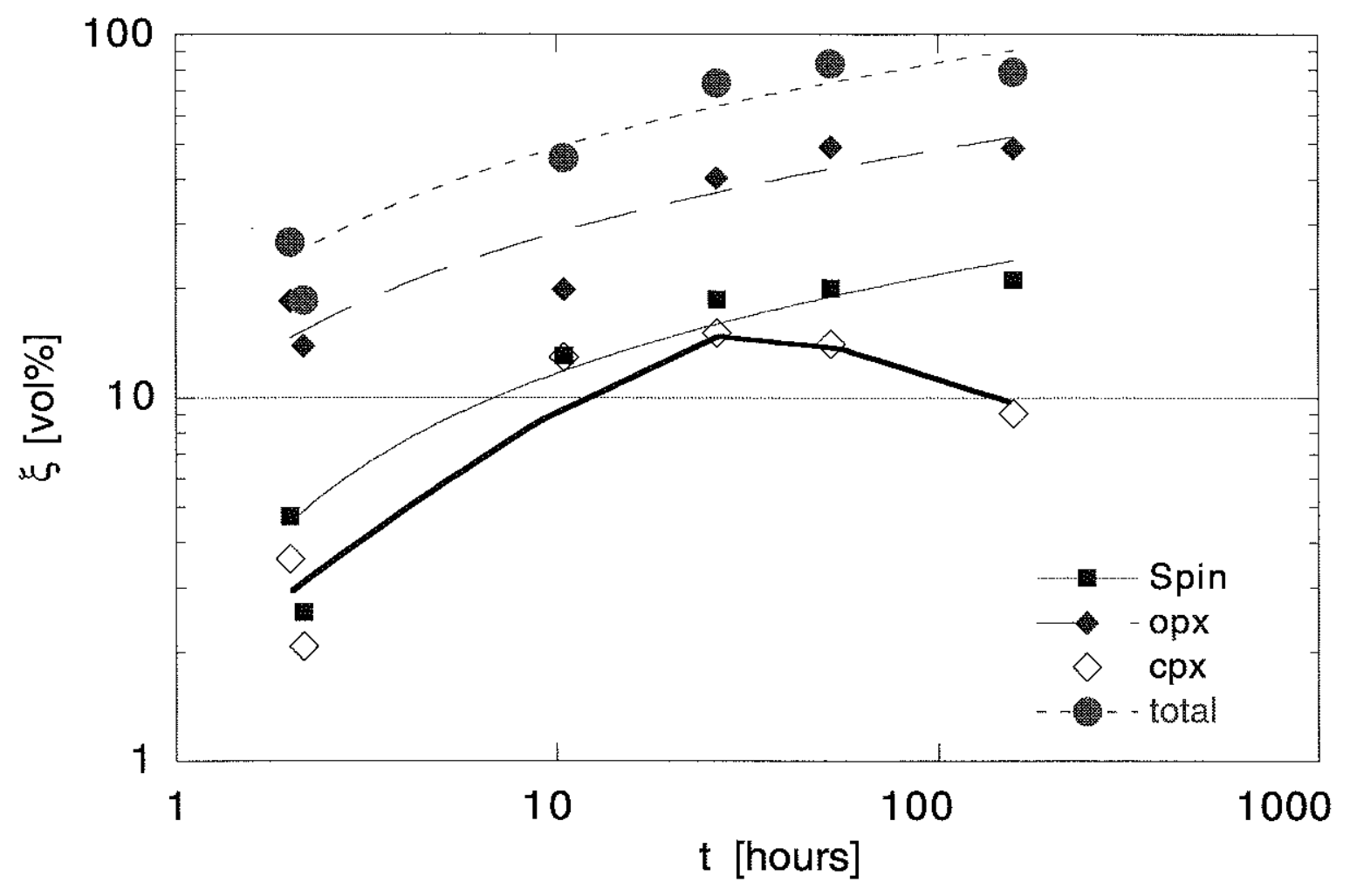


Figure 4.6: Results of linear fit for determining $K$ and $n$. The case of $n=0.5$ agrees well with the data. $\xi$-t and $\xi$-logt are plotted to illustrates differences in the model curve topologies. Solid line, $n=2$; Thin-dashed line, $n=1$ (first order reaction); Thick-dotted line, $\mathrm{n}=0.5$ (diffusion limited); Thick-dashed line, best-fit $\mathrm{n}$. 

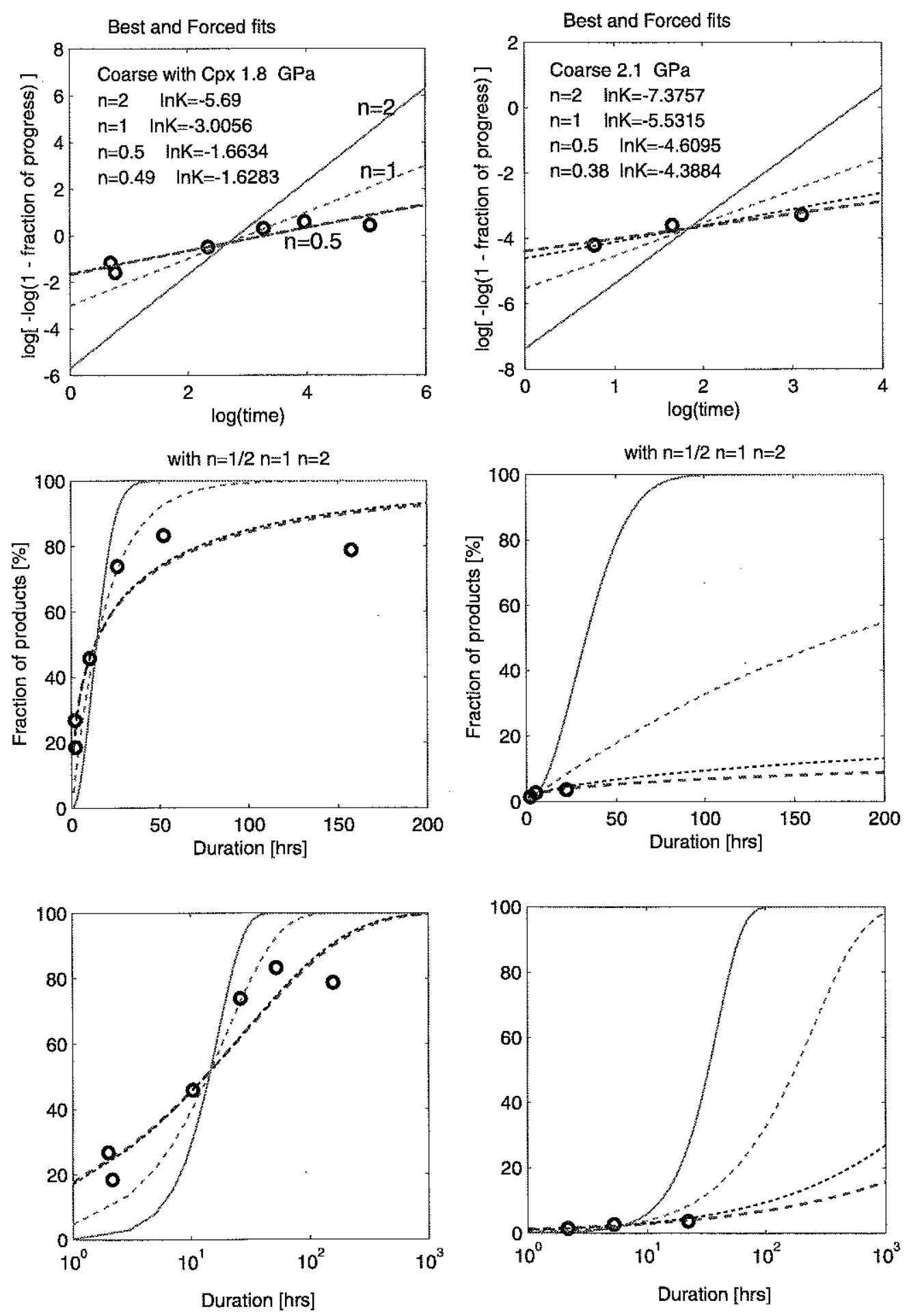
Figure 4.7: $\quad 2 \log \mathrm{K}$ is linearly related with pressure.

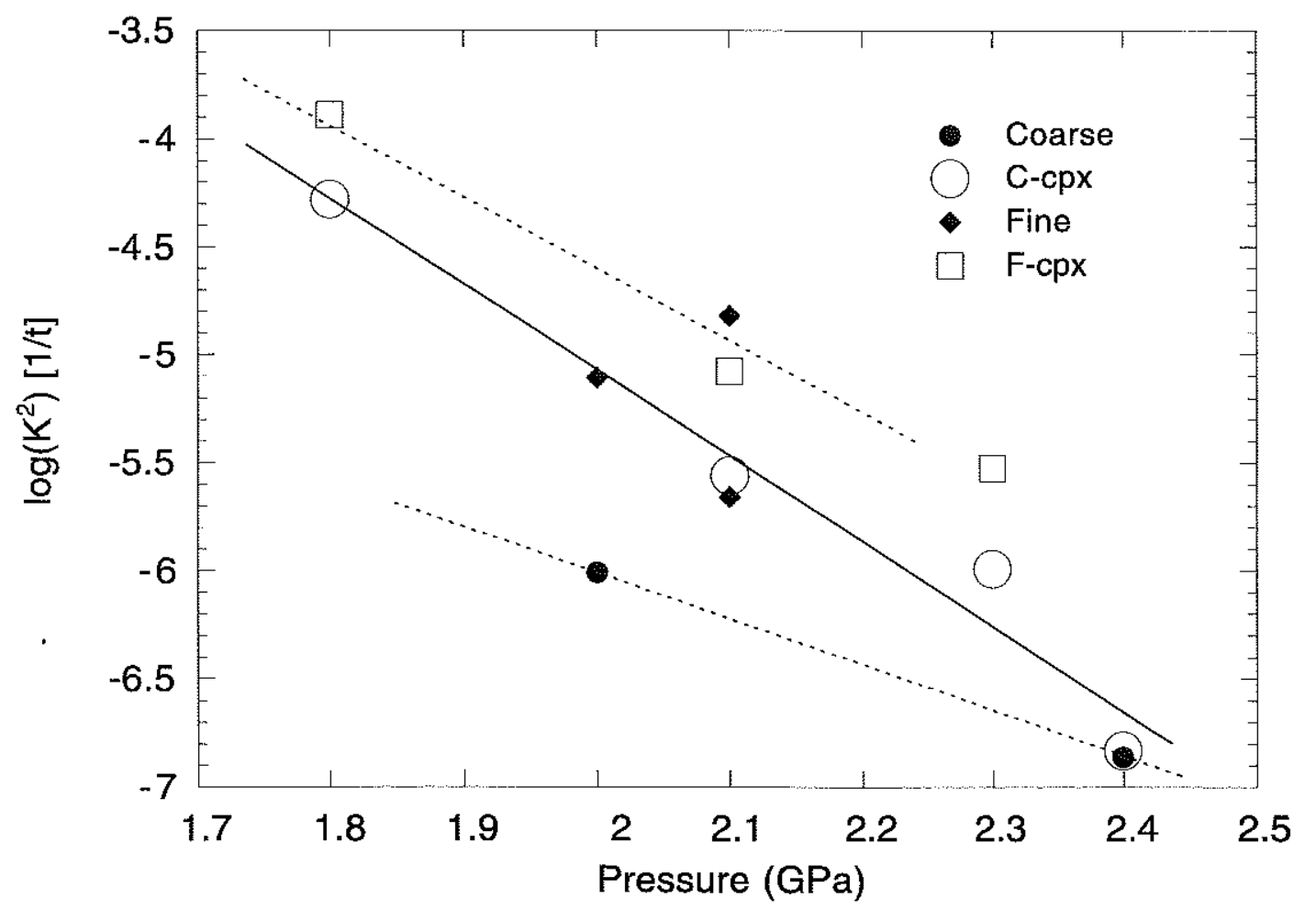


Figure 4.8: Bright phases are spinel and dark background phase is opx. Cpx is medium gray phase with low profile. Medium dark gray material rimming spinel is the growing garnet. Durations are A 14.5, B 30.2, C 73.5, and D 259 hours. Note the change of the thickness of garnet.
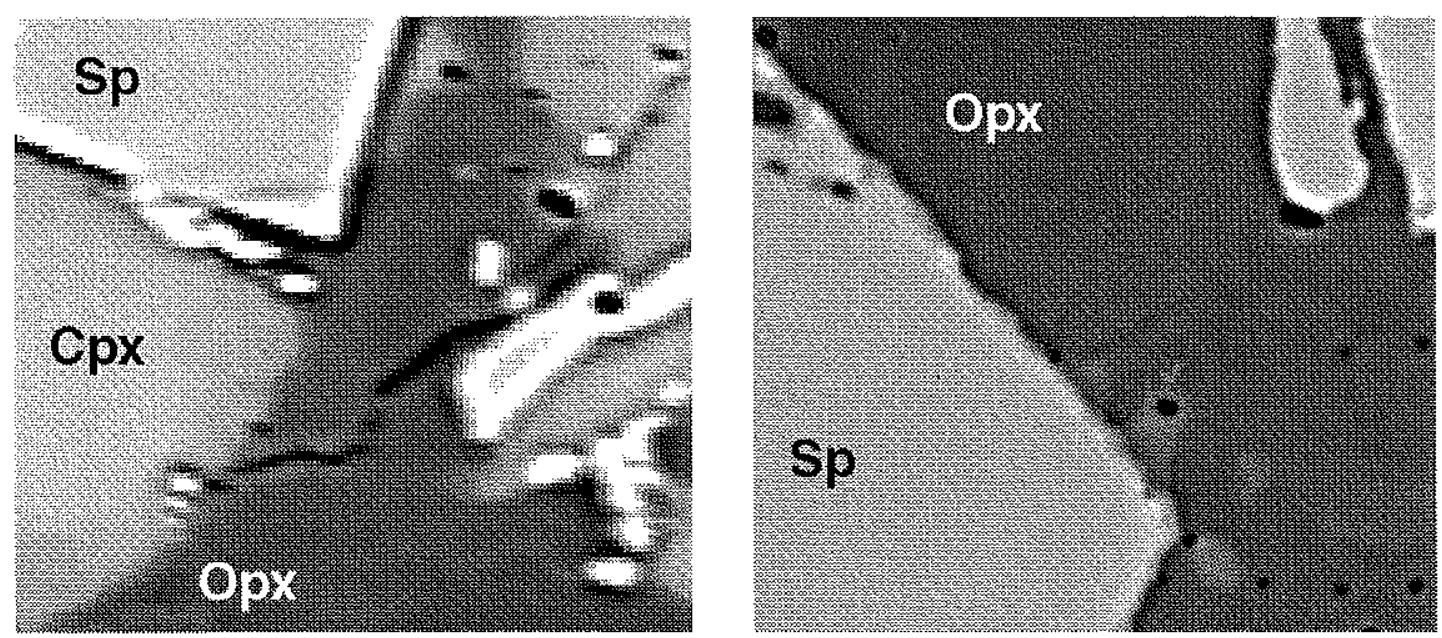
A. $\mathbf{C 2 3 0}$
B. $D 18$

$20 \mu \mathrm{m}$

C. D16

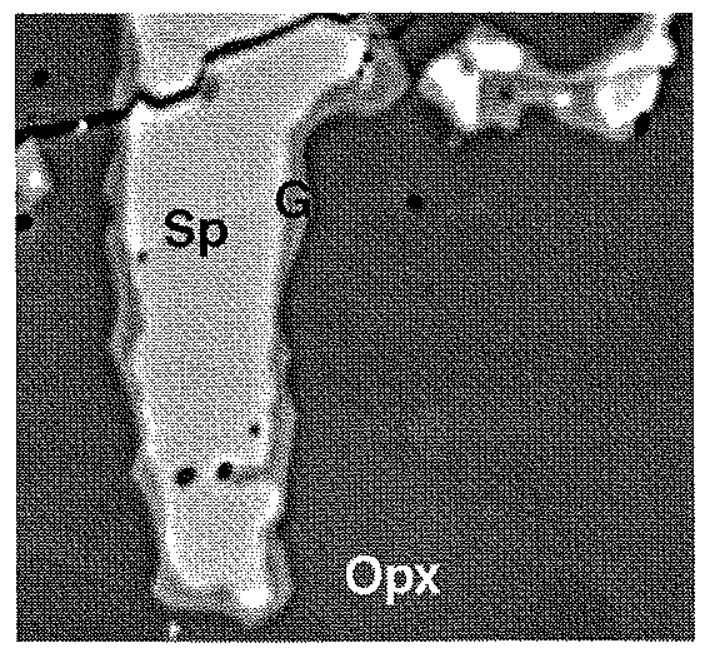

D. D14

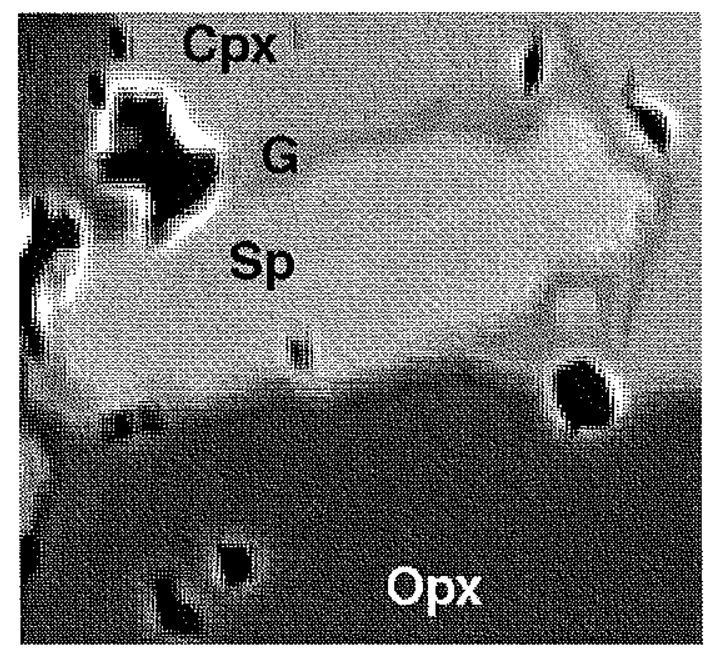


Figure 4.9: Thickness of garnet, $\xi$, is plotted against square root of time. Square symbol is result of D15 which is annealed 6 hours at the stability of spinel prior to reach run condition. Diamond symbol is a result of run with garnet seeds added as layer. It seems increased reaction rate slightly.

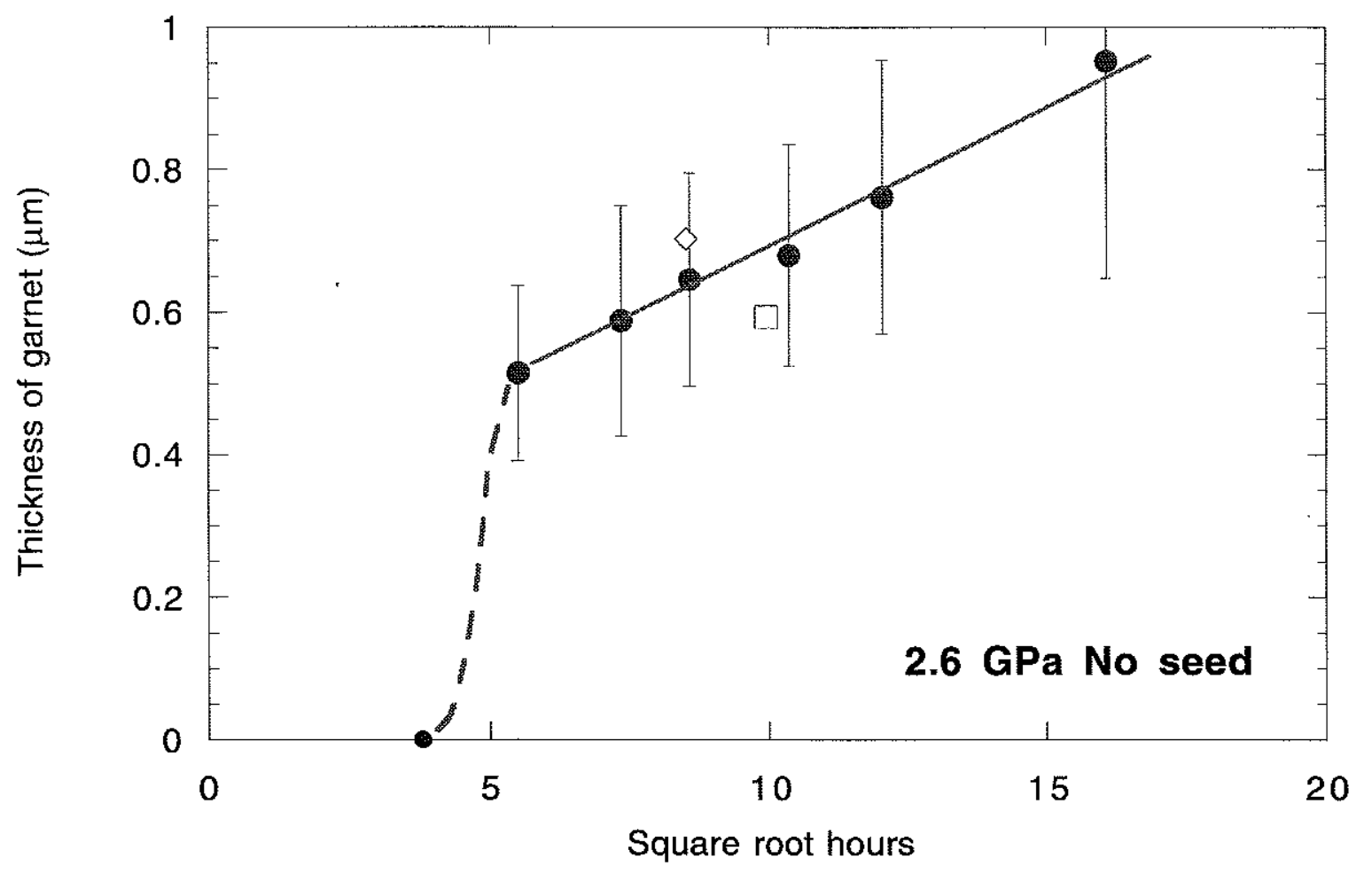


Figure 4.10: A), Reaction rate coefficient, D, is plotted against pressure. An Arrheniustype log linear relationship is clearly shown. Although D has the same unit as diffusivity, the physical meaning of the coefficient is not a simple representation of diffusion (see text). B), K-P relationship of garnet formation and breakdown reaction are shown in the same figure. At $2.4 \mathrm{GPa}$, both reactions can progress indicating the presence of garnet-spinel coexisting region.
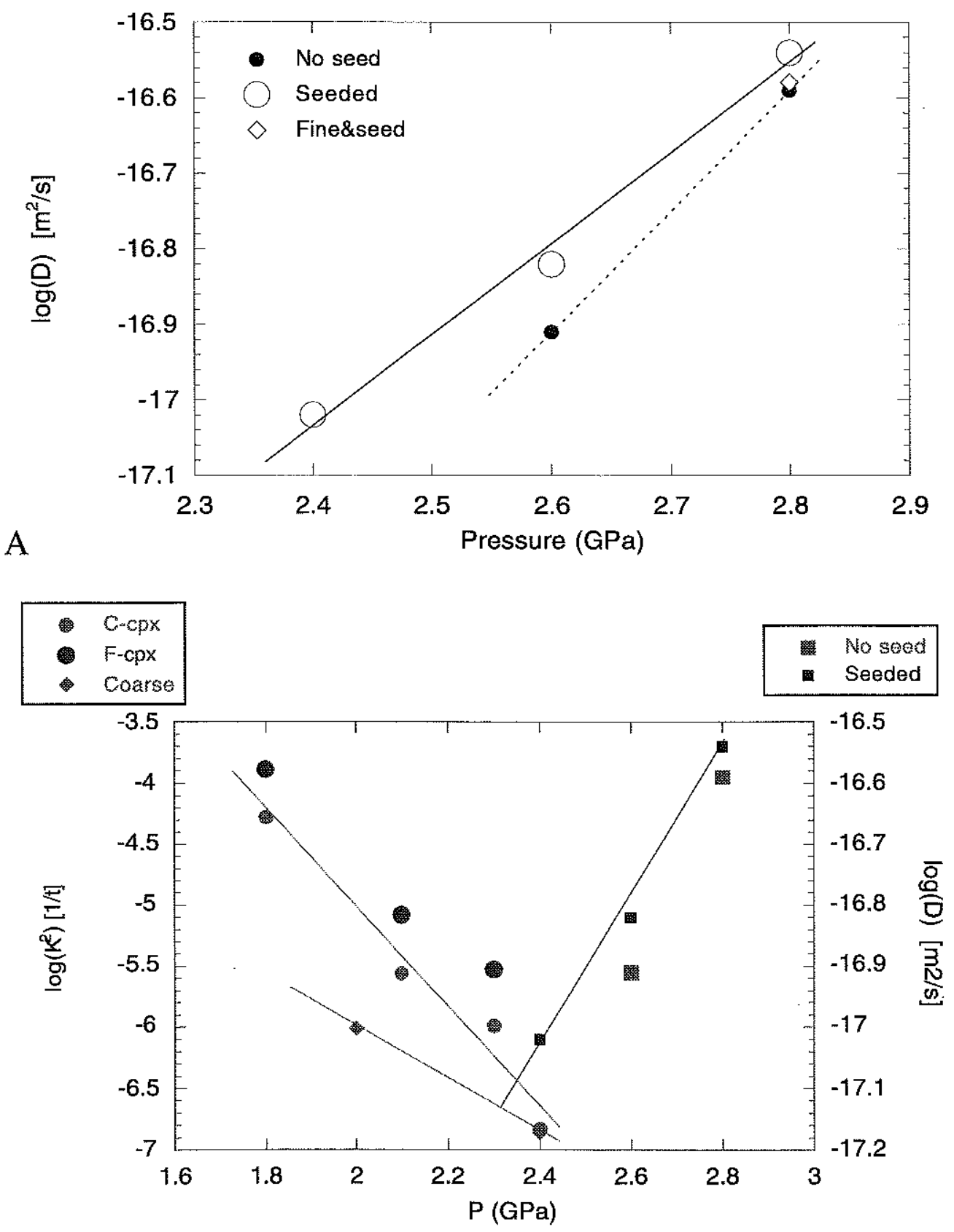
Figure 4.11: Previously determined experimental results. Filled symbols denote garnet formation and open symbols are spinel formation/retention. Square:CMAS [Kushiro, 1966 \#69], diamond: CMAS (O'Neill, 1981), dark circle: natural (O'Hara et al., 1971), light circle: natural (Jenkins and Newton, 1979), large triangle: SMACCr (O'Neill, 1981), small triangle: (Nickel, 1986), 3-point star: NaCMAS (Walter and Presnall, 1994), 4-point star: natural (Walter, 1998), 5-point star: (Kinzler, 1997), 6-point star: (Takahashi and Kushiro, 1983), pentagon: (Robinson and Wood, 1998), and left point arrow is garnet formation, right point arrow is spinel formation in CMAS, (Jenkins and Newton, 1979). Uncorrected nominal pressure is calculated from report and used here. 


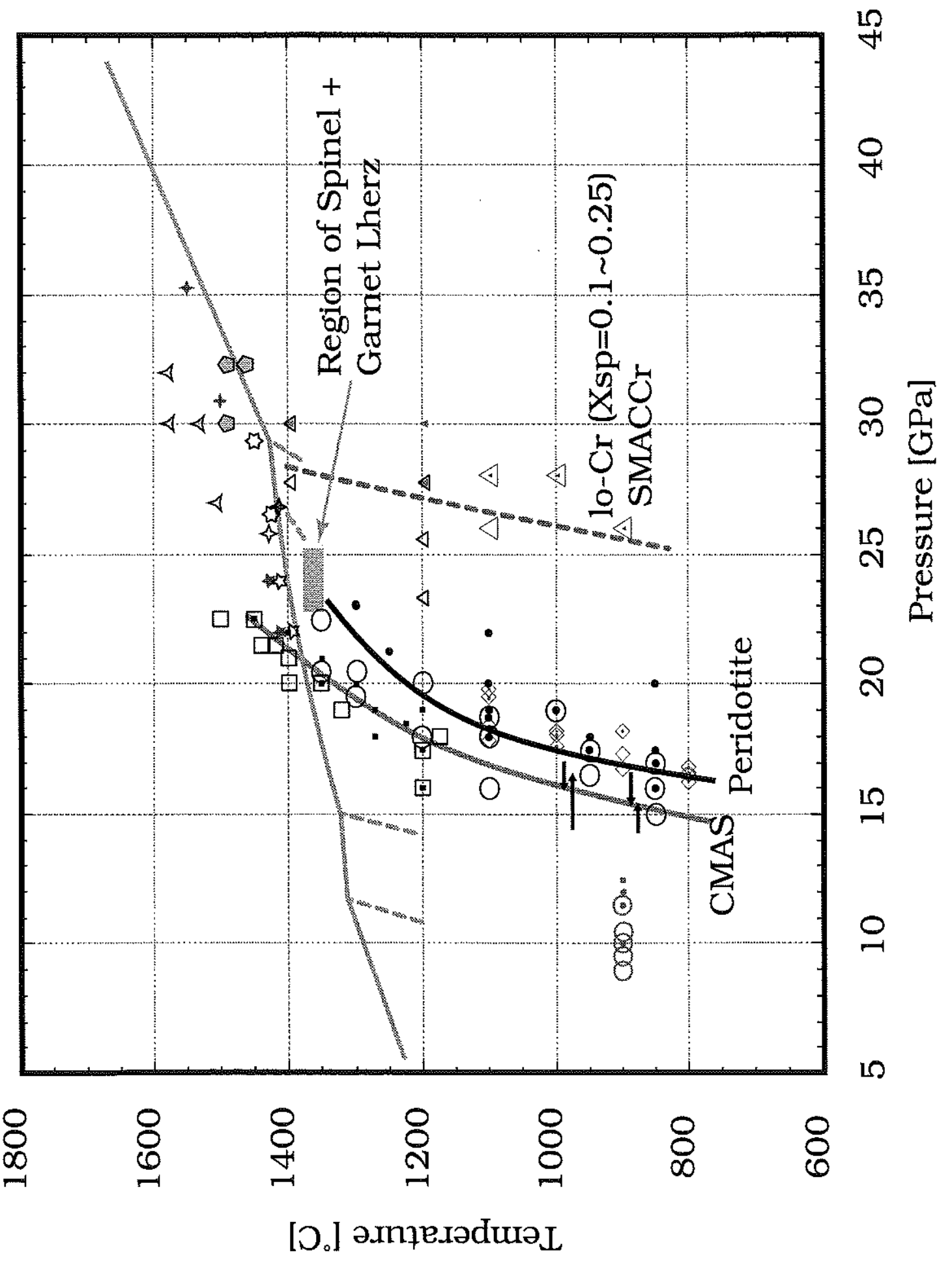




\section{Chapter Five}

\section{Where Do Trace Elements Go, After The Garnet-Spinel Facies Transformation?}

\section{Abstract}

This study reports results obtained by petrologic experiments, trace element measurements on natural rocks, and a diffusion model for subsolidus equilibration. Experiments show the existence of processes that can create disequilibrium trace element distribution among coexisting minerals. Observations of mantle rocks from Lashaine, Tanzania, and the Ronda massif, Spain, indicate the occurrence of a process that leads to disequilibrium trace element distributions as predicted by the experiments. A diffusion model quantifies time scales in which trace element disequilibrium occurs and shows their potential use in modeling time scales of mantle upwelling.

During upwelling, garnet + olivine break down to form orthopyroxene (opx) + clinopyroxene (cpx) + spinel, and it was found that the trace element distributions between opx and cpx are not in equilibrium. Experiments have shown that reaction products (cpx and opx) can achieve major element equilibrium without attaining equilibrium trace element distribution (chapter 4; Koga et al., 1999). In peridotite xenoliths from Lashaine, rare earth element (REE) abundances in cpx, opx and garnet that occur in the garnet breakdown reaction zone are found to be indistinguishable. In contrast, a garnet-websterite from Ronda for which upwelling is expected to have occurred at much slower rates than Lashaine, trace elements in cpx are strongly zoned while opx composition is uniform. The garnet breakdown reaction is found to be instantaneous on geological time scale (chapter 4). Redistribution of trace elements lagged behind and did not reach equilibrium. When the garnet-breakdown reaction is limited by diffusions, differences in diffusivity between major and trace element can also create 
disequilibrium distribution. Once a disequilibrium distribution of trace elements is established, subsequent equilibration can be modeled by diffusive exchange process between cpx and opx. Trace element disequilibrium distribution can persist for time scales ranging from 100 thousand to 1 million years, depending on the size of grains.

\section{Introduction}

Information on trace element abundances in mantle mineral phases within the melting source region is important for determining melt compositions and mechanisms of melting/melt extraction processes beneath mid ocean ridges (e.g., Johnson et al., 1990; Shimizu, 1998). Equilibrium partitioning of trace elements among minerals and melts, and assumptions about styles of melting/melt extraction processes play essential roles in modeling mantle melting. Also important are source mineralogy and melting reactions, which are approximately a function of pressure. Furthermore, mineral-melt partition coefficients are also variable with P, T, and compositions (e.g., Gaetani and Grove, 1995; Wood and Blundy, 1997).

When small melt fractions are efficiently extracted from residues as soon as they form (fractional melting), equilibrium relationships between melt and residual minerals may be severed due to slow diffusion of trace elements in minerals. Indeed, recent determinations of trace element diffusivities in clinopyroxene and garnet suggest that trace element abundances in melt generated from mantle phases may not necessarily be in equilibrium with the mantle residues and significant decoupling could develop between major and trace element chemistry (Van Orman et al., 1998).

This study investigates trace element redistribution associated with the garnet-spinel facies transformation,

Garnet + Olivine $=$ Orthopyroxene $(\mathrm{opx})+$ Clinopyroxene $(\mathrm{cpx})+$ Spinel

Equation 5.1

When upwelling mantle crosses the reaction boundary from the garnet to the spinel facies assemblage, trace elements residing in garnet have to be redistributed among the product phases. Indeed, heavy rare earth element enriched opx that mimics the garnet-like REE pattern has been reported in pyroxenites from Zabargad (Vannucci et al., 1993). If the mantle begins to melt immediately after the transition, the result of this trace element redistribution may exert major influence on the initial condition for melting models. This 
study reports trace element patterns measured in experimental run products of the garnet breakdown reaction. Comparisons are made with those observed in garnet-breakdown reaction products in natural rocks from Lashaine, Tanzania and the Ronda Massif, Spain. A semi-quantitative forward model confirms the persistence of disequilibrium observed in Lashaine and Ronda. The model can also be used to estimate the time scale of the reequilibration process and has potential for an applications in mantle geospeedometry.

\section{Procedures}

\section{Conditions of experiments}

Experiments were conducted at $1.8 \mathrm{GPa} 1360^{\circ} \mathrm{C}$; where garnet break down reaction was promoted. At this pressure, pyroxenes grew large enough $(\sim 20 \mu \mathrm{m})$ for ion probe measurements, but at higher pressures, crystals were too simall. Thus, trace element distributions at conditions near the garnet break-down reaction boundary could not be measured. Experimental run durations varied from 10 to 157 hours.

\section{Starting material}

A coarse granular garnet lherzolite xenolith (TM-0) from Pali Aike, Chile was used as a source for the starting mineral. This locale is known for the rare occurrence of garnet lherzolite in basalt and the relatively fertile composition of this peridotite resembles the possible primary mantle composition (Stern et al., 1989). Each mineral phase was magnetically separated from crushed specimen and was then carefully picked under a binocular microscope. Picked minerals were cleaned re-mixed and ground to $<100 \mu \mathrm{m}$ size. 1:1 garnet to olivine mix was used for most experiments. Crushed cpx was added in some experiments as a separate layer to promote reaction. Mineral compositions are shown in Table 5.1. Based on the geothermobarometry, the primary mineral assemblage was equilibrated at $4.0 \mathrm{GPa}, 1020^{\circ} \mathrm{C}$.

\section{High pressure-temperature apparatus}

High pressure-temperature experiments were conducted using a piston cylinder apparatus (Boyd and England, 1960) to promote reaction from a garnet-olivine starting assemblage. Starting material was packed into a graphite capsule, which was then sealed into a Pt capsule. Pressed $\mathrm{BaCO}_{3}$ was used as pressure transmitting medium, and a graphite sleeve was used as a heater. The temperature of the charge was monitored at $\sim 2 \mathrm{~mm}$ above the 
sample by a $\mathrm{W}_{97} \mathrm{Re}_{3}-\mathrm{W}_{75} \mathrm{Re}_{25}$ thermocouple and temperature was dynamically controlled. The thermocouple did not visibly degrade during the experiments, except for slight discoloration. A good contact of thermocouple was confirmed on some of the experimental charges. Oil pressure was monitored by a gauge to determine sample pressure and was calibrated against known reaction points (Appendix I). There was no "friction" correction to sample pressure and sample temperature was $\sim 20^{\circ} \mathrm{C}$ hotter than at the location of the thermocouple.

\section{Ion probe analysis}

The Cameca 3 f ion probe at Woods Hole Oceanographic Institution was used for measuring trace element abundances in minerals in rocks and experiments. Conditions used are: $\sim 8 \mathrm{kV}$ primary beam acceleration with $4500 \mathrm{~V}$ secondary acceleration with $-90 \mathrm{~V}$ energy offset using $\pm 10 \mathrm{~V}$ window. A $150 \mu \mathrm{m}$ contrast aperture with a $150 \mu \mathrm{m}$ field aperture were used for the secondary beam optics. Element concentrations were determined by empirical working curves using Si-normalized trace element intensities obtained in five consecutive cycles of measurements with 40 seconds count accumulation time for each element (Shimizu and Hart, 1982).

Secondary ion images were used to locate and identify mineral phases present, and the beam was shaped and focused accordingly for trace element analysis. This method allows delicate adjustments of beam size to be aimed at individual crystals, and is especially useful for analysis of small grains in experimental charges and thin sections.

Uncertainties of trace element analysis are derived from counting statistics. In this study, they range from 18 to $15 \%$ relative for Ce and $\mathrm{Sm}$ and 10 to $5 \%$ relative for $\mathrm{Dy}$ and $\mathrm{Yb}$.

\section{Experiments}

\section{Measurements on experiments}

REE abundances and major element compositions were measured in the products of the garnet break-down reaction. For the starting material, TM-0, the average major element composition for each mineral (Chapter 4) are listed on Table 5.1a, and trace element abundances for cpx and garnet are listed Table 5.1b. Trace element abundances for pyroxenes that are products of reaction are shown in Table 5.2b, while major elements are shown in Table 5.2a. Figure 5.1 is a spidergram showing $\mathrm{C} 1$ chondrite (Anders and Grevesse, 1989) normalized REE abundances. It was found that chondrite-normalized 
REE abundances in opx and cpx were similar to the reactant garnet, which is strongly light-REE depleted. Figure 5.2 shows the general texture of the breakdown reaction. Spinel grows within pyroxenes while opx appears on the interface of garnet and olivine (also see chapter 4).

\section{Garnet break-down reaction in experiments}

A comparison of the experimental results (Table 5.2) to partition coefficients (Table 5.3) clearly shows that product pyroxenes are out of equilibrium with reactant garnet (Figure 5.1) and with each other. The most striking observation is that heavy REE (Yb and Er) and $Y$ concentrations of product pyroxenes (both cpx and opx) are very high (Table 5.2) and closely resemble those of reactant garnet (Table 5.1b). It appears that during breakdown, garnet acted completely passively without exerting any control over element partitioning. Furthermore, partition relationships between opx and cpx also appear to be completely out of equilibrium. In contract to the $\mathrm{cpx} / \mathrm{opx}$ partition coefficients found in the literature (ranging from 4 for heavy REE to 98 for light REE), abundances of REE in both phases overlap without showing any systematic trends from LREE to HREE. Additionally, REE abundances in pyroxenes do not show systematic changes with respect to time from 10 to 157 hours.

These disequilibrium distributions of trace elements are in strong contrast to the behavior of major elements discussed in the previous chapters. The distribution of major elements was in accord with that for equilibrium predicted from experimentally calibrated geothermometers (Table 5.2). This confirms achievement of equilibration of major elements among product cpx and opx. These thermometers are principally based on the Fe-Mgm Ca exchange reaction, but the solution model used for temperature calculations requires corrections due to jadeite and $\mathrm{Ca}$-Tschermak's components, and thus involves "slow diffusing" elements such as $\mathrm{Al}_{2} \mathrm{O}_{3}$ and $\mathrm{SiO}_{2}$.

The present results thus document significant decoupling of trace elements from major elements in terms of distribution during the breakdown reaction. It appears that incorporation of trace elements into growing product pyroxenes did not involve intermineral partitioning. 


\section{Rocks}

This study also reports trace element abundances measured in two peridotite xenoliths from Lashaine, Tanzania and one pyroxenite from the Ronda peridotite massif, Spain in which petrographic evidence for garnet-break down reaction exists.

\section{Lashaine peridotites}

Lashaine volcano is located in Northern Tanzania in the East African Rift. Garnet peridotites and other xenoliths are found in Neogene ankaramite scoria and carbonatite tuffs. Sample BD730 (garnet lherzolite) yield equilibration conditions of primary mineral assemblage around $4.0 \mathrm{GPa}, 1000^{\circ} \mathrm{C}$ ( $\mathrm{T}$ using cpx/opx Fe-Mg exchange , $\mathrm{P}$ using cpx/opx Ca exchange, Brey and Köhler, 1990); Reid et al. (1975) reported 5.0 GPa, $1050^{\circ} \mathrm{C}$ (inferred from mineral composition reported in experiments, Boyd, 1970).

A garnet lherzolite (BD730) and a garnet harzburgite (BD796) contain garnets with reaction zones around them. The reaction coronas consist primarily of opx, cpx and spinel and opx and cpx were analyzed for trace element abundances. Reid and Dawson (1972) described mineral assemblages of reaction rims and their textual relationship to garnet and concluded that the coronas were the product of garnet breakdown reaction.

Trace element abundances in cpx and opx in the reaction zone (e.g. Figure 5.3) were carefully measured by adjusting the beam size and location for each analysis. Figure 5.4 shows textures of reaction zones and locations of trace element analyses. Trace element data are summarized in Table 5.4b. Representative major element composition are also reported in Table 5.4a (Reid et al., 1975).

\section{Lashaine garnet lherzolite (BD730)}

Figure 5.5 shows REE patterns for the garnet lherzolite. Reactant garnet shows light REE depleted pattern while reactant cpx pattern crosses that of garnet at middle REE. REE abundances in product opx are variable and "envelope" those of the reactant garnet. Light REE are more variable (0.3 3.1 chondrite for $\mathrm{Ce}$ in opx while 0.3 for garnet) than heavy REE (2.4 7.5 chondrite for $\mathrm{Yb}$ while 7 for garnet); heavy REE contacts are similar to those of garnet. REE abundances of cpx are generally slightly more enriched than opx with moderate light REE depletion. REE patterns in cpx appear less fractionated (flat) than those of opx and REE vary less (2 6.8 chondrite for $\mathrm{Ce}$ and $6 \sim 10$ chondrite for $\mathrm{Yb}$ ). The difference in REE patterns between cpx in reaction zone and primary cpx, 
particularly that of middle to heavy REE, as well as light REE depletion suggest that cpx in the reaction zone is indeed a product of the garnet break-down reaction.

Due to the resolution of the ion beam $(\sim 20 \mu \mathrm{m})$, core to rim zoning in a crystal within the reaction zone could not be determined. Reid (1972) reported compositional variations over a distance of $\sim 70 \mu \mathrm{m}$ within an optically-continuous, coarse grain. Ion probe analyses were not attempted along the comparison of the compositional traverse determined by electron probe.

In this specimen, a disequilibrium distribution of REE for the cpx-opx pair is clear. Their REE abundances overlap, while the opx are very similar to garnet in composition, and "inheritance" of REE from the reactant garnet is evident. Variations in REE abundances opx shown in Figure 5.5 and Figure 5.6, could be due to zoning in crystals. The fact that product cpx and opx differ more strongly for LREE suggests an early stage of reequilibration.

\section{Lashaine garnet harzburgite (BD796)}

Garnet harzburgite also has reaction rims similar to the lherzolite. The rim consists of garnet break-down reaction products. Figure 5.6 shows REE patterns for the garnet harzburgite. Reactant garnet shows a peculiar pattern with light REE enrichment relative to middle REE. Opx REE abundances are variable and generally similar to garnet in heavy to middle REE whereas its light REE are depleted relative to garnet. REE abundances in cpx are variable and more enriched than opx and the pattern is relatively flat. A comparison of data for the two xenoliths suggests that opx-cpx in the harzburgite is closer to equilibrium than opx-cpx in the lherzolite.

Differences in the extent of equilibration between harzburgite and lherzolite should be noted since they likely came from the same lithospheric mantle. If these rocks crossed the garnet breakdown reactions at the same condition, and the same time, the extent of reequilibration should be similar. Considering that the harzburgite seems to have equilibrated more, it may have crossed the breakdown condition before the lherzolite resulting in a longer residence time after the breakdown. If this was the case, the size of the reaction rim should be notably larger for harzburgite than lherzolite. However, quantification the size of rim is relatively difficult in thin section, and was not attempted. 


\section{The Ronda Massif}

The Ronda peridotite massif is a piece of obducted mantle with a complex history associated with melting/upwelling/metasomatism. Van der Wal and Reinoud (1993) describe the massif as a representation of a mantle wedge metasomatized by a subductionrelated metasomatic process. Initially, Cretaceous subduction led to cooling of the massif. Following the cessation of subduction, the slab was detached and subsequent tectonic extension was accompanied by uplifting during the Oligocene. The peridotite reached crustal levels during the Miocene.

One of the four types of mafic rocks in Ronda is spinel websterite with garnet. This type of coarse granular websterite shows textural association of the spinel-pyroxenes assemblage and garnet. It is believed that during uplift from depths perhaps exceeding $\sim 100 \mathrm{~km}$, the massif crossed the boundary of garnet stability and garnet breakdown occurred.

\section{$\underline{\text { Ronda websterite }}$}

A garnet websterite (RO-324) was analyzed for trace elements (Table 5.5), since the rock shows textural relationships indicative of the garnet breakdown reaction. Opx, cpx and spinel form coarse granular clusters around garnet forming a reaction zone(Figure 5.7). Opx grains are larger than cpx. Garnet in the rock has transformed to kelyphitic aggregates that show $\sim 1 \mathrm{~cm}$ banding texture. Plagioclase is also found in the rock. Trace element data are summarized in Table 5.5, and some locations of ion probe analyses are indicated (Figure 5.7). Figure 5.8 shows chondrite-normalized REE patterns.

REE abundances in opx appear to form two groups; one represented by a thick solid and dashed lines with low LREE (La and $\mathrm{Ce}<0.1 \mathrm{x} 1$ ) and high HREE ( $\mathrm{Yb} \sim 10 \mathrm{xC} 1$ ), and the other by dotted lines with low LREE ( $\mathrm{La}$ and $\mathrm{Ce}<0.1 \mathrm{x} \mathrm{C}$ ) and low HREE $(\mathrm{Yb} \leq 1 \mathrm{xC} 1$ ). Considering the large analytical uncertainties associated with $\mathrm{La}$ and Ce concentrations below 0.1 times $\mathrm{C}$, these two groups share the same LREE abundances, whereas HREE contents are different by a factor of 10 . There do not appear to be intra-grain variations, however. In contrast, REE abundances in cpx vary both within a crystal and between crystals. LREE abundances are the same throughout the crystal and between crystals, while HREE vary from $2 \mathrm{x}$ to $120 \mathrm{x}$ chondrite. HREE depleted cpx patterns cross those of HREE opx (Figure 5.8). 
The crossing of chondrite normalized REE patterns is evidence for a disequilibrium relationship between opx and cpx (Figure 5.8). In contrast, LREE distribution between opx and cpx is near equilibrium. The observed REE patterns and their variations in these minerals can be interpreted as follows. (1) HREE-depleted cpx may represent original $\mathrm{cpx}$ that is in equilibrium with the original garnet. This type of cpx is found in the area outside of the reaction zone in a same thin section. (2) HREE depleted opx (dotted lines) are near equilibrium (cpx/opx is $2 \sim 10$ for $\mathrm{Yb}$ and 20 100 for La) with the HREE-depleted cpx and may be original opx. (3) The REE abundance of HREE-enriched opx is inconsistent with inherited garnet that is predicted from the original cpx (thick dotted line crossing cpx). The REE pattern suggests that the opx is in the process of re-equilibration. (4) HREE enriched cpx and HREE enriched opx are in the process towards equilibrium at lower temperature (cpx/opx $>10$ for $\mathrm{Yb}$ and $>20$ for $\mathrm{La}$ ).

\section{A Forward Model}

A simple diffusive equilibration model was derived to illustrate reequilibration between opx and cpx in the context of upwelling mantle that has crossed the garnet-spinel facies transformation boundary and completed the garnet break-down reaction (Figure 5.9). The model simulates reequilibration across an opx-cpx interface using a one-dimensional geometry. The starting point of the model is the assumption that pyroxenes inherited the REE abundances from garnet and had identical composition across the interface. With time, element exchange at the interface increased REE in cpx while depleting them in opx. This initiated diffusive concentration profiles in the pyroxenes. The boundary conditions used here may not apply to all natural setting, but the results of the model provide qualitative understanding of the process of equilibration and the approximate time duration required to reach equilibrium.

From Fick's law, diffusion process in one-dimension can be expressed as a partial differential equation,

$$
\frac{\partial C}{\partial t}=\frac{\partial}{\partial x}\left(D(t, x) \frac{\partial C}{\partial x}\right)
$$

Equation 5.2

For a simple geometry, solution of above equation is analytically determined. Diffusion coefficient changes with time and space from opx to cpx. It is because the model considers mantle upwelling where pressure and temperature changes with time, so does 
diffusivity. Furthermore, since diffusion in opx is approximately a factor of ten slower than in cpx (Cherniak, personal communication), diffusion coefficients should be adjusted for each phase. An analytical solution considering these conditions is not easily available, and the finite difference numerical method of Crank-Nicholson implicit form is used to obtain solutions for the above equation.

The geometry of opx-cpx juxtaposing in one dimension requires three boundary conditions: at the interface of two phases and at the ends of two phases. A no flux boundary condition was taken at the ends of both phases. This means two finite thickness of slabs are put together for diffusive equilibration. Perhaps this may not be a bad geometry, since pyroxene contacts are often planar crystal faces in polycrystalline rocks. A finite length of diffusion also mimics the grain size of mantle minerals. At the opx-cpx interface, mass flux out of opx has to be balanced with mass flux into cpx. In addition, partitioning of an element at the interface is satisfied. Analytical representation of previously described boundary conditions are,

$$
D_{C p x} \frac{\partial C_{C p x}}{\partial x}=-D_{O p x} \frac{\partial C_{o p x}}{\partial x}=-K_{D}^{C p x / o p x} D_{C p x} \frac{\partial C_{O p x}}{\partial x}
$$

Equation 5.3

The subscripts opx and cpx denote the value for each phase. $\mathrm{C}_{\mathrm{Opx}}$ is the concentration of an element within opx at the interface. $\mathrm{K}_{\mathrm{D}}$ is the partition coefficient between cpx and opx.

Abundances of trace elements in opx and cpx are the same at the beginning of the diffusion model (Figure 5.9). This initial condition reflects the consequence of the garnet break-down reaction shown by the experimental observation (Figure 5.1). Arrhenius parameters for diffusivities are reported by Van Orman et al. (1998). Temperatures and pressures of the model decrease along the adiabatic cooling.

\section{Results of the calculation}

The results of the calculation are shown in Figure 5.10a,b. Spatial distributions of REE normalized to the initial concentration are shown for each element. Each panel shows a snap shot of the concentration distribution, and each gray shading represents one element. The second set of figures shows REE diagram normalized to $\mathrm{C} 1$ chondrite in opx and cpx. Lines in each panel shows the time progression steps corresponding to the time shown (Figure 5.10c-f). Figure 5.10c, d represent REE spidergram in cpx and opx $6.5 \mathrm{~mm}$ away 
from the interface, as if cpx was sliced to expose the surface at the distance shown. At $6.5 \mu \mathrm{m}$, diffusion of heavy REE is fast enough to approach equilibrium while light REE

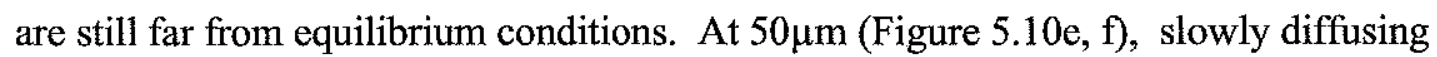
atoms have not moved and the resulting REE diagrams show more variations in HREE over time than the LREE. Decompression rate is $1200 \mathrm{~Pa} / \mathrm{yr}$ or a $\sim 40 \mathrm{~mm} / \mathrm{yr}$ upwelling rate. The model starts at the conditions $1000^{\circ} \mathrm{C}$ and $1.5 \mathrm{GPa}$, and no melting is considered. Results of the calculations are greatly influenced by the starting temperature of the model, which affects diffusivity. For example, when the starting temperature was $1200^{\circ} \mathrm{C}$, Figure $5.10 \mathrm{~b}$ can be taken to represent a snap-shot at 2.4 thousand years, or $750 \mathrm{k}$ years with the distance axis scaled to range from -2 to $2 \mathrm{~mm}$. The final equilibration distance could be substantially longer. When starting temperature is at $800^{\circ} \mathrm{C}$, Figure $5.10 \mathrm{~b}$ represents a snap-shot at two billion years, or $750 \mathrm{k}$ years with distance ranging from -2 to $2 \mu \mathrm{m}$.

\section{Extent of disequilibrium}

As the numerical model shows, disequilibrium can persist for significant lengths of time depending on the thermal history of a rock. The results show persistence of disequilibrium for $\mathrm{Yb}$ for up to two billion years depending on temperature $\left(800^{\circ} \mathrm{C}\right)$ and grain size $(100 \mu \mathrm{m}$-thick plate). Considering the uplifting rates and temperature history estimated for the MORB melting source, the product pyroxenes are highly likely to retain the disequilibrium for a long time.

Partial equilibration is another interesting observation drawn from the numerical models. The extent of equilibration depends on the cooling rate and initial temperature. REE patterns vary considerably with respect to the location in a crystal. When diffusion duration was too short for light REE to move, it would still be sufficient to move the heavy REE. In such a case, heavy REE variations are predicted with LREE unchanged. In contrast, for diffusion times long enough for light REE to move, heavy REE may attain equilibrium. In such cases, variable LREE are expected, whereas HREE can be uniform.

\section{Summary}

It has been shown that disequilibrium distribution of trace elements associated with the garnet breakdown reaction products indeed occurs over wide range of time scale: from laboratory experiments to processes associated with tectonic uplifting. Differences in 
diffusivities between major and trace elements can result in disequilibrium distribution of trace elements. The reequilibration process of the initial disequilibrium distribution is limited by solid-state diffusion thus the disequilibrium can persist for time scales of million years for mantle conditions.

The consequence of disequilibrium trace element distributions is not simple to predict but can exert significant influence on MORB trace element abundances. For models of MORB generation, the initial mineral composition that can be influenced by disequilibrium distribution and subsequent partial equilibration may significantly influence the composition of melt generated. It should be also noted that xenoliths from continental lithosphere often show the garnet breakdown reaction (e.g. Lashaine). The compositional zoning subsequent to the garnet breakdown reaction in minerals can help extracting information about the dynamic processes of the lithosphere.

\section{References}

Anders E. and Grevesse N. (1989) Abundances of the elements: Meteoritic and solar. Geochimica et Cosmochimica Acta 53, 197-214.

Andersen D. J., Lindsay D. H., and Davidson P. M. (1993) QUILF: A PASCAL program to assess equilibria among $\mathrm{Fe}-\mathrm{Mg}-\mathrm{Mn}-\mathrm{Ti}$ oxides, pyroxenes, olivnie, and quartz. Computers and Geosciences 19, 1333-1350.

Boyd F. R. and England J. L. (1960) Apparatus for phase-equilibrium measurements at pressures up to 50 Kilobars and temperatures to 1750 C. J. Geophys. Res. 65, 741-748.

Boyd F. R. (1970) Garnet peridotites and the system $\mathrm{CaSiO}_{3}-\mathrm{MgSiO}_{3}-\mathrm{Al}_{2} \mathrm{O}_{3}$. Mineral. Soc. Amer. Spec. Pap. 3, 63-75

Brey G. P. and Köhler T. (1990) Geothermobarometry in Four-phase Lherzolites II. New Thermobarometers, and Practical Assessment of Existing Thermobarometer. Journal of Petrology 31, 1353-1378.

Gaetani G. A. and Grove T. L. (1995) Partitioning of rare earth elements between clinopyroxene and silicate melt: Crystal-chemical controls. Geochimica et Cosmochimica Acta 59, 1951-1962.

Garrido C. J. and Bodinier J.-L. (submitted) Distribution of REE, LILE, and HFSE in anhydrous spinel peridotite and websterite minerals from the Ronda peridotite: Insights into nature of trace element reservoirs in the subcontinental lithospheric mantle. Earth and Planetary Science Letters.

Hart S. R. and Dunn T. (1993) Experimental cpx/melt partitioning of 24 trace elements. Contribution to Mineralogy and Petrology 113, 1-8.

Johnson K. M., Dick H., and Shimizu N. (1990) Melting in the Oceanic Upper Mantle: An Ion Microprobe Study of Diopside in Abyssal Peridotites. Journal of Geophysical Research 95, 2661-2678. 
Johnson K. T. M. (1998) Experimental determination of partiton coefficients for rare earth and high-field-strength elements between clinopyroxene, garnet, and basaltic melt at high pressures. Contributions to Mineralogy and Petrology 133, 60-68.

Kelemen P. B., Shimizu N., and Dunn T. (1993) Relative depletion of niobium in some arc magmas and the continetal crust: partitioning of $\mathrm{K}, \mathrm{Nb}$, La and Ce during melt/rock reaction in the upper mantle. Earth and Planetary Science Letters 120, 111-134.

Koga K., Shimizu N., and Grove T. (1999) Disequilibrium Trace Element Redistribution During Garnet to Spinel Facies Transformation. Proceedings of 7 th International Kimberlite Conference.

Reid A. M. and Dawson J. B. (1972) Olivine-garnet reaction in peridotite from Tanzania. Lithos 5, 115-124.

Reid A. M., Donaldson C. H., Brown R. W., Ridley W. I., and Dawson J. B. (1975) Mineral chemistry of peridotite xenoliths from the Lashaine volcano, Tanzania. Physics and Chemistry of the Earth 9, 525-543.

Shimizu N. (1998) The geochemistry of olivine-hosted melt inclusions in FAMOUS basalt ALV519-4-1. Physics of the Earth and Planetary Interiors 107, 183-201.

Shimizu N. and Hart S. R. (1982) Application of the Ion Microprobe to Geochemistry and Cosmochemistry. Annual Review of Earth and Planetary Science 10, 483-526.

Shimizu N., Pokhilenko F. R., Boyd F. R., and Pearson D. G. (1997) Geochemical characteristics of mantle xenoliths from the Udachnaya kimberlite pipe. Russian Geology and Geophysics 38, 205-217.

Stern C. R., Saul S., Skewes M. A., and Futa K. (1989) Garnet peridotite xenoliths from the Pali-Aike alkali basalts of southernmost South America. Fourth International Kimberlite Conference, 735-744.

Van der Wal D. and Reinoud L. M. V. (1993) Uplift and emplacement of upper mantle rocks in the western Mediterranean. Geology 21, 1119-1122.

Van Orman J. A., Shimizu N., and Grove T. L. (1998) Rare earth element diffusion in diopside and disequilibrium melting in the mantle. EOS. Transactions, S371.

Vannucci R., Shimizu N., Piccardo G. B., Ottolini L., and Bottazzi P. (1993) Distribution of trace elements during breakdown of mantle garnet: an example from Zabargad. Contributions to Mineralogy and Petrology 113, 437-449.

Wood B. J. and Blundy J. D. (1997) A predictive model for rare earth element partitioning between clinopyroxene and anhydrous silicate melt. Contributions to Mineralogy and Petrology 129, 166-181. 


\section{Tables}

Table 5.1a: TM-0 Garnet lherzolite, primary mineral compositions equilibrated at $1020^{\circ} \mathrm{C}$, 4.0 GPa using cpx-opx and opx-garnet geothermobarometer (Brey and Köhler, 1990).

\begin{tabular}{|c|c|c|c|c|c|c|c|c|c|}
\hline (wt\%) & Garnet(6 & $2 \sigma$ & $\mathrm{CPX}(13)$ & $2 \sigma$ & OPX(17) & $2 \sigma$ & Olivine(16) & $2 \sigma$ & Bulk \\
\hline Mode & 12 & & 13 & & 21 & & 54 & & 100 \\
\hline $\mathrm{SiO}_{2}$ & 42.40 & 0.20 & 53.20 & 0.60 & 56.10 & 0.50 & 40.50 & 0.30 & 45.66 \\
\hline $\mathrm{TiO}_{2}$ & 0.16 & 0.04 & 0.57 & 0.06 & 0.15 & 0.06 & 0.00 & 0.00 & 0.12 \\
\hline $\mathrm{Al}_{2} \mathrm{O}_{3}$ & 23.70 & 0.30 & 5.62 & 0.30 & 3.40 & 0.13 & 0.00 & 0.00 & 4.29 \\
\hline $\mathrm{Cr}_{2} \mathrm{O}_{3}$ & 1.06 & 0.05 & 1.07 & 0.20 & 0.42 & 0.06 & 0.06 & 0.05 & 0.39 \\
\hline $\mathrm{FeO}$ & 8.14 & 0.08 & 3.12 & 0.11 & 6.32 & 0.23 & 9.98 & 0.22 & 8.10 \\
\hline $\mathrm{MgO}$ & 20.70 & 0.20 & 15.60 & 0.30 & 33.90 & 0.40 & 49.30 & 0.30 & 38.25 \\
\hline $\mathrm{MnO}$ & 0.31 & 0.06 & 0.07 & 0.06 & 0.11 & 0.05 & 0.11 & 0.06 & 0.13 \\
\hline $\mathrm{CaO}$ & 4.74 & 0.15 & 19.20 & 0.40 & 0.66 & 0.05 & 0.00 & 0.00 & 3.20 \\
\hline $\mathrm{Na}_{2} \mathrm{O}$ & & & 2.11 & 0.13 & 0.14 & 0.04 & & & 0.30 \\
\hline $\mathrm{NiO}$ & & & & & & & 0.42 & 0.05 & 0.23 \\
\hline Total & 101.21 & & 100.56 & & 101.20 & & 100.37 & & 100.67 \\
\hline
\end{tabular}

Table 5.1b: TM-0 Garnet lherzolite, REE abundance in garnet and cpx normalized by C1 chondrite (Anders and Grevesse, 1989).

\begin{tabular}{lrrrrr} 
& C1(ppm) & Garnet(12) & \multicolumn{1}{c}{$\sigma$} & Cpx $(8)$ & $\sigma$ \\
\hline $\mathrm{La}$ & 0.2347 & 0.12 & 0.05 & 3.61 & 1.67 \\
$\mathrm{Ce}$ & 0.6032 & 0.08 & 0.03 & 3.72 & 1.50 \\
$\mathrm{Nd}$ & 0.4524 & 0.73 & 0.53 & 4.28 & 2.00 \\
$\mathrm{Sm}$ & 0.1471 & 3.27 & 2.44 & 5.06 & 1.79 \\
$\mathrm{Eu}$ & 0.0560 & 4.19 & 2.50 & 5.82 & 2.05 \\
$\mathrm{Dy}$ & 0.2427 & 10.72 & 8.04 & 1.70 & 0.79 \\
$\mathrm{Er}$ & 0.1589 & 15.70 & 14.78 & 1.20 & 0.56 \\
$\mathrm{Yb}$ & 0.1625 & 23.36 & 13.67 & 1.28 & 0.49 \\
\hline $\mathrm{Ti}$ & 436.00 & 2.02 & 0.28 & 7.55 & 0.84 \\
$\mathrm{~V}$ & 56.50 & 2.82 & 0.37 & 6.21 & 0.75 \\
$\mathrm{Cr}$ & 2660.00 & 2.80 & 0.49 & 2.93 & 0.68 \\
$\mathrm{Sr}$ & 7.80 & 0.09 & 0.05 & 11.91 & 2.92 \\
$\mathrm{Y}$ & 1.56 & 38.33 & 12.81 & 2.47 & 0.49 \\
$\mathrm{Zr}$ & 3.94 & 9.62 & 3.36 & 9.20 & 2.30 \\
\hline
\end{tabular}


Table 5.2a: Major element compositions of reaction products in experiments. Using reported composition, equilibrium was tested by geothermometers (Andersen et al., 1993;

Brey and Köhler, 1990). Run conditions of experiments are also reported. 


\begin{tabular}{|c|c|c|c|c|c|c|}
\hline & \multicolumn{2}{|l|}{ BPC129 } & \multicolumn{2}{|l|}{ BPC135 } & \multicolumn{2}{|l|}{ BPC156 } \\
\hline Mineral(n) & $\mathrm{Opx}(8)$ & & Opx $(24)$ & & $\mathrm{Opx}(8)$ & \\
\hline $\mathrm{SiO}_{2}$ & 52.55 & 1.02 & 51.30 & 0.62 & 51.70 & 0.41 \\
\hline $\mathrm{TiO}_{2}$ & 0.08 & 0.02 & 0.12 & 0.03 & 0.07 & 0.02 \\
\hline $\mathrm{Al}_{2} \mathrm{O}_{3}$ & 7.94 & 1.09 & 8.76 & 0.94 & 8.53 & 0.37 \\
\hline $\mathrm{Cr}_{2} \mathrm{O}_{3}$ & 0.27 & 0.05 & 0.34 & 0.03 & 0.23 & 0.04 \\
\hline $\mathrm{FeO}$ & 7.20 & 0.07 & 7.61 & 0.16 & 7.72 & 0.13 \\
\hline $\mathrm{MnO}$ & 0.25 & 0.02 & 0.28 & 0.04 & 0.27 & 0.02 \\
\hline $\mathrm{MgO}$ & 28.58 & 0.57 & 28.42 & 0.45 & 28.34 & 0.26 \\
\hline $\mathrm{CaO}$ & 2.23 & 0.18 & 2.19 & 0.13 & 2.23 & 0.16 \\
\hline $\mathrm{Na}_{2} \mathrm{O}$ & 0.06 & 0.03 & 0.09 & 0.04 & 0.02 & 0.02 \\
\hline \multicolumn{7}{|l|}{$\mathrm{NiO}$} \\
\hline Total & 99.17 & 0.53 & 99.11 & 0.35 & 99.12 & 0.42 \\
\hline $\operatorname{Mineral}(n)$ & \multicolumn{2}{|l|}{$\mathrm{Cpx}(8)$} & \multicolumn{2}{|l|}{$\mathrm{Cpx}(24)$} & \multicolumn{2}{|l|}{$\mathrm{Cpx}(6)$} \\
\hline $\mathrm{SiO}_{2}$ & 51.83 & 0.94 & 50.42 & 0.85 & 50.09 & 0.31 \\
\hline $\mathrm{TiO}_{2}$ & 0.22 & 0.14 & 0.20 & 0.04 & 0.19 & 0.02 \\
\hline $\mathrm{Al}_{2} \mathrm{O}_{3}$ & 7.90 & 1.46 & 8.60 & 0.89 & 9.15 & 0.15 \\
\hline $\mathrm{Cr}_{2} \mathrm{O}_{3}$ & 0.54 & 0.30 & 0.37 & 0.05 & 0.32 & 0.03 \\
\hline $\mathrm{FeO}$ & 5.23 & 0.94 & 6.24 & 0.21 & 5.69 & 0.11 \\
\hline $\mathrm{MnO}$ & 0.23 & 0.07 & 0.31 & 0.04 & 0.30 & 0.02 \\
\hline $\mathrm{MgO}$ & 20.35 & 2.52 & 20.64 & 0.84 & 18.91 & 0.19 \\
\hline $\mathrm{CaO}$ & 13.42 & 3.34 & 11.58 & 0.92 & 14.78 & 0.14 \\
\hline $\mathrm{Na}_{2} \mathrm{O}$ & 0.73 & 0.26 & 0.55 & 0.07 & 0.37 & 0.04 \\
\hline \multicolumn{7}{|l|}{$\mathrm{NiO}$} \\
\hline Total & 100.46 & 0.84 & 98.91 & 0.46 & 99.79 & 0.43 \\
\hline $\operatorname{Mineral}(\mathrm{n})$ & \multicolumn{2}{|l|}{$\mathrm{Sp}(14)$} & \multicolumn{2}{|l|}{$\mathrm{Sp}(5)$} & \multicolumn{2}{|l|}{$\mathrm{Sp}(5)$} \\
\hline $\mathrm{SiO}_{2}$ & 0.20 & 0.39 & 0.00 & 0.00 & 0.84 & 0.22 \\
\hline $\mathrm{TiO}_{2}$ & 0.12 & 0.03 & 0.06 & 0.01 & 0.06 & 0.02 \\
\hline $\mathrm{Al}_{2} \mathrm{O}_{3}$ & 64.57 & 0.68 & 64.78 & 0.34 & 63.11 & 0.29 \\
\hline $\mathrm{Cr}_{2} \mathrm{O}_{3}$ & 3.61 & 0.15 & 4.06 & 0.14 & 3.21 & 0.12 \\
\hline $\mathrm{FeO}$ & 10.15 & 0.12 & 9.45 & 0.13 & 9.99 & 0.10 \\
\hline $\mathrm{MnO}$ & 0.17 & 0.03 & 0.16 & 0.02 & 0.15 & 0.03 \\
\hline $\mathrm{MgO}$ & 21.85 & 0.13 & 22.39 & 0.13 & 23.32 & 0.17 \\
\hline $\mathrm{CaO}$ & 0.08 & 0.07 & 0.06 & 0.01 & 0.14 & 0.05 \\
\hline \multicolumn{7}{|l|}{$\mathrm{Na}_{2} \mathrm{O}$} \\
\hline $\mathrm{NiO}$ & 0.10 & 0.03 & 0.08 & 0.03 & 0.15 & 0.05 \\
\hline Total & 100.85 & 0.57 & 101.04 & 0.67 & 100.97 & 0.59 \\
\hline $\mathrm{T}\left[{ }^{\circ} \mathrm{C}\right]$ & \multicolumn{2}{|l|}{1360} & \multicolumn{2}{|l|}{1360} & \multicolumn{2}{|l|}{1360} \\
\hline $\mathrm{P}[\mathrm{GPa}]$ & \multicolumn{2}{|l|}{1.8} & \multicolumn{2}{|l|}{1.8} & \multicolumn{2}{|l|}{1.8} \\
\hline Diuration [h] & \multicolumn{2}{|l|}{10} & \multicolumn{2}{|l|}{52.5} & \multicolumn{2}{|l|}{157.4} \\
\hline QUILF & \multirow{3}{*}{\multicolumn{2}{|c|}{$1374 \pm 44$}} & \multirow{3}{*}{\multicolumn{2}{|c|}{$\begin{array}{l}1356 \pm 30 \\
1318 \pm 60 \\
\text { 122ட }\end{array}$}} & \multirow{3}{*}{\multicolumn{2}{|c|}{$1367 \pm 20$}} \\
\hline $\mathrm{Ca} \mathrm{Opx}$ & & & & & & \\
\hline riner anev & & & & & & \\
\hline
\end{tabular}


Table 5.2b: Trace element abundances in reaction products, opx and cpx, in experiments normalized by $\mathrm{C} 1$ chondrite

\begin{tabular}{cccccccc}
\hline & BPC 135 & \multicolumn{3}{c}{ BPC 129 } & BPC 156 & \\
Element & CPX3n & OPX8n & opx1 & opx2 & OPX1 & CPX2 & OPX3 \\
\hline La & 0.92 & & & & & & \\
$\mathrm{Ce}$ & 1.20 & & 0.67 & 0.79 & 0.36 & 0.71 & 0.57 \\
$\mathrm{Sr}$ & 0.72 & 2.10 & 0.78 & 1.59 & 0.30 & 0.59 & 0.62 \\
$\mathrm{Nd}$ & 3.58 & & 0.79 & 0.97 & 0.93 & 2.32 & 1.14 \\
$\mathrm{Sm}$ & 9.17 & & & & & & \\
$\mathrm{Zr}$ & 4.49 & 7.72 & 3.68 & 3.89 & 5.23 & 9.12 & 7.48 \\
$\mathrm{Eu}$ & 14.20 & & & & & & \\
$\mathrm{Ti}$ & 1.80 & 3.01 & 2.12 & 2.76 & 1.72 & 2.37 & 2.41 \\
$\mathrm{Dy}$ & 35.51 & & 6.04 & 14.80 & 11.45 & 31.94 & 11.00 \\
$\mathrm{Y}$ & 32.05 & 48.53 & 12.28 & 26.19 & & & \\
$\mathrm{Er}$ & 45.70 & & & & 18.29 & 50.29 & 29.87 \\
$\mathrm{Yb}$ & 58.87 & & 15.51 & 28.94 & 26.31 & 73.53 & 37.59 \\
\hline
\end{tabular}


Table 5.3: Selected mineral-mineral partition coefficients used in this study. Partition coefficient determined by experiments, are applicable for high temperature (near solidus) processes, distribution determined by natural rocks are applicable for low temperature (subsolidus) processes.

\begin{tabular}{|c|c|c|c|c|}
\hline & $\begin{array}{l}\text { Experimental D, } \\
\text { High Temperature }\end{array}$ & $\begin{array}{l}\text { Experimental D, } \\
\text { High Temperature }\end{array}$ & $\begin{array}{c}\text { Purple garnet } \\
25 / 91 \text { from } \\
\text { udachinaya kimb, } \\
735^{\circ} \mathrm{C}, 1.97 \mathrm{GPa}\end{array}$ & $\begin{array}{c}\text { Ronda Websetrite, } \\
\text { Low temperature } \\
800^{\circ} \mathrm{C}\end{array}$ \\
\hline & $\begin{array}{c}\text { Johnson (1998), } \\
\text { Hart and Dunn } \\
(1993)\end{array}$ & $\begin{array}{c}\text { Johnson (1998), } \\
\text { Kelemen et al. } \\
(1993)\end{array}$ & $\begin{array}{l}\text { Shimizu et al. } \\
\text { (1997) }\end{array}$ & $\begin{array}{c}\text { Garrido } \\
\text { (submitted) }\end{array}$ \\
\hline & CPX/Gar & $\mathrm{Cpx} / \mathrm{Opx}$ & $\mathrm{Cpx} / \mathrm{Gar}$ & $\mathrm{Cpx} / \mathrm{Opx}$ \\
\hline$\overline{\mathrm{La}}$ & 30.6 & 98.0 & 244. & 62.5 \\
\hline $\mathrm{Ce}$ & 14.0 & 77.8 & 57.2 & 83.3 \\
\hline $\mathrm{Nd}$ & 3.42 & 19.8 & 5.21 & 76.9 \\
\hline $\mathrm{Sm}$ & 1.17 & 14.7 & 1.34 & 45.5 \\
\hline Eu & 0.875 & 11.7 & 1.14 & 40.0 \\
\hline Dy & 0.173 & 6.33 & 0.364 & 16.7 \\
\hline Er & 0.108 & 5.53 & 0.185 & 10.0 \\
\hline $\mathrm{Yb}$ & 0.061 & 4.00 & 0.036 & 5.56 \\
\hline $\mathrm{Ti}$ & 1.17 & 4.15 & 1.37 & \\
\hline V & 0.816 & 5.08 & 0.961 & \\
\hline $\mathrm{Cr}$ & 0.422 & & 0.479 & \\
\hline $\mathrm{Sr}$ & 38.0 & 186. & 396. & 90.9 \\
\hline$Y$ & 0.133 & 42.9 & 0.212 & \\
\hline $\mathrm{Zr}$ & 0.441 & 36.1 & 1.00 & 10.0 \\
\hline
\end{tabular}


Table 5.4a: Major element compositions for primary phases in Lashaine peridotites, and their equilibrium pressure and temperature. 
BD 730

\begin{tabular}{rccccc} 
& $\begin{array}{c}\text { Cpx-opx, } \\
\text { Gt-Opx }\end{array}$ & $\begin{array}{c}\text { Ca in Opx, } \\
\text { Gt-Opx }\end{array}$ & $\begin{array}{c}\text { QUILF at } \\
4.2\end{array}$ & $\begin{array}{c}\text { QUILF at } \\
3.7\end{array}$ & \\
$\mathrm{~T}\left({ }^{\circ} \mathrm{C}\right)$ & 1080 & 994 & $1025 \pm 50$ & $1012 \pm 46$ & \\
$\mathrm{P} \mathrm{GPa}$ & 4.2 & 3.7 & 4.2 & 3.7 & \\
& & & & & \\
\hline$(\mathrm{wt} \%)$ & Garnet(10) & CPX(4) & OPX(7) & Olivine $(4 \mathrm{c})$ & Oliv(3r) \\
& & & & & \\
$\mathrm{SiO}_{2}$ & 41.60 & 54.40 & 57.70 & 40.60 & 40.30 \\
$\mathrm{TiO}_{2}$ & 0.07 & 0.10 & 0.04 & & \\
$\mathrm{Al}_{2} \mathrm{O}_{3}$ & 22.80 & 2.21 & 1.29 & & \\
$\mathrm{Cr}_{2} \mathrm{O}_{3}$ & 2.41 & 1.14 & 0.33 & & \\
$\mathrm{FeO}$ & 6.85 & 2.19 & 5.12 & 8.45 & 8.85 \\
$\mathrm{MnO}_{\mathrm{MgO}}$ & 0.25 & 0.00 & 0.00 & 0.00 & 0.00 \\
$\mathrm{CaO}$ & 20.70 & 17.60 & 35.30 & 49.40 & 49.20 \\
$\mathrm{Na}_{2} \mathrm{O}$ & 5.21 & 20.80 & 0.50 & 0.00 & 0.00 \\
$\mathrm{NiO}$ & 0.04 & 1.09 & 0.11 & & \\
$\mathrm{Total}$ & & & & 0.34 & 0.31 \\
& 99.93 & 99.53 & 100.39 & 98.79 & 98.66 \\
\hline
\end{tabular}

BD 796

$\begin{array}{rc} & \text { Ca in Opx } \\ \text { Gt-Opx } \\ \mathrm{T}\left({ }^{\circ} \mathrm{C}\right) & 987 \\ \mathrm{P} \mathrm{GPa} & 4.1\end{array}$

\begin{tabular}{cccccc}
\hline (wt\%) & Garnet(6c) & Garnet(1r) & OPX(5) & Olivine(5c) & Oliv(3r) \\
mode & \multicolumn{6}{c}{6.7} & \multicolumn{1}{c}{18} & & 72.6 & \\
$\mathrm{SiO}_{2}$ & 42.20 & 42.40 & 58.20 & 41.50 & 41.40 \\
$\mathrm{TiO}_{2}$ & 0.03 & 0.02 & 0.01 & & \\
$\mathrm{Al}_{2} \mathrm{O}_{3}$ & 21.90 & 22.00 & 1.04 & & \\
$\mathrm{Cr}_{2} \mathrm{O}_{3}$ & 3.53 & 3.54 & 0.35 & & \\
$\mathrm{FeO}$ & 6.33 & 6.40 & 4.42 & 7.61 & 7.73 \\
$\mathrm{MnO}$ & 0.32 & 0.32 & 0.09 & 0.11 & 0.11 \\
$\mathrm{MgO}$ & 21.60 & 21.40 & 36.60 & 50.70 & 50.40 \\
$\mathrm{CaO}$ & 4.63 & 4.54 & 0.45 & 0.04 & 0.04 \\
$\mathrm{Na} O$ & 0.02 & 0.02 & 0.08 & & \\
$\mathrm{NiO}$ & & & & 0.39 & 0.39 \\
$\mathrm{Total}$ & 100.56 & 100.64 & 101.24 & 100.35 & 100.07 \\
\hline
\end{tabular}


Table 5.4b: Trace element abundance in primary and reacted phases in Lashaine peridotites. $\mathrm{C} 1$ chondrite normalized. 


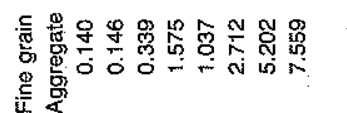

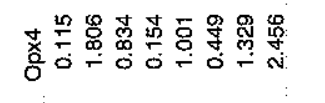

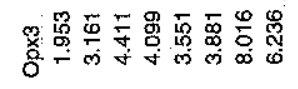

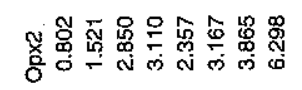

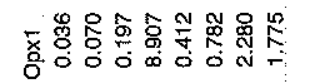

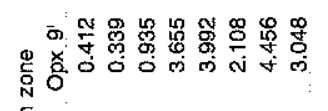

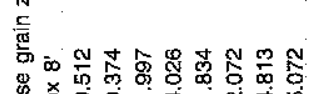

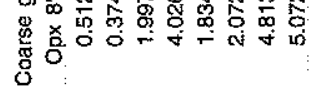

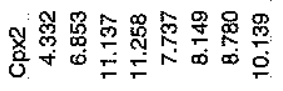

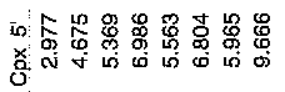

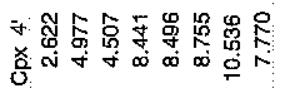

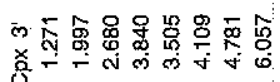

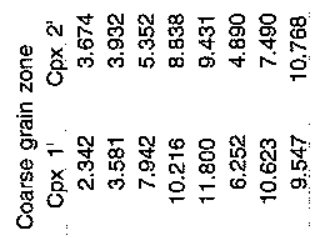

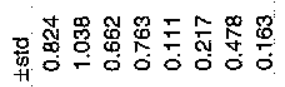

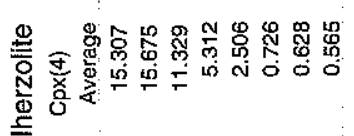

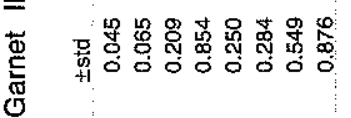

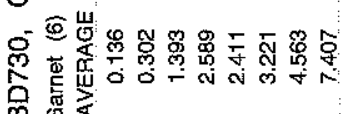

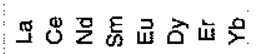

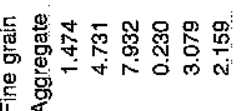

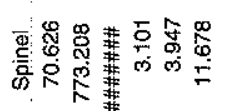

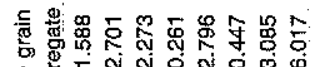

造要

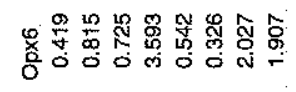

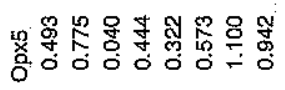

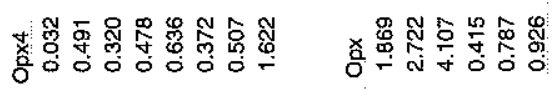

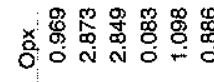

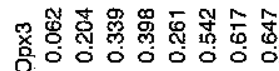

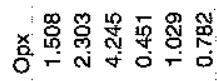

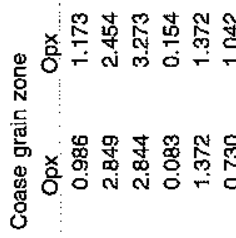

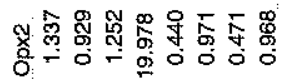

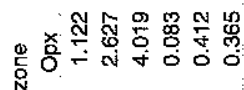

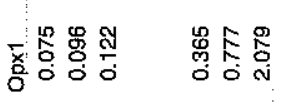

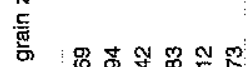

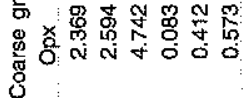

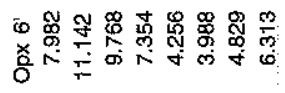

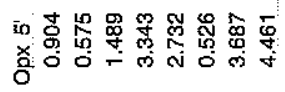

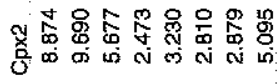

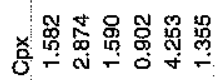

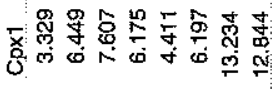

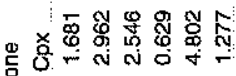

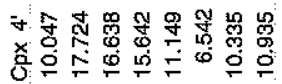

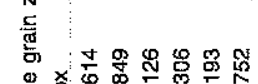

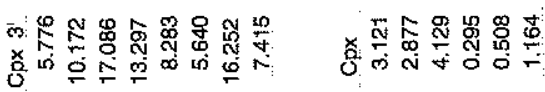

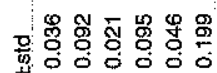

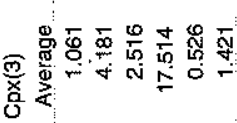

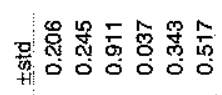

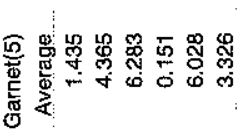

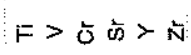

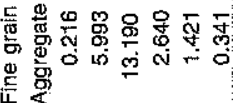


Table 5.5: Trace element abundances in pyroxenite (RO324), Ronda. 
RO-324 Garnet websterite, REE abundance in opx and cpx normalized by $\mathrm{C} 1$ chondrite

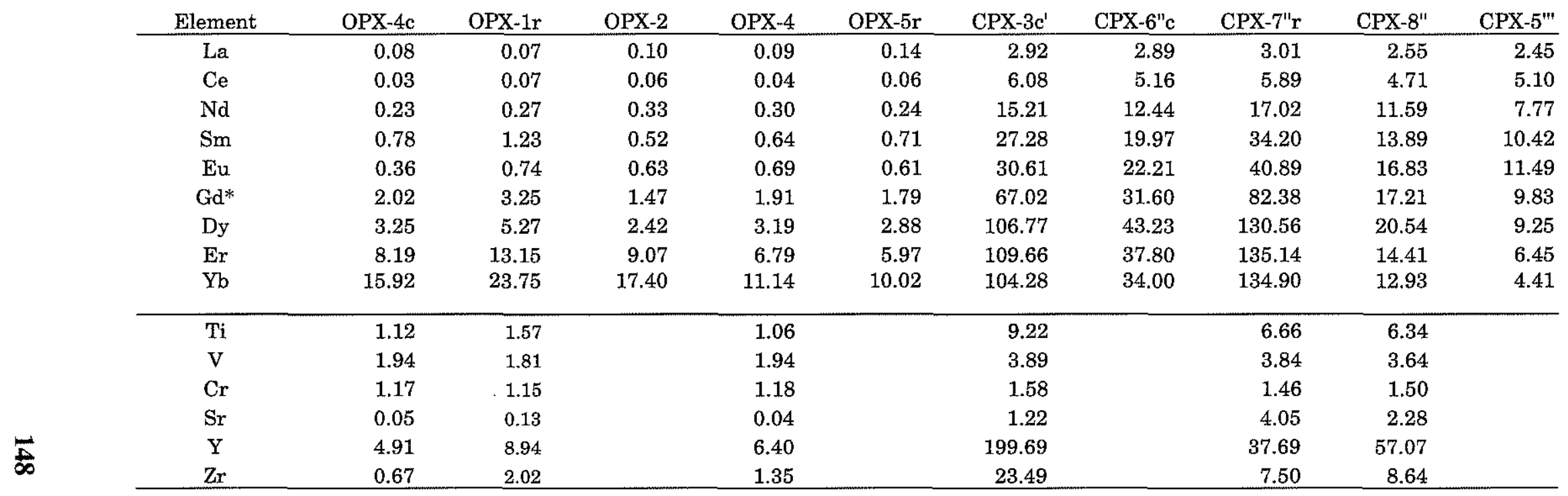




\section{Figures}

Figure 5.1: REE spidergram for reaction products in experiments. The initial garnet compositions are shown by the thick dotted line. Note the similarity between opx and cpx REE abundances, and garnet is also similar to pyroxenes.

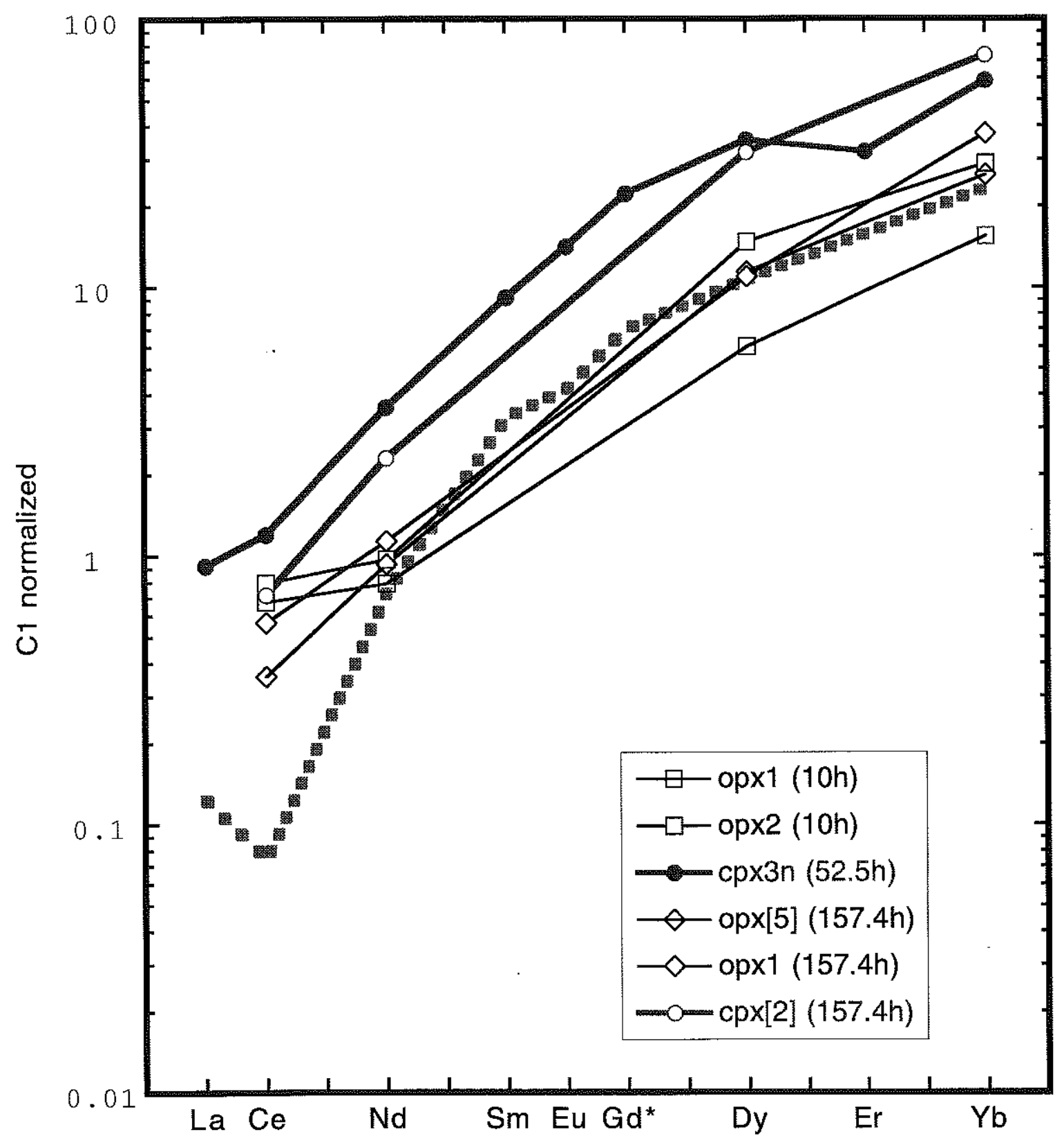


Figure 5.2: BSE image of a representative experimental charge. Note the texture of product opx and spinel. The ion probe beam was aimed to the large area of opx.

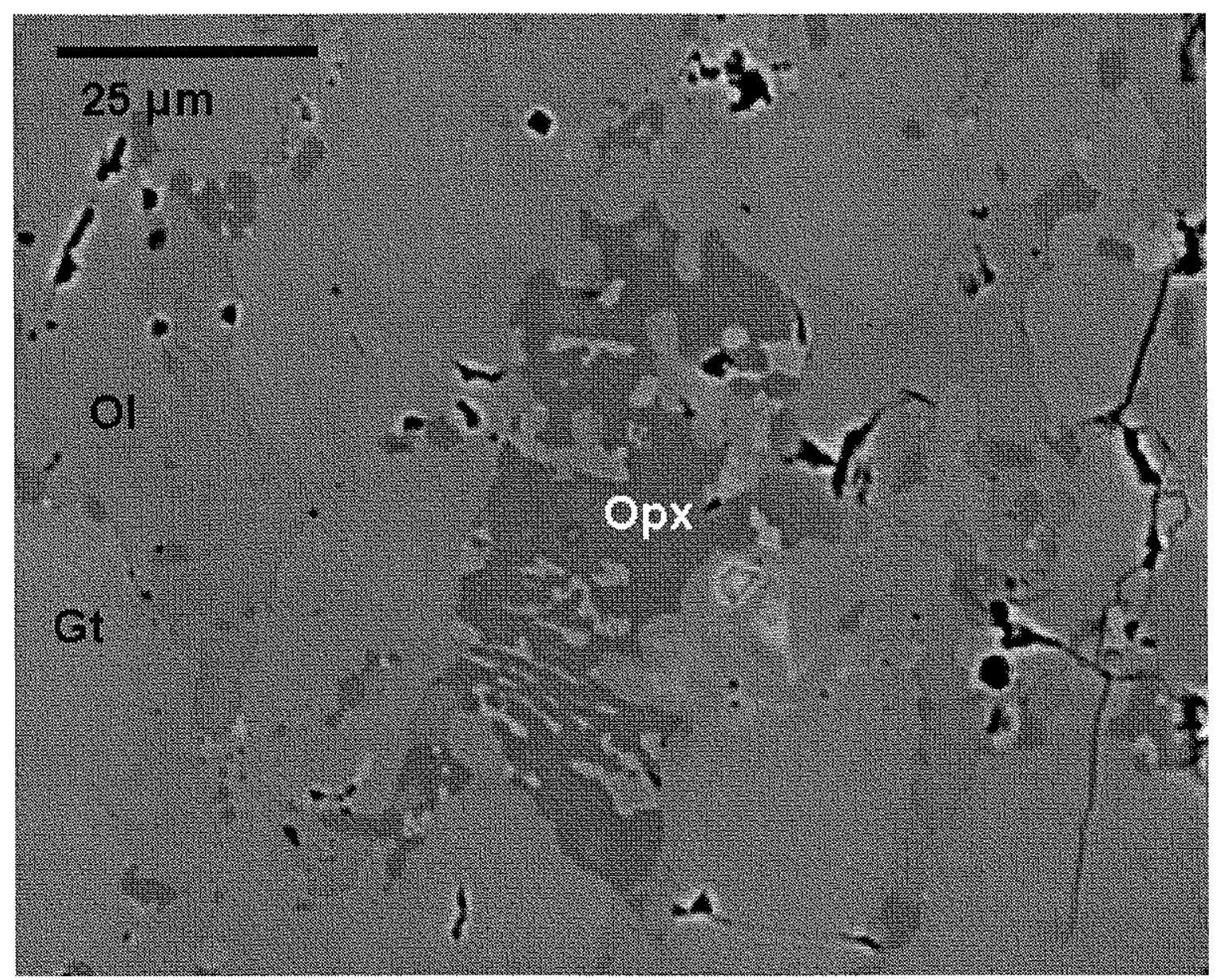


Figure 5.3: Microscope image of reaction rims for Lashaine peridotite (BD796) shows garnet in the center surrounded by fine grain aggregates of opx, cpx and spinel. The grain size progressively coarsen towards the outside. High relief minerals are spinel.

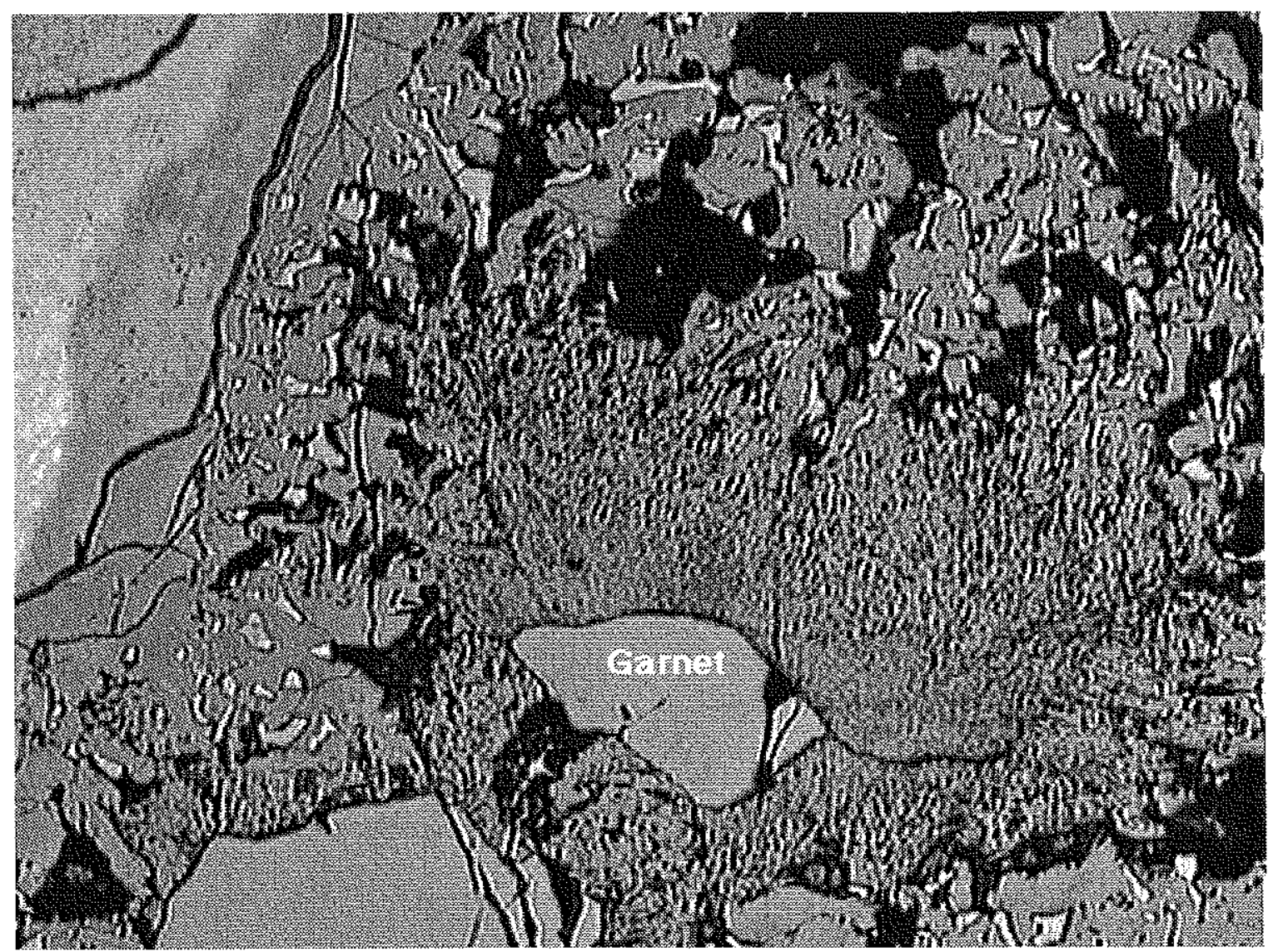


Figure 5.4: BSE image of Lashaine peridotite (BD730). White circles indicate the positions of ion probe beam.

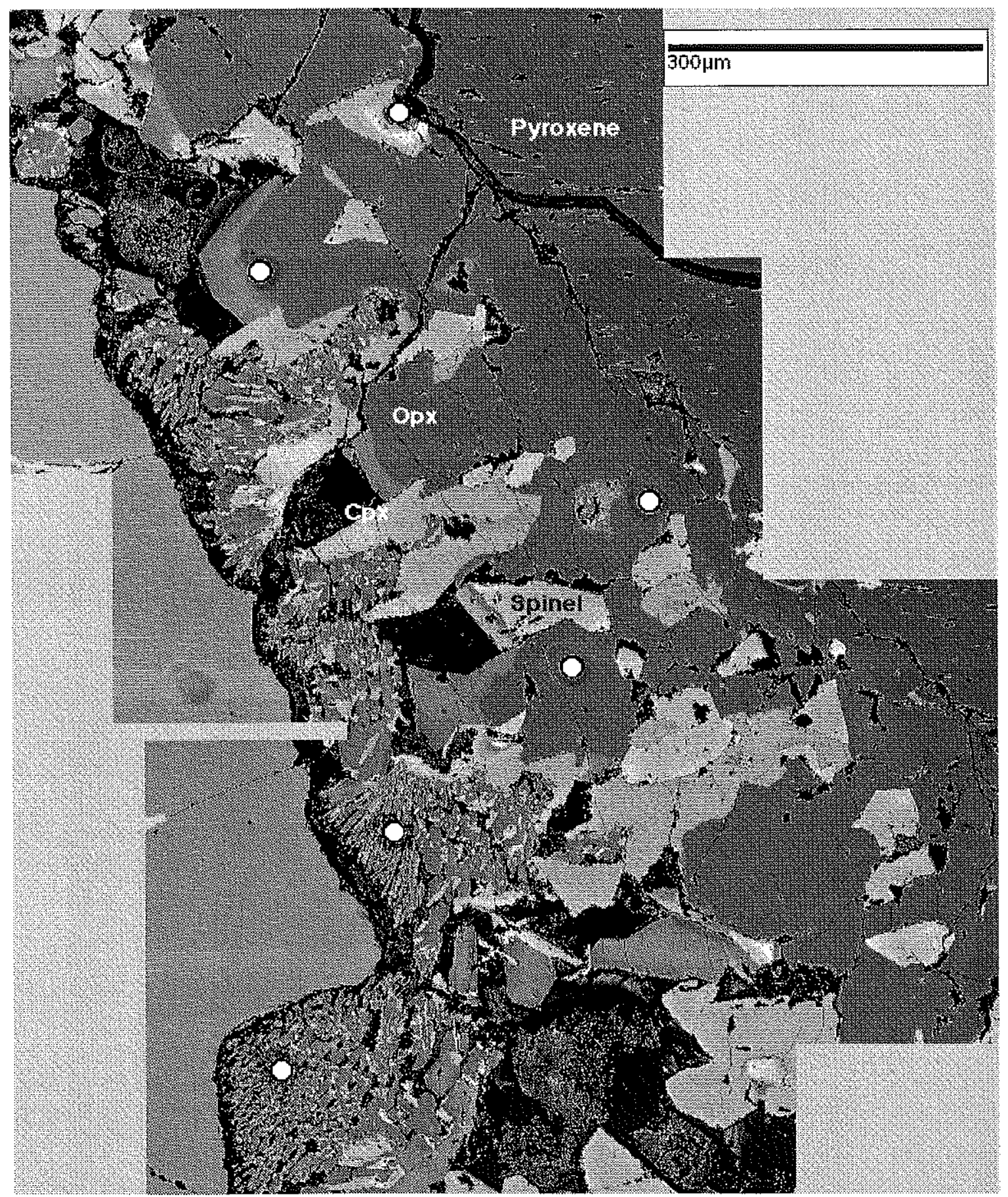


Figure 5.5: BD 730, garnet lherzolite, REE abundance normalized by $\mathrm{C} 1$ chonodrite. Thick lines show the initial REE abundances.
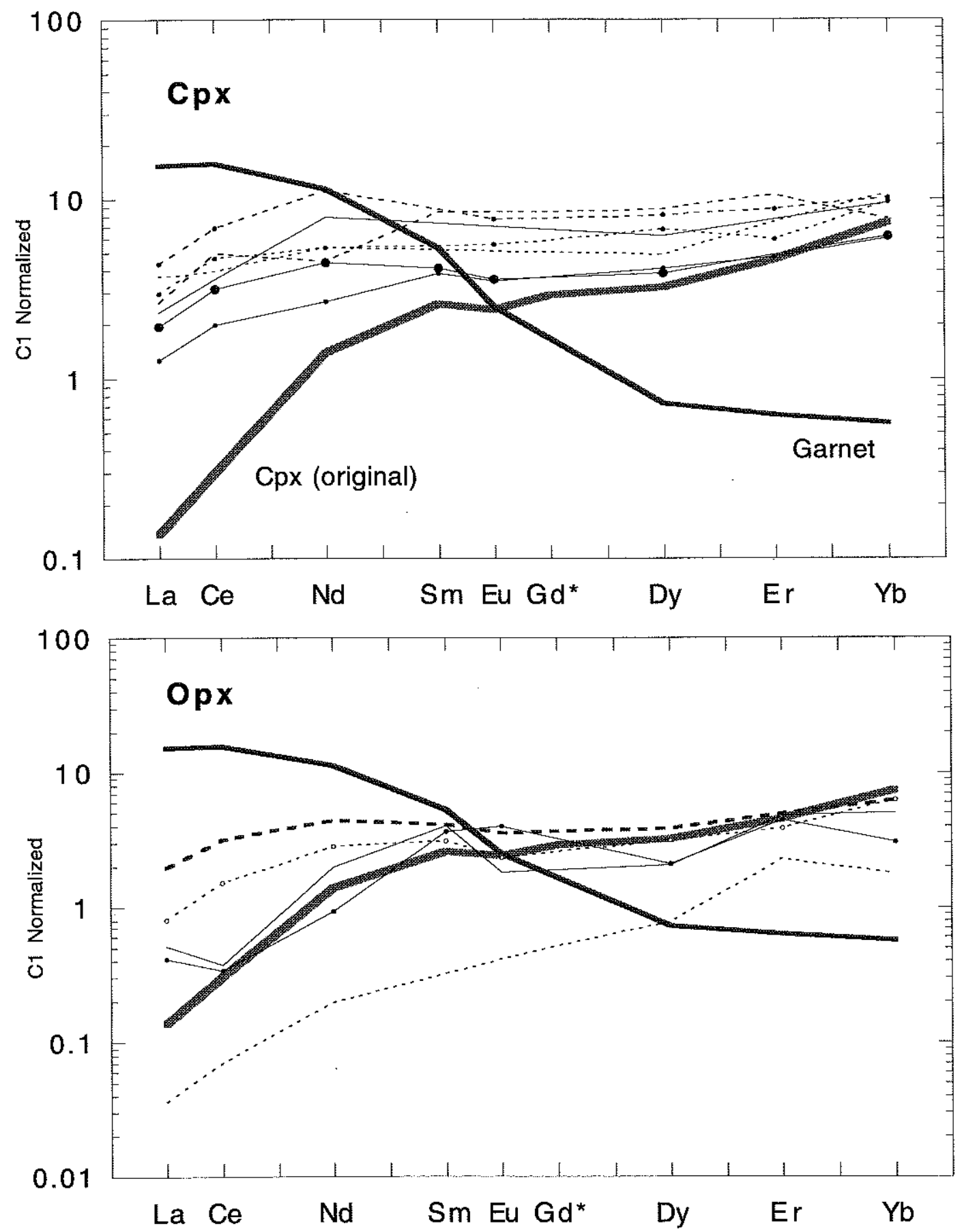
Figure 5.6: BD 796, garnet harzburgite, REE abundance normalized by $\mathrm{C} 1$ chondrite. The thick line is the initial garnet composition.
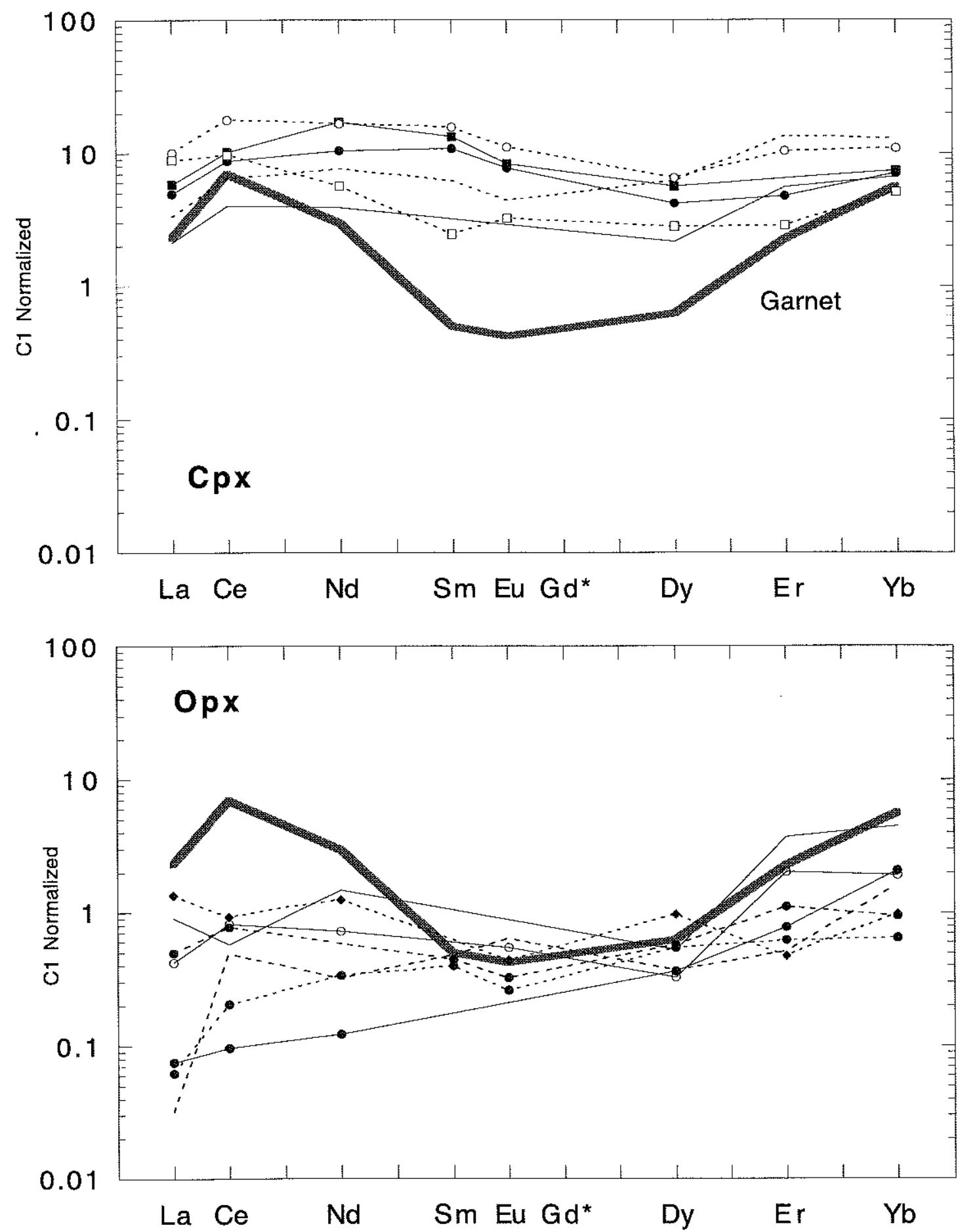
Figure 5.7: Photograph of Ronda websterite (RO324). Black dots are the ion probe holes for opx $(1,2,4,5$, and $A 4 c)$ and $c p x(3,6,7,8)$.

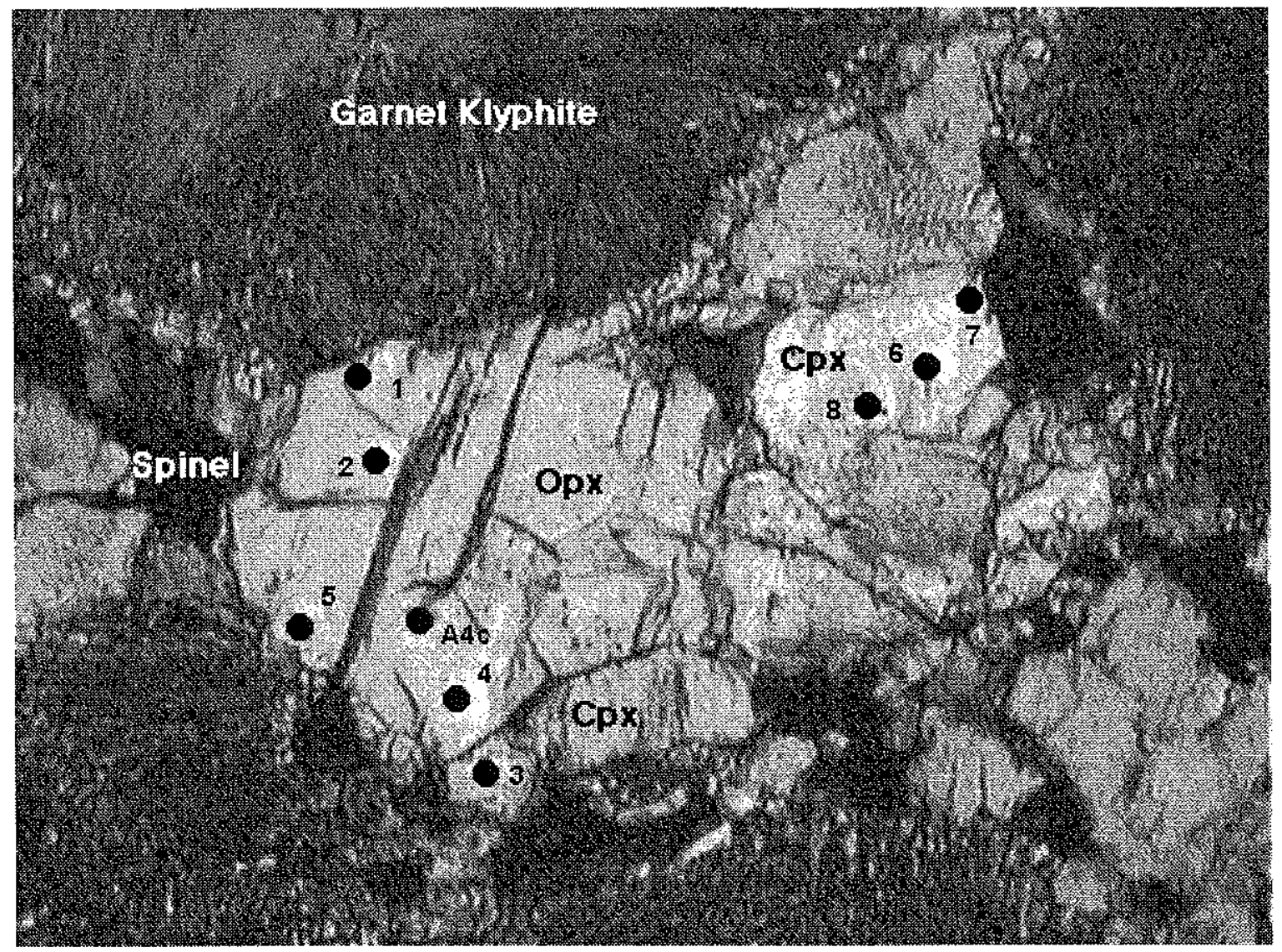


Figure 5.8: RO 324, Garnet websterite from Ronda. REE abundance normalized by C1 chondrite. The number inside the parenthesis is the number of analysis averaged. Cpx composition actually varies between maximum and minimum values but those are not plotted for clarity. Opx with dot lines represent each analysis at the region with less reaction in the thin section. Opx rims corresponds to point $1,3,5$ in previous figure. The points, 2,4 , is included in the average of six points. The cpx point 3, showed the maximum REE abundance. Dot lines with low abundances are opx compositions. Thick dot line is garnet pattern predicted from, D, partition coefficients of cpx..

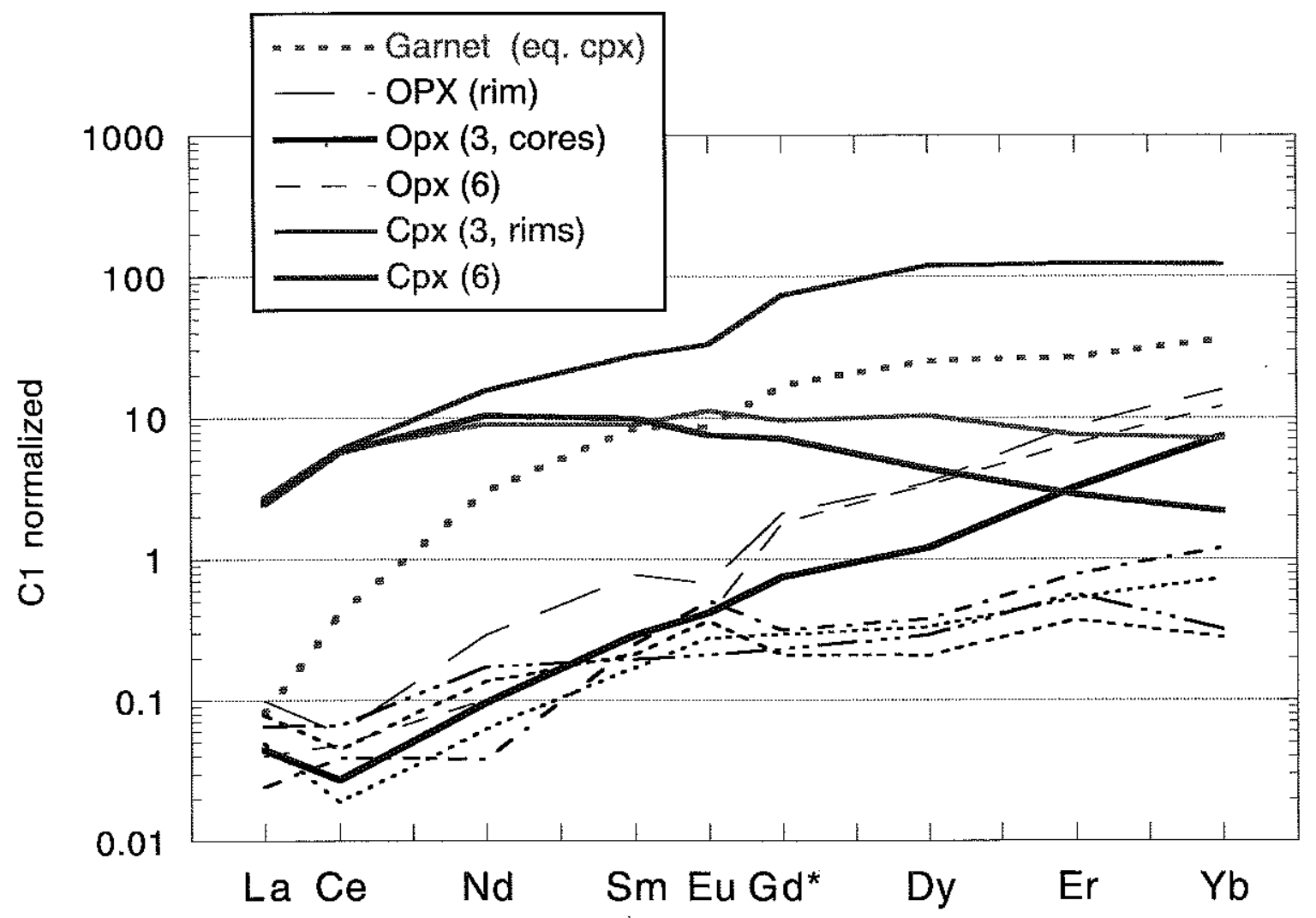


Figure 5.9: Illustration of the two phase (cpx-opx) diffusion model shows a couple of opx and cpx with diffusion coefficient 10 times faster in cpx. At the interface, trace elements are partitioned. To reflect realistic modal proportions of cpx and opx, opx is three times more abundant than cpx.

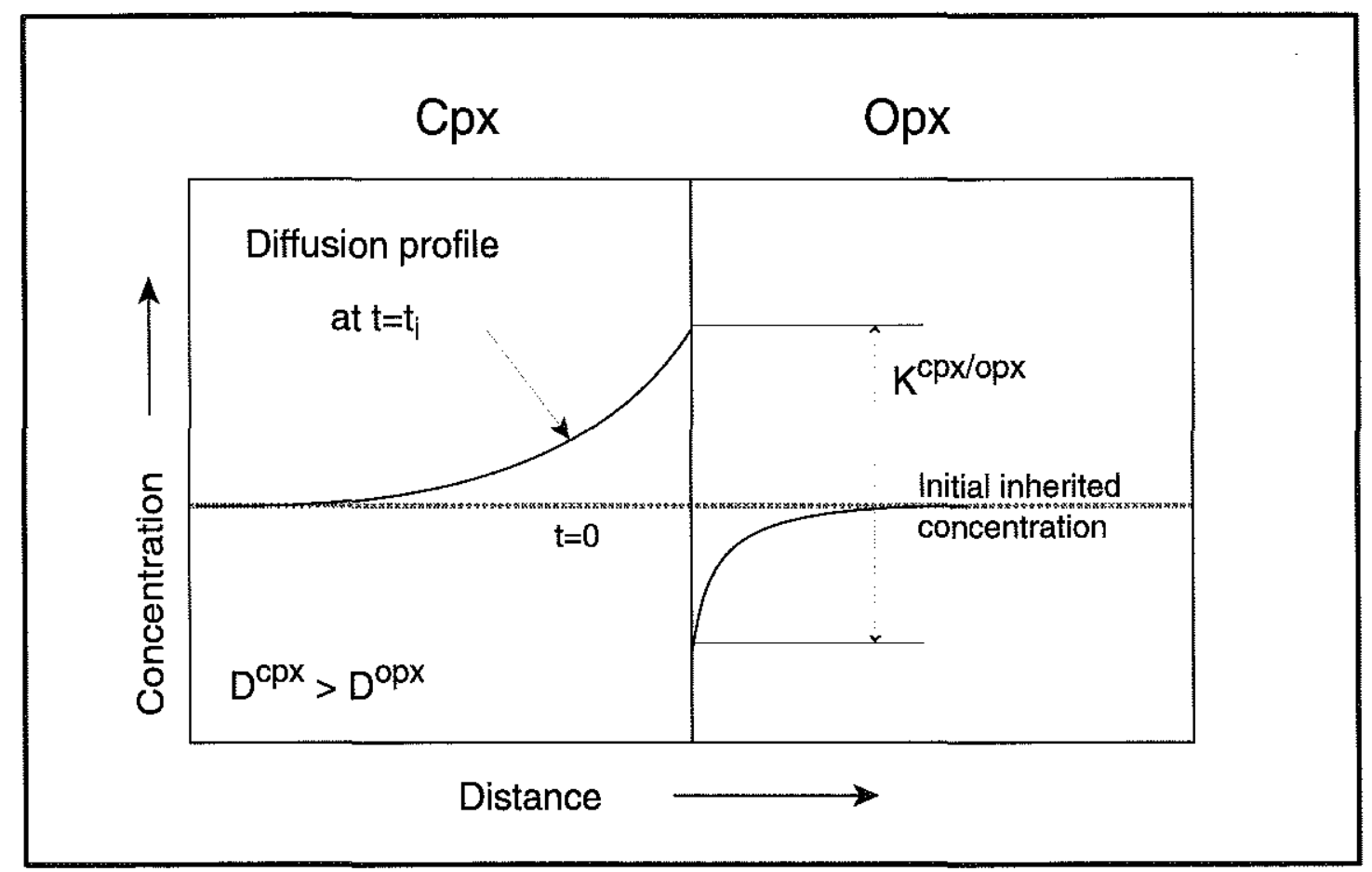


Figure 5.10: Results of the two phase (cpx-opx) diffusion model.
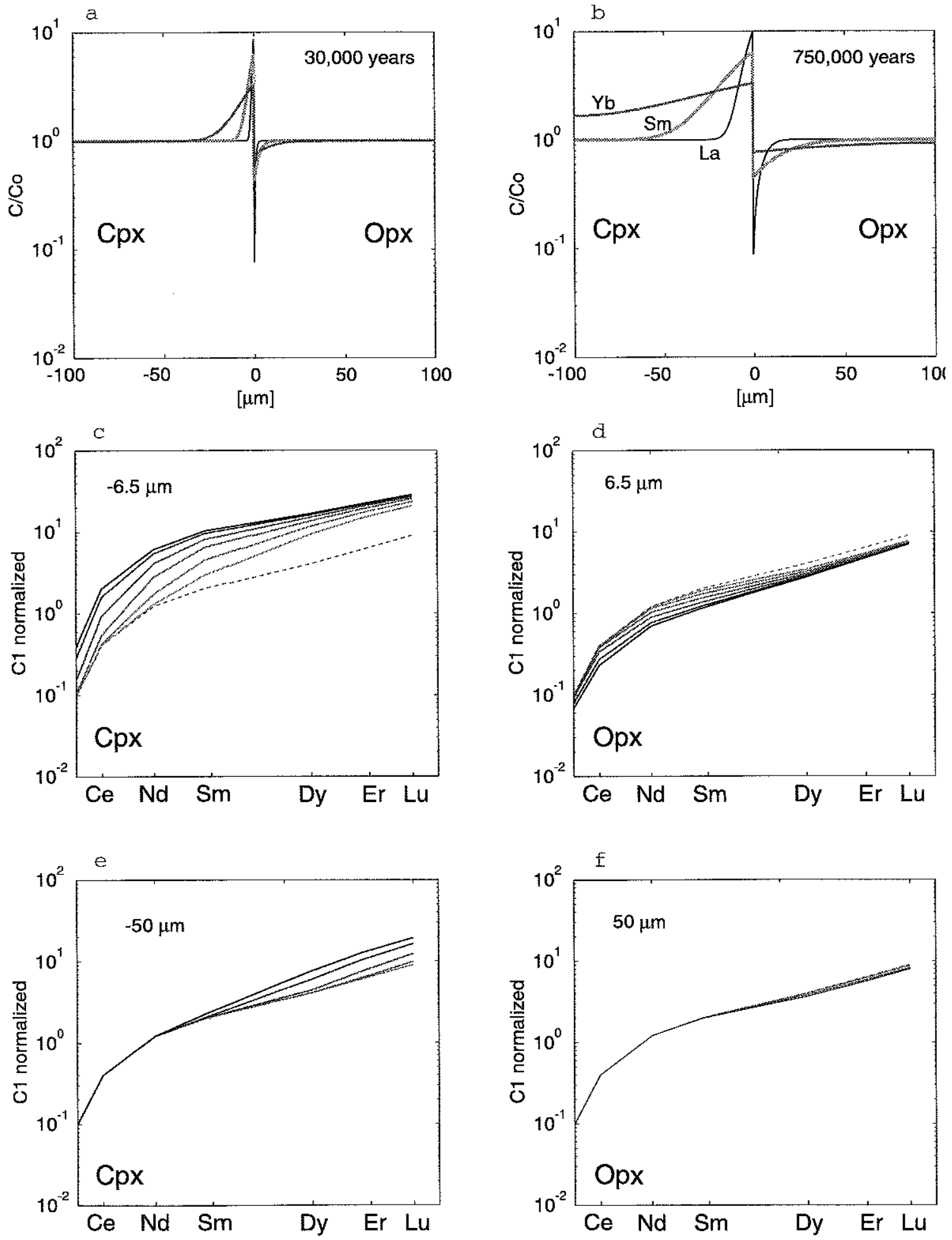


\section{Appendix I}

\section{Piston Cylinder-type Apparati Pressure Calibration}

\section{Equipments}

At the MIT high-pressure experimental petrology lab, three piston-cylinder high-pressure apparati ( $\mathrm{P} / \mathrm{C}$ for hereafter) are available. The design of the $\mathrm{P} / \mathrm{Cs}$ are similar to the one described in Boyd and England (1960), and the details of the modifications are described in Wagner (1995).

\section{Assembly}

The sample was always placed at the center of the assembly where the thermal gradient is lowest. A $20^{\circ} \mathrm{C}$ correction was applied to the temperature monitored by a $\mathrm{W}_{97} \mathrm{Re}_{3}$ $\mathrm{W}_{75} \mathrm{Re}_{25}$ thermocouple, and accounts for the temperature gradient across $2 \mathrm{~mm}$ distance from the center of the sample to the thermocouple. Pressure was monitored by a Bourdon tube type gauge.

$\mathrm{BaCO}_{3}$ is used as the pressure-transmitting medium. This material is preferred over other commonly used material $\mathrm{NaCl}$, Talc, or $\mathrm{CaF}$, for its stability at high temperature and low heat conductivity. The details of the assembly are described by Wagner (1995).

\section{Run Procedure}

The procedure of assembling and stacking the vessel is described in the appendix of Wagner (1995). The ramping procedure is as follows: 1) Pressure is raised to $\sim 10 \mathrm{~kb} ; 2$ ) Temperature is raised at the rate of $100^{\circ} / \mathrm{min}$ to $865^{\circ} \mathrm{C}$; 3) The condition of $865^{\circ} \mathrm{C}$ is kept for $6 \mathrm{~min}$ to allow compaction of porosity; 4) The pressure is raised to the target condition $3-4 \mathrm{~min}$ after reaching $865^{\circ} \mathrm{C}$. Thereafter, the pressure was maintained within \pm 0.05 of the target pressure. 5) Temperature was then raised to the target at the rate of 
$50^{\circ} \mathrm{C} / \mathrm{min}$. The duration of the run is counted from the point when the final temperature is attained. Periodic pressurization of the interval of 15-20 min at the beginning is critical in retaining the stable run conditions.

\section{Calibration}

Two mineral reaction boundaries are used for calibration of the apparati: Ca-Tschermak's pyroxene breakdown reaction (1) and plagioclase to spinel lherzolite facies transformation (2).

$$
\begin{aligned}
& \text { Anorthite }+ \text { Gehlenite }+ \text { Corundum }=3 \mathrm{CaTs} \\
& \mathrm{CaAl}_{2} \mathrm{Si}_{2} \mathrm{O}_{8}+\mathrm{Ca}_{2} \mathrm{Al}_{2} \mathrm{SiO}_{7}+\mathrm{Al}_{2} \mathrm{O}_{3}=3 \mathrm{CaAl}_{2} \mathrm{SiO}_{6} \\
& \text { Anorthite }+ \text { Forsterite }=\text { Diopside }+ \text { Enstatite }+ \text { Spinel } \\
& \mathrm{CaAl}_{2} \mathrm{Si}_{2} \mathrm{O}_{8}+\mathrm{Mg}_{2} \mathrm{SiO}_{4}=\mathrm{CaMgSi}_{2} \mathrm{O}_{6}+\mathrm{Mg}_{2} \mathrm{Si}_{2} \mathrm{O}_{6}+\mathrm{MgAl}_{2} \mathrm{O}_{4}
\end{aligned}
$$

\section{CaTs}

The reaction boundaries of the $\mathrm{CaO}-\mathrm{Al}_{2} \mathrm{O}_{3}-\mathrm{SiO}_{2}$ system was determined by Hays (1967). Reaction (1) is a univariant reaction boundary, and the pressure-temperature relationship of the boundary is reported as,

$$
\mathrm{P}(\text { bars })=12500+9.9\left(\mathrm{~T}^{\circ} \mathrm{C}-1250\right)
$$

We used the appearance of CaTs or gehlenite as the indicator for crossing the reaction boundary. This reaction is ideal for fixed-point calibration because: the rate of the reaction is fast, and $\mathrm{dT} / \mathrm{dP}$ is large so that reaction is relatively insensitive to temperature.

\section{Procedure}

A stoichiometric oxide mixture of CaTs composition was first made and glassed at $1550^{\circ} \mathrm{C}$ for 10 hours. The glass was then powdered in an agate motor. The prepared powder is kept in desiccater, and the same batch of glass was used for all of experiments. The CaTs composition powder is packed tightly into a graphite capsule, and it is dried at least 8 hours in $110^{\circ} \mathrm{C}$ oven to dry atmospheric volatiles. The sample was immediately sealed in Pt capsule after being taken out of oven. It was then fit into an $\mathrm{Al}_{2} \mathrm{O}_{3}$ ring and assembled. MgO rings are also used for comparison of the calibration due to the effects of the stiffness of alumina ring. The rate of reaction is relatively quick and the duration 
40-50 hours was sufficient for the observation of the growth of new phases. We have determined the boundary at $1350^{\circ} \mathrm{C}$ at $1.35 \mathrm{Gpa}$.

$\underline{\text { Results }}$

Calibration results are shown in Table I.1. Determination of the overstepping of the reaction boundary is sometimes not obvious, and the following observations were made.

1) Presence or absence of CaTs was the primary criterion to judge the direction of reaction. As CaTs is dissolves, gehlenite should grow. 2) Anorthite and corundum were not critical in determining the boundary, because metastable corundum can persist for wide range of $\mathrm{P}-\mathrm{T}$ conditions and anorthite forms due to excess $\mathrm{SiO}_{2}$ derived from metastable corundum. 3) Schreinemakers' rule predicts grossular formation reaction boundary to be very close to reaction (1) on the higher-pressure side. As the metastable corundum persists, the excess $\mathrm{SiO}_{2}$ promotes the grossular formation reaction. Thus, grossular is likely to appear for the similar conditions as CaTs.

The $\mathrm{B}$ press was calibrated with experimental assemblies using $\mathrm{Al}_{2} \mathrm{O}_{3}$ and $\mathrm{MgO}$ ring. $\mathrm{A}$ ring was always placed around $\mathrm{Pt}$ capsule to isolate the contact between a graphite heater and metal. Material differences of ring did not effect the pressure calibration. The reaction boundaries were within $0.15 \mathrm{GPa}$ of each other (Table I.1). However, the shapes of Pt capsule at the end of run were notably different depending on the ring material. Experiments conducted with an $\mathrm{Al}_{2} \mathrm{O}_{3}$ ring resulted in the depression of the center of $\mathrm{Pt}-\mathrm{C}$ capsule, while $\mathrm{MgO}$ ring experiments resulted as the pill shaped deformation (rims were shortened instead of center).

The C press calibration agreed with previous calibration by Wagner (1995).

Two experiments were conducted for D press calibration. At $1.50 \mathrm{GPa}$ nominal pressure, CaTs was formed (D12). The result of D6 appears to indicate the growth of anorthitegehlenite-corundum. Although pressure condition ranges from 1.15 to $1.40 \mathrm{GPa}$, the actual condition was mostly at approximately $1.30 \mathrm{GPa}$. Thus, the reaction boundary should be near $1.30 \mathrm{GPa}$ nominal pressure.

All three presses showed CaTs breakdown at $1350^{\circ} \mathrm{C}$ approximately $1.35 \mathrm{GPa}$ nominal pressure, and the calibration agrees within $0.15 \mathrm{GPa}$. The uncertainty is due to the drift of pressure overnight. Theoretically, the precision of pressure calibration can be as good as $0.03 \mathrm{GPa}$ that is determined by the tick marks of the gauge. Realistically, maintaining 
pressure within a tick requires extraordinary diligence and is impossible to conduct experiment for over few days with such precision.

\section{Lherzolite}

The plagioclase to spinel peridotite transformation boundary (Reaction 2) for the CaO$\mathrm{MgO}-\mathrm{Al}_{2} \mathrm{O}_{3}-\mathrm{SiO}_{2}$ system (CMAS) was reported by Kushiro and Yorder (1966), and is the boundary determined by a gas-medium high-pressure apparatus. A CMAS composition used in Gudfinnsson and Presnall (1996) is used for the experiments.

Table I. 1 shows the result of experiments that are conducted at sub- and super-solidus conditions. The rate of the subsolidus reaction appears to be slower than that of CaTs reaction, while the presence of melt increased the reaction rate. In the 1.0 and $1.3 \mathrm{GPa}$ experiments at subsolidus conditions, opx formed around olivine, although equant grains of spinel were never observed. Above solidus, appearance and disappearance of spinels are observed (C233 and C234). This confirms that reaction boundary should be between 0.85 to $1.00 \mathrm{GPa}$. The absence of anorthite at above solidus is partly due to melt that depletes residue in $\mathrm{Al}_{2} \mathrm{O}_{3}$.

\section{Summary}

The calibrations of three $\mathrm{P} / \mathrm{C}$ presses are within $0.15 \mathrm{GPa}$ of each other, and do not require pressure corrections. The lack of the correction suggests that the combination of the lubrications and $\mathrm{BaCO}_{3}$ cell may be the effective on reducing friction to negligible quantity.

\section{References Cited}

Boyd F. R. and England J. L. (1960) Apparatus for phase-equilibrium measurements at pressures up to 50 Kilobars and temperatures to 1750 C. J. Geophys. Res. 65, 741-748.

Gudfinnsson G. H. and Presnall D. C. (1996) Melting relations of model therzolite in the system CaO-MgO- $\mathrm{Al}_{2} \mathrm{O}_{3}-\mathrm{SiO}_{2}$ at 2.4-3.4 GPa and the generation of komatiites. Journal of Geophysical Research 101, 27701-27709.

Hays J. F. (1967) Lime-Alumina-Silica. Carnegie Institution Year Book 65, 234-239.

Kushiro I. and Yoder H. S. J. (1966) Anorthite-Forsterite and Anorthite-Enstatite Reaction and bearing on the Basalt-Eclogite Transformation. Journal of Petrology 7, 337-362.

Wagner T. P. (1995) Experimental and Geochemical Studies of Terrestrial and Lunar Magmatic Process. Ph. D., Massachusetts Institute of Technology. 


\section{Tables}

Table I.1

\begin{tabular}{|c|c|c|c|c|c|c|c|c|}
\hline Sample & Ring & $\begin{array}{l}\text { Temp } \\
{ }^{\circ} \mathrm{C}\end{array}$ & $\begin{array}{l}\text { Target P } \\
\text { GPa }\end{array}$ & $\begin{array}{l}\text { Duration } \\
\text { hours }\end{array}$ & $\begin{array}{l}\text { Max P } \\
\text { GPa }\end{array}$ & $\begin{array}{l}\mathrm{Min} P \\
\mathrm{GPa}\end{array}$ & In & Out \\
\hline $\bar{B} 601$ & $\mathrm{Al}_{2} \mathrm{O}_{3}$ & 1351 & 1.65 & 2.5 & 1.60 & 1.68 & CaTs & $\begin{array}{l}\text { An, Geh, } \\
\text { Corr }\end{array}$ \\
\hline B602 & $\mathrm{Al}_{2} \mathrm{O}_{3}$ & 1351 & 1.65 & 10 & 1.65 & 1.55 & CaTs & $\begin{array}{l}\text { Gros,Cor, } \\
\text { An }\end{array}$ \\
\hline B606 & $\mathrm{Al}_{2} \mathrm{O}_{3}$ & 1351 & 1.5 & 13.6 & 1.50 & 1.41 & CaTs & $\begin{array}{l}\text { An, Geh, } \\
\text { Cor }\end{array}$ \\
\hline B630 & $\mathrm{Al}_{2} \mathrm{O}_{3}$ & 1350 & 1.50 & 68 & 1.51 & 1.47 & CaTs & An, Corr \\
\hline B615 & $\mathrm{Al}_{2} \mathrm{O}_{3}$ & 1350 & 1.35 & 10 & 1.35 & 1.32 & CaTs & $\begin{array}{l}\text { An, Geh, } \\
\text { Cor }\end{array}$ \\
\hline B621 & $\mathrm{Al}_{2} \mathrm{O}_{3}$ & 1350 & 1.20 & 20 & 1.26 & 1.17 & $\begin{array}{l}\text { An, Geh, } \\
\text { Cor }\end{array}$ & CaTs \\
\hline B 605 & $\mathrm{MgO}$ & 1351 & 1.65 & 13.5 & 1.66 & 1.59 & CaTs & $\begin{array}{l}\text { Gros, Cor, } \\
\text { An }\end{array}$ \\
\hline B611 & $\mathrm{MgO}$ & 1351 & 1.5 & 15.7 & 1.50 & 1.45 & CaTs & $\begin{array}{l}\text { Geh, An, } \\
\text { Cor }\end{array}$ \\
\hline B617 & $\mathrm{MgO}$ & 1350 & 1.35 & 12.3 & 1.36 & 1.35 & CaTs & $\begin{array}{l}\text { An, Geh, } \\
\text { Cor }\end{array}$ \\
\hline B622 & $\mathrm{MgO}$ & 1350 & 1.20 & 21.7 & 1.23 & 1.15 & $\begin{array}{l}\text { An, Geh, } \\
\text { Cor }\end{array}$ & \\
\hline $\mathrm{C} 113$ & $\mathrm{Al}_{2} \mathrm{O}_{3}$ & 1280 & 1.4 & 24 & 1.422 & 1.188 & CaTs & An, Cor \\
\hline $\mathrm{C} 126$ & $\mathrm{Al}_{2} \mathrm{O}_{3}$ & 1280 & 1.3 & 24 & 13 & 1.203 & $\begin{array}{l}\text { Cor, An, } \\
\text { Ghe }\end{array}$ & CaTs \\
\hline C128 & $\mathrm{Al}_{2} \mathrm{O}_{3}$ & $? ?$ & 1.25 & & & & $\begin{array}{l}\text { Melted, } \\
\text { Cor }\end{array}$ & \\
\hline D6 & $\mathrm{Al}_{2} \mathrm{O}_{3}$ & 1350 & 1.35 & 10.4 & 1.40 & 1.15 & $\begin{array}{l}\text { An, Geh, } \\
\text { Cor }\end{array}$ & CaTs \\
\hline D12 & $\mathrm{Al}_{2} \mathrm{O}_{3}$ & 1350 & 1.5 & 11.5 & 1.56 & 1.52 & CaTs & An, Cor \\
\hline B684 & $\mathrm{Al}_{2} \mathrm{O}_{3}$ & 1300 & 0.85 & 10 & 0.83 & 0.86 & $\begin{array}{l}\text { Ol, Cpx, } \\
\text { Opx, Pl }\end{array}$ & Sp?? \\
\hline B688 & $\mathrm{Al}_{2} \mathrm{O}_{3}$ & 1300 & 1.00 & 24 & 0.99 & 0.94 & $\begin{array}{l}\text { Ol, Cpx } \\
\text { Pl, Opx }\end{array}$ & Opx \\
\hline $\mathrm{C} 232$ & $\mathrm{Al}_{2} \mathrm{O}_{3}$ & 1300 & 1.3 & 67.7 & 1.41 & 1.08 & Ol, An & Opx, Cpx \\
\hline $\mathrm{C} 233$ & $\mathrm{Al}_{2} \mathrm{O}_{3}$ & 1330 & 1.0 & & 1.09 & 0.83 & $\mathrm{Ol}, \mathrm{Cpx}$ & $\begin{array}{l}\text { Opx, Sp, } \\
\text { Melt }\end{array}$ \\
\hline $\mathrm{C} 234$ & $\mathrm{Al}_{2} \mathrm{O}_{3}$ & 1320 & 0.85 & 60 & 0.94 & 0.62 & $\begin{array}{l}\text { Cpx, O1, } \\
\text { Opx }\end{array}$ & Melt \\
\hline
\end{tabular}




\section{Appendix II}

\section{8. "clrphase2.m", MATLAB script files for the image analysis}

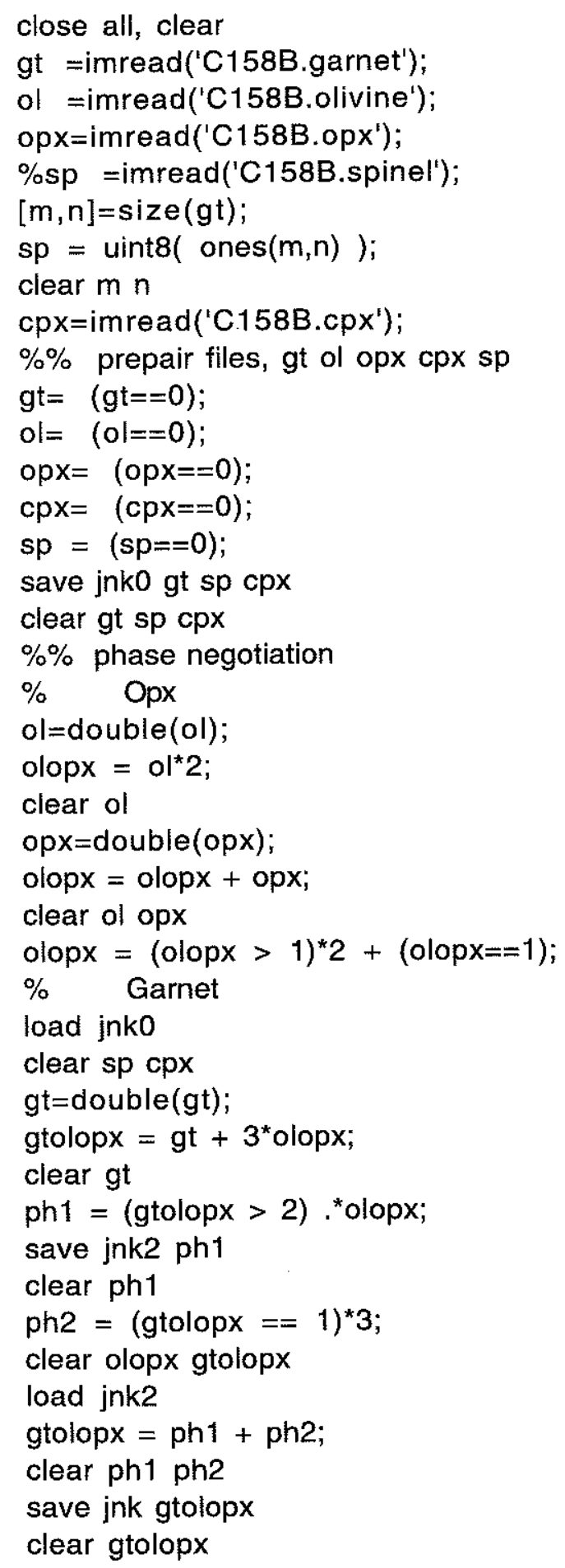




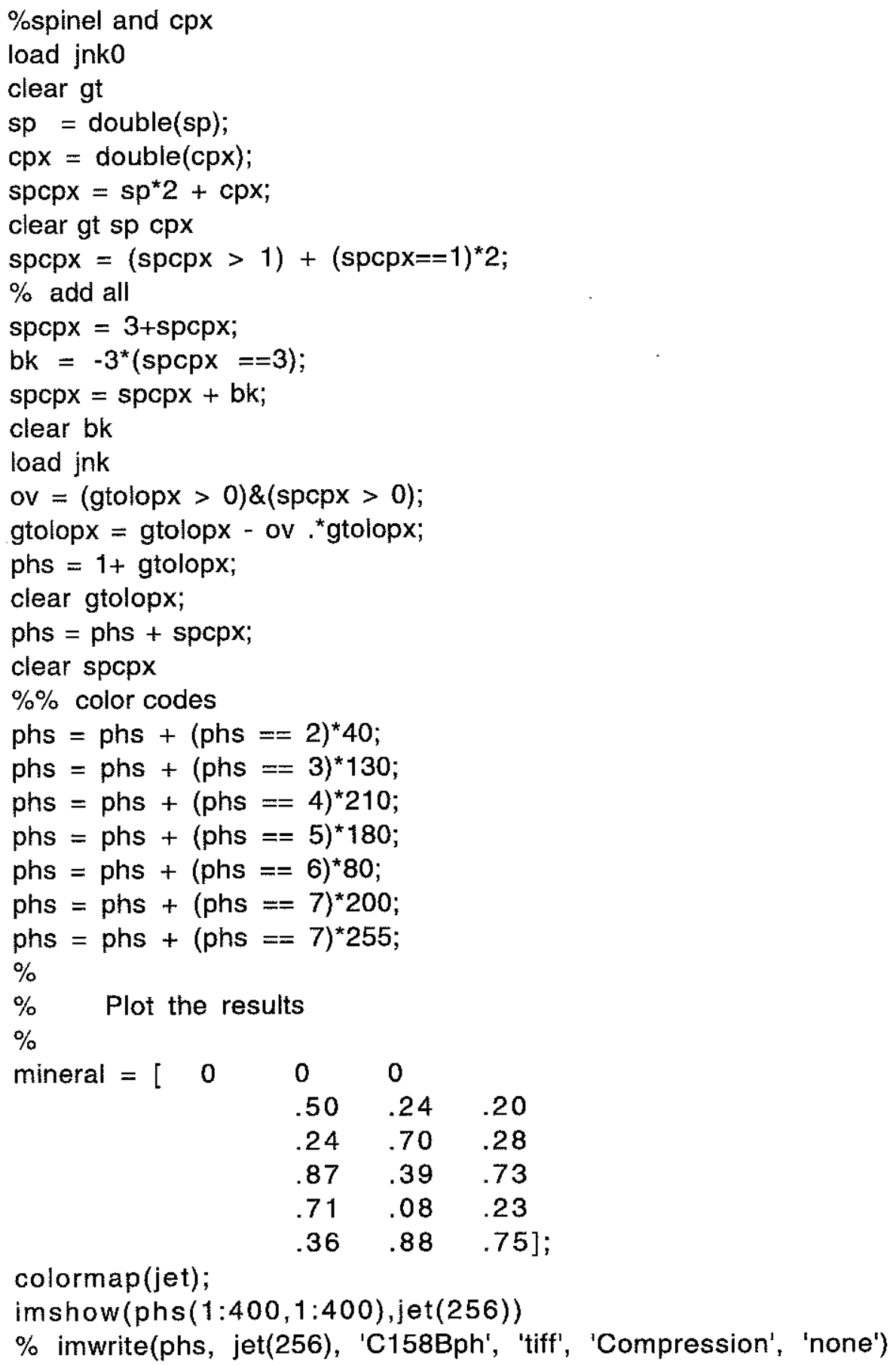

\section{9. "phdet.m", a MATLAB script file for determination of phase}

$\% \%$ Test script file for image analysis

$\% \% \quad$ Determines the phase abundance

$\%$

$\% \quad 10 / 24 / 98 \quad$ Ken Koga 


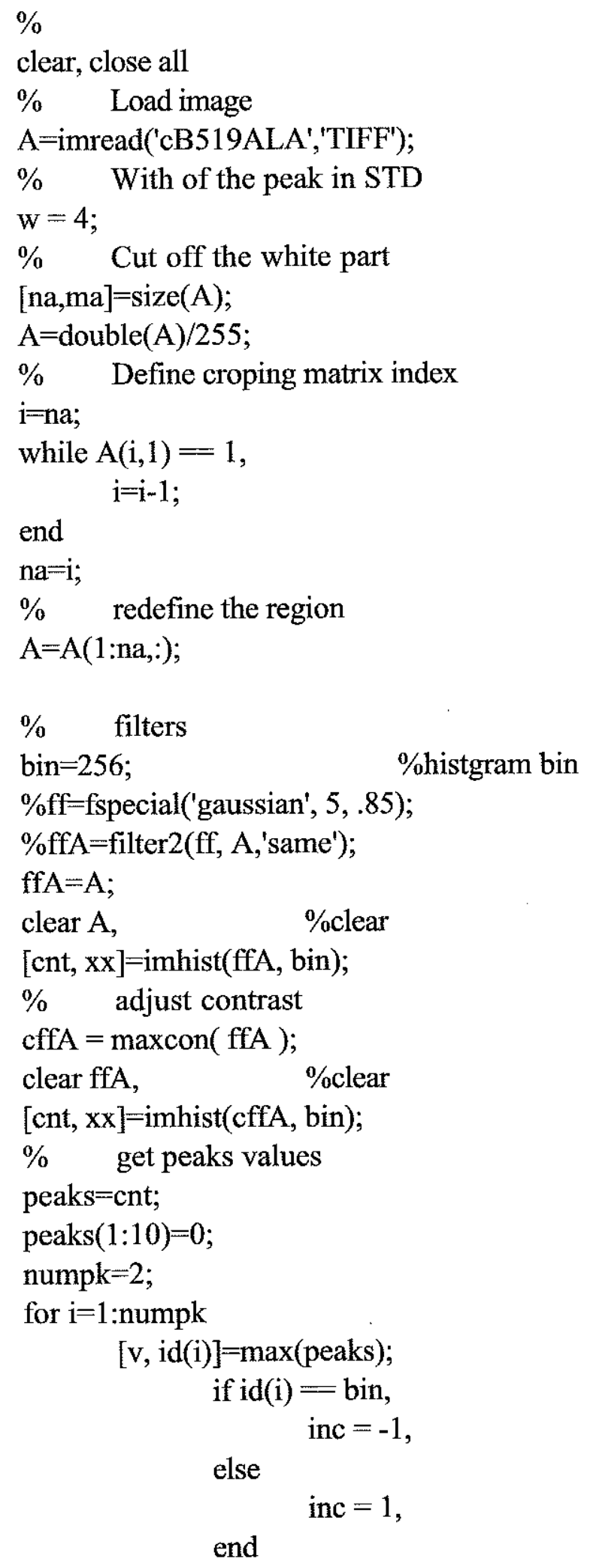


$\mathrm{j}=\mathrm{id}(\mathrm{i})+\mathrm{inc}$;

while $\mathrm{v} / 2<=$ peaks $(\mathrm{j})$,

$j=j+$ inc;

if peaks $(\mathrm{j})>$ peaks $(\mathrm{j}-1)$

peaks $(j)=v / 2-1$;

end

end

rng $=\operatorname{abs}(\mathrm{j}$-id(i) );

apk $=$ normpdf([-w*rng:+w*rng], 0, 2.5*rng);

$\mathrm{apk}=\mathrm{v} / \max (\mathrm{apk}){ }^{*} \mathrm{apk}$;

if id(i)-w*ng $<=1$, peaks $\left(1: i d(i)+w^{*}\right.$ ng $)=\operatorname{peaks}\left(1: i d(i)+w^{*} \operatorname{rng}\right)-\operatorname{apk}\left(1: i d(i)+w^{*} \operatorname{rng}\right)^{\prime}$;

else if id(i) $+w^{*}$ rng $>=$ bin, peaks(id(i)-w*rng:bin)=peaks(id(i)-w*rng:bin) - apk(1:bin-

id(i) $+\mathrm{w}^{*}$ rng +1$)^{\prime}$;

else

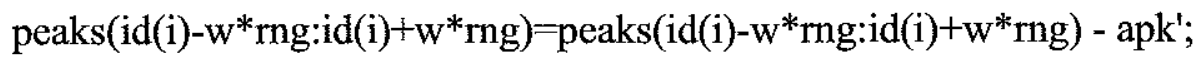

end

end

peaks $=($ peaks $>=0) \cdot{ }^{*}$ peaks;

end

$\% \quad$ plot peak extraction

figure, plot(xx, cnt, $x x$, peaks, $x x(i d), \operatorname{cnt}(i d),{ }^{\prime}$ '),

$\% \quad$ determine local maximums by taking delivatives

$\% \mathrm{n}=4 ; \quad \%$ size of averaging filter

$\%$ cntc $=\operatorname{conv}\left(\mathrm{cnt}, 1 / \mathrm{n}^{*}\right.$ ones $\left.(1, \mathrm{n})\right)$;

$\%$ delcnt $=(-\operatorname{cntc}(3: \operatorname{bin}+2)+\operatorname{cntc}(1:$ bin $)) / 2$;

$\% \quad$ near zero values

$\%$ pks $=$ cnt. $*([($ delcnt $<5) \&($ delcnt $>-5)])$;

$\%$ figure, plot( $x x$, pks, 'o', xx, cnt, '-')

$\% \quad$ get peaks values

$\%$ numpk $=2$;

$\%$ for $\mathrm{i}=1: 2$

$\% \quad[\mathrm{v}, \mathrm{id}(\mathrm{i})]=\max (\mathrm{pks})$;

$\% \quad$ pks(id(i)) $=$ pks(id(i))-v;

$\%$ end

figure

subplot(222), imshow ( [(cffA $>$ (id(1)-20)/bin) \& (cffA $<($ id(1)+20)/bin) $])$

subplot(223), imshow $([(\mathrm{cffA}>(\mathrm{id}(2)-50) / \mathrm{bin}) \&(\mathrm{cffA}<(\mathrm{id}(2)+50) / \mathrm{bin})])$ 